FÁBIO SANTOS DA SILVA

PERSONALTVWARE: UMA INFRAESTRUTURA DE SUPORTE A SISTEMAS DE RECOMENDAÇÃO SENSÍVEIS AO CONTEXTO PARA TV DIGITAL PERSONALIZADA

Tese apresentada à Escola Politécnica da Universidade de São Paulo para a obtenção do título de Doutor em

Engenharia 
FÁBIO SANTOS DA SILVA

\title{
PERSONALTVWARE: UMA INFRAESTRUTURA DE SUPORTE A SISTEMAS RECOMENDAÇÃO SENSÍVEIS AO CONTEXTO PARA TV DIGITAL PERSONALIZADA
}

\author{
Tese apresentada à Escola Politécnica \\ da Universidade de São Paulo para a \\ obtenção do título de Doutor em \\ Engenharia \\ Área de Concentração: \\ Sistemas Digitais \\ Orientadora: \\ Profa. Dra. Graça Bressan
}


Este exemplar foi revisado e alterado em relação à versão original, sob responsabilidade única do autor e com a anuência de seu orientador.

São Paulo, de maio de 2011.

Assinatura do autor

Assinatura do orientador

FICHA CATALOGRÁFICA

Silva, Fábio Santos da

PersonalTVware: uma infraestrutura de suporte a sistemas de recomendação sensíveis ao contexto para TV digital personalizada / F.S. da Silva. -- ed.rev. -- São Paulo, 2011. $207 \mathrm{p}$.

Tese (Doutorado) - Escola Politécnica da Universidade de São Paulo. Departamento de Engenharia de Computação e Sistemas Digitais.

1. Televisão digital 2. Televisão interativa 3. Sistemas de recomendação 4. Computação sensível ao contexto I. Universidade de São Paulo. Escola Politécnica. Departamento de Engenha-ria de Computação e Sistemas Digitais II. t. 


\section{DEDICATÓRIA}

Dedico este trabalho aos meus queridos pais, José Cipriano e Fernanda Santos. 


\section{AGRADECIMENTOS}

Agradeço primeiramente a Deus por tudo que tenho sem o qual nada seria possível.

À minha orientadora, Profa. Dra. Graça Bressan, pelo apoio dispensado para condução deste trabalho. As suas reflexões e conselhos foram essenciais para o comprimento deste trabalho. Agradeço também pela atenção, dedicação e oportunidade dada para fazer doutorado, o que sem dúvida contribuiu significativamente para o meu crescimento profissional.

Ao Prof. Dr. Marcel Bergerman, exemplo de profissionalismo para mim. Agradeço pela amizade, confiança, apoio inestimável dado para participar do doutorado e ensinamentos que foram primordiais para o meu aprimoramento pessoal e formação acadêmica. Sempre será exemplo de sabedoria e competência a ser perseguido.

À Profa. Dra. Regina Silveira pelo incentivo, observações e sugestões feitas durante a qualificação deste trabalho.

Aos membros da banca da banca avaliadora pelas valiosas contribuições dadas.

A todos os amigos e companheiros do LARC com quem tive a oportunidade de conviver nestes últimos cinco anos. Júnior, Romeo, Marco Simplício, Alexandre, Reinaldo, Gustavo, Raoni e Daniel, sendo pessoas nas quais aprendi bastante e que considero excelentes profissionais. Foram muitos os momentos de descontração. Ana Maria e Selma, pela atenção e prontidão. Peço desculpas caso tenha esquecido de alguém, sintam-se agradecidos, um abraço a todos.

Ao apoio recebido da Universidade do Estado do Amazonas, especialmente aos colegas da Escola Superior de Tecnologia (EST).

Ao meu amigo e afilhado Luiz Gustavo pelo apoio, sugestões, compartilhamento de ideias, parceria, principalmente pela ajuda nas revisões de texto sempre bem- 
vindas, além das discussões mesmo que tendo que debatê-las à distância. Seu incentivo foi valioso para condução deste trabalho.

Ao meu amigo Fernando Almeida pela troca de experiências profissionais e pessoais, principalmente nos momentos mais difíceis. Seu apoio foi fundamental durante a realização deste trabalho.

Aos demais amigos e familiares pela compreensão pelos momentos de ausência destinados à conclusão deste trabalho.

Não poderiam faltar alguns agradecimentos especiais.

Aos meus pais, José Cipriano e Fernanda Santos, pelo amor incondicional, dedicação e ensinamentos da vida, e todo apoio dado a cada passo na minha vida. Tenham certeza, esta conquista é nossa!

Aos meus irmãos Fabiane e Fabrício, e sobrinhos José Eduardo e Fabrício José pelo convívio, carinho e momentos de descontração. 


\section{RESUMO}

O processo de digitalização da TV em diversos países do mundo tem contribuído para o aumento do volume de programas de TV, o que gera uma sobrecarga de informação. Consequentemente, o usuário está enfrentando dificuldade para encontrar os programas de TV favoritos dentre as várias opções disponíveis. Diante deste cenário, os sistemas de recomendação destacam-se como uma possível solução. Tais sistemas são capazes de filtrar itens relevantes de acordo com as preferências do usuário ou de um grupo de usuários que possuem perfis similares. Entretanto, em diversas recomendações o interesse do usuário pode depender do seu contexto. Assim, torna-se importante estender as abordagens tradicionais de recomendação personalizada por meio da exploração do contexto do usuário, o que poderá melhorar a qualidade das recomendações. Para isso, este trabalho descreve uma infraestrutura de software de suporte ao desenvolvimento e execução de sistemas de recomendação sensíveis ao contexto para TV Digital Interativa - intitulada de PersonalTVware. A solução proposta fornece componentes que implementam técnicas avançadas para recomendação de conteúdo e processamento de contexto. Com isso, os desenvolvedores de sistemas de recomendação concentram esforços na lógica de apresentação de seus sistemas, deixando questões de baixo nível para o PersonalTVware gerenciar. As modelagens de usuário, e do contexto, essenciais para o desenvolvimento do PersonalTVware, são representadas por padrões de metadados flexíveis usados na TV Digital Interativa (MPEG-7 e TV-Anytime), e suas devidas extensões. A arquitetura do PersonalTVware é composta por dois subsistemas: dispositivo do usuário e provedor de serviços. A tarefa de predição de preferências contextuais é baseada em métodos de aprendizagem de máquina, e a filtragem de informação sensível ao contexto tem como base a técnica de filtragem baseada em conteúdo. O conceito de perfil contextual também é apresentado e discutido. Para demonstrar e validar as funcionalidades do PersonalTVware em um cenário de uso, foi desenvolvido um sistema de recomendação sensível ao contexto como estudo de caso.

Palavras-chave: TV Digital Interativa. Sistemas de Recomendação. Computação Sensível ao Contexto. Metadados. Aprendizagem de Máquina. 
ABSTRACT

The process of digitalization of TV in several countries around the world has contributed to increase the volume of TV programs offered and it leads, to information overload problem. Consequently, the user facing the difficulty to find their favorite TV programs in view of various available options. Within this scenario, the recommender systems stand out as a possible solution. These systems are capable of filtering relevant items according to the user preferences or the group of users who have similar profiles. However, the most of the recommender systems for Interactive Digital TV has rarely take into consideration the user's contextual information in carrying out the recommendation. However, in many recommendations the user interest may depend on the context. Thus, it becomes important to extend the traditional approaches to personalized recommendation of TV programs by exploiting the context of user, which may improve the quality of the recommendations. Therefore, this work presents a software infrastructure in an Interactive Digital TV environment to support context-aware personalized recommendation of TV programs - entitled PersonalTVware. The proposed solution provides components which implement advanced techniques to recommendation of content and context management. Thus, developers of recommender systems can concentrate efforts on the presentation logic of their systems, leaving low-level questions for the PersonalTVware managing. The modeling of user and context, essential for the development of PersonalTVware, are represented by granular metadata standards used in the Interactive Digital TV field (MPEG-7 and TV-Anytime), and its extensions required. The PersonalTVware architecture is composed by two subsystems: the user's device and the service provider. The task of inferring contextual preferences is based on machine learning methods, and context-aware information filtering is based on content-based filtering technique. The concept of contextual user profile is presented and discussed. To demonstrate the functionalities in a usage scenario a context-aware recommender system was developed as a case study applying the PersonalTVware.

Keywords: Interactive Digital TV. Recommender Systems. Context-Aware Computing. Metadata. Machine Learning. 


\section{LISTA DE ILUSTRAÇÕES}

Figura 1 - Componentes de um Sistema de TV Digital Terrestre (ABNT NBR 15607-

1, 2008) .26

Figura 2 - Carrossel de dados / objetos (ALVES, 2008) .................................28

Figura 3 - Middleware como plataforma para aplicações (ALVES, 2008) ...............30

Figura 4 - Exemplo de um documento XML ...............................................4 41

Figura 5 - Exemplo de componentes de um Esquema XML .............................42

Figura 6 - Visão geral do MPEG-7 Multimedia Description Schemes (MDS) (ALVES,

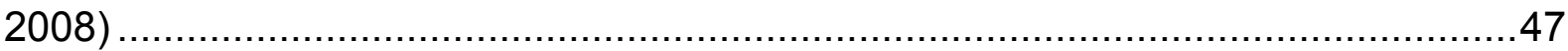

Figura 7- UserPreferences DS sumarizado (ISO/IEC 15938-5, 2003)..................48

Figura 8 - Categorias de metadados do TV-Anytime - "TVA Main" como elemento

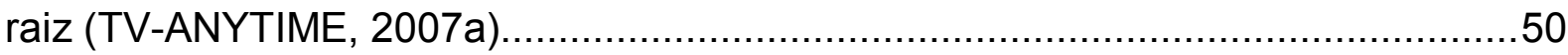

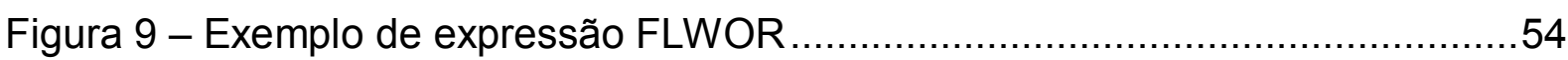

Figura 10 - Metadados recuperados como resultado da consulta ........................54

Figura 11 - Esquema de classes Adaptado de (SCHMIDT et al. 1999)..................61

Figura 12 - Classificação do contexto quanto à relevância em relação ao foco de atenção (VIEIRA et al. 2009)

Figura 13 - Sistema tradicional (a) vs. Sistema Sensível ao Contexto (b). Adaptado de (VIEIRA et al., 2009).

Figura 14 - Árvore de decisão para o conceito comprar computador (HAN; KAMBER, 2006)

Figura 15 - Modelo básico de um neurônio artificial (McCULLOCH; PITTS, 1943)...85

Figura 16 - Rede Neural Artificial Perceptron Multicamadas .86

Figura 17 - Ciclo típico de RBC. Adaptado de (PAL; SHIU, 2004) .87

Figura 18 - Casos possíveis de relações entre precisão e revocação .92

Figura 19 - Diagrama de Casos de Uso Nível 0 do PersonalTVware. 118

Figura 20 - Modelo do Usuário empregado pelo PersonalTVware 122

Figura 21- Modelagem do Contexto do Usuário. 125

Figura 22 - Etapa de aprendizagem ou treinamento 128

Figura 23 - Etapa de predição 129

Figura 24 - Arquitetura do PersonalTVware 131

Figura 25 - Exemplo de descrição de um perfil de usuário. 
Figura 26 - Exemplo de descrições de um contexto do usuário ..............................135

Figura 27 - Fragmento de uma expressão XQuery ..........................................136

Figura 28 - Fragmento do resultado da filtragem de programas de TV ................137

Figura 29 - Exemplo da descrição completa de um programa de TV......................138

Figura 30 - Diagrama de Atividades do Processo de Recomendação ....................141

Figura 31 - Diagrama de Classes - Dispositivo do Usuário ..................................... 143

Figura 32 - Diagrama de Classes - Provedor de Serviços....................................... 146

Figura 33 - Caso de uso: Solicitar Recomendação de Programas de TV ...............150

Figura 34 - Exemplo de perfil de usuário com preferências inferidas...................... 151

Figura 35- Exemplo de uma lista de programas de TV filtrados...........................153

Figura 36 - Caso de uso: Executar Realimentação de Relevância de forma explícita 155

Figura 37 - Caso de uso: Executar Realimentação de Relevância de forma implícita 157

Figura 38 - Caso de uso: Gerar Modelos de Conhecimento ................................159

Figura 39- Integração entre sistema de recomendação e PersonalTVware API .....162

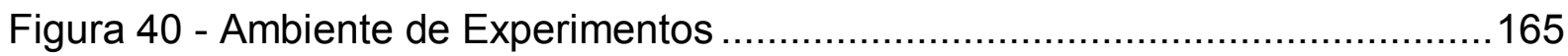

Figura 41 - Tela de Recomendação de Programas de TV ....................................166

Figura 42 - Tela de Informações sobre Programa de TV .....................................166

Figura 43 - Método Holdout. Adaptado de (HAN; KAMBER, 2006)....................... 168

Figura 44 - Etapas da metodologia para realização de experimentos......................168

Figura 45 - Arquivo ARFF com perfis contextuais de usuários...............................169 


\section{LISTA DE GRÁFICOS}

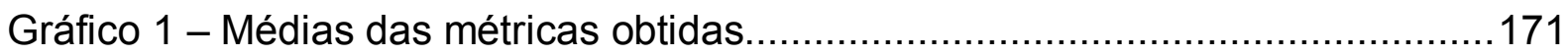

Gráfico 2 - Precisão-Revocação da eficiência do sistema de recomendação .........173

Gráfico 3 - Recomendações baseadas em perfil do usuário ...............................176

Gráfico 4 - Recomendações sensíveis ao contexto...................................... 177 


\section{LISTA DE TABELAS}

Tabela 1- Técnicas de representação de contexto (VIEIRA et al. 2009)..... 71

Tabela 2 - Comparação entre Projetos de Suporte a Sistemas de Recomendação para TV Digital

Tabela 3 - Descrição do Modelo do Usuário ………………..............................123

Tabela 4 - Descrição do Contexto do Usuário.....................................................126

Tabela 5 - Atributos que compõem o perfil contextual do usuário...........................127

Tabela 6 - Comparação entre as médias da métricas obtidas ................................170

Tabela 7 - Tempo de criação dos modelos de conhecimento ................................174 


\section{LISTA DE ABREVIATURAS E SIGLAS}

8-VSB $\quad 8$ Level - Vestigial Side Band

AAC Advanced Audio Coding

ABNT Associação Brasileira de Normas Técnicas

API Application Programming Interface

ARFF Attribute-Relation File Format

ARIB Association of Radio Industries and Businesses

ATSC Advanced Television Systems Committee

AVATAR Advanced Telematic search of Audiovisual contents by

BML Broadcast Markup Language

BST-OFDM Band Segmented Transmission - OFDM

CART Classification and Regression Trees

CDMA Code-Division Multiple Access

COFDM Coded Orthogonal Frequency Division Multiplexing

CSS Context-Sensitive System

CRID Content Reference IDentifier

DASE DTV Application Software Environment

DAVIC Digital Áudio Video Council

DDL Description Definition Language

DS Description Scheme

DSL Digital Subscriber Line

DSM-CC Digital Storage Media - Command and Control

DVB Digital Video Broadcasting

DVD Digital Video Disk

DVB-H Digital Video Broadcasting - Handheld

DVR Digital Video Recorder

EPG Electronic Program Guide

EIT Event Information Table

FBC Filtragem Baseada em Conteúdo 


\begin{tabular}{ll} 
FC & Filtragem Colaborativa \\
FH & Filtragem Híbrida \\
GPS & Global Positioning System \\
GSM & Global System for Móbile Communication \\
HDTV & High Definition Television \\
HTML & Hypertext Markup Language \\
HTTP & Hypertext Transfer Protocol \\
ID3 & Iteractive Dichotomiser \\
IP & Internet Protocol \\
ISDB & Integrated Services Digital Broadcasting \\
ISDB-TB & International Service Digital Broadcasting - Terrestrial Brazil \\
ISDN & Integrated Services Digital Network \\
ISO & International Organization for Standardization \\
ITU & International Telecommunication Union \\
LDTV & Low Definition Television \\
MDS & Multimedia Description Schemes \\
MID & Mobile Internet Device \\
MHP & Multimedia Home Plataform \\
MPE & MultiProtocol Encapsulation \\
MPEG & Moving Picture Experts Group \\
MVC & Model View Controller \\
NCL & Nested Context Language \\
OWL & Web Ontology Language \\
PDA & Personal Digital Assistant \\
PDR & Personal Digital Recorder \\
PMT & Programs Mapping Table \\
PSI & Program Specific Information \\
PSTN & Public Swiched Telephone Network \\
PTV & Personal TV \\
PVR & Personal Video Recorder \\
\hline
\end{tabular}




\begin{tabular}{|c|c|}
\hline P3P & Platform for Privacity Preference \\
\hline QoS & Quality of Service \\
\hline RNAs & Redes Neurais Artificiais \\
\hline SAX & Simple API for XML \\
\hline SBC & Sociedade Brasileira da Computação \\
\hline SBTVD & Sistema Brasileiro de Televisão Digital \\
\hline SDTV & Standard Definition Television \\
\hline SDT & Service Description Table \\
\hline SOAP & Simple Object Access Protocol \\
\hline SI & Service Information \\
\hline SQL & Structured Query Language \\
\hline STB & Set-Top Box \\
\hline TCP & Transmission Control Protocol \\
\hline TDT & Time and Data Table \\
\hline TS & Transport Stream \\
\hline UML & Unified Modeling Language \\
\hline UMTS & Universal Mobile Telecommunication System \\
\hline URI & Uniform Resource Identifier \\
\hline URL & Uniform Resource Locator \\
\hline URN & Universal Resource Name \\
\hline USB & Universal Serial Bus \\
\hline VOD & Video on Demand \\
\hline WAP & Wireless Application Protocol \\
\hline W3C & World Wide Web Consortium \\
\hline WEKA & Waikato Environment for Knowledge Analysis \\
\hline WSDL & Web Service Definition Language \\
\hline WWW & World Wide Web \\
\hline XML & eXtensible Markup Language \\
\hline XSD & XML Schema Definition \\
\hline
\end{tabular}




\section{SUMÁRIO}

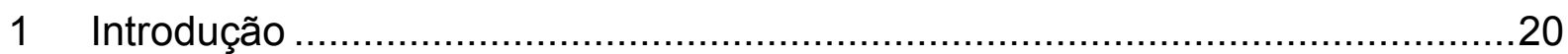

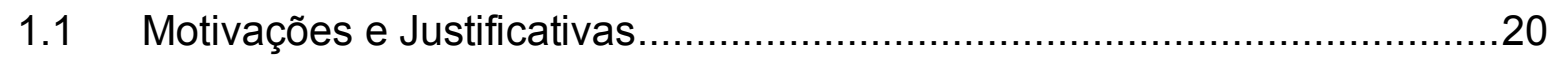

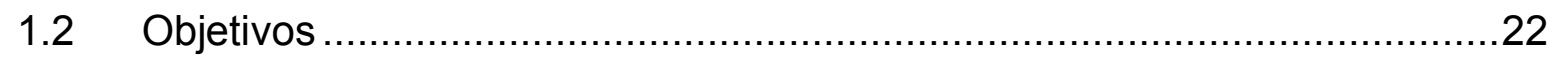

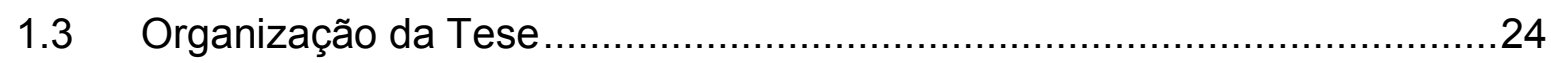

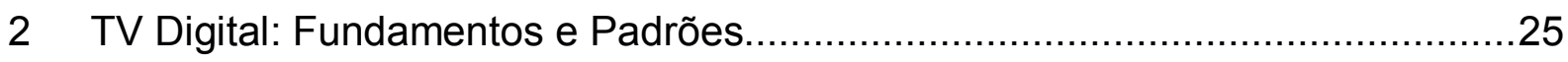

2.1 Componentes de um Sistema de TV Digital .........................................26

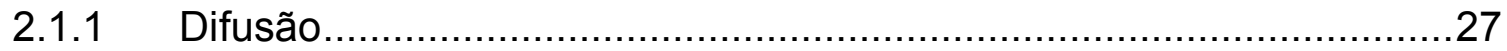

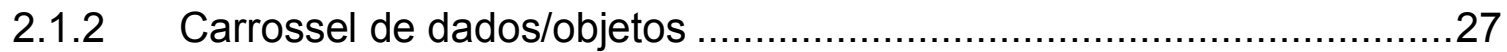

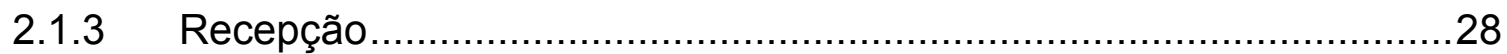

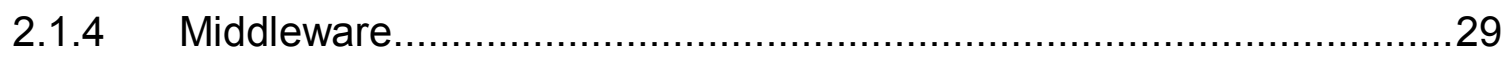

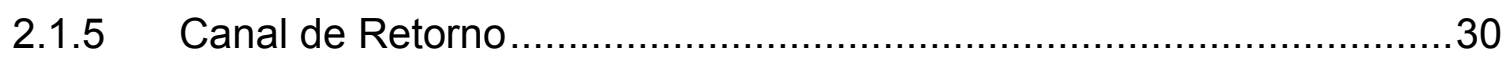

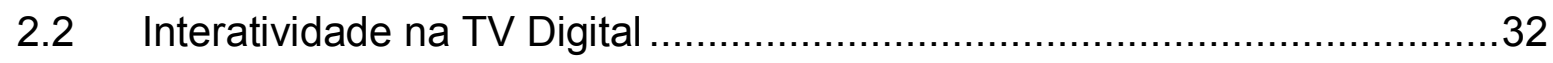

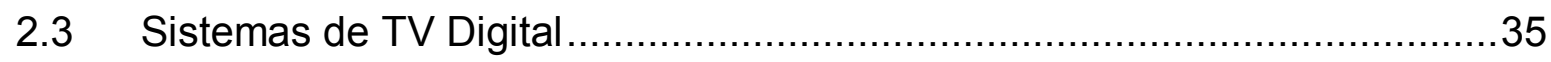

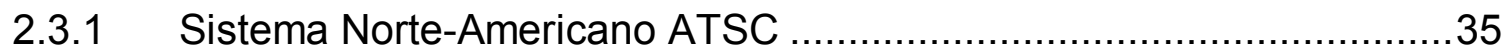

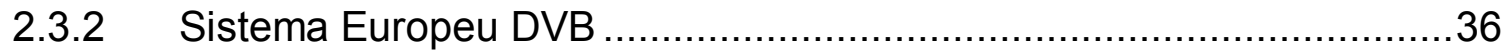

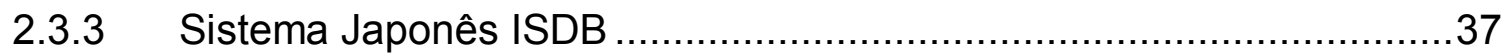

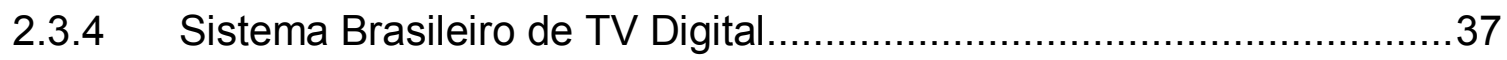

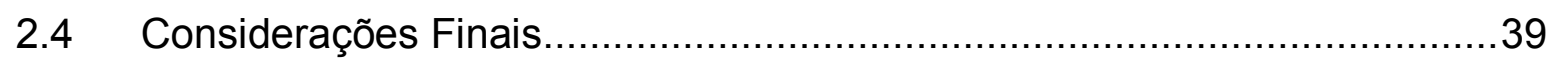

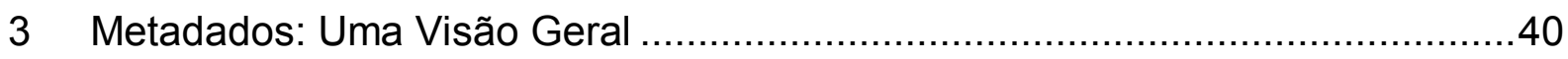

3.1 Representação de Metadados: XML e Esquemas XML ............................40

3.2 Metadados no Cenário da TV Digital Interativa.......................................43

3.3 Padrões de Metadados para TV Digital Interativa..................................44

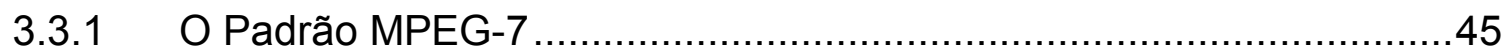

3.3.1.1 Preferências do Usuário (UserPreferences DS) ……….................47

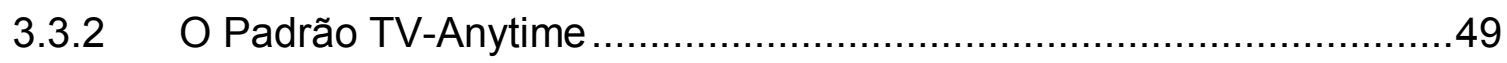

3.3.2.1 Metadados de Descrição de Conteúdo ..........................................52

3.3.2.2 Metadados de Descrição de Instância............................................52

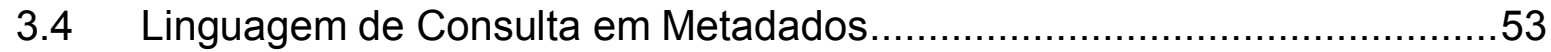

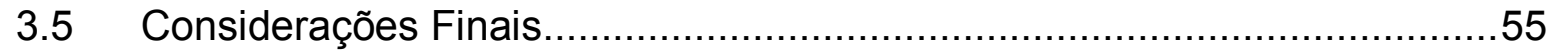

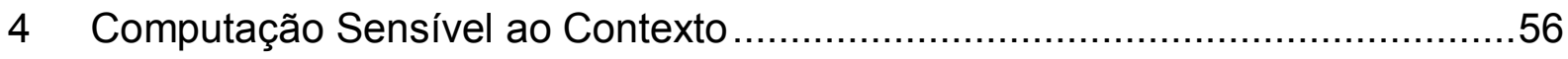




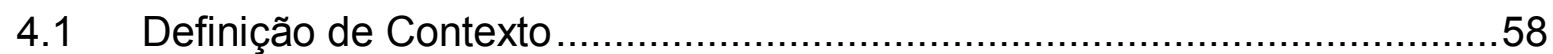

4.2 Dimensões Semânticas de Informações de Contexto.................................60

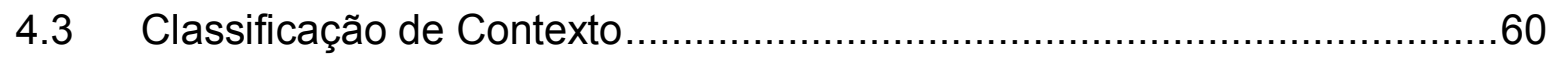

4.4 Sistemas Sensíveis ao Contexto............................................................63

4.4.1 Sistemas Tradicionais vs Sistemas Sensíveis ao Contexto ..................64

4.5 Requisitos para o Desenvolvimento de Sistemas Sensíveis ao Contexto ..66

4.5.1 Especificação de Informação de Contexto..........................................66

4.5.2 Separar Aquisição da Utilização da Informação de Contexto ...............67

4.5.3 Interpretação de Informações de Contexto ........................................67

4.5.4 Comunicação Distribuída e Transparente.........................................68

4.5.5 Aquisição Contínua de Informações de Contexto ..................................68

4.5.6 Armazenamento de Informações de Contexto .....................................69

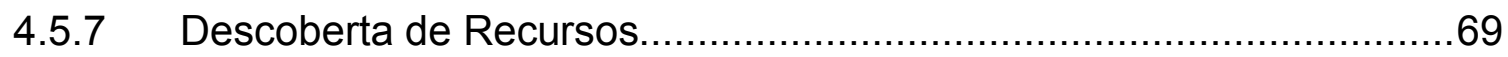

4.6 Técnicas para Representação de Contexto ............................................70

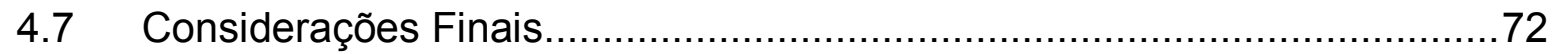

5 Recomendação Personalizada de Conteúdo ..................................................73

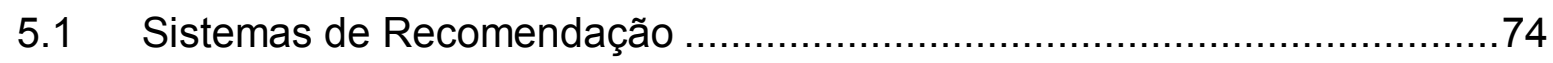

5.1.1 Sistemas de Recomendação Sensíveis ao Contexto …………….......75

5.2 Coleta de Informações Sobre os Usuários...............................................76

5.3 Técnicas de Filtragem de Informação ....................................................77

5.3.1 Filtragem Baseada em Conteúdo (FBC) .....................................78

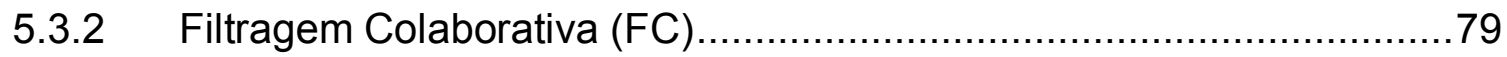

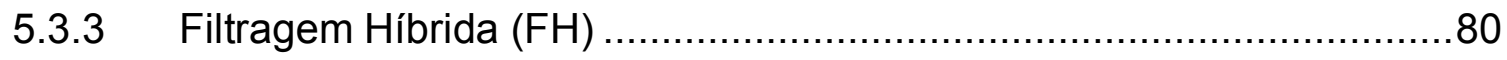

5.4 Aprendizagem de Máquina e Predição ..................................................

5.4.1 Indução de Árvore de Decisão...................................................... 83

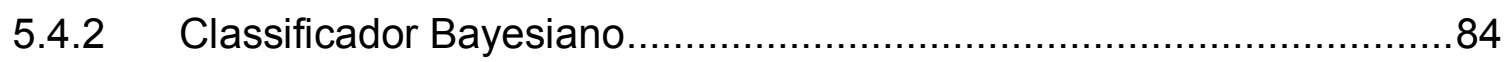

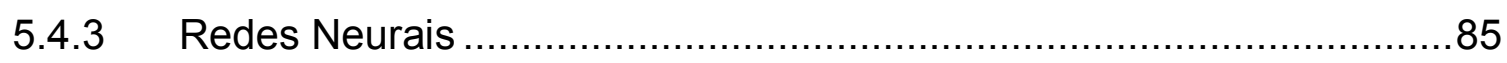

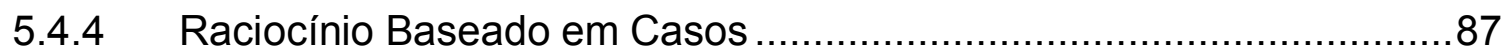

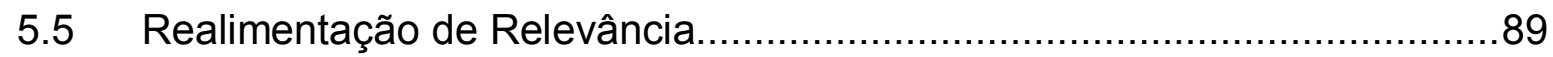

5.6 Métricas para Avaliação de Sistemas de Recomendação ..........................90

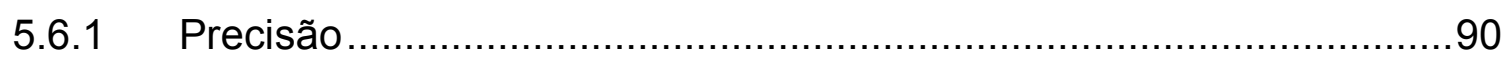

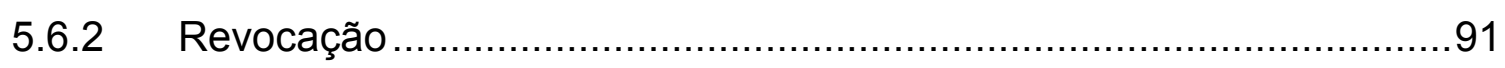

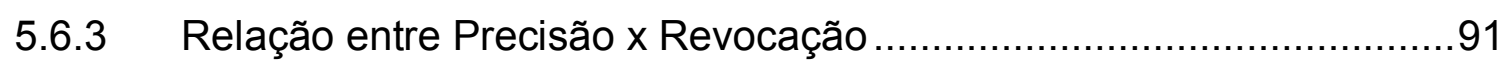

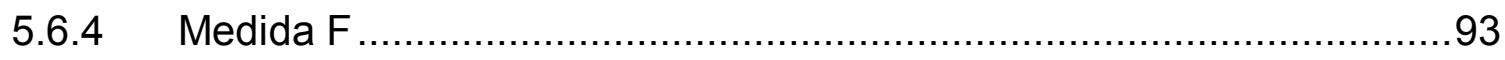


5.7 Privacidade e Segurança das Informações ...............................................93

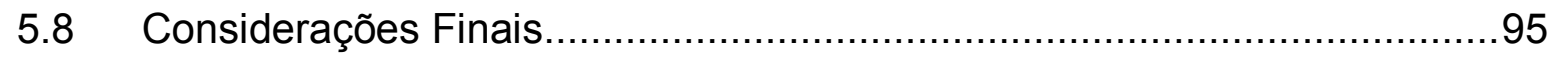

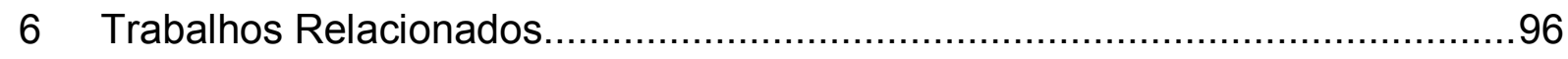

6.1 Um Sistema de Guia de TV Personalizada: Uma Abordagem para Televisão

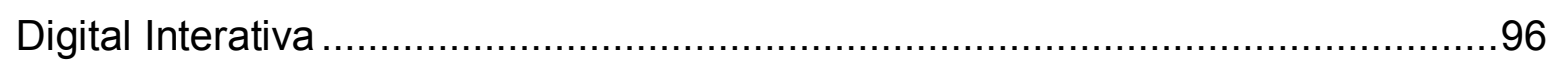

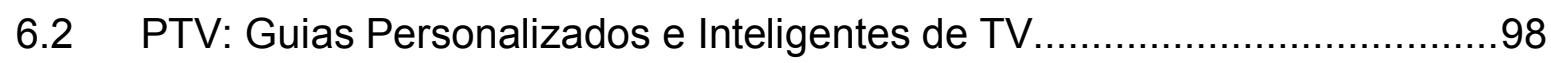

6.3 Personalização para Televisão Digital Utilizando a Estratégia de Sistemas de Recomendação para Ambientes Multiusuário ………………………….......99

6.4 Um Sistema de Guia de TV Personalizada Compatível com MHP ...........101

6.5 AVATAR: Uma Solução Aprimorada para TV Personalizada baseada em

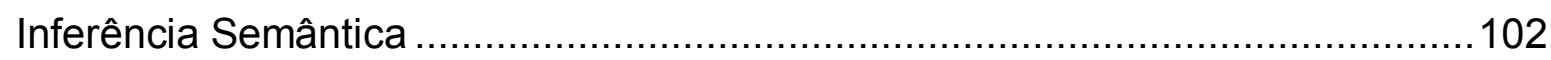

6.6 Recomendação Personalizada de Programas de TV baseada em

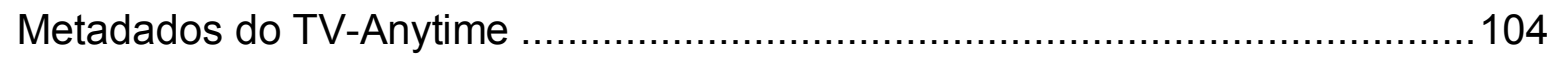

6.7 IndexTV: Um Sistema de Recomendação baseado em MPEG-7 para TV Digital 106

6.8 Sistema de Recomendação de TV Personalizada Dinâmica ....................107

6.9 SenSee Framework para Acesso Personalizado ao Conteudo da TV ......108

6.10 Comparação entre os Trabalhos Apresentados ........................................110

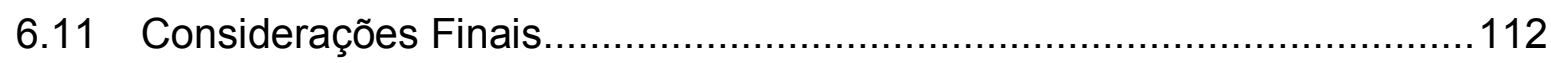

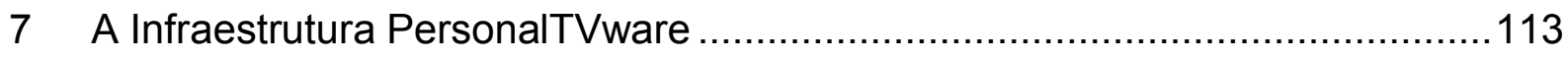

7.1 Descrições de Cenários de Uso.......................................................113

7.2 Levantamento de Requisitos da Infraestrutura.....................................114

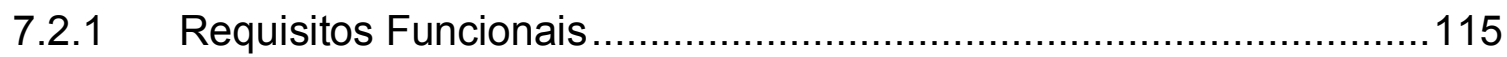

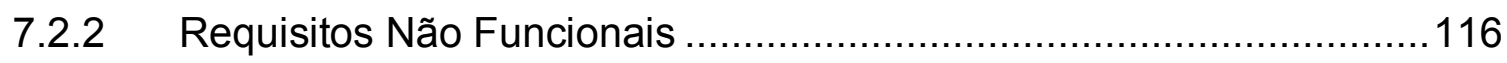

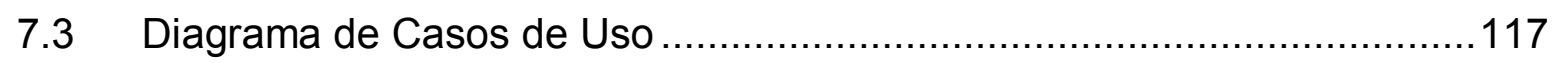

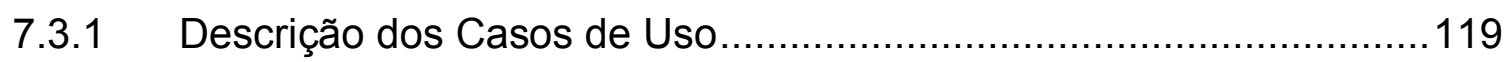

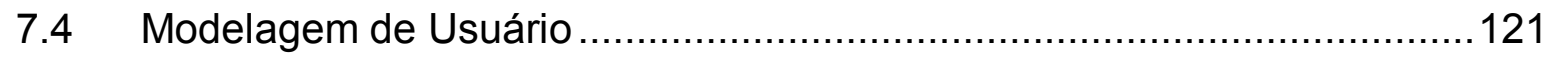

7.5 Modelagem de Contexto do Usuário ..................................................124

7.6 Abordagem de Recomendação Personalizada Sensível ao Contexto ......126

7.6.1 Conceito de Perfil Contextual do Usuário ..........................................127

7.6.2 Aprendizagem Supervisionada Dependente do Contexto ..................128

7.6.3 Predição de Preferências Contextuais .............................................129

7.6.4 Filtragem de Informação Sensível ao Contexto ...............................130

7.7 Arquitetura do PersonalTVware ........................................................ 131 


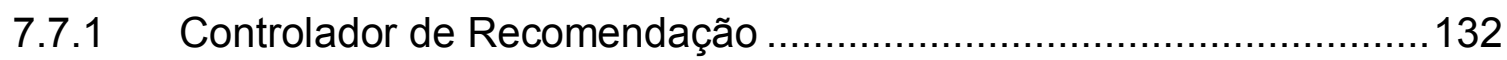

7.7.2 Gerenciador de Perfil do Usuário ....................................................133

7.7.3 Gerenciador de Contexto do Usuário.................................................. 134

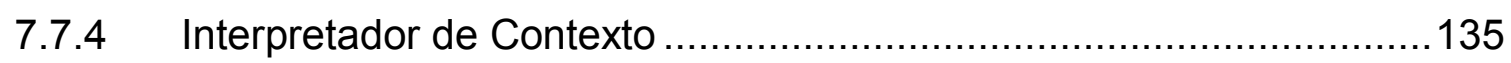

7.7.5 Filtro Sensível ao Contexto ......................................................... 136

7.7.6 Gerenciador de Programas de TV .................................................. 137

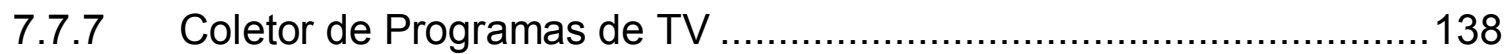

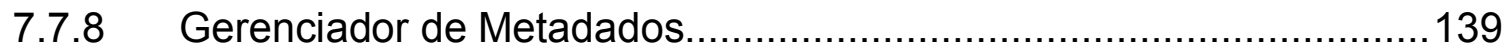

7.7.9 Interface de Comunicação ...........................................................139

7.7.10 Despachante de Requisição .................................................... 140

7.8 Processo de Recomendação Sensível ao Contexto ................................140

7.9 Projeto e Implementação do Protótipo ..................................................... 142

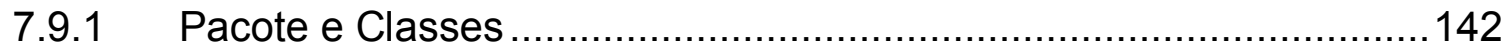

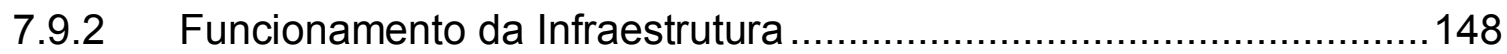

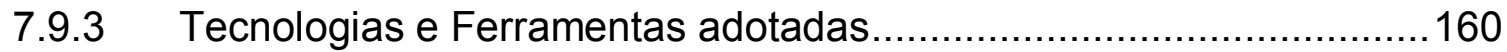

7.10 Integração do PersonalTVware com os Sistemas de Recomendação......161

7.11 Considerações Finais......................................................................... 162

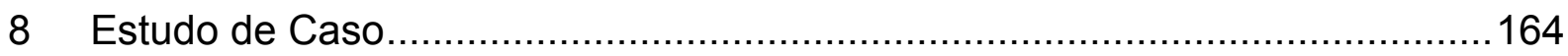

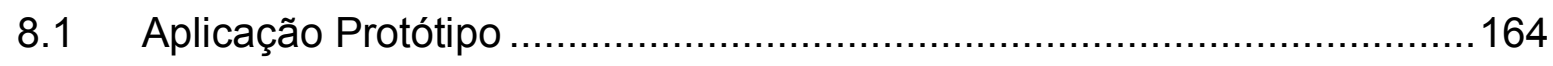

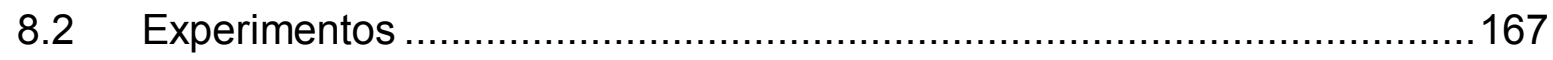

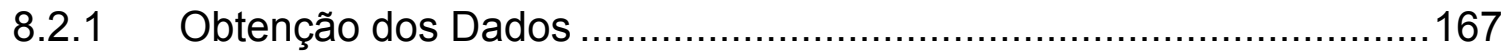

8.2.2 Metodologia para Realização de Experimentos...............................168

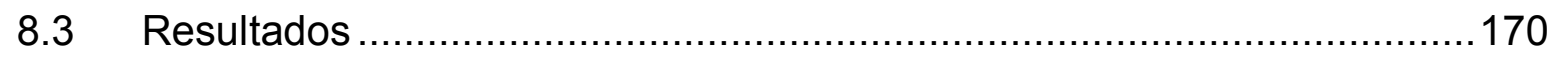

8.3.1 Avaliação Centrada no Usuário - Grau de Satisfação .......................175

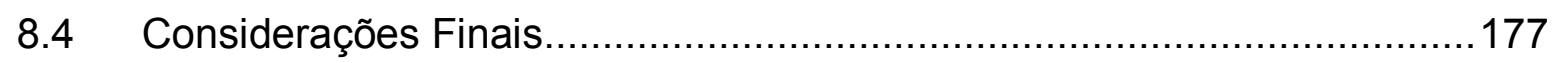

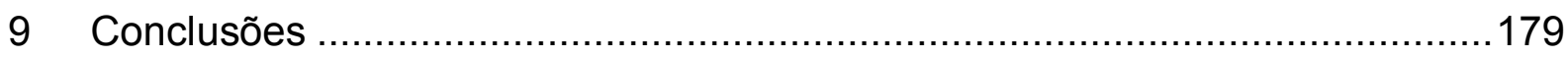

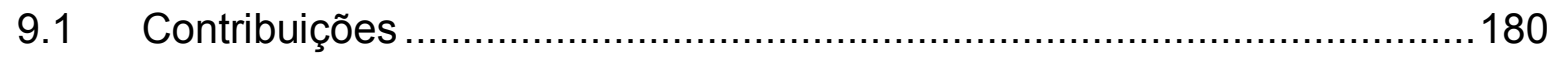

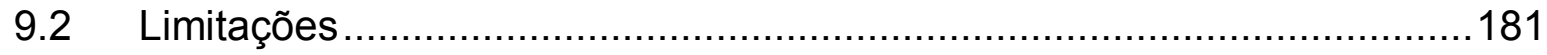

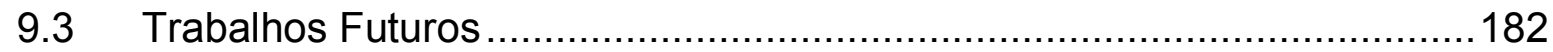

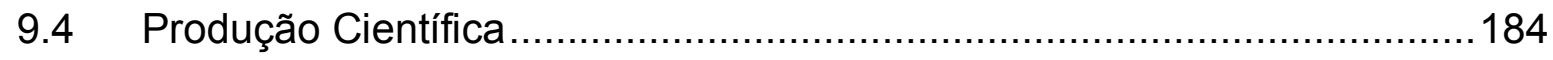

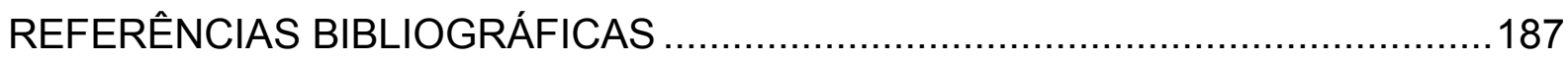

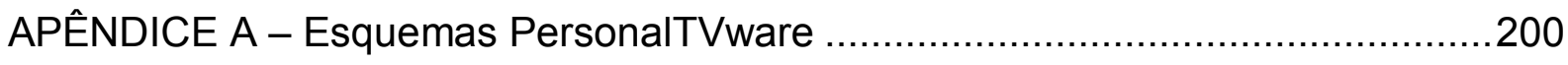

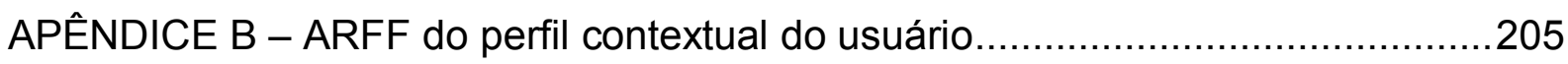

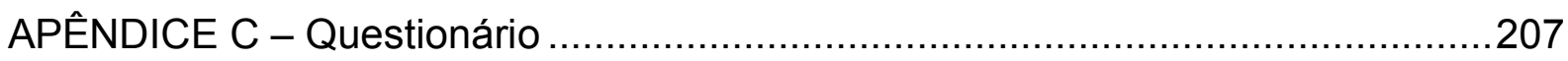




\section{Introdução}

Nos últimos anos, em diversos países do mundo, incluindo o Brasil, a televisão passa por um processo de transição do modelo analógico para o digital, o que representa um importante avanço deste popular meio de comunicação. $O$ modelo analógico apresenta diversas limitações que inviabilizam a possibilidade de desenvolvimento de serviços audiovisuais mais avançados, e que ofereçam uma experiência televisiva mais rica para os usuários.

Em contraste, por meio da TV Digital é possível a transmissão de conteúdo de alta qualidade de imagem e som, o acesso ao conteúdo de forma ubíqua, ou seja por meios de dispositivos portáteis e móveis, a multiprogramação, e a interatividade. Vale ressaltar que a TV Digital Interativa possibilita aos usuários a comunicação com os provedores de serviço, substituindo o modelo unidirecional da TV analógica de sentido único.

Desta forma, a TV Digital Interativa amplia a experiência televisiva dos usuários por meio da exploração de recursos avançados. Além disso, possibilita a criação de novos modelos de negócios, e o desenvolvimento de serviços sociais relevantes, que podem viabilizar o acesso ao mundo digital para uma grande parcela da população. Dentro desse contexto, a TV Digital Interativa é um área que tem despertado interesse da comunidade acadêmica e também da indústria no que se refere ao desenvolvimento de pesquisas, padrões, novas tecnologias e produtos.

\subsection{Motivações e Justificativas}

Um dos aspectos mais importantes do advento da TV Digital Interativa foi o crescimento do volume de conteúdos oferecidos ao usuário no ambiente da televisão. Consequentemente, o usuário está enfrentando dificuldade para encontrar e escolher de forma amigável os programas de TV que são de seu interesse dentre as várias opções disponíveis (ZHANG; ZHENG; YUAN, 2005). Este problema supracitado é conhecido na literatura como sobrecarga de informação, sendo muito 
comum na Internet (BLANCO-FERNANDEZ, 2007). De acordo com o SBC (2006), torna-se um grande desafio para pesquisa em computação nos próximos anos, o desenvolvimento de soluções para recuperação e gerenciamento de grandes volumes de informação e conteúdo multimídia distribuído. Por exemplo, de acordo com os pesquisadores Zhang, Zheng e Yuan (2005), em Shangai, uma operadora de TV pode agora fornecer 110 diferentes canais (ou serviços) de TV Digital os quais correspondem ao dobro dos canais analógicos e este número está aumentando numa taxa de $20 \%$ por ano.

Diante deste cenário, a ferramenta tradicional para pesquisa e seleção de conteúdo na TV Digital denominada de Guia Eletrônico de Programação (do inglês, Electronic Program Guide - EPG) apresenta uma grande quantidade de páginas com informações sobre os programas de TV transmitidos. Normalmente, o usuário não tem paciência de investir muito tempo navegando pelas páginas a procura de informações sobre um conteúdo que é de seu interesse (SILVA; ALVES; BRESSAN, 2010). Além disso, as informações apresentadas através do EPG são sempre as mesmas para todos os usuários, pois o EPG normalmente não distingue os diferentes usuários que buscam informações.

Assim, as ferramentas de pesquisa e acesso personalizado a programação da TV ocupam papel relevante. Os sistemas de recomendação destacam-se como uma possível solução para permitir acesso personalizado ao conteúdo da TV Digital. Os sistemas de recomendação filtram de forma automática itens relevantes de acordo com as preferências do usuário ou de um grupo de usuários que possuem perfis similares. No entanto, a maioria da geração atual dos sistemas de recomendação raramente considera informações contextuais e o processo de recomendação é baseado em um espaço de duas dimensões Usuário x Item (ADOMAVICIUS; TUZHILIN, 2005). Com isso, a incorporação das informações de contexto durante o processo de recomendação é ressaltado em (BALTRUNAS, 2008), como uma abordagem inovadora e promissora para aprimoramento dos sistemas de recomendação tradicionais.

No domínio da TV Digital Interativa, em diversos cenários de uso, a relevância de um gênero de programa de TV para o usuário pode depender também do contexto do usuário, e do conteúdo. Deste modo, no caso dos sistemas de recomendação para TV Digital Interativa, torna-se necessário considerar além do perfil do usuário também informações contextuais. Por exemplo, quem é o usuário e 
quando ele assiste a um determinado programa de TV? No domingo pela manhã? Ou na segunda-feira ao anoitecer quando chega do trabalho? Onde e como o programa de TV será visto? Em sua casa por meio de um receptor de TV Digital fixo conectado na TV de alta resolução? Ou na escola no intervalo das aulas por meio de sua TV portátil? Qual é o gênero de programa de TV considerado apropriado naquela situação em que o usuário assiste TV? $O$ que o usuário está fazendo enquanto assiste TV? (SILVA; ALVES; BRESSAN, 2009).

Diante dos fatos expostos, a hipótese levantada nesta tese é que dependendo do perfil do usuário e também do contexto, o usuário poderá ter preferências diferentes por gêneros de programas de TV. Desta forma, incorporação de informações contextuais em sistemas de recomendação voltados para TV Digital Interativa poderá melhorar a qualidade das recomendações. Surge, assim, à necessidade de predizer as preferências contextuais por gêneros de programas de TV por meio da exploração do perfil e contexto do usuário de forma agregada para então fornecer recomendações de programas de TV.

A princípio, o contexto não deve ser somente explorado como fonte de informação adicional para expansão de consultas (AROYO et al., 2007), ou incorporado antes, ou depois da etapa de recomendação para adaptação da apresentação, abordagens comumente empregadas em muitos trabalhos (ADOMAVICIUS; TUZHILIN, 2008). Este trabalho advoga a possibilidade de aprendizagem sobre o contexto e consequentemente raciocínio para predição de preferências contextuais do usuário no domínio da TV Digital Interativa. Neste sentido, é preciso investigar e desenvolver infraestruturas especialmente projetadas de suporte a sistemas de recomendação sensíveis ao contexto para o domínio da TV Digital Interativa, que explorem o estado da arte dos métodos de recomendação de conteúdo, aprendizagem de máquina e processamento de contexto.

\subsection{Objetivos}

Conforme a motivação apresentada na seção anterior referente ao problema da sobrecarga de informação no domínio da TV Digital definiu-se como título para este trabalho: "PersonalTVware: Uma Infraestrutura de Suporte a Sistemas de 
Recomendação Sensíveis ao Contexto para TV Digital Personalizada". Esta tese tem como objetivo principal mostrar que a exploração do contexto além do perfil do usuário pode melhorar a qualidade das recomendações de sistemas de recomendação voltados para TV Digital Interativa. Desta forma, foi concebida uma infraestrutura de software alinhada aos padrões de TV Digital Interativa para suporte ao desenvolvimento e execução de sistemas de recomendação sensíveis ao contexto para TV Digital Interativa.

A solução proposta foi intitulada de PersonalTVware, pois deverá oferecer componentes que abstraem a complexidade das técnicas para recomendação de conteúdo e processamento de contexto. Com isso, os desenvolvedores de sistemas de recomendação concentram esforços na lógica de apresentação de seus sistemas, deixando questões de baixo nível para o PersonalTVware gerenciar. Para atingir o objetivo geral descrito acima será necessário cumprir uma série de objetivos específicos listados a seguir:

- Modelar as principais informações do perfil do usuário e contexto que possam ser úteis para a infraestrutura;

- Investigar as técnicas utilizadas para representação do perfil do usuário e o seu contexto;

- Empregar padrões de metadados flexíveis para descrição de conteúdo na TV Digital e, quando necessário estendê-los;

- Implementar técnica de filtragem de informação de suporte a sistemas de recomendação;

- Implementar diferentes técnicas e métodos de aprendizagem de máquina para a tarefa de predição de preferências contextuais;

- Validar a infraestrutura proposta por meio do desenvolvimento de um sistema de recomendação sensível ao contexto para TV Digital Interativa;

- Conduzir experimentos para analisar e avaliar a qualidade das recomendações obtidas a partir da infraestrutura. 


\subsection{Organização da Tese}

Esta tese está estruturada em nove capítulos. Neste primeiro capítulo foram apresentadas as motivações e justificativas do trabalho, além dos objetivos. O capítulo 2 visa apresentar uma visão geral da TV Digital Interativa, descrevendo os seus principais componentes, tecnologias e sistemas de TV Digital correntes. Além disso, são discutidos também aspectos sobre interatividade.

O capítulo 3 aborda os fundamentos sobre metadados, técnicas para representação, linguagem de consulta e padrões de metadados empregados na TV Digital Interativa (MPEG-7 e TV-Anytime), destacando a importância da exploração de metadados flexíveis neste trabalho. O capítulo 4 apresenta os principais conceitos relacionados à Computação Sensível ao Contexto. São definidos contexto e sistemas sensíveis ao contexto, também são descritos os tipos de informação de contexto e as classes de contexto. Além disso, são apresentados os requisitos necessários para o desenvolvimento de sistemas sensíveis ao contexto.

O capítulo 5 aborda os principais conceitos relacionados aos sistemas de recomendação. É apresentada a definição de sistemas de recomendação e são descritas as principais técnicas para filtragem de informação, aprendizagem de máquina e atualização do perfil do usuário. Também são apresentadas métricas para avaliação da qualidade de sistemas de recomendação. O capítulo 6 apresenta uma análise de trabalhos encontrados na literatura que exploram contexto e sistemas de recomendação para TV Digital que mais se correlacionam com o tema proposto.

A infraestrutura PersonalTVware é apresentada no capítulo 7. Este capítulo descreve os possíveis cenários de uso nos quais a solução proposta está inserida, o levantamento de requisitos, bem como o projeto do PersonalTVware em si, incluindo a arquitetura, o detalhamento do projeto através de diagramas UML (Unified Modeling Language) (BOOCH; RUMBAUGH; JACOBSON, 1999) e a implementação do protótipo. O capítulo 8 apresenta um estudo de caso que tem como objetivo validar as funcionalidades da infraestrutura e avaliar a qualidade das recomendações obtidas. Finalmente, o capítulo 9 encerra esta tese apresentando as conclusões, contribuições, limitações encontradas e sugestões de trabalhos futuros que poderão dar continuidade a este trabalho. 


\section{TV Digital: Fundamentos e Padrões}

Com o avanço da tecnologia digital surge um novo sistema para difusão e recepção do sinal de TV, denominado de TV Digital Interativa que apresenta novos recursos, como a flexibilidade para oferecer multiprogramação, alta qualidade de imagem e som, acesso à Internet e principalmente a possibilidade de execução de aplicativos interativos. Um dos principais avanços da TV Digital Interativa é a mudança de comportamento do usuário com relação ao modo como este assiste TV. Neste novo cenário, de forma similar como ocorre na WWW (World Wide Web) o usuário tem agora a possibilidade de usar seu dispositivo de acesso fixo, portátil ou móvel para interagir com conteúdos, o que representa uma evolução na forma como o conteúdo é produzido, distribuído e consumido.

Os formatos de resolução de imagem mais utilizados são: HDTV (High Definition Television), SDTV (Standard Definition Television), e LDTV (Low Definition Television). O HDTV possui imagem superior em relação aos demais formatos e a razão de aspecto 16:9 que fornece a visão tela ampla (widescreen). No entanto, necessita de elevada taxa de transmissão de dados, o que ocupa praticamente toda a banda do canal. O formato SDTV é equivalente ao sinal de vídeo de um DVD, cuja razão de aspecto é 4:3. Este formato, pelo fato de possuir uma resolução menor do que o formato HTDV permite que até quatros subcanais sejam multiplexados e transmitidos em uma mesma largura de banda. Por fim, o formato LDTV é o que possui menor resolução sendo normalmente utilizado em transmissões para unidades receptoras portáteis.

No que se refere ao som, é possível por meio das técnicas de compressão de dados a transmissão de áudio no padrão 5.1 (multicanal), proporcionando ao usuário maior sensibilidade auditiva e sensação de imersão nas cenas. Assim, o principal objetivo deste capítulo é apresentar os fundamentos sobre a TV Digital Interativa. Na seção seguinte 2.1 serão descritos os principais componentes de um sistema de TV Digital. Em seguida, na seção 2.2, aborda o assunto interatividade na TV Digital. A seção 2.3 apresenta uma visão geral dos principais sistemas de TV Digital existentes no mundo, descrevendo, ainda nesta seção, o sistema brasileiro. 
Finalmente, na seção 2.4 apresenta algumas considerações sobre o emprego dos conceitos apresentados neste capítulo para realização deste trabalho.

\subsection{Componentes de um Sistema de TV Digital}

A Figura 1 apresenta uma visão geral do modelo clássico de funcionamento da TV Digital, que é baseado em um modelo de referência criada pela União Internacional de Telecomunicações (International Telecommunication Union - ITU) e é adotado pelos sistemas de TV Digital (ABNT NBR 15607-1, 2008).

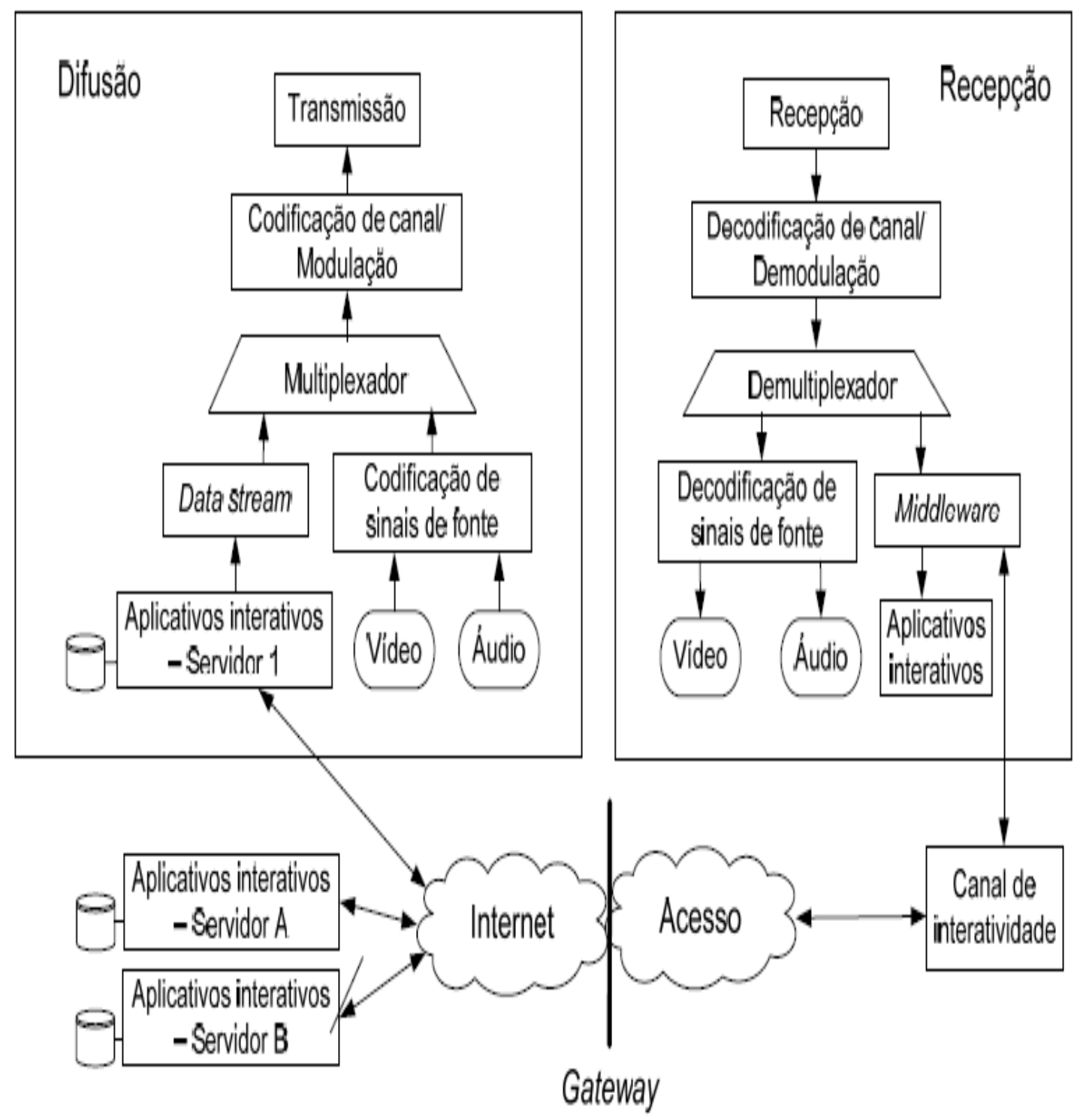

Figura 1 - Componentes de um Sistema de TV Digital Terrestre (ABNT NBR 15607-1, 2008) 


\subsubsection{Difusão}

A TV Digital Interativa é um sistema de radiodifusão que utiliza técnicas avançadas de codificação, multiplexação e modulação para transmitir dados digitais (vídeo, áudio e software) para a unidade receptora do consumidor (REIMERS, 2004). A Figura 1 ilustra o modelo de difusão para TV Digital Interativa, que é dividido em três etapas. A primeira delas consiste na codificação e compressão dos sinais de vídeo e áudio analógicos em um formato digital, usualmente utilizando os padrões MPEG.

Os fluxos de áudio e vídeo são denominados de fluxo elementar (elementary stream). Além da codificação de fluxos de áudio de vídeo, também é possível a transmissão de fluxo de dados, que podem ser aplicações interativas, informações adicionais para as aplicações em forma de metadados, dentre outros. A próxima etapa consiste na multiplexação de todos os fluxos elementares, de modo a formar um fluxo de transporte.

Este fluxo de transporte é codificado e transportado de acordo com as especificações do MPEG-2 System: Transport Stream (ISO/IEC 13818-1, 2000). Além dos fluxos elementares multiplexados, o fluxo de transporte também pode incluir as tabelas de informações de serviços (SI - Service Information) que descrevem os canais e programas de TV (agora denominados de serviços e eventos). Por fim, na ultima etapa é executada a modulação do sinal digital para que este possa ser transmitido por meios de difusão.

\subsubsection{Carrossel de dados/objetos}

São os mecanismos que permitem a transmissão de dados (transmissão das aplicações interativas assim como seus recursos), de forma periódica (ou cíclica) de um determinado conjunto de dados / objetos sobre um fluxo de transporte (Figura 2), para os receptores. Deste modo, quando o receptor necessitar de um conjunto de dados que ainda não tenha recebido, deverá aguardar a próxima repetição. 
Os carrosséis são definidos por meio do padrão DSM-CC (Digital Storage Media - Command and Control) (ISO/IEC 13818-6, 1996). Existem dois tipos de mecanismos utilizados para difusão de dados: carrossel de dados e carrossel de objetos.

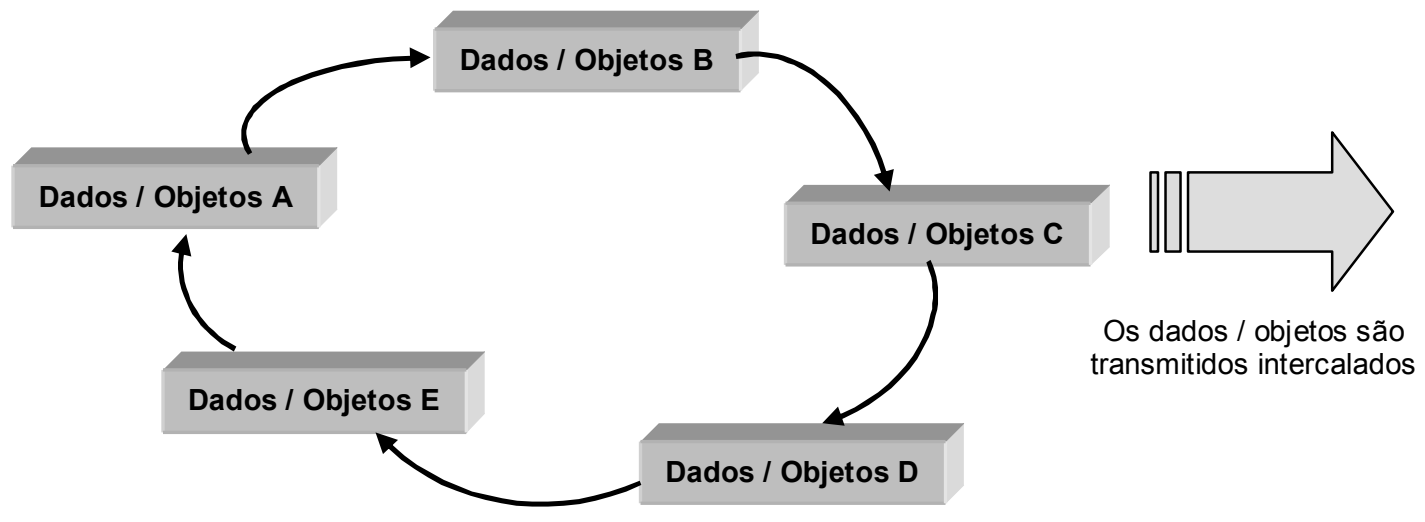

Figura 2 - Carrossel de dados / objetos (ALVES, 2008)

O carrossel de dados organiza os dados logicamente em módulos que devem ser tratados pela aplicação. Um módulo é definido como um item simples e completo de dados. Por exemplo, arquivos de imagens JPEG, de música MID, documento XML etc. Já o carrossel de objetos trata as informações na forma de objetos, sendo que na difusão de dados, há os objetos do tipo arquivo e do tipo diretório que formam um sistema de arquivo simples. Por meio deste sistema de arquivos o receptor é capaz de acessar arquivos que estão sendo difundidos como se os mesmos estivessem disponíveis localmente (MONTEZ; BECKER, 2005).

\subsubsection{Recepção}

Conforme ilustrado na Figura 1 a recepção do sinal da TV Digital Interativa é realizada por meio de receptores dotados de componentes, que realizam as etapas: demodulação, demultiplexação e decodificação. Na etapa de demodulação, é onde se obtêm o fluxo de transporte MPEG-2. Em seguida na etapa de demultiplexação, os fluxos elementares são extraídos, e finalmente, na etapa de decodificação os fluxos elementares são convertidos para o formato apropriado de exibição. 
Os receptores também são dotados de poder computacional, o qual permite a execução de aplicativos interativos. Com isso, o hardware possui tecnologias que são utilizadas também em computadores, tais como processador, memórias, discos rígidos para armazenamento de dados, modem para canal de retorno e interfaces de entrada e saída. No entanto, quando comparados a um computador, os receptores possuem capacidades menores de processamento e limitações de memória e armazenamento.

Os receptores podem estar embarcados nos próprios aparelhos de TV, ou ser um dispositivo independente como um conversor digital (ou set-top box). Além disso, também é possível utilizar placas de captura do sinal digital ou receptores USB acoplados em computadores pessoais, assim como dispositivos portáteis como PDAs, telefone celulares, dentre outros. Deste modo, a recepção do sinal da TV Digital Interativa por meio desta diversidade de dispositivos viabiliza o acesso aos conteúdos em qualquer lugar, a qualquer hora, o que tornar ubíqua a experiência de assistir TV.

\subsubsection{Middleware}

A possibilidade de execução de aplicações interativas em diversos tipos de receptores, com diferentes plataformas de hardware e software, e independente de fabricante é viabilizada por meio da adoção de uma camada de software comum denominada de middleware. Tal camada deve abstrair as características específicas da plataforma de hardware e software de um receptor, o que facilita a portabilidade das aplicações interativas. Com isso, é possível a execução de aplicações interativas em diferentes receptores que possuem o mesmo middleware embarcado (MORRIS; SMITH-CHAIGNEAU, 2005).

Na pratica o middleware é um dos principais componentes de um sistema de TV Digital, porque o mesmo regula a relação entre as indústrias de produção de conteúdo e fabricação de receptores de TV Digital (SOARES; BARBOSA, 2009). 


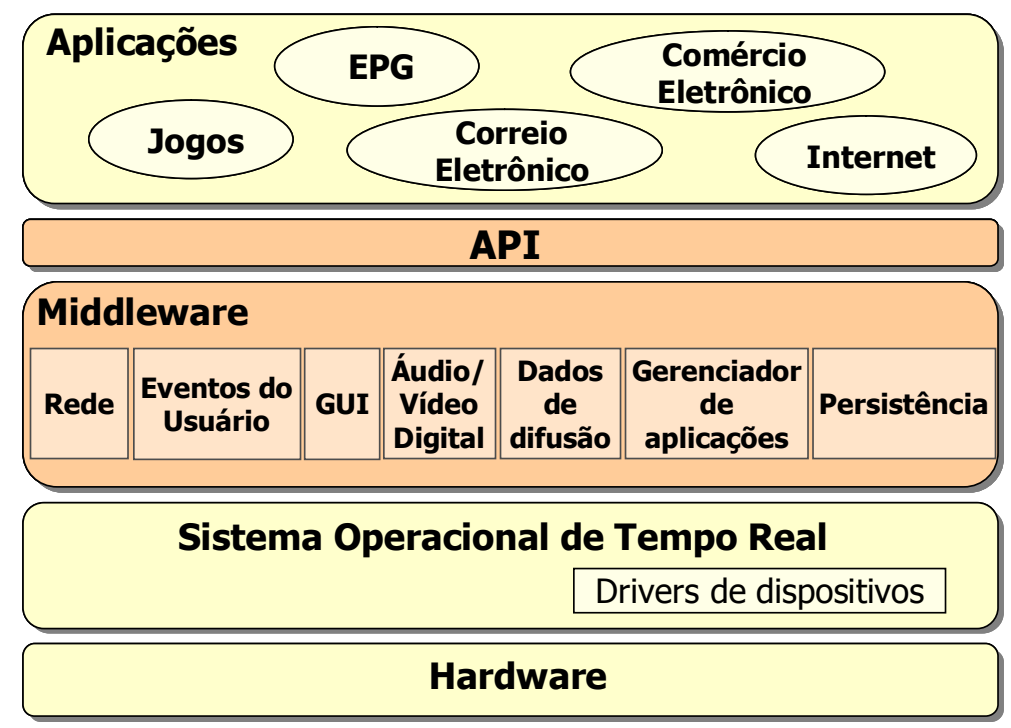

Figura 3 - Middleware como plataforma para aplicações (ALVES, 2008)

A Figura 3 ilustra a arquitetura típica de um middleware por meio de uma representação em camadas. Um middleware é composto por componentes de software e um conjunto de APIs (Application Programming Interface) padronizadas que permitem o acesso aos serviços de tais componentes. Para os desenvolvedores de aplicações interativas o middleware esconde os detalhes e complexidade das camadas inferiores das plataformas de hardware e software dos receptores.

\subsubsection{Canal de Retorno}

Na TV Digital Interativa, determinadas aplicações interativas necessitam de um canal de comunicação conhecido como canal de retorno (ou canal de interatividade) para que seja possível a transferência de dados entre receptor e provedor de serviços (Figura 1). Segundo Reimers (2004), o canal de retorno pode ser implementado por meio de diversas tecnologias de rede tais como telefonia fixa e móvel, radiofrequência, cabo, dentre outras. Entretanto, as especificações de sistemas de TV Digital Interativa, incluindo o Sistema Brasileiro de TV Digital normalmente exigem o suporte à pilha TCP/IP (ABNT NBR 15607-1, 2007) no canal de retorno, o que permite acesso a servidores de aplicações em qualquer localidade na Internet. A seguir é apresentada uma breve descrição de algumas tecnologias de suporte ao canal de retorno: 
- Telefonia fixa (PSTN, família de tecnologias XDSL, ou ISDN) - é uma tecnologia amplamente utilizada para acesso à Internet que aproveita a própria rede de telefonia das residências para troca de dados por meio de um simples modem integrado ao receptor. Em algumas regiões é o único meio de acesso à Internet, e tem grande alcance. No entanto, dependendo do padrão de rede utilizada a taxa de transferência de dados é baixa;

- Telefonia móvel (GSM, CDMA, ou UMTS) - é uma tecnologia muito difundida no mercado brasileiro e deverá ser utilizada quando o receptor for um dispositivo portátil, contudo o alcance é dependente da cobertura da operadora e ainda possui um alto custo;

- Radiofrequência (Wi-Fi, ou WiMAX-700) - é uma tecnologia que realiza a transferência de dados por meio de ondas eletromagnéticas pelo ar, também conhecidas como redes sem fio (ou wireless). Dependo do padrão possui amplo alcance e alta taxa de transferência de dados, porém pode ser limitada se a banda for compartilhada por um número elevado de usuários;

- Cabo - é uma tecnologia normalmente utilizada em redes de TV a cabo, onde é possível receber o sinal de TV e realizar transferência de dados pelo mesmo meio de comunicação. Possui alta taxa de transferência de dados, contudo o alcance é dependente da cobertura da operadora e ainda possui um alto custo;

- Power Line Communications (PLC) - estudos apontam que é possível usar as linhas de distribuição de eletricidade (linhas de baixa tensão) como alternativa para o canal de retorno (CARVALHO; ALENCAR, 2005). Esta tecnologia possui grande cobertura geográfica, contudo é penalizada principalmente pelos excessivos níveis de ruído e atenuação do sinal.

Cada uma dessas tecnologias possui diferentes características que podem permitir ou limitar a execução de algumas aplicações interativas. Além disso, a escolha da tecnologia para o canal de retorno deve ser feita de acordo com o contexto da região e as necessidades e disponibilidade do usuário. 


\subsection{Interatividade na TV Digital}

A interatividade na televisão não é nova. Este conceito começou a ser explorado antes mesmo do advento da TV Digital Interativa. Uma das primeiras experiências foi na década de 70 por meio da implantação de uma forma de vídeo sob demanda nos Estados Unidos. Posteriormente, nos anos 80 surgiram as primeiras experiências com um sistema de teletexto no continente europeu que permitia interatividade unidirecional (somente da emissora para o dispositivo de acesso). Dentre os serviços que o teletexto oferecia os principais eram: um guia de programação do canal sintonizado, um portal de notícias gerais, com as manchetes do dia e os resultados esportivos, e um serviço de informação de vôos dos principais aeroportos do país, que informava ao usuário sobre os frequentes atrasos, o que permitia a este se programar antes de sair de casa (MORRIS; SMITH-CHAIGNEAU, 2005).

Por questões culturais, sócio-econômicas e também limitações tecnológicas da época muitas destas iniciativas de fornecimento de interatividade tiveram que ser adiadas. Desde então, as emissoras de TV têm procurado utilizar outros meios de comunicação como cartas, e-mail e telefone a fim de viabilizar uma experiência televisiva muito mais rica para os usuários. No entanto, os meios de comunicação supracitados não permitem uma interatividade plena, o que limita a participação do público. Os recentes avanços da tecnologia digital e as mudanças no próprio mercado contribuíram significativamente para que seja possível a exploração de todo o potencial de interatividade na televisão.

Além disso, o surgimento de novas redes de telecomunicações, redes de broadcasting e a tendência de infraestruturas de redes convergentes para comunicação, distribuição e compartilhamento de conteúdo multimídia têm habilitado o desenvolvimento de novos serviços interativos (INSTINCT, 2004). Diante deste cenário, surge a TV Digital interativa (IDTV) ou TV Interativa (ITV), em que o usuário passa a ter um papel proativo, podendo interagir com os programas de TV por meio de aplicações rodando em dispositivos de acesso fixos, portáteis ou móveis, de forma similar como interage na WWW. As aplicações interativas são executadas sob uma camada de software denominada de middleware (descrita na subseção 2.1.4). 
Segundo Schwald (2003), a TV Digital interativa pode ser vista como a convergência entre Internet e TV Digital, onde o nível de interatividade dependerá dos serviços oferecidos e, principalmente, da largura de banda do canal de retorno. Neste novo cenário é possível identificar algumas modalidades de interatividade tais como a local, com conectividade intermitente e a com conectividade permanente, ou plena (MONTEZ; BECKER, 2005).

$\mathrm{Na}$ interatividade local, as emissoras transmitem os aplicativos que são executados no receptor sem a utilização de canal de retorno. Na modalidade de interatividade com conectividade intermitente, os aplicativos executados nos receptores podem enviar ou solicitar dados para os provedores de serviços por meio de uma conexão temporária sobre o canal de retorno. Também é possível a interatividade com conectividade permanente, em que o receptor permanece conectado à emissora por meio de um canal de retorno com banda larga. Desta forma, torna-se possível o desenvolvimento de uma diversidade de aplicações interativas. Dentre as principais é possível destacar:

- Guia Eletrônico de Programação (Electronic Program Guide - EPG): O EPG é um serviço básico da TV Digital que fornece de forma eletrônica informações sobre a programação de TV disponível. Tem o mesmo objetivo das revistas especializadas na publicação das grades de programação das TVs a cabo. Por meio de um controle remoto o usuário pode pesquisar navegando entre as páginas do EPG, o canal, a data e hora inicial de um determinado programa de TV que queira assistir. Em alguns modelos mais avançados é possível a busca de informações sobre os programas de TV baseada em palavras-chave;

- Comércio eletrônico (comércio televisivo ou T-commerce): A compra de produtos por meio da TV não é algo novo, existem canais que transmitem programas de TV especializados em vendas de diversos tipos de produtos. No entanto, a interatividade é bastante limitada não permitindo que o usuário possa adquirir produtos de forma similar como ocorre em comércio eletrônico via Web. Desta forma, a TV Digital Interativa é um promissor meio para realizar compras eletrônicas, pois os programas de TV especializados em vendas podem se beneficiar das vantagens desta nova mídia e oferecer aplicações interativas que permitirão compras em tempo real; 
- Governo eletrônico (governo televisivo ou T-goverment): Os serviços governamentais que estão atualmente disponíveis na WWW podem ser oferecidos para os usuários também por meio da TV Digital Interativa. Os serviços são aplicações de utilidade pública como declarações de imposto de renda, votação eletrônica, consulta de dados da previdência, dentre outros, que utilizam a TV como meio de integração entre governo e os cidadãos;

- Banco eletrônico (banco televisivo ou T-bank): Este serviço permite ao usuário acessar dados da sua conta bancária e também realizar transações financeiras por meio da TV de forma similar como ocorre em serviços do mesmo tipo disponibilizados na WWW;

- Educação à distância (T-learning): Os programas tradicionais de educação à distância transmitidos pelos canais de TV são considerados instrumentos importantes para formação das pessoas. Entretanto, os cursos oferecidos atualmente apresentam interação limitada entre professores e alunos. Com o advento da TV Digital Interativa, os programas de TV de educação à distância podem ser potencializados por meio da exploração dos benefícios oferecidos pelas aplicações interativas. Assim, poderá ser desenvolvido um conjunto de novas aplicações a fim de melhorar o processo de ensino e aprendizagem;

- Jogos: Uma diversidade de jogos pode ser desenvolvida para TV Digital Interativa por meio de aplicações interativas, sendo associadas a programas de TV infantis ou para o público jovem. De forma similar aos vídeos games também é possível o desenvolvimento de jogos multiusuários que explorem o canal de retorno;

- Internet: O acesso à WWW é um dos serviços da TV Digital Interativa que possui forte apelo social, pois pode viabilizar o acesso ao mundo digital para uma grande parcela da população brasileira que não tem condições de adquirir um computador. Assim, a televisão por ser o meio de comunicação mais popular em diversos países incluindo o Brasil, tende a ser usada como instrumento de inclusão digital. 
Diante desta diversidade de aplicações interativas apresentadas, é possível constatar que o potencial de interatividade na TV Digital é ilimitado. Deste modo, esta nova mídia oferecerá ao usuário inúmeras possibilidades, não ficando limitada somente a estes aplicativos citados, uma vez que muitos outros aplicativos poderão ser idealizados. Com o surgimento de novos dispositivos de recepção como TV móvel e portátil, a TV Digital Interativa está cada vez mais ubíqua e sensível ao contexto, o que favorece o desenvolvimento de aplicações para personalização e adaptação de conteúdo.

\subsection{Sistemas de TV Digital}

Os sistemas de TV Digital são compostos por uma família de especificações que padronizam as tecnologias que viabilizam a difusão, recepção do sinal digital e interatividade. Atualmente, existem cinco sistemas de TV Digital no cenário mundial. O sistema norte-americano, Advanced Television Systems Committee (ATSC), o sistema europeu, Digital Vídeo Broadcasting (DVB), o sistema japonês, Integrated Services Digital Broadcasting (ISDB), o sistema chinês, Digital Terrestrial Multimedia Broadcast (DTMB), ainda pouco discutido na literatura, e o Sistema Brasileiro de TV Digital, denominado ISDB-TB (International Service Digital Broadcasting - Terrestrial Brazil). Nas próximas subseções serão descritos os três principais sistemas de TV Digital adotados em diferentes regiões do mundo, e também o ISDB-TB.

\subsubsection{Sistema Norte-Americano ATSC}

O Advanced Television Systems Committee (ATSC) (ATSC, 2001) foi criado nos Estados Unidos em 1998, e originalmente proposto para atender requisitos de TV de alta definição de imagem (HDTV). Além disso, serviu de base para outras plataformas tais como OpenCable Application Platform (OCAP) usado em sistemas a cabo. Para codificação de vídeo e áudio, foi especificado o uso dos padrões MPEG-2 Video e Dolby Digital AC-3. Em termos de multiplexação foi especificado o 
uso do padrão MPEG-2 TS. Já o middleware utilizado é o DASE (DTV Application Software Environment).

A modulação do sinal para radiodifusão utiliza o padrão 8-VSB (8 Level Vestigial Side Band) em uma largura de banda de $6 \mathrm{MHz}$ (possibilidade de ser escalonado para $8 \mathrm{MHz}$ ), podendo alcançar a taxa de transmissão de 19,4 Mbps. Os maiores problemas do 8-VSB são os ruídos excessivos, mau desempenho em difusão para terminais móveis e problemas de multi-percurso (ALVES, 2009). Até o momento em que esta tese foi finalizada, o sistema ATSC é adotado nos Estados Unidos, Canadá, México, Coréia do sul e Taiwan.

\subsubsection{Sistema Europeu DVB}

O sistema Digital Video Broadcasting (DVB) (DVB, 1999) foi desenvolvido pelo consórcio The Digital Video Broadcasting Project fundado em 1993, sendo constituído por companhias relacionadas à indústria de televisão e organizações reguladoras. O resultado do trabalho deste consórcio foi o desenvolvimento de uma família de especificações DVB. O consórcio DVB definiu um padrão para transmissão por meio de satélite (DVB-S), o qual é usado por várias operadoras de TV por satélite ao redor do mundo,um padrão para transmissão por meio de cabo (DVB-C) e um padrão para transmissão terrestre (DVB-T). O DVB-T foi criado para ser o sistema de TV Digital terrestre da Europa. O consórcio DVB também especificou um middleware para interatividade conhecido como MHP (Multimedia Home Platform) (MORRIS; SMITH-CHAIGNEAU, 2005).

Para codificação de vídeo e áudio, foram escolhidos inicialmente pelo DVB o padrão MPEG-2 Vídeo e MPEG-2 Layer II para áudio. Especificações atuais do sistema DVB apontam para o uso do padrão H.264, para a codificação de vídeo, assim como o padrão MPEG-4 AAC para o áudio. A multiplexação, de forma similar ao ATSC, também segue o padrão MPEG-2 TS.

Para modulação o DVB-T utiliza a técnica COFDM (Coded Orthogonal Frequency Division Multiplexing) com largura de banda original de $8 \mathrm{MHz}$, e a taxa de transmissão pode alcançar $31 \mathrm{Mbps}$, dependendo dos parâmetros utilizados na modulação do sinal. Este tipo de modulação é menos suscetível a ruídos e aos 
problemas de multi-percurso quando comparado com o 8-VSB. O DVB-T foi adotado em países como Austrália, Rússia, Nova Zelândia, Malásia, Hong Kong, Singapura, Índia, África do Sul, dentre outros.

\subsubsection{Sistema Japonês ISDB}

O Integrated Services Digital Broadcasting Terrestrial (ISDB) é o sistema de TV Digital japonês. Foi criado em 1999 pelo grupo Digital Broadcasting Experts Group (DiBEG) (DiBEG, 1999), consiste em uma família de especificações para padronizar a transmissão digital por satélite (ISDB-S), via redes de TV a cabo (ISDB-C) e também para transmissão terrestre (ISDB-T). Inicialmente, o desenvolvimento deste sistema foi orientado para atender requisitos de flexibilidade e principalmente mobilidade.

A codificação de vídeo e a multiplexação, assim como os sistemas ATSC e DVB, utiliza o padrão MPEG-2 Vídeo e o padrão MPEG-2 TS. Já o áudio segue o padrão MPEG-2 AAC (Advanced Audio Coding). Para a modulação, o ISDB utiliza a técnica BST-OFDM (Band Segmented Transmission - OFDM), que é uma variação do COFDM melhorando a recepção de sinais em dispositivos móveis, com largura de banda original de $6 \mathrm{MHz}$ e taxa de transferência média de $24 \mathrm{Mbps}$.

O middleware é baseado nos padrões Data Coding and Transmission Specification for Digital Broadcasting (ARIB STD-B24), que define uma linguagem declarativa denominada BML (Broadcast Markup Language); e o Application Execution Engine Platform for Digital Broadcasting (ARIB STD-B23). Até o momento em que esta tese foi finalizada, o ISDB-T é adotado no Japão, e no Brasil com algumas inovações tecnológicas.

\subsubsection{Sistema Brasileiro de TV Digital}

Instituído por meio do Decreto $\mathrm{n}^{\circ} 4.901$ de 26.11.2003, o sistema de TV Digital do Brasil foi denominado de Sistema Brasileiro de Televisão Digital Terrestre 
(SBTVD-T), que tem como um dos objetivos principais a inclusão digital, o que permitirá ao povo brasileiro ter acesso de maneira eficiente a vídeo, áudio de alta qualidade e aplicações interativas por meio da televisão (SBTVD, 2003). Após um período de análise dos três principais sistemas internacionais de TV Digital, foi escolhido o sistema japonês ISDB-T. Assim, em 2006 entrou em vigor um novo Decreto $n^{\circ} 5820$ que versa sobre a implantação do Sistema Brasileiro de TV Digital (SBTVD, 2006). Neste decreto foi definido que o Sistema Brasileiro de TV Digital deveria adotar o sistema japonês de TV Digital.

Por ser o mais recente desenvolvido, o sistema japonês oferece vários benefícios técnicos, como a possibilidade de transmissão do sinal de TV por meio do uso da tecnologia one segment (1seg) para dispositivos de acesso portáteis e móveis. Dentre as principais inovações do sistema brasileiro em relação ao sistema japonês foi adoção do padrão de compressão de vídeo H.264 (ISO/IEC 14496-10, 2005), também conhecido como MPEG-4 Part 10 ou MPEG-4 AVC (Advanced Video Conding). O H.264/AVC possui capacidade de compressão superior ao MPEG-2 e ainda prover um vídeo com boa qualidade. Isso porque o H.264 é baseado em um algoritmo que analisa todos os quadros de um vídeo a fim de identificar os objetos comuns entre um quadro e outro e envia para o próximo apenas os objetos que não são redundantes no quadro anterior.

Outra inovação tecnológica foi a especificação de um middleware denominado de GINGA (ABNT NBR 15606-4, 2008; ABNT NBR 15606-2, 2007). A arquitetura do middleware brasileiro permite a execução de um conjunto de aplicações interativas baseadas em paradigmas de programação procedural (SOUZA FILHO; LEITE; BATISTA, 2007) e declarativa (SOARES; RODRIGUES; MORENO, 2007).

As aplicações declarativas são desenvolvidas por meio da linguagem NCL (Nested Context Language), enquanto que as aplicações procedurais podem ser desenvolvidas por meio da linguagem Java. O Sistema Brasileiro de TV Digital é atualmente chamado de International Service Digital Broadcasting - Terrestrial Brazil (ISDB-TB). Até o momento em que esta tese foi finalizada, o sistema ISDB-TB foi adotado na Argentina, Costa Rica, Peru, Chile, Equador, Venezuela, Bolívia e Filipinas. 


\subsection{Considerações Finais}

Conforme foi destacado neste capítulo, a TV Digital interativa é composta por um conjunto de tecnologias, padrões, conceitos que viabilizam uma experiência de entretenimento mais rica para o usuário. Diante deste novo cenário, aumentará a demanda por novos serviços de valores agregados. Um desses serviços é o acesso personalizado ao conteúdo da TV Digital. Para este trabalho é preferível o modelo de interatividade plena com conectividade permanente em banda larga, contudo o modelo de canal de retorno intermitente já é suficiente para atender as características de interatividade que serão exploradas na infraestrutura proposta. 


\section{Metadados: Uma Visão Geral}

$\mathrm{Na}$ literatura é possível encontrar frequentemente que metadados significam "dados sobre dados", o que torna uma definição padrão utilizada por vários autores (LUGMAYR; NIIRANEN; KALLI, 2004). Metadados são definidos como dados adicionais que descrevem outros dados, e podem fornecer uma visão sintática e semântica de dados complexos. Por meio de metadados é possível estruturar, representar, manipular e gerenciar informações em diversos cenários, como no caso da TV Digital Interativa.

Os Metadados viabilizam a realização de várias operações como a pesquisa, filtragem e gerenciamento de conteúdo de várias fontes. Além disso, define uma forma padrão para descrever o conteúdo, perfis de usuários, o que permite o desenvolvimento de aplicações personalizadas. Assim, é necessário associar metadados aos conteúdos para facilitar a localização dos conteúdos de interesse.

Cada vez mais os metadados estão sendo aplicados em diversas áreas tais como Sistemas de Informação Geográfica, Educação à Distância, Web Semântica, Serviços Web, TV Digital Interativa, dentre outras. Desta forma, vários padrões de metadados surgiram para oferecer o suporte adequado as aplicações. Nas próximas seções deste capítulo serão descritas algumas técnicas de representação de metadados, linguagem de consulta e padrões de metadados empregados no cenário da TV Digital Interativa.

\subsection{Representação de Metadados: XML e Esquemas XML}

Diferentes técnicas podem ser utilizadas para representação de metadados (ALVES et al., 2006). Cada técnica oferece estruturas que permitem representar os metadados de forma organizada, flexível e semântica. Por questões de interoperabilidade com os padrões de metadados empregados no cenário da TV Digital Interativa, este trabalho se concentra no estudo e utilização do XML e Esquema $\mathrm{XML}$, que é base de tais padrões. 
XML (eXtensible Markup Language) é uma linguagem de marcação extensível padronizada pelo World Wide Web Consortium (W3C, 2006) que permite a representação estruturada de dados. Por meio de XML é possível compartilhar dados entre aplicações, descrever o conteúdo, armazenar dados, separar dados e apresentação etc. Diferentemente do HTML, o XML permite de forma flexível a definição de novos elementos (tags) e atributos de acordo com a necessidade da aplicação, enquanto que o HTML possui um número finito de elementos utilizados para formatação do conteúdo.

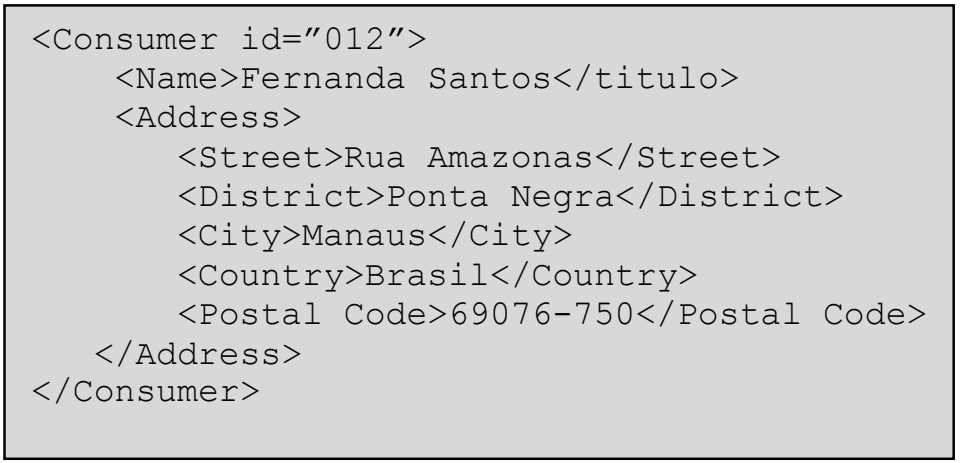

Figura 4 - Exemplo de um documento XML

A Figura 4 ilustra um exemplo de um documento $X M L$ ou instância $X M L$, como também é conhecido e utilizado para descrever dados de um consumidor. O processamento ou interpretação do documento XML pode ser realizado por meio de um analisador (parser), o qual permite o acesso aos dados representados no documento. É possivel notar que um documento XML possui uma estrutura em forma de árvore onde cada elemento (tag) pode conter outros elementos filhos.

Para a definição da estrutura, conteúdo e semântica do documento XML dever ser empregada uma linguagem que permita expressar as restrições sobre este documento. Tais restrições podem ser expressas por meio de um Esquema XML (do inglês, XML Schema) (W3C, 2001) que deve estar associado ao documento XML. Um Esquema XML também pode ser usado para validação de um documento $\mathrm{XML}$, onde o mesmo será considerado válido se estiver de acordo com as restrições definidas pelo Esquema XML.

Por meio de um Esquema XML é possível a declaração de atributos e elementos de tipos simples, complexos, abstratos e anônimos. Um espaço de nomes (do inglês, namespaces) permite evitar conflito de nomes atribuídos aos elementos, pois um documento XML pode conter elementos com nomes similares, porém oriundos de outros vocabulários XML. Assim, é necessário indicar qual 
vocabulário determinado elemento representa. Essa flexibilidade permite que seja possível utilização de múltiplos Esquemas em um documento XML ou até mesmo serem reusados para criar novos Esquemas, como é o caso deste trabalho. A Figura 5 apresenta um exemplo de Esquema XML que define o documento XML apresentado na Figura 4.

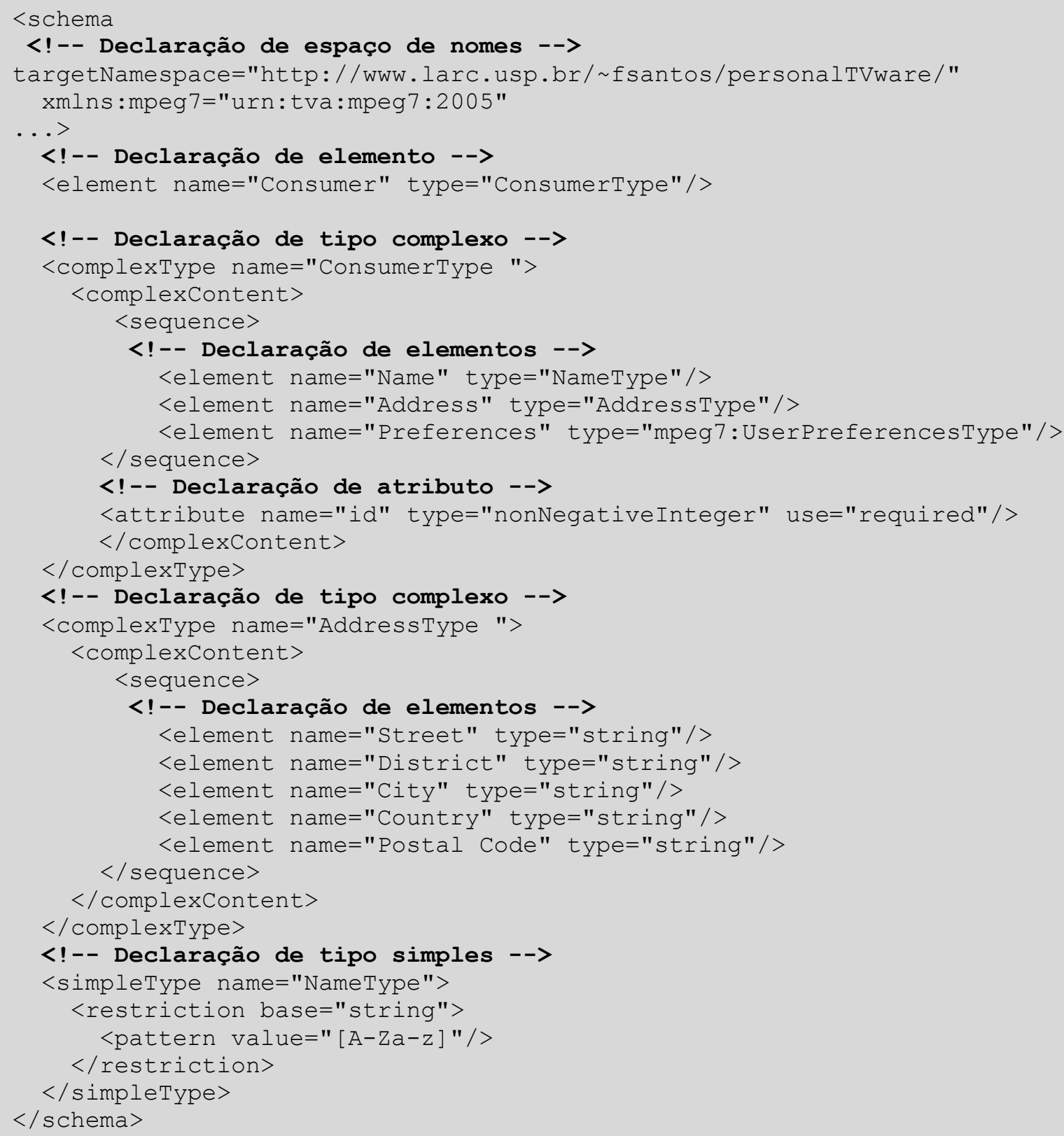

Figura 5 - Exemplo de componentes de um Esquema XML

Neste exemplo é possível identificar algumas declarações mandatórias em um Esquema XML tais como: o targetNamespace utilizado para identificar um espaço de nomes por meio da URL (Uniform Resource Locator), (http://www.larc.usp.br/ fsantos/personaltVware/); uma referência a 
um Esquema importado do MPEG-7 (xmlns:mpeg7) que é do tipo URN (Universal Resource Name) (urn:tva:mpeg 7:2005).

Ainda há a declaração de um elemento denominado consumer que é de um tipo complexo (ConsumerType) sendo composto por uma sequência de elementos e um atributo (id). Além disso, é possível notar que um dos elementos (Preferences) é de um tipo importado do MPEG-7 (mpeg 7:UserPreferencesType).

\subsection{Metadados no Cenário da TV Digital Interativa}

$\mathrm{Na}$ TV Digital Interativa os metadados devem cobrir a descrição de serviços e conteúdos multimídias transmitidos por meio do canal de difusão ou canal de retorno. Os metadados apoiam a abstração das características do conteúdo multimídia e o desenvolvimento de serviços inovadores para TV Digital Interativa. Segundo Lugmayr; Niiranen e Kalli (2004), os sistemas de TV Digital atuais utilizam para a transmissão de informações as estruturas de metadados rígidos das tabelas de Informação Especifica de Programa (do inglês, Program Specific Information PSI) e Serviço de Informação (do inglês, Service Information - SI). O uso de tais tabelas facilita a criação, o tratamento, e a rápida extração das informações (ALVES et al., 2006).

No entanto, estão surgindo aplicações mais complexas (como os sistemas de recomendação ou personalização e adaptação de conteúdo) que requerem informações mais ricas semanticamente (GOULARTE, 2003). Tais informações não podem ser definidas de maneira satisfatória por meio dos metadados rígidos das tabelas PSI e SI (LUGMAYR; NIIRANEN; KALLI, 2004).

Desta forma, surgiu a necessidade de estruturas de metadados flexíveis, ou seja, metadados que apresentem estruturas customizáveis para suportar os novos serviços em cenários de uso mais complexos. Com isso, alguns padrões de metadados estão sendo empregados como MPEG-7, e o TV-Anytime, sendo esse último criado especialmente para o cenário da TV Digital Interativa. A seguir serão 
descritos os principais padrões de metadados estudados e explorados neste trabalho.

\subsection{Padrões de Metadados para TV Digital Interativa}

De acordo com Lugmayr; Niiranen e Kalli (2004), nos sistemas atuais de TV Digital (DVB, ATSC, ISDB e ISDB-TB), a transmissão de informações está baseada nas definições de metadados das tabelas de informações de serviços (SI - Service Information). As tabelas SI estendem as tabelas PSI (Program Specific Information) do padrão MPEG-2 definindo um conjunto de tabelas hierarquicamente associadas que possuem dados descritivos que carregam informações de serviços específicos do domínio da TV Digital. O emprego de tais tabelas facilita a criação, o tratamento, e a rápida extração das informações (ALVES et al. 2006).

Com os dados das tabelas SI, torna-se possível a seleção de serviços e eventos existentes. Já os dados que permitem ao receptor configurar automaticamente os serviços para sua apresentação são, em sua maioria, obtidos por meio das tabelas PSI (ABNT NBR 15603-1, 2007). A seguir será apresentada uma breve descrição das tabelas PSI e SI que foram analisadas para emprego neste trabalho:

- Tabela de Mapeamento de Programas (PMT) - deve identificar e indicar a localização das transmissões que compõem cada serviço, e a localização de referência de hora do programa para cada serviço;

- Tabela de Informação de Eventos (EIT) - deve prover informações em ordem cronológica referentes à grade de programação da emissora, tais como data e hora de inicio do programa, duração, gênero, sinopse, dentre outras. Por meio da EIT o receptor poderá montar o guia de programação para o usuário;

- Tabela SDT - transporta informações sobre os provedores de serviços como o nome do provedor de serviço (ou emissoras de TV);

- Tabela de data e horário (TDT) - deve ser utilizada como referência para informar data e hora do sistema. 
A descrição de todas as tabelas PSI e SI pode ser obtida por meio da norma ABNT NBR 15603-1. De acordo com Lugmayr; Niiranen e Kalli (2004), Alves et al. (2006) e Zhang, Zheng e Yuan (2005), as tabelas SI e PSI são consideradas estruturas de metadados rígidos, pois são destinados para um propósito específico e, que não passam por uma padronização de metadados passível de ser customizável. Muitas aplicações como os sistemas de recomendação necessitam de informações mais detalhadas, que não podem ser definidos de maneira satisfatória por meio das tabelas SI. Assim, surgiu a necessidade de utilização de estruturas de metadados mais flexíveis e extensíveis a fim de oferecer um suporte adequado para atender as novas aplicações em cenários mais complexos.

\subsubsection{O Padrão MPEG-7}

O MPEG-7 (ISO/IEC 15938-1, 2004) é um padrão ISO/IEC introduzido em 1997 pelo MPEG (Moving Picture Experts Group). Este grupo de trabalho definiu uma série de padrões como o MPEG-2 que é empregado em codificação de áudio e vídeo, e o MPEG-4 voltado para codificação de objetos audiovisuais. O MPEG-7 é oficialmente conhecido como "interface de descrição de conteúdo multimídia", pois padroniza a descrição de conteúdo audiovisual por meio da definição de um conjunto padronizado de descritores (do inglês, Descriptor - D), e esquemas de descrição (do inglês, Description Schemes - DS), (LUGMAYR; NIIRANEN; KALLI, 2004).

Cada descritor contém uma informação a respeito do conteúdo que está sendo descrito de forma sintática e semanticamente. Já os Esquemas de descrição são responsáveis por especificar a estrutura e a semântica dos interrelacionamentos entre seus componentes, que podem ser descritores ou até mesmo outros Esquemas de descrição (ALVES et al., 2006).

O MPEG-7 foi especialmente concebido de forma mais genérica possível a fim de fornecer estruturas pré-definidas de descritores adaptáveis e extensíveis. Com isso, estes elementos podem ser reutilizados na definição de novos padrões de metadados. De acordo com Lugmayr; Niiranen e Kalli (2004), a organização do padrão MPEG-7 está dividida em oito partes diferentes. As principais são: 
1. Sistema - especifica como as descrições MPEG-7 serão transportadas para os terminais, sincronizadas com os conteúdos e armazenadas. Também é responsável por descrever a arquitetura de um terminal MPEG7 ;

2. Linguagem de Definição de Descrição (oriunda do inglês, Description Definition Language - DDL) - é a linguagem que define a sintaxe para elaboração de relacionamentos entre os descritores e esquemas de descrição. Também permite a criação de novos esquemas de descrição ou modificação de esquemas já existentes. Esta linguagem é baseada em Esquemas XML;

3. Visual - especifica um conjunto padronizado de descritores e esquemas de descrição relacionados com descrição de vídeo;

4. Áudio - especifica um conjunto padronizado de descritores e esquemas de descrição relacionados com a descrição de áudio;

5. Software de Referência - definição de software que suporta diferentes partes do padrão MPEG-7;

6. Teste de Compatibilidade - especifica testes para verificar se as descrições estão sintaticamente bem estruturadas e válidas conforme as especificações MPEG-7;

7. Extração e Uso de Descrições MPEG-7 - define interfaces de descrição de conteúdo multimídia e procedimentos para o uso das ferramentas MPEG-7 e a implementação do software de referência;

8. Esquemas de Descrição de Multimídia (oriunda do inglês, Multimedia Description Schemes - MDS) - são conjunto padronizado de descritores e esquemas de descrição genéricos para descrição de conteúdo multimídia e também usuário.

Conforme ilustrado na Figura 6, os MDSs (Multimedia Description Schemes) são organizados em cinco diferentes categorias de acordo com as suas características. 


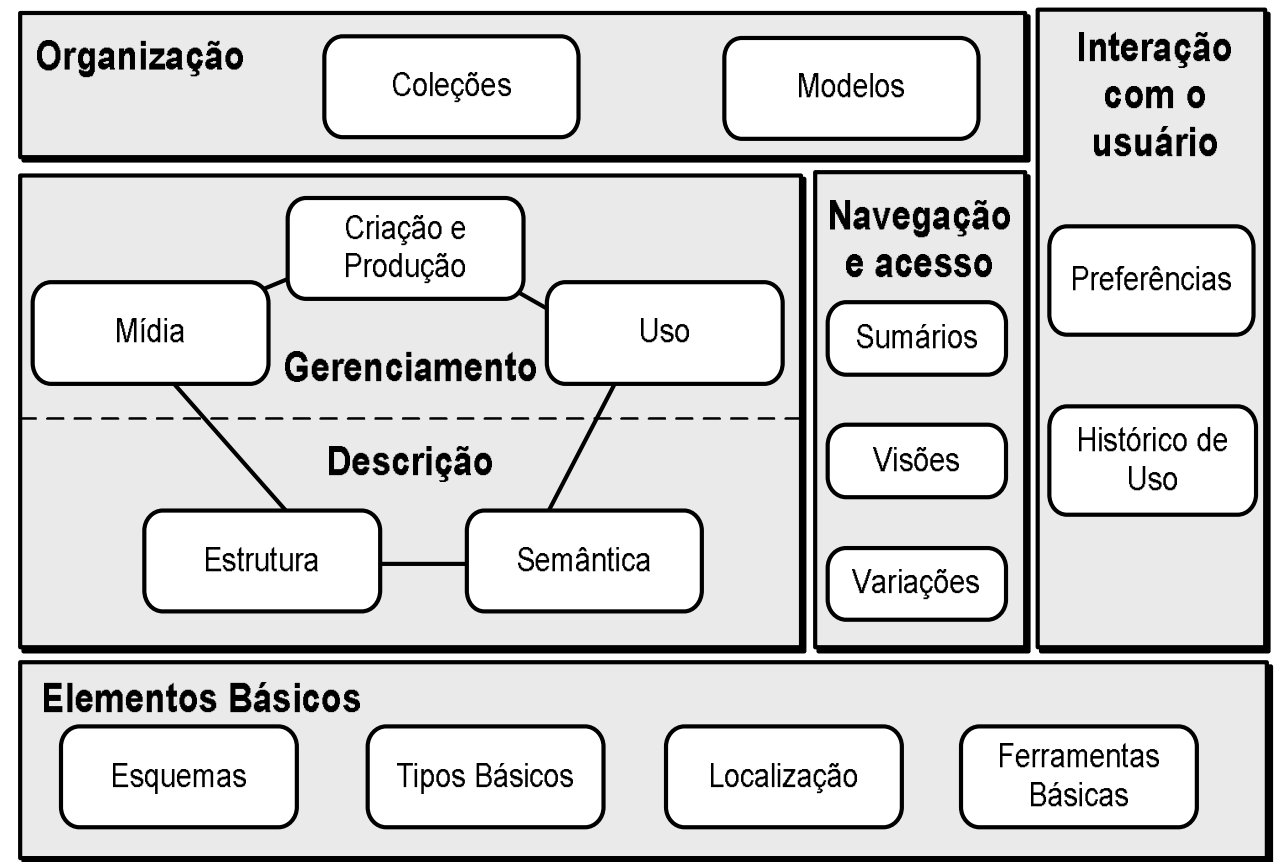

Figura 6 - Visão geral do MPEG-7 Multimedia Description Schemes (MDS) (ALVES, 2008)

Para este trabalho serão explorados os metadados do MPEG-7 relacionados à categoria interação com o usuário. Nesta categoria são definidos os esquemas de descrição: preferências do usuário (UserPreferences DS) e históricos de uso (UsageHistory DS).

\subsubsection{Preferências do Usuário (UserPreferences DS)}

O UserPreferenceDS é usado para descrever as preferências do usuário relacionadas ao consumo de conteúdo multimídia. A correlação entre as preferências do usuário e os descritores de conteúdos permite a filtragem de conteúdos, consequentemente o acesso personalizado. Desta forma, diversos cenários de uso são possíveis como os a seguir (TV-ANYTIME, 2007b):

- Identificação de múltiplos usuários;

- Filtragem de acordo com uma rica combinação das preferências do usuário (gêneros e canais favoritos, títulos, horários de preferência, formato de mídia, dentre outros); 
- Especificação de preferências (por um diretor favorito, por exemplo) com uma duração de tempo em particular;

- Especificação de palavras-chave preferidas ligadas com outras preferências, tais como gênero (notícias, esporte, por exemplo);

- Descrição do desejo do usuário de manter todos os dados de preferência, ou partes selecionadas, privativos;

- Descrição de preferências por tipos particulares de destaque (destaque de determinada duração ou destaques compostos por segmentos que contenham determinados eventos, por exemplo);

- Troca de perfis pessoais sob controle do usuário;

- Especificação de perfis para diferentes países.

O UserPreferences DS está associado com um usuário em particular (ou um grupo de usuários) por meio do Userldentifier DS. A entidade principal no diagrama UserPreferences DS contém dois componentes principais, são 0 BrowsingPreferences DS e FilteringAndSearchPreferences DS (vide Figura 7). 0 Userldentifier DS pode ser usado para associar um usuário específico (grupo de usuários) com uma descrição de preferência em particular.

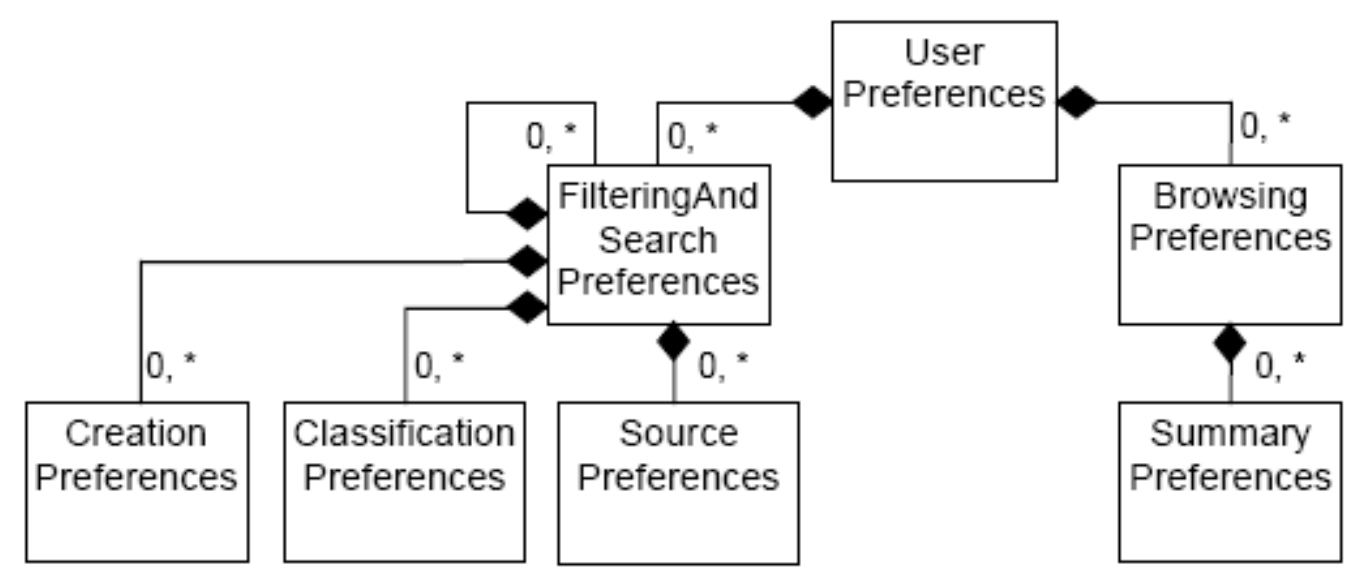

Figura 7- UserPreferences DS sumarizado (ISO/IEC 15938-5, 2003)

O BrowsingPreferences DS pode ser usado para especificar as preferências sobre a forma de navegação e como o conteúdo é acessado e contém o SummaryPreferences DS. O SummaryPreferences DS descreve as preferências do usuário para navegação não linear de conteúdo. O FilteringAndSearchPreferences DS pode ser usado para especificar as preferências do usuário com relação ao tipo 
de conteúdo a ser pesquisado, filtrado, selecionado e consumido. As preferências podem ser especificadas em temos de criação, classificação e propriedades relacionadas às fontes de conteúdo. O FilteringAndSearchPreferences DS é composto pelo ClassificationPreferences DS, CreationPreferences DS e SourcePreferences DS.

O ClassificationPreferences DS é usado para especificar as preferências do usuário com relação à classificação do conteúdo, tais como gênero, assunto, idioma e o país de origem. O CreationPreferences DS é usado para especificar as preferências do usuário relacionadas com a criação e descrição do conteúdo audiovisual, como preferência sobre um título, ou um ator, diretor preferido, ou conteúdo de um determinado lugar. Por fim, o SourcePreferences DS é usado para especificar as preferências com relação as fontes de conteúdo audiovisual, como formato de distribuição, ou fonte de distribuição, ou local de distribuição, formato de mídia, dentre outros.

De modo geral, as descrições de preferências do usuário podem ser construídas manualmente ou automaticamente. Uma preferência de usuário pode ser construída baseada em informações fornecidas pelo usuário de maneira explícita ou implícita (inferida) a partir do seu histórico de uso, ou do seu contexto conforme será explorado neste trabalho e descrito no capítulo 7.

\subsubsection{O Padrão TV-Anytime}

O TV-Anytime é um padrão aberto contendo um conjunto de especificações definidas pelo TV-Anytime Fórum (TV-ANYTIME, 1999). Esse fórum foi fundado em 1999 por importantes empresas visando desenvolver um conjunto de especificações que permita aos fabricantes de produtos eletrônicos, produtores de conteúdo, provedores de serviço e usuários, explorar o alto volume de conteúdo em dispositivos com capacidade de armazenamento digital. Este fórum produziu especificações que abrangem segmentos relacionados à modelo de negócio, arquitetura de sistema, metadados, referência ao conteúdo e gerenciamento de direitos autorais. 
No que se refere ao modelo para metadados, o TV-Anytime destaca a relevância da exploração de metadados em sistemas de TV Digital Interativa. Para o propósito de interoperabilidade, o TV-Anytime Fórum adotou XML como formato para representação dos metadados, e Esquemas XML para a definição formal da estrutura e da sintaxe dos metadados.

Segundo Alves et al. (2006), o conjunto de metadados do TV-Anytime também reutiliza alguns Esquemas XML especificados no padrão MPEG-7 (linguagem DDL), particularmente no que se refere à descrição de mídias, preferências de usuário e histórico de uso. Os elementos descritivos que pertencem ao TV-Anytime e MPEG-7 são diferenciados por meio do conceito de espaço de nomes (do inglês, namespaces). Assim, o espaço de nomes do TV-Anytime é definido como: xmlns=http://www.tv-anytime.org/2001/04/metadata.

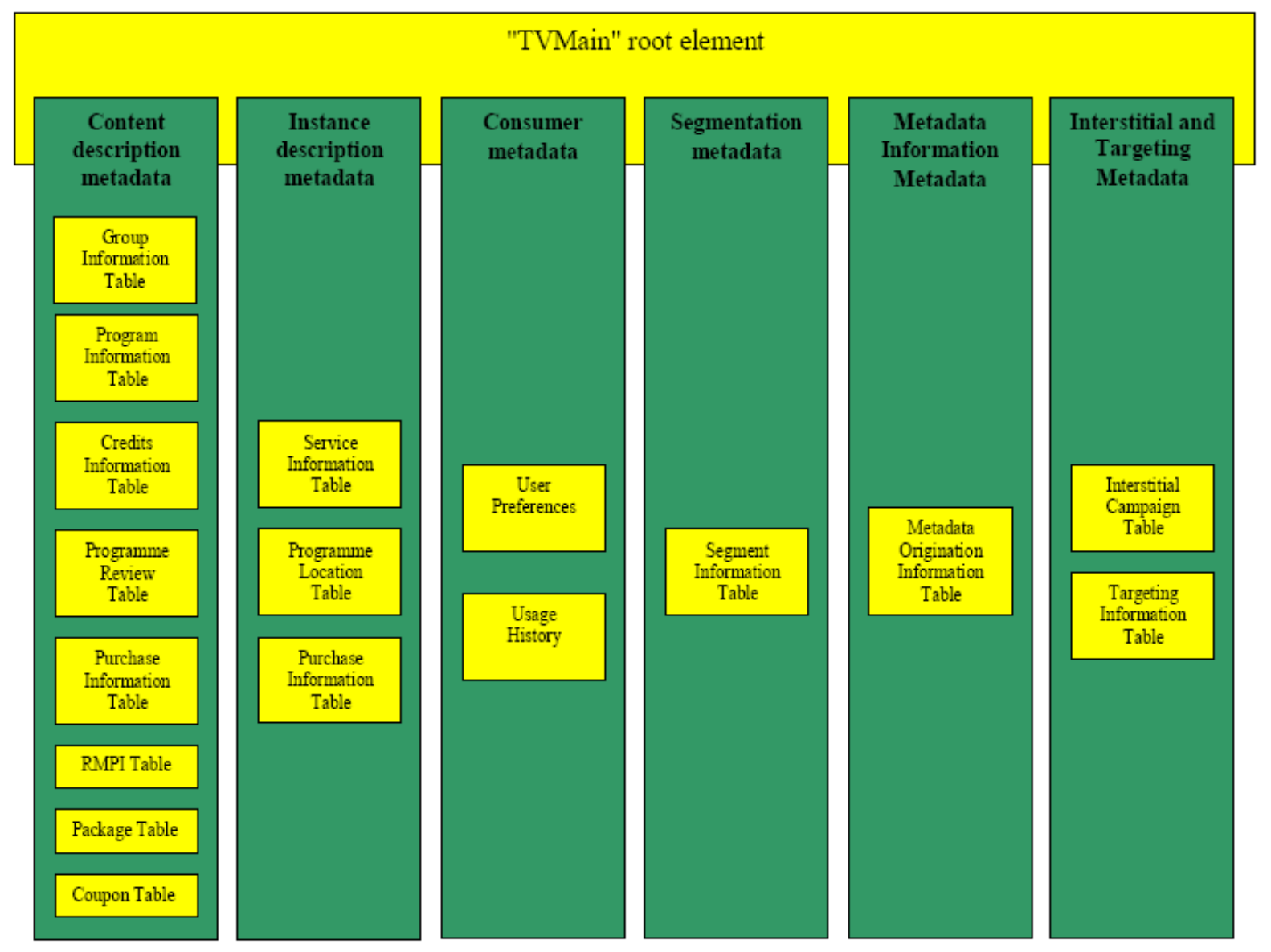

Figura 8 - Categorias de metadados do TV-Anytime - "TVA Main" como elemento raiz (TV-ANYTIME, 2007a)

Foram definidas duas fases de trabalho pelo TV-Anytime Fórum. Na primeira delas definiram as quatro categorias de metadados (TV-ANYTIME, 2007a): descrição de conteúdo (content description), descrição de instância (instance 
description), usuário (consumer) e segmentação (segmentation). A primeira lida com a descrição de programas de TV por completo (título, assunto, sinopse, gêneros de programas de TV, informações de áudio e vídeo) e descritores específicos para os serviços de busca personalizada de conteúdo da TV Digital Interativa. A segunda, descrição de instância, é dividida em duas áreas: descrição de localização particular de conteúdo e descrição de serviços de um sistema. A primeira delas fornece descritores relacionados à grade de programação do programa de TV, tais como hora inicial de exibição do programa de TV, duração do programa de TV, uma referência para o provedor de serviço responsável pelo programa de TV, dentre outros. Já a segunda contem descritores relacionados aos provedores de serviços.

A terceira categoria, usuário, define os descritores para identificação de um usuário (ou grupo de usuários), preferências do usuário e histórico de uso. Já a quarta categoria possui elementos que permitem descrever fluxos de áudio e vídeo para viabilizar o acesso e manipulação em intervalos temporais e também de forma aleatória a determinados segmentos.

$\mathrm{Na}$ segunda fase de trabalho do TV-Anytime Fórum as categorias para descrição de conteúdo e das características de usuário foram aperfeiçoadas incluindo informações biográficas e de acessibilidade (TV-ANYTIME, 2007b). Também foram adicionadas duas novas categorias: informações de metadados (metadata information), e informações de alvo e interstícias (interstitial and targeting information). A primeira, as informações de metadados oferecem suporte para publicação dos próprios metadados. A segunda, informações de alvo e intersticiais, é uma categoria voltada para representar informações sobre o ambiente de uso do conteúdo (informações sobre características naturais do ambiente, terminal e rede).

Por meio de tais categorias de metadados é possível o desenvolvimento de serviços interativos inovadores, que possibilitem a busca, seleção, aquisição e apresentação de conteúdo no domínio da TV Digital Interativa de maneira personalizada. Deste modo, este trabalho se propõe a estudar e explorar os metadados do TV-Anytime relacionados às categorias: descrição de conteúdo (content description), descrição de instância (instance description) e usuário (consumer).

Para descrição de conteúdo, instância e usuário serão utilizados os descritores e esquemas de descrição: (ProgramlnformationTableType), 
(ProgramLocationTableType),

(ServicelnformationTableType),

(CreditsInformationTableType) do TV-Anytime, e (UserPreferences DS) do MPEG-7.

\subsubsection{Metadados de Descrição de Conteúdo}

ProgramInformationTableType é usado para descrever um típico programa de TV que está associado ha um CRID (Content Reference IDentifier) (TV-ANYTIME, 2007a). O CRID é um identificador que referencia um conteúdo independentemente da sua localização ou momento que estará disponível (LUGMAYR; NIIRANEN; KALLI, 2004). O ProgramInformationTableType é composto pelos componentes BasicDescription, Otherldentifier, AVAttributes, MemberOf, DerivedFrom, EpisodOF, PartOfAggregatedProgram e AggregationOf.

O BasicDescription é usado para descrever um programa de TV por meio descritores subordinados tais como título, sinopse, palavra-chave, idioma, gênero, dentre outros. O Otherldentifier é um código que pode ser usado adicionalmente ao CRID para identificar uma peça de conteúdo. O AVAttributes é usado para especificar parâmetros de áudio e vídeo relacionados ao programa de TV. O MemberOf é usado para indicar o grupo que um programa de TV pertence. O DerivedFrom é usado para indicar que um programa de TV é derivado de outro programa de TV. Já o PartOfAggregatedProgram é usado para especificar que o conteúdo é parte de um programa de TV agregado. O AggregationOf é usado para descrever um programa de TV agregado.

Por fim, o CreditsInformationTableType é usado para descrever os participantes da produção de um programa de TV tais como ator, atriz, diretor, dentre outros.

\subsubsection{Metadados de Descrição de Instância}

O ProgramLocationTableType é usado para criação de EPGs, é composto pelos componentes BroadcastEventType, ScheduleType, OnDemandProgramType 
etc. Para este trabalho foi utilizado o componente BroadcastEventType, que possui descritores associados como PublishedStartTime, PublishedEndTime e PublishedDuration utilizados para descrever o horário inicial e final de transmissão de um programa de TV, assim como a sua duração total.

Já o ServicelnformationTableType pode ser usado para descrever um provedor de serviço (emissora de TV) por meio de descritores associados tais como nome do provedor de serviços, seu logotipo, URL do serviço, dentre outros.

\subsection{Linguagem de Consulta em Metadados}

A realização de consultas em metadados representados por meio de documentos XML é possível através da linguagem XQuery ou XQL (XML Query Language) (W3C, 2007) quando executada sobre um banco de dados XML (EXIST, 2009). Tais ferramentas são inclusive recomendadas pelo TV-Anytime Fórum (TVANYTIME, 2007b). A linguagem XQuery é padronizada pela W3C, e representa para documentos XML, o que a linguagem SQL (Structured Query Language) representa para tabelas relacionais. A linguagem XQuery oferece flexibilidade para definição de expressões de consultas complexas em documentos XML, e também pode ser usada na construção de novos documentos XML.

Para construção de consultas mais elaboradas devem ser utilizadas expressões FLWOR (For, Let, Where, Order by e Return) que são baseadas em cláusulas. Por meio destas cláusulas é possível realizar iteração, ordenação, entre outras operações sobre os metadados obtidos a partir de um documento XML. A seguir uma breve descrição de cada cláusula:

For - configura uma iteração para que o restante da consulta possa ser avaliado contra o elemento selecionado e armazenado em uma variável;

Let - instância de uma variável que poderá ser referenciada posteriormente na consulta;

Where - permite estabelecer restrições para a filtragem dos resultados da consulta;

Order by - permite realizar uma ordenação dos elementos obtidos; 
Return - indica o que deve ser retornado em cada iteração da consulta.

Este trabalho empregou a linguagem XQuery para definição de expressões FLWOR para consultas complexas que viabilizaram o gerenciamento dos metadados relacionados aos programas de TV. Além disso, XQuery também foi utilizada para implementação da filtragem sensível ao contexto de programas de TV. A seguir será apresentado na Figura 9 um exemplo de uma expressão FLWOR empregada para obter os metadados referentes aos horários de transmissão e tempo de duração de um determinado programa de TV.

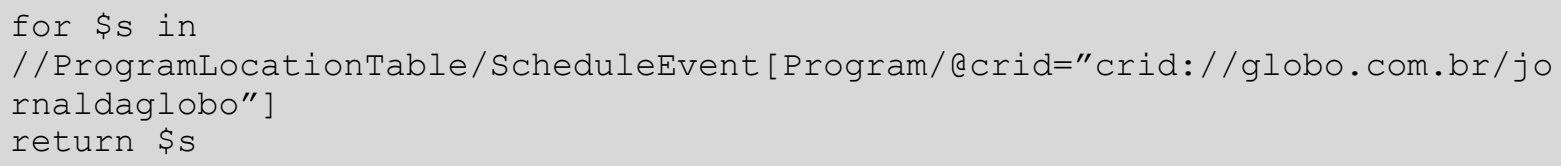

Figura 9 - Exemplo de expressão FLWOR

Neste exemplo, foi implementada uma iteração simples sobre o elemento ScheduleEvent dentro de ProgramLocationTable. Para cada avaliação da iteração, o resultado foi armazenado na variável $\$ s$, e para cada iteração, é retornado o conteúdo da variável $\$ S$, que serão os elementos referentes à programação de um determinado programa de TV identificado por meio do seu respectivo CRID passado como argumento ao atributo crid do elemento Program. Neste caso, o resultado dessa execução será todos os elementos apresentados na Figura 10 a seguir.

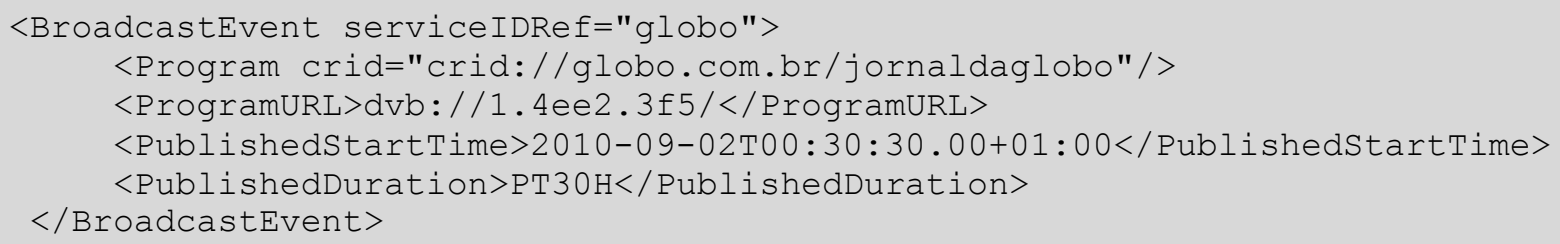

Figura 10 - Metadados recuperados como resultado da consulta 


\subsection{Considerações Finais}

Este capítulo abordou os principais fundamentos sobre metadados que foram estudados e utilizados durante o desenvolvimento deste trabalho. Conforme foi destacado na seção 3.2 os sistemas de TV Digital existentes utilizam as definições de metadados das tabelas SI e PSI para transmissão de informações. O emprego de tais tabelas facilita a criação, o tratamento e a rápida extração das informações (ALVES et al. 2006), porém são metadados rígidos. Uma alternativa para contornar a limitação das tabelas SI e PSI consiste em utilizar os descritores e esquemas de descrição propostos pelos padrões MPEG-7 e TV-Anytime.

Desta forma, foi apresentada uma visão geral dos principais metadados utilizados neste trabalho e potencial oferecido pelo padrão TV-Anytime. Maiores informações podem ser obtidas nas especificações produzidas pelo TV-Anytime Fórum (TV-ANYTIME, 2007a). Vale ressaltar que já existem iniciativas importantes conduzidas pelo TV-Anytime Fórum para promover a utilização das suas especificações em sistemas de TV Digital como é o caso do sistema europeu (DVBTVA, 2005). Assim, este trabalho também reforça a relevância do uso dos padrões de metadados flexíveis no cenário da TV Digital Interativa. 


\section{Computação Sensível ao Contexto}

A área da computação sensível ao contexto investiga o uso das informações presentes na interação entre o humano-computador com o objetivo de melhorar a qualidade da comunicação entre ser humano e sistemas computacionais (VIEIRA et al., 2009). As informações abstraídas do processo de interação são denominadas de informações de contexto. Tais informações podem ser utilizadas como insumo pelos sistemas para automaticamente, em circunstâncias diversas, adaptarem seus serviços e conteúdos, ou fornecerem informações personalizadas aos usuários, levando em consideração, por exemplo, a sua localização, dia e horário de acesso, e/ou as características dos dispositivos (GOULARTE, 2003). Deste modo, torna-se possível o surgimento de uma nova geração de sistemas de recomendação que leva em consideração os diversos tipos de contextos (SILVA; ALVES; BRESSAN, 2009).

A computação sensível ao contexto (do inglês, context-sensitive computing) é um tema de pesquisa oriundo das áreas da Computação Ubíqua e Inteligência Artificial. Outros termos considerados sinônimos são: computação baseada em contexto ou computação ciente de contexto (do inglês context-aware computing). Mark Weiser em 1991 foi um dos pioneiros na realização de estudos e utilização do conceito de contexto. Wesier (1991) vislumbrou ambientes dotados de recursos computacionais capazes de auxiliar os humanos em suas atividades diárias, fornecendo aos usuários informações e serviços de forma contínua, onipresente, e o mais transparente possível.

De acordo com a visão de Weiser (1991), os recursos computacionais devem ser adaptados automaticamente ao comportamento humano de modo não intrusivo, em vez de o usuário se adaptar aos dispositivos. Desta forma, é necessário compreender e apoiar as atividades cotidianas das pessoas, por meio de sistemas computacionais que ofereçam diferentes serviços a partir do contexto. O termo context-aware computing foi utilizado pela primeira vez por Schilit e Theimer (1994), que o definiram como o estudo de softwares que: 
"Adaptam-se de acordo com a sua localização de uso, com a coleção de pessoas e objetos próximos, bem como as mudanças ocorridas com esses objetos ao longo do tempo."

Desde então, diversas tentativas foram feitas para definir computação sensível ao contexto (ou computação ciente de contexto). Dey e Abowd (2000) realizaram uma profunda revisão das definições encontradas na literatura e categorizaram as definições em duas categorias: (i) usando o contexto; (ii) adaptando ao contexto. A primeira categoria "usando o contexto" refere-se à habilidade de um sistema ser capaz de detectar, interpretar e responder ao contexto. As definições da segunda categoria "adaptando ao contexto" referem-se aos estudos dos sistemas que dinamicamente mudam ou adaptam seu comportamento ou conteúdo baseados em contextos.

De acordo com Goularte (2003), um dos projetos pioneiros na exploração de contexto em sistemas computacionais foi o desenvolvimento do sistema Olivetti Active Badge (Want et al., 1992). Este sistema foi projetado e prototipado nos laboratórios de pesquisa da Olivetti Research Lab's entre 1989 e 1992. O objetivo do sistema era automaticamente encaminhar chamadas telefônicas baseado em informação de localização dos membros da equipe. Para este propósito as pessoas usavam crachás especiais que periodicamente emitiam sinais para um sistema de localização centralizada fornecendo informações sobre a localização deles.

Este capítulo tem o objetivo de discutir os principais conceitos da área da Computação Sensível ao Contexto, que serviram de referência para o desenvolvimento deste trabalho. Na seção 4.1 é apresentada uma visão geral do conceito de contexto e uma revisão das suas principais definições, de modo a compreender como este conceito é empregado no desenvolvimento de sistemas sensíveis ao contexto. Na seção 4.2, são discutidas as dimensões semânticas clássicas para apoio à modelagem de informações de contexto que serão utilizadas no processo de modelagem realizado neste trabalho.

A seção 4.3 apresenta algumas classificações de contexto encontradas na literatura. A seção 4.4 apresenta a definição de sistema sensível ao contexto. A seção 4.5 apresenta um conjunto de requisitos de software propostos na literatura para apoiar o processo de desenvolvimento de sistemas sensíveis ao contexto. A seção 4.6 revisa as principais técnicas empregadas para representação de contexto 
e por fim, a seção 4.7 apresenta algumas considerações sobre o emprego dos conceitos apresentados neste capítulo para realização deste trabalho.

\subsection{Definição de Contexto}

O contexto é um conceito que está presente de forma intrínseca nas atividades cotidianas das pessoas. Durante um processo de interação humana o contexto é usado naturalmente e de forma implícita para melhorar a qualidade da comunicação. A percepção do contexto também permite a pessoa fazer avaliações, tomar decisões e adaptar seu comportamento de acordo com a situação. Segundo Vieira et al., (2009), compreender o contexto em que ocorre uma interação é fundamental para que as pessoas possam tomar ações de forma apropriada à situação. No entanto, perceber o contexto e executar ações automaticamente de acordo com esse contexto não é uma tarefa trivial em sistemas computacionais.

Assim, o contexto tem sido objeto de estudo em vários trabalhos de pesquisa, e na literatura é possível encontrar uma variedade de trabalhos baseados em contexto em diversas áreas, tais como Psicologia Cognitiva, Linguística, Inteligência Artificial, Computação Ubíqua, Visão Computacional, Interação UsuárioComputador, Sistemas Colaborativos, Hipermídia Adaptativa, dentre outras (BREZILLON; ROCHA, 2004). Desta forma, por causa da diversidade de domínios de aplicação e propósitos distintos, a definição de contexto ainda não é um consenso entre os pesquisadores. A seguir serão apresentadas algumas definições de contextos geradas ao longo do tempo:

- No trabalho pioneiro que introduziu o termo ciente do contexto (do inglês, context-aware), Schilit and Theimer (1994), definiram o contexto como localização, identificação de pessoas próximas e objetos, informações sobre ambiente, como nível de iluminação e ruído. Os mesmos consideram aspectos importantes do contexto como: onde o usuário está? Com quem usuário está? E quais recursos computacionais estão próximos do usuário?

- Brown et al. (1997), expandem a definição de Schilit e Theimer (1994), sugerindo informações sobre situação, estado, temperatura do ambiente; 
- Na visão de Ryan et al. (1998), referem-se a contexto como a localização, identificação de pessoas e objetos, informações físicas do ambiente e tempo;

- Brezillon e Pomerol (1999), pesquisadores da área de Inteligência Artificial definem o contexto como todo o conhecimento que restringe a solução de um problema, sem interferir nele explicitamente.

Entretanto, há uma definição genérica e clássica de contexto fornecida por (DEY, 2001), que é bastante referenciada e aceita na comunidade acadêmica:

"Contexto é qualquer informação que pode ser utilizada para caracterizar a situação de uma entidade. Uma entidade, por sua vez, pode ser uma pessoa, lugar ou objeto que é considerado relevante para a interação entre um usuário e uma aplicação, incluindo o usuário e aplicação em si."

De acordo com a definição acima, é possível perceber que o contexto abrange informações tais como tempo, localização, identificação, atividades, estado de pessoas e objetos físicos ou computacionais que caracterizam uma situação. Segundo Brezillon e Rocha (2004), a definição de Dey inclui tanto entradas explícitas (informação fornecida por um usuário via interface de usuário) e entrada implícita que necessita um processo computacional antes do uso efetivo (como informação sobre o estado de uma rede local).

Segundo Vieira (2006), em (BAZIRE; BREZILLON, 2005), os autores pesquisaram um conjunto de 150 definições de contexto, oriundas de várias áreas e domínios diferentes e chegaram a duas conclusões: (i) o contexto atua como um conjunto de restrições que influenciam o comportamento de um sistema embutido em uma dada tarefa; (ii) a definição de contexto depende da área de conhecimento a qual pertence. Diante das várias definições existentes, é possível concluir que algumas são complementares e outras refletem a natureza das áreas de conhecimento na qual o contexto é investigado. 


\subsection{Dimensões Semânticas de Informações de Contexto}

Para poder explorar todo o potencial do contexto é primeiramente necessário descobrir o conjunto de informações de contexto que é relevante para uma determinada aplicação. Assim, tais informações são abstraídas durante o processo de modelagem do contexto. Diante deste fato, Abowd e Mynatt (2000) propuseram cinco dimensões semânticas, também referenciadas na literatura como dimensões contextuais para especificação e modelagem de informações de contexto, sendo bastante citadas em trabalhos e conhecidas como os $5 \mathrm{Ws}$ semânticos.

Em linhas gerais, as informações de contexto podem ser identificadas utilizando as dimensões semânticas: when (tempo), where (localização), who (identificação), what (atividade), why (utilizada para se indicar o porquê da execução de uma determinada atividade, qual motivação) (DEY, 2001; ABOWD; MYNATT, 2000). Estas dimensões ajudam ao desenvolvedor decidir quais informações são relevantes para um determinado sistema (GOULARTE, 2003).

Adicionalmente, uma sexta dimensão how (como) foi proposta por (TRUONG et al., 2001) relacionada à forma como as informações de contexto são capturadas. Diversos autores (VIEIRA et a. 2009; ALVES, 2008; BULCÃO NETO, 2006) indicam que as informações de contexto podem ser abstraídas por meio da análise das seis dimensões semânticas, referenciadas como $5 \mathrm{~W}+1 \mathrm{H}$. Assim, cabe ao projetista da aplicação definir por meio de tais dimensões quais informações de contexto são relevantes para aplicação.

\subsection{Classificação de Contexto}

$\mathrm{Na}$ literatura é possível encontrar uma diversidade de propostas de classificação de contexto. Em Schmidt et al. (1999), é apresentado um esquema hierárquico de classes ilustrado na Figura 11 que permite classificar informações contextuais relevantes para um sistema. De acordo com este esquema, a 
classificação de informações contextuais é baseada em duas classes principais: fatores humanos ou ambiente físico.

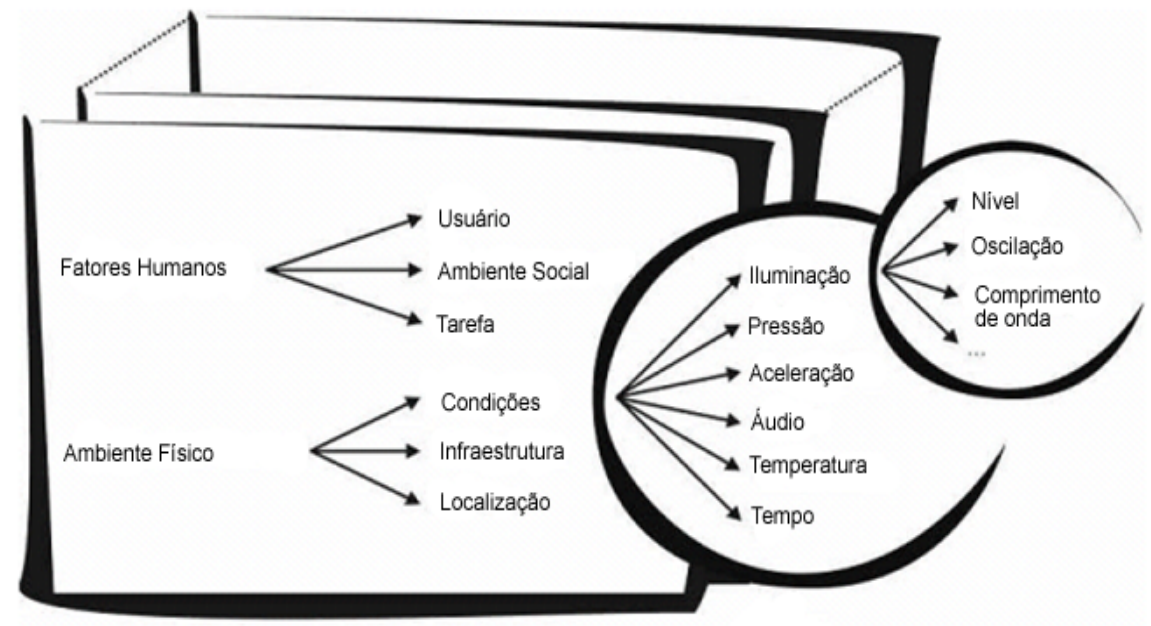

Figura 11 - Esquema de classes Adaptado de (SCHMIDT et al. 1999)

Já os trabalhos de (SCHILIT, 1995; DIX et al. ,2000; CHALMERS, 2002 e CROWLEY et al. 2002) referenciados por (GOULARTE, 2003) propuseram que além do contexto do usuário, os conjuntos de características frequentemente empregados em sistemas sensíveis ao contexto podem ser classificados nas seguintes classes de contexto:

- Infraestrutura - possui informações relacionadas à situação corrente da infraestrutura de comunicação utilizada pelo usuário para acessar aplicação;

- Sistema - contem informações que viabilizam saber até que ponto um dispositivo está ciente de outros dispositivos nas suas proximidades e, relacionado a isso, até que ponto uma aplicação está ciente de outras aplicações oferecendo serviços;

- Domínio - engloba informações sobre a semântica do domínio da aplicação, no que tange os relacionamentos entre os dispositivos e usuários e como pode ser usado para determinar a natureza da interface ou serviço a ser apresentado;

- Ambiente - representa informações sobre o ambiente onde uma determinada entidade se encontra tais como nível de luminosidade, temperatura, localização, dentre outros. 
O trabalho de (GWIZDKA, 2000), faz uma distinção entre dois tipos de contexto: interno e externo. O contexto interno descreve o estado do usuário e pode incluir o contexto do trabalho (p.e. projetos atuais e a sua situação), eventos pessoais (p.e. eventos experimentados pelo usuário), contexto de comunicação (p.e. situação da comunicação interpessoal via e-mail) e situação emocional do usuário. O contexto externo descreve a situação do ambiente. Este pode incluir a proximidade de outros objetos (tanto pessoas e dispositivos) e contexto temporal.

Em outra classificação do contexto, é considerada a relevância do contexto em relação ao foco de atenção atual do usuário (VIEIRA et al. 2009). Essa classificação lida com o aspecto dinâmico do contexto e indica que o contexto deve ser sempre visto como relativo ao foco. Um foco pode ser um passo na tomada de uma decisão ou na execução de determinada tarefa.

Por meio do foco é possível identificar quais elementos contextuais (ou informações de contexto) devem ser instanciados e utilizados para compor um contexto. A Figura 12 ilustra as classes obtidas a partir de um dado foco, o contexto pode ser classificado em conhecimento contextual, conhecimento externo e contexto proceduralizado.

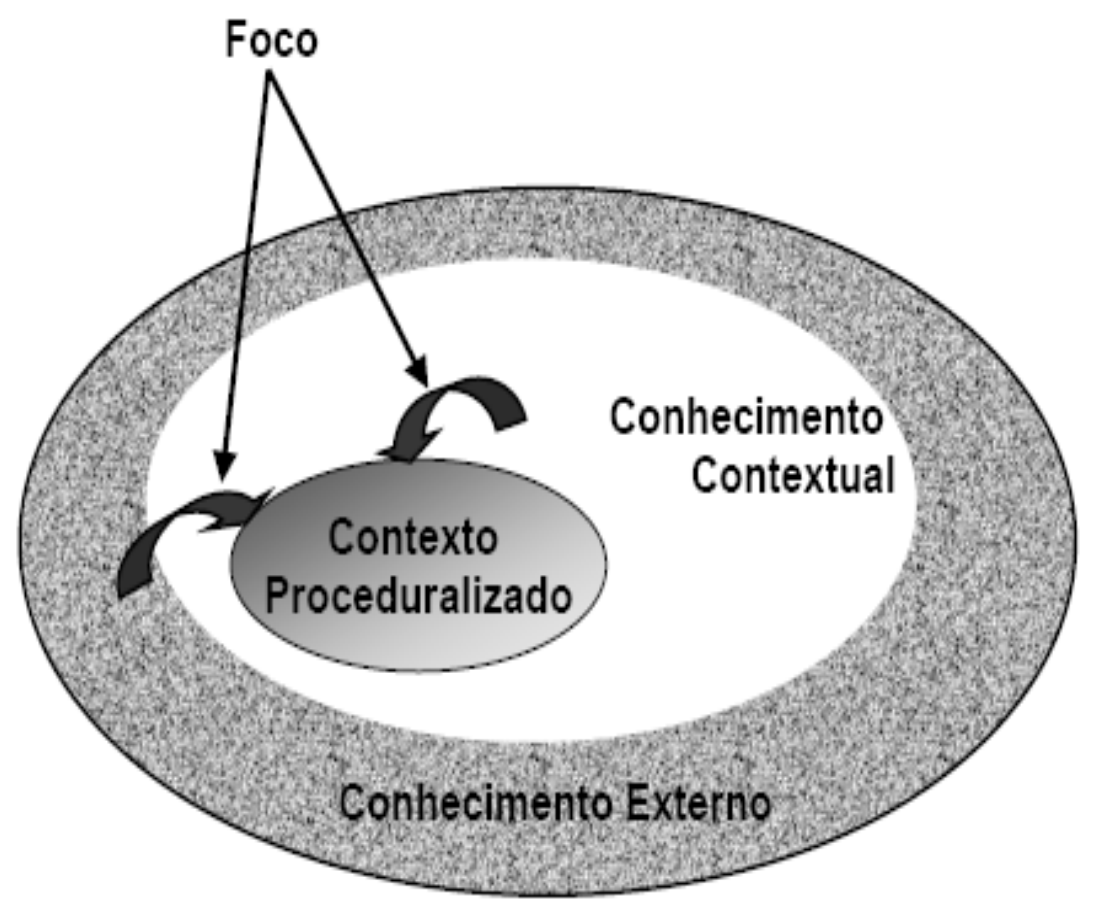

Figura 12 - Classificação do contexto quanto à relevância em relação ao foco de atenção (VIEIRA et al. 2009) 
Segundo Vieira et al. (2009), o conhecimento contextual indica quais elementos contextuais estão diretamente relacionados com o foco, enquanto conhecimento externo são os elementos contextuais que não possuem qualquer relação com o foco. Já o contexto proceduralizado é quando os elementos contextuais que compõem o conhecimento contextual são instanciados, ou seja, são efetivamente utilizados em um foco, como seus valores instanciados de acordo com a situação atual no foco.

Por fim, torna-se possível concluir a partir das propostas de classificação anteriores, que ainda não existe um esquema genérico de classificação de contexto. Cada trabalho segue uma proposta de abordagem de classificação, e a escolha depende da forma como o contexto será utilizado pelo sistema. Neste trabalho foram estudadas e empregadas as classes de contexto do usuário e do domínio, pois abrange informações contextuais identificadas em cenários de uso (como os descritos na seção 7.1) e obtidas por meio das dimensões semânticas, referenciadas na literatura como $5 \mathrm{~W}+1 \mathrm{H}$.

\subsection{Sistemas Sensíveis ao Contexto}

O termo sistema sensível ao contexto (CSS, do inglês, context-sensitive system) é um dos termos utilizado na literatura para referenciar sistemas que empregam o contexto na realização de tarefas. Outros termos considerados sinônimos são: sistema ciente de contexto ou sistema baseado em contexto (do inglês context-aware system). Segundo Schilit e Theimer (1994), um sistema ciente de contexto é um tipo de sistema que se adapta de acordo com a sua localização de uso, o conjunto de pessoas próximas e também objetos, bem como as mudanças de estado destes objetos sobre o tempo.

Entretanto, Dey e Abowd (2001), argumentaram que a definição anterior limita a localização como único objeto de estudo e restringe o comportamento do sistema sensível ao contexto. Logo, esses autores propuseram uma definição mais genérica, que tem sido bastante referenciada na literatura: 
“Um sistema é sensível ao contexto se usa o contexto para fornecer informação e/ou serviços relevantes para o usuário, onde a relevância depende da tarefa do usuário."

Posteriormente em (VIEIRA et al. 2009), é apresentada outra definição de sistemas sensíveis ao contexto:

"São aqueles que gerenciam elementos contextuais (CEs) relacionados a uma aplicação em um domínio e usam esses elementos para apoiar um agente na execução de alguma tarefa. Esse apoio pode ser alcançado pelo aumento da percepção do agente em relação à tarefa sendo executada ou pelo provimento de adaptações que facilitem a execução da tarefa."

A partir desta revisão de definições de sistemas computacionais que exploram o contexto, neste trabalho será empregado o termo sistema sensível ao contexto, pois consideramos que esse termo traduz melhor a semântica de um sistema capaz de perceber as mudanças de contexto, adapta-se e reagir a tais mudanças.

\subsubsection{Sistemas Tradicionais vs Sistemas Sensíveis ao Contexto}

Conforme ilustrado na Figura 13 os sistemas tradicionais consideram apenas as informações fornecidas explicitamente pelos usuários na forma de dados de entrada. Diferentemente, os sistemas sensíveis ao contexto consideram as informações explícitas fornecidas pelos usuários, aquelas armazenadas em uma base de conhecimento contextual, aquelas inferidas por meio de raciocínio e/ou ainda aquelas percebidas a partir do monitoramento do ambiente. Por meio dessas informações contextuais, o sistema pode enriquecer semanticamente a solicitação explícita do usuário e, com isso, fornecer serviços e/ou informações mais próximas às suas necessidades (VIEIRA et al., 2009). 


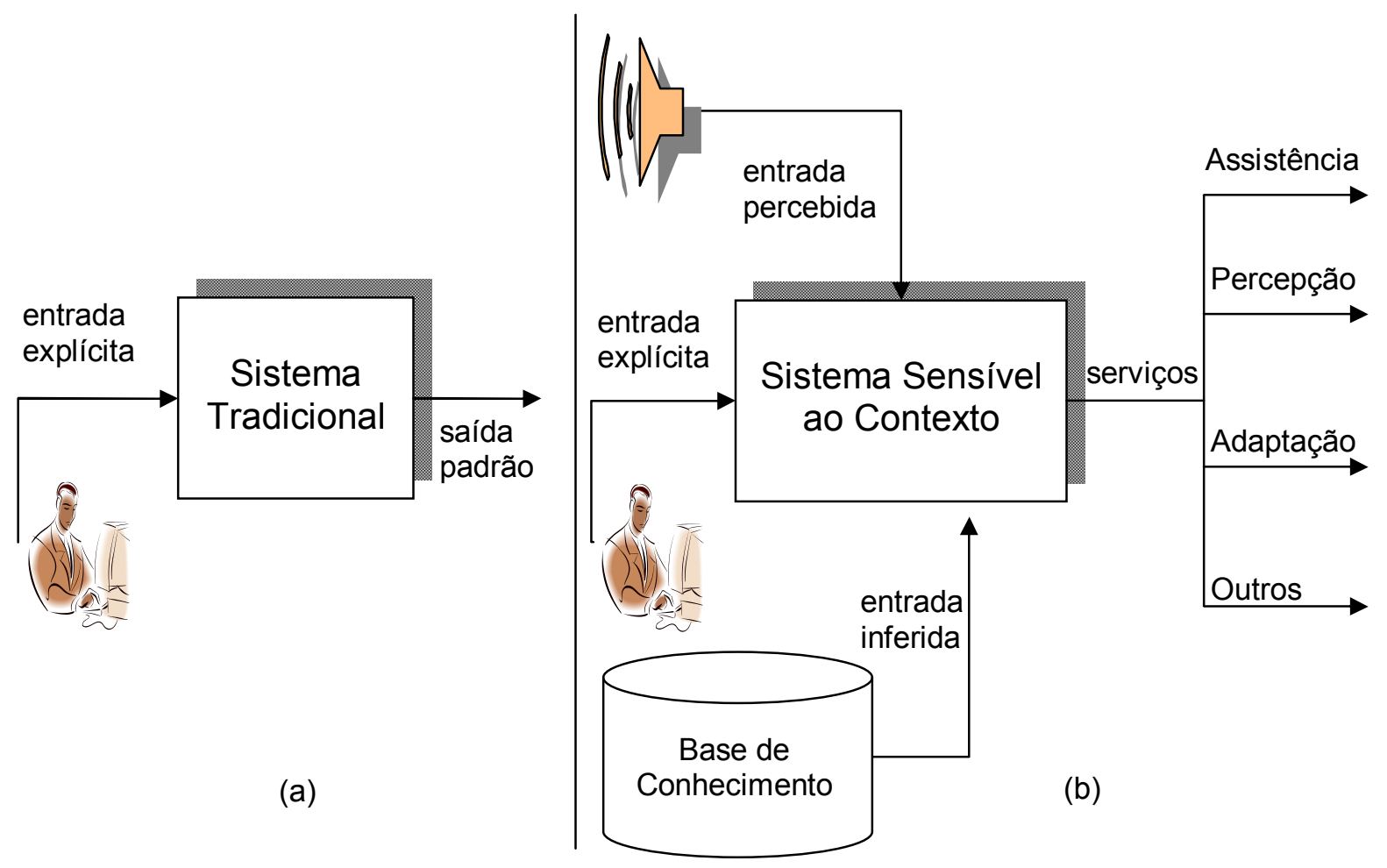

Figura 13 - Sistema tradicional (a) vs. Sistema Sensível ao Contexto (b). Adaptado de (VIEIRA et al., 2009)

O desenvolvimento de sistemas sensíveis ao contexto requer a superação de vários desafios técnicos e de projeto. Pesquisas estão sendo realizadas com 0 objetivo de criar ferramentas e metodologias para apoiar o desenvolvimento deste tipo de sistema e tratar os desafios tecnológicos, como é o caso da solução proposta neste trabalho, que oferece suporte arquitetural e de programação. As soluções propostas categorizaram em metodologias (Vieira et al. 2009), ferramentas arquiteturais (DEY; ABOWD, 2001), infraestruturas (ALVES, 2008; GOULARTE 2003), processadores de contexto (BELOTTI, 2004) e middlewares (GU; PUNG; ZHANG, 2005).

Essas ferramentas objetivam implementar os requisitos básicos para suportar o desenvolvimento de sistemas sensíveis ao contexto, simplificando o processo de desenvolvimento, oferecendo componentes que escondam a complexidade do processamento de contexto. Desta forma, na próxima seção 4.5 será apresentado um conjunto de requisitos essenciais para desenvolvimento de sistemas sensíveis ao contexto. 


\subsection{Requisitos para o Desenvolvimento de Sistemas Sensíveis ao Contexto}

O contexto tem sido explorado de forma distinta em diversas áreas de aplicação. Deste modo, os requisitos necessários para o desenvolvimento de sistemas sensíveis ao contexto possuem graus de relevância diferentes de acordo com domínio e aplicação. Este trabalho utilizará um conjunto de requisitos que são comuns e bastante discutidos na literatura (RAATIKAINEN et al. 2002), (STRANG; LINNHOFF, 2004), (HENRICKSEN et al. 2005), e (VIEIRA et al., 2006). Este levantamento de requisitos é genérico, e visa orientar o desenvolvimento de sistemas sensíveis ao contexto. Nesta seção estão descritos alguns desses principais requisitos.

\subsubsection{Especificação de Informação de Contexto}

Torna-se necessária a especificação de quais informações de contexto são relevantes para uma aplicação. Assim, cabe ao desenvolvedor a utilização de modelos formais que viabilizem a especificação das principais entidades, com suas respectivas informações de contexto e relacionamentos que um sistema sensível ao contexto pode explorar. Esses modelos formais devem fornecer uma abstração de alto nível das principais entidades e informações de contexto. Segundo Vieira et al. (2009), o modelo também deve levar em consideração fatores como interoperabilidade, extensibilidade, compartilhamento e reusabilidade. As informações de contexto podem ser identificadas a partir da análise das dimensões semânticas básicas, referenciadas como $5 \mathrm{~W}+1 \mathrm{H}$ conforme descrito na seção 4.2. 


\subsubsection{Separar Aquisição da Utilização da Informação de Contexto}

Separar aquisição da utilização da informação de contexto permite omitir das aplicações a complexidade do processo de aquisição das informações de contexto. Em outras palavras, a separação destas tarefas, deve viabilizar um fraco acoplamento entre aplicações e mecanismos de aquisição, pois permitirá que uma aplicação possa simplesmente utilizar as informações de contexto obtidas a partir de fontes heterogêneas sem se preocupar com os detalhes de como as informações foram adquiridas e tratadas. Tais informações podem ser obtidas (percebidas) a partir de sensores físicos ou lógicos, de bases de dados, agentes inteligentes, ou até mesmo em último caso fornecidas explicitamente pelo próprio usuário. Com isso, a complexidade do tratamento das informações contextuais é abstraída para as aplicações.

\subsubsection{Interpretação de Informações de Contexto}

A interpretação das informações de contexto é um dos requisitos fundamentais de sistemas sensíveis ao contexto, e compreende um conjunto de métodos e processos que viabilizam a manipulação, a agregação, o raciocínio, a derivação, e a predição de tendências sobre as informações de contextos adquiridas. O objetivo é produzir outras informações mais refinadas e relevantes de modo a melhorar o entendimento de um determinado contexto pelas aplicações e auxiliá-las na tomada de decisões.

Bases de conhecimento permitem o armazenamento de históricos de contexto e juntamente com maquinas de aprendizagem e métodos de predição é possível a interpretação do contexto corrente. Este trabalho propõe empregar na tarefa de interpretação de contexto, diferentes métodos aprendizagem de máquina e de predição tais como o raciocínio baseado em casos (RBC), rede bayesiana, árvore de decisão e redes neurais (WITTEN; FRANCK, 2005).

Desta forma, é possível obter informação contextual de alto nível que será posteriormente explorada pelas aplicações para diversas finalidades. Por exemplo, 
predizer a melhor rota de ambulâncias para hospitais a partir de informações contextuais sobre as condições do trânsito, gravidade em que se encontram os pacientes, e informações de lotação das unidades hospitalares da vizinhança (CALVI; PESSOA; FILHO, 2005).

\subsubsection{Comunicação Distribuída e Transparente}

Visto que os sistemas sensíveis ao contexto são modulares e distribuídos por natureza, a comunicação entre seus componentes necessita ser tratada de forma apropriada. Desta forma, protocolos de comunicação, padrões para integração de componentes devem ser utilizados em sistemas sensíveis ao contexto. Além disso, questões relacionadas à segurança, privacidade e escalabilidade também devem ser consideradas.

Neste trabalho será adotada a tecnologia de Serviços Web (do inglês, Web Services) (W3C, 2002), que oferece um conjunto de padrões que propiciam uma comunicação padronizada entre diferentes aplicações, promovendo a integração entre elas. A descrição dos principais serviços é feita por meio da WSDL (Web Service Definition Language). Já a comunicação é viabilizada por meio da troca de mensagens XML baseada em SOAP (Simple Object Acess Protocol) (W3C, 2003). Tais mensagens XML são transportadas por meio de protocolos da família TCP/IP (W3C, 2002).

\subsubsection{Aquisição Contínua de Informações de Contexto}

A aquisição de informação de contexto dever ser realizada de forma contínua, pois uma aplicação pode requerer informação a qualquer momento. Assim, é necessário que os componentes responsáveis pela aquisição de informação sejam executados continuamente e independentemente das aplicações. A disponibilidade constante destes componentes viabiliza a aquisição de informação de contexto em diversas situações. 
Além disso, a independência destes componentes em relação às aplicações permite que diversas aplicações possam fazer uso destes, de forma compartilhada. Os sistemas sensíveis ao contexto devem oferecer mecanismos para aquisição de contexto de forma mais automática possível, em outras palavras, de modo não intrusivo, sem que o usuário tenha que ser questionado insistentemente sobre o contexto em que se encontra.

\subsubsection{Armazenamento de Informações de Contexto}

Devido à necessidade da disponibilidade constante das informações de contexto, e compartilhamento entre aplicações, tais informações após coletadas devem ser armazenadas para que posteriormente sejam processadas pelos componentes. Assim, torna-se necessário manter um repositório de contexto com todas as informações coletadas. Neste trabalho as informações de contexto serão representadas e armazenadas por meio de documentos XML.

\subsubsection{Descoberta de Recursos}

Em determinadas situações pode ser necessário ao sistema descobrir serviços relevantes que apoiam o processamento do contexto. Por exemplo, se um serviço que fornece determinada informação não estiver funcionando, torna-se necessário encontrar automaticamente outros serviços similares, ou até mesmo efetuar uma composição de serviços de forma a fornecer uma resposta adequada. Assim, automatizar a descoberta de recursos é um requisito importante em sistemas distribuídos.

Devido ao aumento do número de serviços disponibilizados, surge um problema para os serviços de descobertas, que é o de localizar o recurso mais apropriado para determinada operação (FORSTADIUS et al. 2005). Sendo assim, a descoberta de recursos pode ser viabilizada por meio da computação orientada a serviços (PAPAZOGLOU, 2003), o qual utiliza os serviços Web, considerados 
recursos remotos, como elemento fundamental na construção de aplicações distribuídas.

\subsection{Técnicas para Representação de Contexto}

A representação de contexto visa fornecer uma abstração de alto nível, para que seja possível o intercâmbio, a utilização e a compreensão semântica das informações de contexto por usuários e sistemas computacionais. Para isso, uma representação de contexto apropriada deve formalizar as principais entidades e informações de contexto que deverão ser exploradas pelo sistema. Na literatura é possível encontrar alguns trabalhos que apresentam propostas de categorização das técnicas de representação de contexto e análises comparativas entre as principais técnicas (STRANG; LINNHOFF-POPIEN, 2004).

Diversas técnicas vêm sendo utilizadas por diferentes sistemas para representar o contexto, tais como par chave-valor, linguagem de marcação, orientação a objetos, mapas de tópicos e ontologias. No trabalho de Vieira et al. (2009), é apresentada uma profunda análise comparativa das principais técnicas mais utilizadas, onde são sumarizadas as vantagens e desvantagens de cada uma delas, assim como, a dos métodos utilizados para processamento e recuperação de contexto de cada uma das abordagens. Algumas dessas principais técnicas são sumarizadas na Tabela 1. 
Tabela 1- Técnicas de representação de contexto (VIEIRA et al. 2009)

\begin{tabular}{|c|c|c|c|}
\hline Técnica & Vantagens & Desvantagens & $\begin{array}{l}\text { Processamento } \\
\text { e Recuperação }\end{array}$ \\
\hline Par chave-valor & $\begin{array}{l}\text { Estrutura simples, de } \\
\text { fácil implementação e } \\
\text { uso. }\end{array}$ & $\begin{array}{l}\text { Não considera hierarquia. } \\
\text { Inadequado para } \\
\text { aplicações com estruturas } \\
\text { complexas. }\end{array}$ & $\begin{array}{l}\text { Busca linear com } \\
\text { casamento exato } \\
\text { de nomes. }\end{array}$ \\
\hline $\begin{array}{l}\text { Linguagem de } \\
\text { marcação }\end{array}$ & $\begin{array}{l}\text { Baseado em XML. } \\
\text { Prevê hierarquia. } \\
\text { Esquema de marcação } \\
\text { implementa o próprio } \\
\text { modelo. Utilização } \\
\text { típica em perfis. }\end{array}$ & $\begin{array}{l}\text { Incompletude e } \\
\text { ambiguidade na informação } \\
\text { devem ser tratadas pelo } \\
\text { sistema. Inadequado para } \\
\text { representar estruturas } \\
\text { complexas. }\end{array}$ & $\begin{array}{l}\text { Linguagem de } \\
\text { consulta } \\
\text { baseada em } \\
\text { marcação. }\end{array}$ \\
\hline $\begin{array}{l}\text { Mapas de } \\
\text { tópicos }\end{array}$ & $\begin{array}{l}\text { Facilita a navegação } \\
\text { entre os contextos. } \\
\text { Facilita a modelagem } \\
\text { por humanos. }\end{array}$ & $\begin{array}{l}\text { Estágio inicial. Tecnologia } \\
\text { imatura. Faltam exemplos } \\
\text { reais. }\end{array}$ & $\begin{array}{l}\text { Navegação por } \\
\text { redes } \\
\text { semânticas. }\end{array}$ \\
\hline Ontologias & $\begin{array}{l}\text { Contextos modelados } \\
\text { como conceitos e fatos. } \\
\text { Viabiliza formalização, } \\
\text { compreensão e } \\
\text { compartilhamento por } \\
\text { humanos e } \\
\text { computadores. }\end{array}$ & $\begin{array}{l}\text { Tecnologia de manipulação } \\
\text { imatura. }\end{array}$ & $\begin{array}{l}\text { Motor de } \\
\text { inferência, } \\
\text { linguagem de } \\
\text { consulta } \\
\text { baseada em } \\
\text { OWL }\end{array}$ \\
\hline $\begin{array}{l}\text { Modelos } \\
\text { Gráficos }\end{array}$ & $\begin{array}{l}\text { Facilita a especificação } \\
\text { dos conceitos e } \\
\text { definição do } \\
\text { comportamento do } \\
\text { CSS. }\end{array}$ & $\begin{array}{l}\text { Não permite processar os } \\
\text { conceitos: mapeamento } \\
\text { para estruturas de dados. }\end{array}$ & $\begin{array}{l}\text { Pode ser } \\
\text { traduzido para } \\
\text { XML e usa } \\
\text { processamento } \\
\text { em XML. }\end{array}$ \\
\hline
\end{tabular}

Além das técnicas analisadas por Vieira et al. (2009), pode ser adicionada a técnica baseada em Orientação a Objetos, que oferece como vantagens: encapsulamento, herança, e reusabilidade. Como desvantagem: aumento da complexidade para formalismo do modelo. Em (BULCÃO, 2006), foi apresentado um modelo de representação de contexto baseado em ontologia e padrões da Web Semântica. Este modelo foi denominado de SeCom (Semantic Context Model) voltado para o domínio do ensino universitário.

No domínio da TV Digital, em (BLANCO-FERNANDEZ et al., 2006), (LEITE et al., 2007), os autores propuseram ontologias para representar formalmente o conhecimento sobre o domínio da TV. Em (GOULARTE, 2003), foi utilizada a linguagem de marcação (XML) e Esquema XML para criar uma biblioteca extensível de elementos contextuais estruturados. Tal biblioteca foi utilizada para o desenvolvimento de um serviço de adaptação e personalização de conteúdo para TV Digital. 
Segundo Vieira et al. (2009), cada técnica de representação possui vantagens e desvantagens. Deste modo, não há uma técnica que seja considerada ideal para todos os sistemas sensíveis ao contexto, uma vez que diferentes sistemas impõem diferentes restrições. Com isso, para representação de contexto neste trabalho, será adotada a linguagem de marcação (XML) juntamente com Esquema XML, por motivos de interoperabilidade e facilidade de integração com os descritores e esquemas de descrição dos padrões de metadados TV-Anytime e MPEG-7, os quais também foram desenvolvidos por meio destas técnicas.

\subsection{Considerações Finais}

Este capítulo abordou os principais fundamentos sobre Computação Sensível ao Contexto que foram estudados e utilizados durante o desenvolvimento deste trabalho. No cenário da TV Digital Interativa, a exploração do contexto pode enriquecer a experiência de televisiva do usuário, principalmente quando empregado em aplicações interativas para prover conteúdos e/ou informações de forma personalizada. O projeto de um sistema sensível ao contexto exige a superação de vários desafios tecnológicos. Cada vez mais pesquisas estão sendo realizadas com o objetivo de construir ferramentas para auxiliar o tratamento desses desafios, de modo que desenvolvedores possam fazer uso de tais ferramentas, para simplificar o desenvolvimento de sistemas sensíveis ao contexto.

A solução proposta neste trabalho tem o objetivo de apoiar o desenvolvimento de sistemas de recomendação sensíveis ao contexto para TV Digital Interativa. Além dos requisitos que foram apresentados, outros requisitos também podem ser considerados como aquisição menos intrusiva das informações de contexto, questões de privacidade e segurança, e escalabilidade do sistema. O tratamento de tais requisitos está fora do escopo deste trabalho, ficando como sugestão para trabalhos futuros. 


\section{Recomendação Personalizada de Conteúdo}

Com o crescimento do volume de conteúdos, produtos e serviços oferecidos em ambientes como a Web e TV Digital Interativa aumentou a dificuldade para o usuário selecionar conteúdo relevante dentre as várias opções disponíveis. Esse problema é conhecido na literatura como sobrecarga de informação (BLANCOFERNANDEZ et al., 2006). Nesse contexto, a estratégia da recomendação personalizada de conteúdo está sendo empregada por meio de sistemas de recomendação como uma possível solução para ajudar o usuário a encontrar itens que provavelmente serão de seu interesse (CHORIANOPOULOS, 2008). Assim, torna-se um grande desafio para pesquisa em computação nos próximos anos, o desenvolvimento de soluções para acesso personalizado e gerenciamento de grandes volumes de informação e conteúdo multimídia distribuídos (SBC, 2006).

Recomendar de forma personalizada itens para um usuário por meio de um sistema de recomendação implica na superação de vários desafios técnicos. Questões relacionadas à qualidade das recomendações geradas, a eficiência da abordagem de aquisição dos dados que especificam os interesses do usuário, assim como dos métodos de predição de preferências, e da filtragem de conteúdo exigem técnicas de recomendação cada vez mais sofisticadas. Diante deste cenário o tema "sistemas de recomendação" tem despertado cada vez mais interesse da comunidade acadêmica, se tornando uma importante área de pesquisa (ADOMAVICIUS; TUZHILIN, 2005).

Este capítulo tem o objetivo de apresentar uma visão geral sobre os principais conceitos e técnicas que viabilizam o funcionamento de sistemas de recomendação. A seção 5.1 apresenta a definição de sistemas de recomendação. A seção 5.2 discute as abordagens utilizadas para coleta de informações sobre os usuários. A seção 5.3 discute as técnicas de filtragem empregadas na recomendação de conteúdo. A seção 5.4 versa sobre os métodos de aprendizagem de máquina para predição de preferências. A seção 5.5 discute o método de realimentação de relevância, enquanto que na seção 5.6 são descritas as métricas para avaliação da qualidade das recomendações geradas. A seção 5.7 discute aspectos de 
privacidade de segurança das informações, e a finalmente a seção 5.8 apresenta as considerações finais.

\subsection{Sistemas de Recomendação}

O primeiro sistema de recomendação foi o Tapestry (GOLDBERG et al., 1992), desenvolvido por pesquisadores da Xerox Palo Alto Research Center. A motivação para o Tapestry foi a sobrecarga de e-mails que os pesquisadores estavam recebendo e tinha o objetivo de substituir o sistema tradicional de e-mail usado no centro de pesquisa. O Tapestry foi projetado para receber, filtrar, arquivar os e-mails que chegavam diariamente. Na literatura é possível encontrar várias definições para sistema de recomendação. A seguir será apresentada uma revisão de algumas definições.

De acordo com Burke (2002), um sistema de recomendação é um sistema que guia o usuário de forma personalizada para objetos úteis ou de interesse a partir de um largo espaço de opções possíveis. Para Vozalis e Margaritis (2003) sistemas de recomendação foram definidos como uma técnica inteligente para lidar com o problema da sobrecarga de informação. Na visão de Herlocker et al. (2004), um sistema de recomendação antecipa quais itens um usuário achará relevante, e apresenta sugestões ao usuário que é beneficiado pela filtragem de itens.

Segundo Baltrunas (2008), sistemas de recomendação são ferramentas poderosas que podem ajudar o usuário a enfrentar o problema da sobrecarga de informação, fornecendo recomendações personalizadas sobre vários tipos de produtos e serviços. De acordo com Chorianopolis (2008), o principal objetivo dos sistemas de recomendação é apresentar sugestões de serviços diversos de acordo com o perfil do usuário pré-determinado. Para Blanco-Fernandes et al. (2010), sistemas de recomendação podem auxiliar o usuário a escolher um plano de viagem, indicando lugares para visitar, opções de hotéis, companhias aéreas, de acordo com as preferências do usuário indicadas em seu perfil. 


\subsubsection{Sistemas de Recomendação Sensíveis ao Contexto}

A geração atual de sistemas de recomendação necessita de aprimoramentos para tornar os métodos de recomendação mais eficientes. Tradicionalmente tais sistemas são baseados somente em perfis dos usuários, e não levam em consideração as mudanças de contexto que podem influenciar os interesses do usuário. Desta forma, a incorporação de informações contextuais no processo de recomendação é destacada na literatura como uma possível extensão para os sistemas de recomendação tradicionais (ADOMAVICIUS; TUZHILIN, 2008) (SETTEN; POKRAEV; KOOLWWAIJ, 2004).

O objetivo de um sistema de recomendação sensível ao contexto é gerar sugestões de itens ou prevê a relevância de itens para um usuário em particular ou grupo de usuários a partir da exploração do perfil do usuário e também de informações de contexto. Assim, a nova geração de sistemas de recomendação deverá explorar as informações de contexto para fornecer melhores recomendações (BALTRUNAS, 2008).

De acordo com Adomavicius e Tuzhilin (2008), diferentes abordagens estão sendo investigadas para incorporar informações de contexto em sistemas de recomendação. Tais abordagens podem ser classificadas em dois grupos: (1) contexto dirigido a consultas e pesquisas; e (2) estimação e elicitação de preferências contextuais. A primeira abordagem tem sido utilizada por uma grande variedade de sistemas de recomendação (AROYO et al., 2007),(BLANCOFERNANDEZ et al., 2010), que usam as informações de contexto para expandir as consultas e pesquisas. Na segunda abordagem as informações contextuais são empregadas no processo de recomendação para predizer preferências contextuais. A estimação e elicitação de preferências contextuais é ressaltada na literatura como abordagem promissora e tendência para sistemas de recomendação sensíveis ao contexto (ADOMAVICIUS; TUZHILIN, 2008),(SILVA; ALVES; BRESSAN, 2009).

Desta forma, este trabalho segue a segunda abordagem, onde as informações de contexto foram modeladas por meio das seis dimensões semânticas $5 \mathrm{~W}+1 \mathrm{H}$ (descritas na seção 4.2), e incorporadas ao processo de recomendação como características descritivas adicionais do usuário por meio do conceito Perfil 
Contextual do Usuário. Tal conceito (conforme descrito na seção 7.6) é utilizado nas tarefas de aprendizagem supervisionada e predição de preferências contextuais.

\subsection{Coleta de Informações Sobre os Usuários}

Os sistemas de recomendação utilizam informações sobre o usuário tais como dados demográficos, estereótipos, preferências, avaliações de itens, dentre outros, para selecionar itens que provavelmente serão de seu interesse. Desta forma, torna-se necessário coletar e armazenar as informações sobre o usuário para que posteriormente sejam empregadas no processo de recomendação. As informações devem ser coletadas, representadas e armazenadas de acordo com um modelo do usuário especificado.

Neste trabalho, o modelo do usuário foi representado por meio de linguagem de marcação XML juntamente com Esquema XML. Outros métodos podem ser empregados para representar o perfil do usuário como modelo baseados em ontologia, vetores de características, matrizes de avaliações etc. Cada método é utilizado de acordo com o domínio de aplicação e os requisitos do sistema (BLANCO-FERNANDEZ, 2007).

A coleta das informações pode ser realizada de forma explícita ou implícita. $\mathrm{Na}$ coleta explícita o usuário é incentivado a manualmente especificar as informações que descrevem os seus interesses por meio da utilização de uma interface gráfica como um formulário. Nesta modalidade o usuário deve fornecer alguns dados, por exemplo, idade, ocupação, sexo, e preferências explícitas. De acordo Zimmerman et al. (2004), esta técnica assegura certa precisão na representação do perfil do usuário, e pode gerar alta qualidade recomendação.

No entanto, segundo Cotter e Smyth (2000), devido ao fato que alguns usuários não especificam os seus dados completamente, deve ser empregado um mecanismo complementar que permita atualizar o perfil do usuário, principalmente suas preferências de forma implícita. No domínio da TV Digital, alguns exemplos de sistemas de recomendação para TV que empregaram esta técnica são: (DAl; COHEN, 2003), PTV (COTTER; SMYTH, 2000), (ZHANG; ZHENG, 2005) e (ZIMMERNMAN, 2004). 
$\mathrm{Na}$ coleta implícita o sistema infere os interesses do usuário por meio da análise das ações de interação ou a partir do seu histórico de uso. Nesta modalidade à medida que o usuário avalia um item, realiza uma consulta ou efetua a leitura de um conteúdo o sistema armazena as informações em um histórico de uso. Posteriormente, essas informações serão utilizadas em um processo de predição, que visa identificar quais são os interesses do usuário e o seu padrão de comportamento. Esta modalidade tem a vantagem de não ser intrusiva, pois é possível descobrir os interesses do usuário sem que seja necessário que o mesmo forneça explicitamente seus dados.

Deste modo, a atenção do usuário não será desviada do conteúdo que estiver sendo acessado, e a recomendação será gerada de forma transparente. Além disso, a abordagem implícita é apropriada para sistemas de TV Digital, pois não exige que usuário forneça seus dados, que é uma dificuldade quando se utiliza um controle remoto. No domínio da TV Digital Interativa, alguns exemplos de sistemas de recomendação para TV que empregaram esta técnica são: (BLANCO-FERNANDEZ et al., 2006), (LUCAS; ZORZO, 2009), (ZHANG; ZHENG; YUAN, 2005) e (COTTER; SMYTH, 2000).

\subsection{Técnicas de Filtragem de Informação}

O problema da sobrecarga de informação tem motivado a exploração de técnicas de filtragem de informação da área de Recuperação de Informações (RI) em sistemas de recomendação. Tais sistemas podem ser classificados de acordo com a técnica de filtragem explorada. Nas próximas subseções serão descritas as principais técnicas de filtragem de informação: Filtragem Baseada em Conteúdo (FBC), Filtragem Colaborativa (FC) e Filtragem Híbrida (FH). 


\subsubsection{Filtragem Baseada em Conteúdo (FBC)}

Segundo Adomavicius e Tuzhilin (2005), a FBC tem sua origem em pesquisas na área de Recuperação de Informação (RI). A FBC é uma técnica que consiste em comparar as descrições de conteúdos contidas em documentos com os assuntos de interesses especificados no perfil do usuário a fim de selecionar os conteúdos relevantes. Segundo Herlocker et al. (2004) os interesses são fornecidos explicitamente pelo próprio usuário, por meio de um perfil, ou obtidas por meio da avaliação de conteúdos que o usuário consome ao longo do tempo.

Nos sistemas de recomendação baseados em FBC, o usuário deverá receber uma lista de itens similares aqueles que o mesmo gostou no passado (ADOMAVICIUS; TUZHILIN, 2005), onde a relevância de um conteúdo para o usuário é proporcional à similaridade entre o conteúdo e o seu perfil. A FBC é uma técnica normalmente empregada em sistemas de recomendação, onde o foco é recomendar itens contendo informação textual, tais como páginas Web, artigos científicos, dentre outros.

No ambiente da TV Digital, alguns sistemas de recomendação de programas de TV adotaram a FBC tais como PTV (COTTER e SMYTH, 2000), IndexTV (ROVIRA et al., 2004), (NETO et al. 2010) e o Recommender TV (ÁVILA, 2010). Neste trabalho a FBC deverá ser implementada por meio de expressões definidas a partir da linguagem de consulta em metadados XQuery conforme descrita na seção 3.4 .

Segundo Adomavicius e Tuzhilin (2005), sistemas de recomendação que empregam a FBC tem as seguintes limitações:

1. Problema da análise limitada do conteúdo: a técnica FBC é limitada pelas características que estão explicitamente associadas ao conteúdo. $O$ conteúdo deve estar numa forma (por exemplo, texto) que possa ser analisado automaticamente por um computador. Assim, é mais complexo empregar técnica FBC para análise e extração de conteúdo multimídia (imagens, vídeos, áudios) do que para extração de conteúdo textual. Outro problema com a análise de conteúdo é que, a técnica FBC não consegue distinguir documentos diferentes que possuem os mesmos termos; 
2. Problema da super especialização: ocorre quando um sistema de recomendação pode recomendar somente itens semelhantes a itens avaliados anteriormente como relevantes. Com isso, a diversidade das recomendações e comprometida;

3. Problema do novo usuário: o usuário necessita avaliar um número suficiente de itens para que um sistema de recomendação possa realmente obter as preferências do usuário e apresentar ao usuário recomendações confiáveis.

\subsubsection{Filtragem Colaborativa (FC)}

A expressão Filtragem Colaborativa foi criada pelos desenvolvedores do primeiro sistema de recomendação, o Tapestry (GOLDBERG et al., 1992). De acordo com Chen (2005), a FC trabalha combinando as opiniões de pessoas que expressaram inclinações similares no passado para predizer o que poder ser de interesse agora para uma determinada pessoa. Assim, nos sistemas de recomendação baseados em $\mathrm{FC}$, o usuário receberá uma lista de itens, que pessoas com preferências similares gostaram no passado (ADOMAVICIUS; TUZHILIN, 2005).

Os sistemas de recomendação baseados em FC se diferenciam dos demais, justamente porque não exigem um processamento das características (descrições) dos conteúdos. Em contraste, esta técnica procura explorar o intercâmbio de experiências entre os usuários e usa as opiniões deles para predizer os interesses de outros. Adomavicius e Tuzhilin (2005) destacam que uma característica importante da FC é ser uma técnica de recomendação independente de domínio, especialmente indicada para recomendação de conteúdo que não pode ser descrito adequadamente por metadados.

Neste tipo de filtragem, o usuário pode indicar suas opiniões em forma de avaliações de vários itens e o filtro colaborativo correlaciona suas avaliações com aquelas de outros usuários a fim de determinar usuários com perfis semelhantes e fazer futuras recomendações. Herlocker et al. (2004) ainda destaca que a FC viabiliza a criação de comunidades, pela agregação de pessoas que possuem 
interesses comuns. No ambiente da TV Digital Interativa, a FC também foi adotada por alguns sistemas de recomendação de programas de TV tais como PTV (COTTER e SMYTH, 2000), AVATAR (BLANCO-FERNANDEZ et al., 2006).

Segundo Adomavicius e Tuzhilin (2005), sistemas de recomendação que empregam a FC tem as seguintes limitações:

1. Problema do novo item: novos itens são adicionados regularmente em sistemas de recomendação. Um novo item somente poderá ser recomendado para o usuário quando o item for avaliado por um número considerável de usuários;

2. Problema da esparcidade: o sucesso de um sistema de recomendação baseado em FC depende da disponibilidade de uma massa crítica de usuários. Este problema ocorre quando o número de avaliações obtido é muito menor ao número de avaliações que necessita ser previsto. Com isso, é importante conseguir predição eficiente de avaliações a partir de um pequeno número de exemplos;

3. Problema do novo usuário: este é o mesmo problema da técnica FBC. Para fazer recomendações precisas o sistema de recomendação deve primeiro aprender as preferências do usuário a partir de etapa de treinamento, onde o usuário efetua avaliações.

\subsubsection{Filtragem Híbrida (FH)}

A técnica de $\mathrm{FH}$ combina as técnicas de FBC e FC visando superar as suas respectivas limitações. Esta abordagem procura explorar as vantagens da FBC e FC com o objetivo apresentar melhores resultados, que possam atender às expectativas dos usuários. Na literatura é possível encontrar diferentes propostas para combinação de tais técnicas (BURKE, 2002), (LI; KIM, 2003), (BASILICO; HOFMANN, 2004). Segundo Adomavicius e Tuzhilin (2005), as propostas para sistemas híbridos podem ser classificados como segue:

1. O primeiro grupo é composto por propostas de sistemas que realizam uma combinação linear dos resultados da FBC e FC. A ideia consiste 
em utilizar cada técnica de filtragem de forma separada, de forma que os resultados gerados possam ser ou não combinados;

2. O segundo grupo é formado por propostas de sistemas que incorporam na FC algumas características da FBC;

3. O terceiro grupo é formado por propostas de sistemas que incorporam na FBC algumas características da FC;

4. O quarto grupo abrange propostas de sistemas que geralmente constroem um modelo unificado. Tal modelo incorpora as características de ambas às técnicas de filtragem.

No domínio da TV personalizada, alguns exemplos de sistemas de recomendação para TV que empregaram a técnica FH são: (COTTER; SMYTH, 2000), (BLANCO-FERNANDEZ et al., 2006). Uma das suas limitações é ausência de suporte semântico na realização da filtragem.

\subsection{Aprendizagem de Máquina e Predição}

Além das técnicas tradicionais para filtragem de informação da área de Recuperação de Informações (RI), os sistemas de recomendação também podem utilizar técnicas de aprendizagem de máquina e predição com o intuito de aprender e fornecer predições ou tendências de preferências do usuário a partir do seu histórico de uso (BLANCO-FERNANDEZ et al., 2006). Com isso, qualquer algoritmo que possa ser utilizado para execução do processo de aprendizado é chamado algoritmo de aprendizado ou classificação. Segundo Han e Kamber (2006), as principais abordagens de aprendizagem de máquina são:

- Aprendizagem supervisionada: envolve a aprendizagem de uma função a partir de registros de treinamento com rótulos de classes fornecidos. Tais rótulos correspondem ao valor que se espera que o algoritmo possa predizer sempre que receber registros específicos como argumentos de entradas; 
- Aprendizagem não-supervisionada: envolve a aprendizagem de registros treinamento, em que não são fornecidos os rótulos de classes.

No que tange a predição qualquer algoritmo que possa ser utilizado para predizer o rótulo de classe do registro de entrada é chamado algoritmo de predição.

Neste trabalho foi empregada a abordagem de aprendizagem supervisionada que tem como base a tarefa de classificação. Segundo Han e Kamber (2006) a tarefa de classificação é realizada em duas etapas. $\mathrm{Na}$ primeira delas um classificador (ou modelo de conhecimento) é construído descrevendo um conjunto predeterminado de classes de dados ou conceitos. Esta é a etapa de aprendizagem (ou treinamento), onde o algoritmo de classificação constrói o modelo de conhecimento por meio da aprendizagem do conjunto de treinamento composto de registros (ou tuplas) com seus rótulos de classes conhecidos. No contexto da classificação os registros podem ser referenciados como instâncias, exemplos, ou dados de testes.

Segundo Han e Kamber (2006) a etapa de aprendizagem da tarefa de classificação pode também ser compreendida como a aprendizagem de uma função $y=f(X)$, que pode predizer o rótulo $y$ da classe associada para um dado registro $X$. A função obtida é justamente o modelo de conhecimento. Uma vez identificada, essa função pode ser aplicada a novos registros de forma a predizer o rótulo da classe que tais registros pertencem. Esta etapa é a chamada predição de classe ou etapa de predição. Para contextualizar o emprego desta abordagem serão apresentados alguns exemplos:

- Um pesquisador médico deseja analisar dados obtidos sobre um determinado tipo de câncer para predizer dentre os três tratamentos específicos qual o seu paciente deverá receber.

- Um gerente de marketing de uma loja virtual deseja analisar o histórico de compras para predizer se um cliente desejará comprar um determinado tipo de computador.

Em cada um destes exemplos, a análise de dados consiste na tarefa de classificação, onde um modelo de conhecimento é construído para predizer um rótulo de classe, tais como "tratamento A" ou "tratamento B" ou "tratamento C" para o primeiro exemplo por meio de dados médicos, ou ainda "computador A" ou 
"computador B" para o segundo exemplo. Para este trabalho foi especificada uma abordagem de aprendizagem supervisionada dependente do contexto para predição de preferências contextuais (gêneros de programas de TV) posteriormente empregadas na filtragem de conteúdo (descrita detalhadamente na seção 7.6).

Nas próximas subseções será apresentado um conjunto de técnicas empregadas neste trabalho para tarefa de classificação. Vale ressaltar que não é objetivo desta seção, e nem deste trabalho, fazer uma análise profunda de tais técnicas, sendo que uma discussão mais rica em detalhes sobre esse assunto está fora do escopo deste trabalho. A metodologia para escolha das técnicas consiste em elencar as técnicas comumente empregadas em sistemas de recomendação com suas características relevantes, segundo os requisitos da infraestrutura proposta nesta pesquisa.

\subsubsection{Indução de Árvore de Decisão}

Indução de árvore de decisão é a aprendizagem de árvores de decisão a partir de registros (ou tuplas) de treinamento com rótulos de classe. Uma árvore de decisão é uma estrutura em forma de árvore, onde cada nó interno (nó não folha) denota um teste em um atributo, cada ramo representa um resultado do teste, e cada folha nó (ou nó terminal) possui um rótulo de classe. O nó mais alto em uma árvore é o nó raiz. Desta forma, uma árvore de decisão é um modelo de conhecimento cujo objetivo é classificar uma dada entrada em uma classe específica.

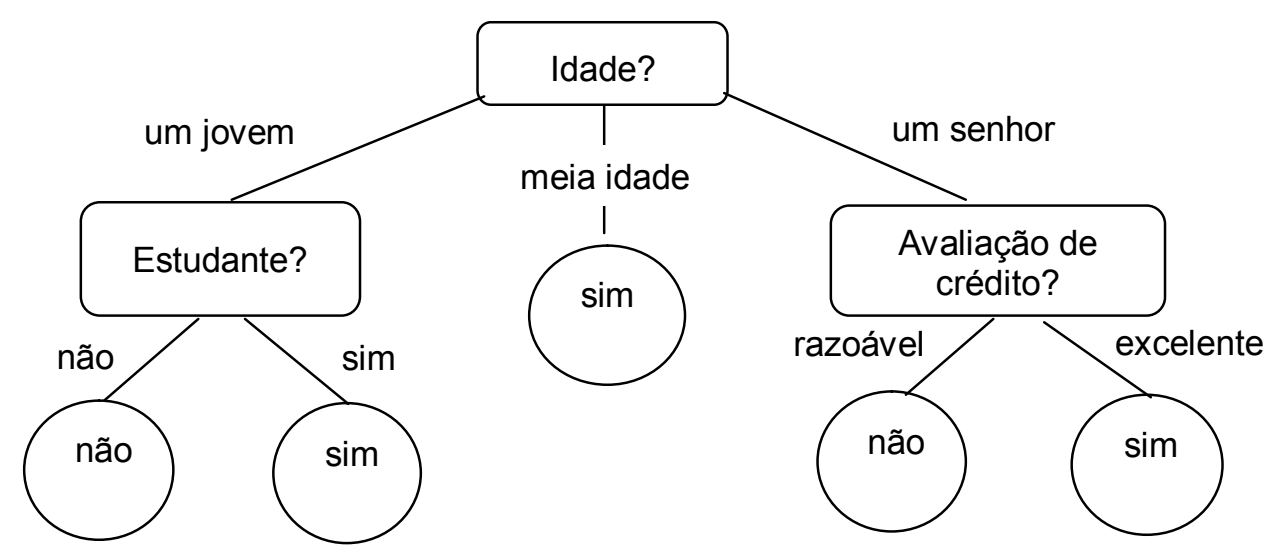

Figura 14 - Árvore de decisão para o conceito comprar computador (HAN; KAMBER, 2006) 
É ilustrada na Figura 14 uma típica árvore de decisão, que representa o conceito compra de computador, e pode ser utilizada para predizer se um cliente é susceptível a adquirir um computador. Nós internos são indicados por retângulos, e nós folhas são indicados por elipses. Cada nó interno representa um teste em um atributo, e cada nó folha representa uma classe (um dos dois comprar computador = sim ou comprar computador $=$ não). Deste modo, dada um registro, $X$, para o qual o rótulo $y$ da classe é desconhecido, os valores dos atributos do registro são testados contra a árvore de decisão. Um caminho é traçado a partir do nó raiz até um nó folha, que mantém a previsão da classe para este registro.

A representação do conhecimento adquirido por meio de uma árvore é intuitiva e geralmente de fácil assimilação por humanos. Segundo Han e Kamber (2006), as etapas de aprendizagem (ou classificação) e predição da árvore de decisão são simples e rápidas, em geral, os classificadores de árvore de decisão têm uma boa precisão. Entretanto, o uso bem sucedido pode depender dos dados obtidos. Algoritmos de indução de árvore de decisão têm sido utilizados para classificação em muitas áreas de aplicação, tais como medicina, análise financeira, astronomia, produção e manufatura. O ID3 (Interactive Dichotomiser), CART (Classification and Regression Trees) e o C4.5 são os algoritmos de indução de árvore de decisão estão entre os mais tradicionais.

\subsubsection{Classificador Bayesiano}

Um classificador bayesiano é fundamentado em princípios e teorias estatísticas, como o Teorema de Bayes que tem como base o cálculo das probabilidades condicionais. Desta forma, um classificador bayesiano prevê a probabilidade de que um determinado registro (ou tupla) representado por um vetor de atributos n-dimensional, $X=\left(x_{1}, x_{2}, \ldots, x_{n}\right)$, pertence a uma classe particular $C_{i}$.

Segundo Han e Kamber (2006) o classificador bayesiano ingênuo é o mais comum dentre os métodos existentes de classificação bayesiana. Classificador bayesiano ingênuo tem como base a hipótese de que o efeito de um valor de atributo em uma determinada classe é independente dos valores dos outros atributos. Esta hipótese é chamada independência condicional de classe, sendo 
empregada para simplificar os cálculos e, neste sentido é considerado "ingênuo". Segundo Han e Kamber (2006) a probabilidade de que um registro representado por um vetor de atributos $n$-dimensional, $X=\left(x_{1}, x_{2}, \ldots, x_{n}\right)$, pertence a uma classe particular $C_{i}$ é dada por:

$$
\mathrm{P}\left(\mathrm{X} \mid \mathrm{C}_{\mathrm{i}}\right)=\prod_{\mathrm{k}=1}^{\mathrm{n}} \mathrm{P}\left(\mathrm{X}_{\mathrm{k}} \mid \mathrm{C}_{\mathrm{i}}\right)
$$

Segundo Adomavicius e Tuzhilin (2005), o classificador bayesiano ingênuo apresenta alta precisão e velocidade quando aplicado a grandes bases de dados.

\subsubsection{Redes Neurais}

Redes Neurais Artificiais (RNAs) são algoritmos baseados em modelos matemáticos inspirados na estrutura do cérebro humano, em particular nos princípios de funcionamento dos neurônios biológicos para realização de tarefas tais como previsão de séries temporais, reconhecimento de padrões, classificações, dentre outros. Segundo Han e Kamber (2006), uma rede neural é um conjunto de unidades (ou neurônios) com entradas e saídas conectadas para formar uma rede na qual cada conexão tem um peso associado.

Durante a fase de aprendizado, a rede aprende, ajustando os pesos de modo a ser capaz de prevê corretamente o rótulo de classe dos registros (ou tuplas) de entrada. Rede neural também é referenciada como aprendizagem conexionista devido às ligações entre as unidades. O modelo básico de uma unidade ou um neurônio artificial (perceptron) proposto por McCulloch e Pitts (1943) pode ser visto na Figura 15.

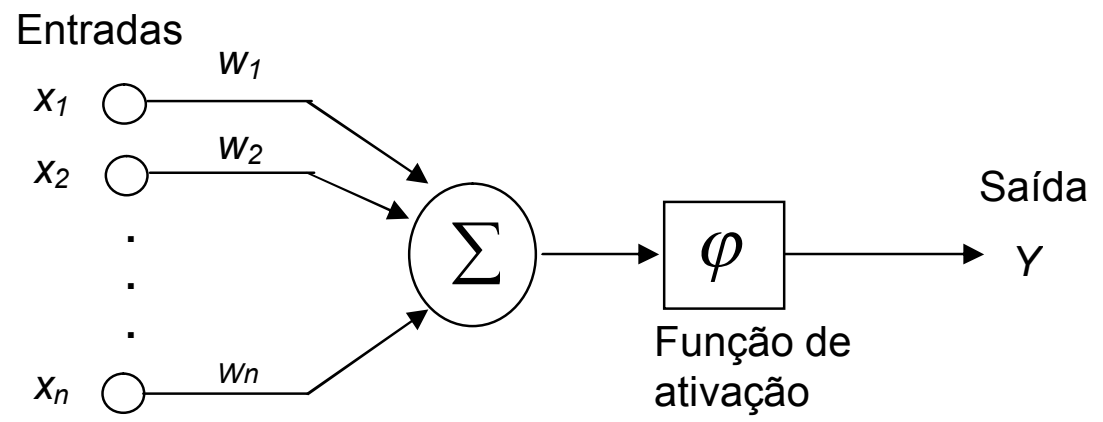

Figura 15 - Modelo básico de um neurônio artificial (McCULLOCH; PITTS, 1943) 
Este modelo é composto pelos os seguintes elementos: (i) um conjunto de $n$ conexões de entrada $\left(x_{1}, x_{2}, \ldots, x_{n}\right)$, onde cada entrada tem um peso multiplicativo correspondente $\left(w_{n}\right)$; um somador $\left(\sum\right)$ para acumular os sinais de todas as entradas; uma função de ativação $(\varphi)$ que determina a saída efetiva $(Y)$ do neurônio. Na literatura é possível encontrar diversas propostas de funções de ativação tais como linear, limiar, ou ainda uma função que simule mais precisamente as características não lineares do neurônio biológico. Neste último caso, é muito comum a utilização da função sigmóide (HAM; KAMBER, 2006).

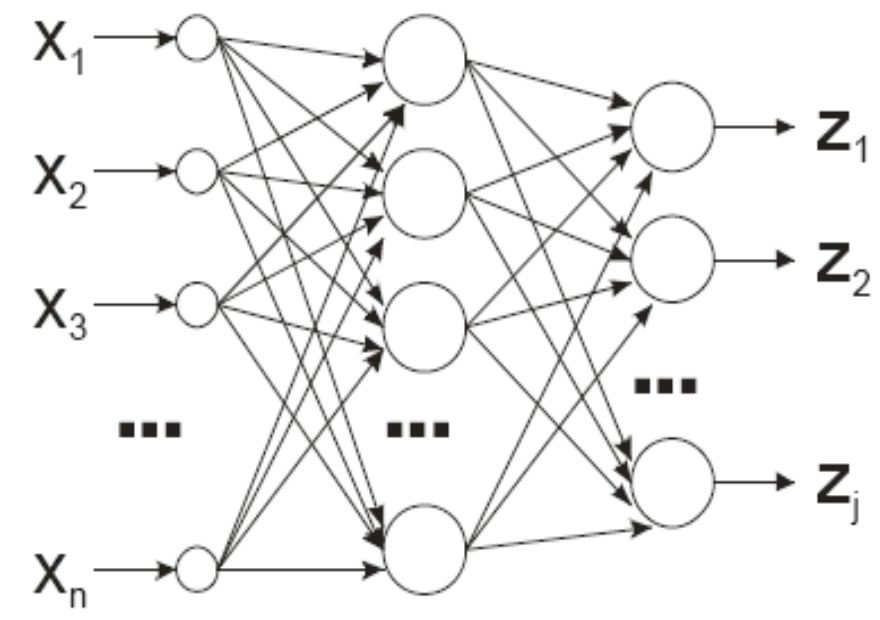

Figura 16 - Rede Neural Artificial Perceptron Multicamadas

Conforme ilustrado na Figura 16 por meio da combinação de diversos neurônios artificiais é possível forma uma rede neural artificial. A arquitetura de uma rede neural pode ser baseada em uma ou múltiplas camadas. Por exemplo, uma rede neural com três camadas (Perceptron Multicamadas) é composta por uma camada de entrada, em quem que os neurônios recebem os estímulos (ou sinais); a camada intermediária, onde é realizado o processamento; e a camada de saída, que apresenta o resultado final. Deste modo, a arquitetura da rede neural, o número de nós em cada camada, e o tipo de conexão entre os nós (feed-forward ou feedback) restringe o tipo de problema no qual a rede poderá ser explorada (HAYKIN, 2001).

Existem diferentes tipos de algoritmos de rede neural. Um dos mais populares é o algoritmo de aprendizado supervisionado baseado em redes neurais denominado de backpropagation (HAN; KAMBER, 2006). O backpropagation aprende iterativamente por meio de um agente externo (usuário) que fornece a rede neural um conjunto de registros de entrada e seus rótulos de classes 
correspondentes. Para cada registro de entrada, o usuário compara a predição da rede obtida com o valor rótulo de classe esperado. Este processo permite a rede neural ajustar o conjunto de pesos a fim de melhorar as futuras predições de rótulos de classes de registros.

\subsubsection{Raciocínio Baseado em Casos}

O raciocínio baseado em casos (RBC) é uma técnica de aprendizagem de máquina que explora as experiências passadas (problemas com suas soluções) para resolver um novo problema de uma experiência atual. Basicamente, neste tipo de raciocínio, para resolver um novo problema, a experiência atual é comparada com as experiências passadas armazenadas em uma base de casos (ou base de conhecimento).

Deste modo, o conjunto de experiências mais similares (os $K$ mais predominantes e similares, ou aquelas cujo valor de similaridade é superior ao um limiar) é recuperado. Por fim, as experiências recuperadas são empregadas para resolver o problema da experiência atual, que poderá ser posteriormente retida na base de casos para futuras predições.

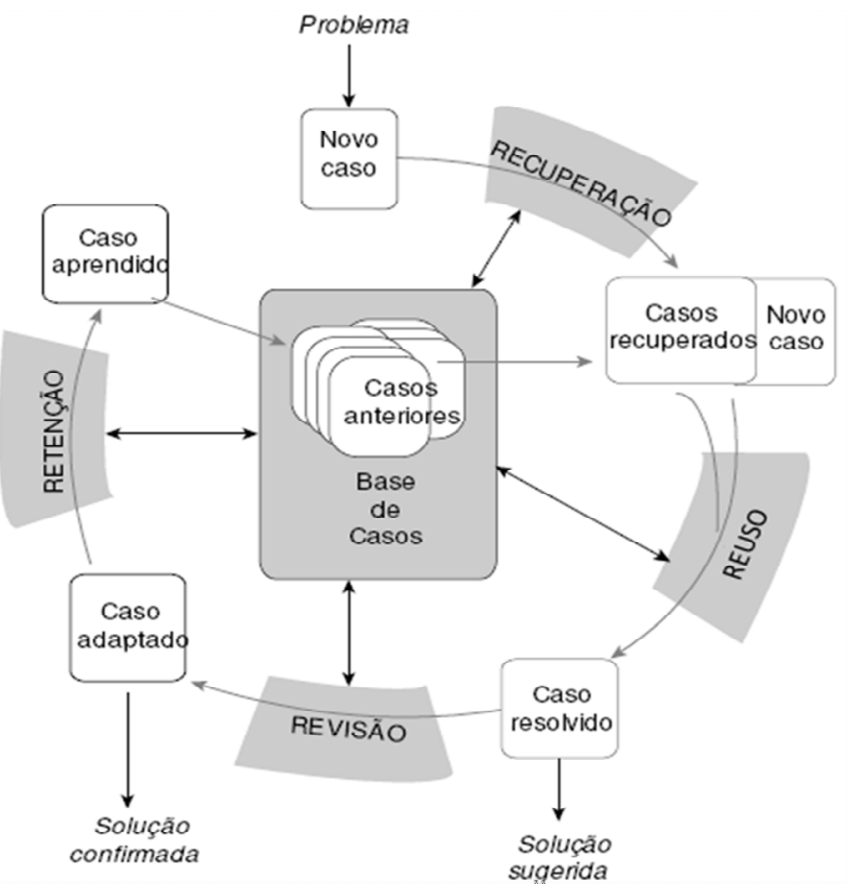

Figura 17 - Ciclo típico de RBC. Adaptado de (PAL; SHIU, 2004) 
Segundo Pal e Shiu (2004), as experiências passadas são denominadas "casos". Um caso é a representação de uma experiência, sendo composto por atributos que representam o problema e a solução correspondente. Tais atributos podem ser codificados por meio de um vetor de atributos $n$-dimensional, $X=\left(x_{1}, x_{2}\right.$, $\left.\ldots, x_{n}\right)$ usados em métricas de similaridades. Conforme ilustrado na Figura 170 método $\mathrm{RBC}$ é baseado em um processo de resolução de problemas cíclico e integrado que suporta aprendizagem das experiências e possui quatro etapas:

1. Recuperação: definido o problema em um novo caso, recuperar os casos anteriores que sejam similares ao novo caso;

2. Reuso: reusa os casos recuperados para o novo problema, obtendo a solução sugerida;

3. Revisão: a solução obtida é revisada por meio de uma avaliação para averiguar se é satisfatória;

4. Retenção: caso a solução seja satisfatória, o caso adaptado é persistido na base de casos para ser utilizado em futuras predições.

Dentre os desafios do método RBC incluem encontrar uma boa métrica de similaridade e métodos adequados para combinar soluções.

$$
\operatorname{Sim}(C, P)=\frac{C \times P}{\|C\| \times\|P\|}=\frac{\sum_{i=1}^{n} u_{i} w_{i}}{\sqrt{\sum_{i=1}^{n} u_{i}^{2}} \sqrt{\sum_{i=1}^{n} w_{i}^{2}}}
$$

Conforme é apresentada na equação eq.(1). Uma das métricas de similaridade mais empregadas é o cálculo do cosseno do ângulo entre vetores, onde $C=\left(u_{1}, u_{2}, \ldots, u_{n}\right)$, e $P=\left(w_{1}, w_{2}, \ldots, w_{n}\right)$ correspondem aos vetores de cada caso representados em um espaço vetorial (ADOMAVICIUS; TUZHILIN, 2005). Outros desafios incluem a seleção de características importantes para indexação de casos da base de conhecimento e desenvolvimento de técnicas de indexação eficiente. A eficiência do método RBC tende a melhorar conforme aumenta o número de casos armazenados na base de casos. No entanto, o desempenho sofrerá com o tempo requerido para pesquisar e processar casos vizinhos. Deste modo, torna-se 
necessária adoção de soluções para otimização da base de casos, como a eliminação de casos redundantes ou que não se revelaram úteis em prol da melhoria do desempenho (HAN; KAMBER, 2006).

\subsection{Realimentação de Relevância}

A técnica de realimentação de relevância (do inglês, relevance feedback) é normalmente empregada em sistemas de recomendação para atualizar automaticamente os interesses especificados no perfil do usuário ao longo do tempo, a partir das avaliações de itens recomendados ou por meio da interação entre o usuário e sistema (COTTER; SMYTH, 2000), (BLANCO-FERNANDEZ, 2007). Segundo Blanco-Fernandez (2007), a realimentação de relevância pode ser realizada de três formas: explícita, implícita ou ainda híbrida.

A realimentação explícita envolve justamente a avaliação de satisfação do usuário, onde o mesmo declara explicitamente a sua satisfação com relação a cada item recomendado, indicando se o item recomendado é relevante ou irrelevante (YU; ZHOU, 2004). Também é possível a realimentação explícita por meio de comentário textual (GOLDBERG et al., 1992) ou ainda especificação de um nível de interesse (ALVES, 2008). Com isso será possível ao sistema obter indicações sobre as preferências para atualizar o perfil do usuário visando alcançar melhores resultados em recomendações futuras.

Já a realimentação implícita o interesse do usuário pode ser inferido a partir do monitoramento de suas ações, o que viabiliza um reconhecimento automático das suas preferências. Dependendo do domínio de aplicação, o sistema adota uma estratégia de realimentação. Por exemplo, ao acessar um site (MORITA; SHINODA, 1994), realizar uma compra, ou assistir um determinado gênero de programa de TV durante um período de tempo (SILVA; ALVES; BRESSAN, 2010). Por fim, a realimentação híbrida combina os dois métodos anteriores para se beneficiar das vantagens de ambos os métodos. A solução proposta neste trabalho emprega um método híbrido de realimentação de relevância. 


\subsection{Métricas para Avaliação de Sistemas de Recomendação}

Segundo Jiangshan et. al. (2002) a eficiência de um sistema de recomendação pode ser mensurada por meio das métricas: precisão (do inglês, precision, revocação ou cobertura (do inglês, recall) e medida $F$ (do inglês, $F$ measure). De acordo com Herlocker et al. (2004) tais métricas são as mais populares para avaliar sistemas de recuperação de informação. Na literatura é possível encontrar vários trabalhos que empregam precisão, revocação e medida $F$ para avaliar os sistemas de recomendação propostos (YU; ZHOU, 2004). A seguir nas próximas subseções será apresentada uma breve descrição de cada métrica.

\subsubsection{Precisão}

Segundo Jiangshan et. al. (2002), conforme o seu nome indica, mensura o quão precisa foi a resposta, em uma proporção de itens recomendados que seja realmente relevantes. Em outras palavras, a fração de itens recomendados pelo sistema que é relevante ou de interesse do usuário, no universo total de itens recuperados. Quanto maior for a quantidade de itens relevantes na resposta, maior será a precisão do sistema. A precisão é definida pela seguinte fórmula form. (1):

$$
\text { Precisão }=\frac{|N \cap R|}{|R|}
$$

Onde, $\mathrm{N}$ representa o conjunto de itens relevantes que foram indicados pelos usuários;

$\mathrm{R}$ representa o conjunto de itens recomendados pelo sistema que foram examinados.

Assim, a precisão pode ser usada para mensurar a habilidade de o sistema apresentar somente itens relevantes. 


\subsubsection{Revocação}

Segundo Jiangshan et. al. (2002), a revocação é usada para mensurar a fração de todos os itens relevantes que o sistema conseguiu recomendar dentre o número total de itens relevantes disponíveis na coleção. Caso seja considerado que um sistema tem $100 \%$ de revocação, significa que este conseguiu recuperar todos os itens relevantes da coleção. A revocação é definida pela seguinte fórmula form. (2):

$$
\text { Revocação }=\frac{|N \cap R|}{|N|}
$$

Onde,

$\mathrm{N}$ representa o conjunto de itens relevantes que foram indicados pelos usuários;

$\mathrm{R}$ representa o conjunto de itens recomendados pelo sistema que foram examinados.

Assim, a revocação pode ser usada para mensurar a habilidade de o sistema apresentar todos os itens relevantes da coleção.

\subsubsection{Relação entre Precisão x Revocação}

A Figura 18 ilustra as combinações possíveis entre revocação e precisão onde os itens recuperados são aqueles que se encontram no interior dos retângulos. O desafio da maioria dos sistemas de recomendação é atingir o caso ideal, que é o de revocação e precisão total.

Entretanto, é muito comum é aceitável que o sistema de recomendação não possua $100 \%$ de revocação e precisão, ou seja, atinja valores aproximados. 
Onde,

$\checkmark$ São os itens relevantes; $\bigcirc$ São itens não relevantes; retornados;

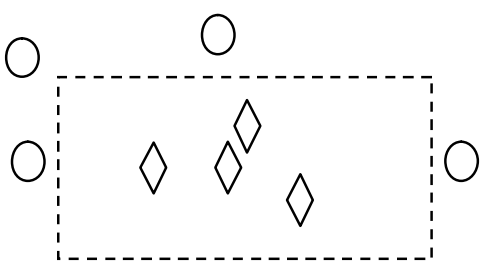

Melhor caso: todos os itens relevantes são retornados e somente eles.

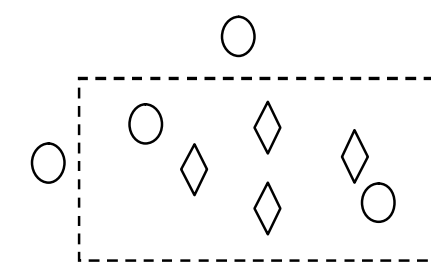

Caso aceitável:

abrangente, contudo impreciso. Todos os itens relevantes e mais alguns não relevantes são retornados.

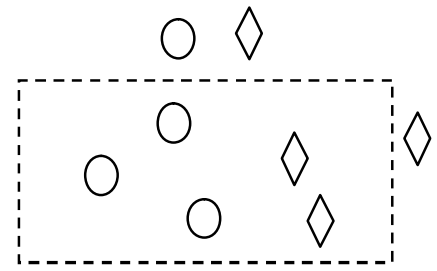

Pior caso: impreciso e não abrangente. Muitos itens não relevantes são retornados. Além disso, nem todos os itens relevantes são retornados.

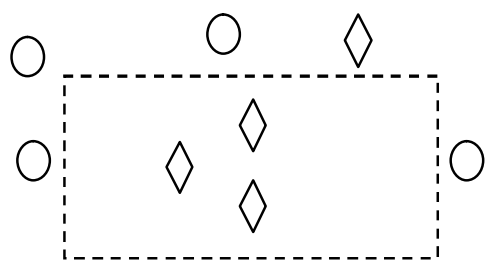

Caso aceitável:
preciso, contudo não
abrangente. Todos os itens
retornados são relevantes,
mas nem todos os itens
relevantes retornam.

Figura 18 - Casos possíveis de relações entre precisão e revocação 


\subsubsection{Medida F}

Segundo Zaier, Godin e Fucher (2008), a precisão e revocação possuem o mesmo grau de importância. Assim, pode ser utilizada a métrica medida $F$ que combina em única fórmula as métricas de precisão e revocação. Pode-se afirmar que a medida $F$ é precisamente uma métrica harmônica.

Segundo Jiangshan et. al. (2002), quanto mais próximo de um for o valor da medida $F$ mais eficiente será o sistema. A medida $F$ é definida pela seguinte fórmula form. (3):

$$
\text { MedidaF }=\frac{2 \times \text { precisão } \times \text { revocação }}{\text { precisão }+ \text { revocação }}
$$

\subsection{Privacidade e Segurança das Informações}

Os sistemas de recomendação coletam informações sobre o usuário para fornecer recomendações de itens que provavelmente serão de seu interesse. Em uma modalidade de coleta de informações sobre o usuário, tais informações são obtidas de forma não intrusiva sem que o usuário perceba que à medida que interage com o sistema, suas informações são armazenadas em um histórico de uso. Segundo Pimentel e Goularte (2007), problemas com privacidade e segurança tendem a se agravar em sistemas de computação ubíqua e cientes de contexto, pois quanto mais dependente o usuário fica do sistema, mais informações o sistema tem do usuário.

Desta forma, questões relacionadas à privacidade e segurança das informações são relevantes. Torna-se necessária a adoção de tecnologias, políticas de privacidade e segurança em sistemas de recomendação, a fim de assegurar que as informações dos usuários não sejam acessadas por terceiros. Segundo Setten et al. (2004), a segurança é um fator relevante para assegurar que os dados pessoais somente sejam utilizados por aqueles que têm o direito de acesso e de utilização de 
dados. Schreck (2003) apresenta vários métodos que permitem ao usuário permanecer anônimo e assegurar que os dados pessoais estão seguros durante o transporte. No entanto, não existe um consenso sobre padrões ou métodos de privacidade empregados em sistemas de recomendação, normalmente cada sistema adota uma determinada solução.

Uma iniciativa está sendo conduzida pelo World Wide Web Consortium (W3C), cujo objetivo é aumentar a confiança de sistemas que utilizam informações pessoais. Um padrão chamando de Platform for Privacity Preferences (P3P) está sendo desenvolvido (W3C, 2006). O P3P é um protocolo que fornece uma forma automática para o usuário ter maior controle sobre a utilização de informações pessoais em sites que visitam. A ideia básica do P3P é permitir que cada site ou serviço descreva suas práticas de privacidade, e como lidam com informação pessoal por meio de políticas de privacidade padronizadas. A fim de que possam ser recuperadas e interpretadas por aplicações clientes P3P.

Por meio de um perfil de privacidade, as políticas de privacidade são tornadas públicas, sendo publicadas juntamente com o site ou serviço. Aplicações clientes P3P tais como navegadores podem ler este perfil de privacidade e compará-lo com preferências de privacidade do usuário. Com isso, por meio desta comparação o aplicativo cliente informa ao usuário algumas questões de privacidade e pergunta a este como deve proceder. Por exemplo, um usuário pode definir quais informações deseja compartilhar, tais como endereço, número de telefone, definindo assim suas preferências de privacidade.

Neste trabalhou a privacidade dos dados do usuário foi assegurada por meio da adoção de algumas políticas tais como (i) identificação dos dados que realmente devem ser compartilhados com os provedores, ou seja, definir o que é de caráter confidencial; (ii) armazenamento dos dados pessoais do usuário no dispositivo de acesso; (iii) anonimato do usuário durante o transporte de dados pessoais e contextuais. 


\subsection{Considerações Finais}

Este capítulo apresentou os principais fundamentos sobre sistemas de recomendação que serviram de base para desenvolvimento da solução proposta neste trabalho. Os sistemas de recomendação têm despertado cada vez mais atenção da comunidade acadêmica e da indústria. Consequentemente, sistemas de recomendação foram propostos em vários domínios de aplicação, e se tornaram uma importante área de pesquisa (ADOMAVICIUS; TUZHILIN, 2005). O interesse por esta área aumenta porque é rica em desafios técnicos e aplicações práticas que ajudam o usuário a lidar com o problema da sobrecarga de informação. No entanto, apesar de todos os avanços, a geração atual de sistemas de recomendação necessita de aprimoramento, de novas abordagens de recomendação para melhorar a qualidade das recomendações.

Segundo Admavcius e Tuzhilin (2005), estes aprimoramentos incluem melhores métodos para representar o comportamento do usuário e informações sobre os itens que serão recomendados, métodos de recomendação mais avançados, flexíveis e menos intrusivos, e também métricas para determinar eficiência dos sistemas de recomendação. Além disso, a nova geração de sistemas de recomendação deve incorporar informação de contexto dentro do processo de recomendação (BALTRUNAS, 2008), como foi estudado e proposto neste trabalho, onde o domínio de aplicação foi a TV Digital Interativa. 


\section{Trabalhos Relacionados}

$\mathrm{Na}$ literatura é possível encontrar uma vasta quantidade de trabalhos acadêmicos presentes em diversos domínios de aplicação que empregam os sistemas de recomendação para solucionar o problema da sobrecarga de informação. No entanto, o objetivo deste capítulo consiste na análise de trabalhos encontrados na literatura (dos últimos 10 anos, no máximo) que exploram sistemas de recomendação no domínio da TV Digital Interativa, e que mais se correlacionam com o tema proposto, buscando assim contextualizar e identificar a complementaridade deste trabalho no estado da arte.

\subsection{Um Sistema de Guia de TV Personalizada: Uma Abordagem para Televisão Digital Interativa}

Mais recentemente, Ávila e Zorzo (2009) propõem um módulo de suporte a recomendação de conteúdo para TV Digital Interativa denominado de Recommender $T V$, que tem o objetivo de resolver o problema da sobrecarga de informação no domínio da TV Digital brasileira. O módulo Recommender TV procura ser aderente ao middleware brasileiro GINGA, e propõe a inclusão de funcionalidades adicionais relacionadas à mineração de dados, coleta e armazenamento de histórico de comportamento de usuário e gerenciamento de perfis, na camada Common Core do GINGA. Com relação à arquitetura, o módulo Recommender TV é composto por duas camadas bem delineadas denominadas: Recommender Engine e Recommender API. A camada Recommender Engine é transparente aos aplicativos de recomendação, e tem como principal objetivo realizar processamento de dados e comunicação com os demais módulos da implementação do middleware GINGA.

De acordo com os autores é de responsabilidade dessa camada, coletar e armazenar informações sobre o comportamento de visualização do telespectador em uma base de dados, também realizar mineração de dados com essas informações para extrair padrões de comportamento, e ainda efetuar a manutenção da base de dados. Tal camada comunica-se diretamente com módulos do 
middleware GINGA. Já camada Recommender API é visível aos aplicativos de recomendação, sendo responsável por prover um conjunto de APIs que possibilitem aos sistemas ofertarem serviços personalizados. Os serviços da Recommender API podem ser acessados por aplicações escritas em NCL e LUA (LUA, 2009) bem como aplicações escritas em Java.

O módulo Recommender TV utiliza as tabelas de informações de serviços SI (Service Information) entre elas: EIT e SDT não sendo empregados padrões de metadados flexíveis como no PersonalTVware. No que se refere à tarefa de mineração de dados é realizada no próprio receptor de TV Digital (set-top box) por meio de algoritmo Apriori (AGRAWAL; SRIKANT, 1994) que é baseado em regras de associação. Tal algoritmo não foi empregado no PersonalTVware porque o uso de regras simples do tipo IF-THEN não é adequado para expressar o comportamento reativo de um sistema sensível ao contexto, pois as regras obtidas não expressam de forma apropriada as relações causais entre as condições contextuais.

Além disso, em virtude da escassez de recursos computacionais em dispositivos de acesso a TV Digital, a tarefa de mineração de dados pode se tornar inviável, pois é a tarefa que mais demanda recursos. Diferentemente do PersonalTVware, o processo de predição é executado no lado servidor. De acordo com os autores para contornar esse problema, foi implementado um mecanismo que dispara o processo de mineração em horários de ociosidade do dispositivo. Tal mecanismo faz uma análise do histórico de comportamento do usuário e desta maneira, decide em quais horários existe pouca interação. Não ficou claro que tipo de informação é obtido por meio da mineração de dados a partir do histórico de comportamento do usuário e informações da tabela SI. Segundo os autores essas informações devem ser utilizadas posteriormente no procedimento de filtragem para produzir recomendação de programas de TV aos usuários.

A estratégia de recomendação adotada pelo módulo Recommender TV se difere do PersonalTVware, pois não explorar o contexto no processo de recomendação. As recomendações geradas têm como base, somente o histórico do comportamento do usuário, sendo que o perfil do usuário também não é explorado, e nem a realimentação de relevância como empregado no PersonalTVware. 


\subsection{PTV: Guias Personalizados e Inteligentes de TV}

O projeto do sistema de listagem de televisão personalizada (PTV) (COTTER; SMYTH, 2000) foi um dos projetos pioneiros de recomendação personalizada de conteúdo para TV, sendo uma referência para muito outros trabalhos que também investigam o problema da sobrecarga de informação na TV. O PTV é um serviço inovador baseado em Internet que aplica técnicas de personalização de conteúdo a fim de automaticamente aprender sobre as preferências de TV de cada usuário, e fornecer guias de TV altamente personalizados e customizados diariamente. Diferentes versões do sistema foram vislumbradas, uma voltada para Web, e uma nova versão desenvolvida para telefones celulares e assistentes pessoais digitais (PDAs) baseados em WAP (Wireless Application Protocol).

O projeto PTV defende a ideia de que o domínio de listagem de TV pode beneficiar significativamente um EPG que incorpora técnicas de personalização como meio de filtragem e customização de informações de TV para usuários. O PTV personaliza o acesso a informação de TV por meio de técnicas de filtragem como a filtragem colaborativa, filtragem baseada em conteúdo e técnicas para captura do perfil de usuário.

O resultado é uma estratégia de recomendação híbrida que permite a recomendação de programas de TV ser feita de acordo com o tipo de programas de TV que o usuário assistiu no passado, bem como a recomendação de programas de TV que outros usuários de perfis similares gostaram. O sucesso de um sistema de recomendação depende largamente da qualidade dos perfis de usuários e na sua habilidade para representar os interesses por conteúdos dos usuários. No PTV cada usuário contém dois tipos de informação: (1) preferências de domínio e (2) preferência de programas.

As preferências de domínio descrevem as preferências gerais do usuário tais como lista de canais de TV disponíveis, preferências de gêneros, palavras-chave sobre assuntos diversos e preferências pelo formato do guia. As preferências de programas são representadas como duas listas de títulos de programas, uma lista positiva contendo os programas que o usuário gostou no passado e uma lista negativa contendo programas que o usuário não gostou. 
A informação de perfil é obtida de duas formas. O usuário é encorajado para manualmente especificar suas preferências e devido ao fato que alguns usuários não especificarem seus perfis completamente, é empregado um mecanismo que permite a atualização do perfil do usuário por meio de uma avaliação (realimentação de relevância) dos programas de TV como positivos ou negativos dentre os apresentados na lista de TV.

O PTV é baseado em uma arquitetura cliente e servidor, onde os usuários podem acessar guias de TV personalizados especialmente customizado em páginas HTML (para acesso convencional por meio de PC) ou páginas WAP (para acesso via telefone celular) e, todas as interações com os usuários são tratadas pelo protocolo HTTP. O núcleo do sistema está situado nos componentes do lado servidor, os quais tratam todas as principais funções de processamento das informações tais como registro e autenticação, obtenção de perfil, geração de guia, e todos os componentes responsáveis pela recomendação.

A estratégia de recomendação adotada pelo PTV se difere do PersonalTVware por não incorporar informação de contexto em nenhuma etapa do processo de recomendação. Além disso, o PTV é baseado em Internet e implementado por meio de um Web site, sendo acessado via navegador. Já a solução proposta nesta tese foi especialmente desenvolvida para o ambiente da TV Digital Interativa, e pode ser acessada por meio de uma aplicação interativa rodando em um dispositivo de acesso.

\subsection{Personalização para Televisão Digital Utilizando a Estratégia de Sistemas de Recomendação para Ambientes Multiusuário}

Em Lucas e Zorzo (2009) é descrito o sistema de recomendação RePTVD, que tem o objetivo de também fazer recomendações para usuários de TV Digital Interativa. O RePTVD realiza o monitoramento do comportamento de visualização dos usuários para obter informações sobre os seus interesses de forma implícita. De forma similar ao PersonalTVware tais informações são posteriormente armazenadas em um arquivo ARFF (Attribute Relation File Format), que é um formato próprio da API Weka (WAIKATO, 2010). 
Para recomendar conteúdo o RePTVD utiliza os metadados rígidos obtidos das tabelas SI (Service Information) e as preferências são obtidas por meio de mineração de dados de todos os usuários do sistema. No projeto RePTVD foi empregado regras de associação, pois segundo os autores, as regras geradas adaptaram-se às necessidades do sistema. Com relação à arquitetura do RePTVD os principais módulos do sistema são: Módulos Metadados, Módulo Perfil do Grupo de Usuários e Módulo Recomendador.

O Módulo de Metadados é responsável por analisar os dados provenientes da emissora, e extrair as informações referentes aos programas de TV. O módulo Perfil do Grupo de Usuários contém informações de visualização do grupo de usuários coletadas de forma implícita. Já o Módulo Recomendador é responsável por aplicar a mineração de dados no arquivo ARFF visando descobrir padrões de comportamento e mapear as preferências descobertas com o conteúdo que virá das emissoras.

Todos os módulos do sistema ficam localizados no receptor, incluindo o módulo responsável pela mineração de dados, o que poderá inviabilizar o uso do sistema em dispositivos com escassez de recursos computacionais, como dispositivos portáteis. De forma similar ao RePTVD, o PersonalTvware utiliza o arquivo ARFF e API Weka. No entanto, o RePTVD não implementa métodos de aprendizagem de máquina baseados em classificação, que são utilizados posteriormente para predizer preferências contextuais a partir do contexto e perfil do usuário.

O RePTVD, utiliza um conjunto de regras de associação que não é adequado para expressar o comportamento reativo de um sistema sensível ao contexto. No RePTVD, o perfil do usuário não é explorado, o que inviabiliza acesso personalizado baseado em características pessoais de cada usuário. Além disso, as informações de contexto não foram incorporadas no processo de recomendação como empregado no PersonalTVware. 


\subsection{Um Sistema de Guia de TV Personalizada Compatível com MHP}

O projeto de (ZHANG; ZHENG; YUAN; 2005) versa sobre a complexidade da próxima era da TV, que impõe certos desafios no projeto de novos dispositivos inteligentes para os lares dos usuários. Principalmente por causa do problema da sobrecarga de informação e da grande quantidade de possibilidades criadas pelas novas mídias de comunicação. Zhang, Zheng e Yuan (2005), também defendem a ideia da recomendação personalizada de conteúdo e, evidenciam que serviços de TV personalizada poderão ajudar aos usuários a lidar com este problema.

Assim, este trabalho apresenta a arquitetura de um sistema de TV personalizada que possui como base o histórico de uso da TV e a avaliação que o usuário realiza da recomendação de conteúdo apresentada. $O$ projeto é baseado em padrões de TV Digital tais como Digital Video Broadcast - Service Information (DVBSI) e Multimedia Home Platform (MHP). O sistema proposto não apenas pode ordenar programas de TV por gêneros, bem como mostrar todas as informações dos programas de TV em ordem cronológica. Além disso, o que é mais importante: o sistema pode obter as preferências do usuário baseado em coleta explícita e implícita. Desta forma, o sistema pode recomendar futuros programas de TV que melhor combinam com as preferências dos telespectadores.

Com relação à arquitetura, pode ser dividida dentro de 4 camadas: camada de aplicação, camada de sistema, camada de função e camada de portabilidade. A camada de aplicação se refere às aplicações denominadas de Xlets de acordo com a especificação MHP. As aplicações podem ser divididas em dois tipos: aplicações residentes e aplicações enviadas pelas operadoras de TV.

O EPG é implementado como Xlet Java e enviado multiplexado com o sinal da TV. A camada de sistema atua como o ambiente de execução para as aplicações Java. É o núcleo do middleware de TV Digital. Esta camada compreende os pacotes da API JavaTV ${ }^{1}$, Máquina Virtual Java (JVM), API DAVIC ${ }^{2}$, APIs MHP para acessar SI DVB e API proprietária composta por pacotes Java responsáveis por rastrear o

\footnotetext{
1 JavaTV API especificada pela Sun, que oferece pacotes de classes para o desenvolvimento de aplicações interativas para TV Digital.

${ }_{2}^{2}$ DAVIC - Digital Áudio Video Council é a API que fornece um mecanismo geral para permitir o acesso aos dados em seções privadas MPEG-2.
} 
comportamento de visualização dos usuários e recomendar programas os quais podem ser chamados de componentes de aquisição e de recomendação.

A camada de função serve de base para as funções da camada de sistema, sendo implementada em $\mathrm{C} / \mathrm{C}++$ por questões de desempenho e compatibilidade com as funções de acesso ao hardware, fornecidas pelo fabricante. A camada de sistema consiste no núcleo do middleware proposto. Por fim, a camada de portabilidade concentra todas as funções relacionadas ao hardware, sendo acompanhadas pelos drivers dos dispositivos fornecidos pelos fabricantes.

Durante os testes do sistema de TV personalizada Zhang, Zheng e Yuan (2005) constataram que apesar do protótipo do sistema ter trabalhado bem, a informação fornecida pelo DVB-SI não é suficiente para suportar adequadamente a filtragem de programas de TV. Assim, extensões para este padrão são requeridas e, o TV-Anytime pode oferecer uma solução adequada para o desenvolvimento das aplicações.

O sistema de TV personalizada possui algumas correlações com o PersonalTVware no que tange a utilização da técnica de filtragem baseada em conteúdo e, principalmente a exploração dos modelos de descrição de conteúdo do padrão TV-Anytime. Entretanto, a estratégia de recomendação de programas de TV adotada por questão de simplicidade, é limitada ao perfil do usuário e, o contexto do usuário não é considerado diferentemente do método de filtragem sensível ao contexto explorado no PersonalTVware.

\subsection{AVATAR: Uma Solução Aprimorada para TV Personalizada baseada em Inferência Semântica}

Diante do cenário da sobrecarga de informação no domínio da TV Digital, o artigo (BLANCO-FERNANDEZ et al., 2006) apresenta uma proposta de abordagem de recomendação personalizada de conteúdo que explora os conceitos e tecnologias da Web Semântica. Essa nova abordagem foi proposta no projeto AVATAR (Advanced Telematic search of Audiovisual contents by semantic Reasoning) em que foi desenvolvido um sistema de recomendação híbrido que faz 
uso de padrões bem conhecidos tais como MHP, TV-Anytime e Web Ontology language (OWL).

De acordo com o autor, devido ao fato de que os sistemas de recomendação de TV existentes estão focados no processo de filtragem sem capacidade de fazer inferência semântica, a qualidade da recomendação deles é claramente limitada, justamente como tem acontecido com as ferramentas de pesquisa da Web. $\mathrm{O}$ projeto AVATAR incorporou uma estratégia de recomendação híbrida, em que foram combinadas as técnicas de filtragem baseada em conteúdo e filtragem colaborativa, melhorando a qualidade das recomendações pela adição de capacidade de inferência semântica. Isso permitiu definir uma nova métrica flexível para afirmar a similaridade entre dois conteúdos de TV, cujos valores dependem da relação semântica entre estes.

O AVATAR foi projetado para um ambiente no qual um receptor de TV Digital (set-top box) está permanentemente conectado em uma rede de banda larga. Desta forma, o usuário pode baixar dados do provedor de serviço e enviar informação em qualquer momento. Para atingir os objetivos planejados, o projeto levou em conta os seguintes requisitos: (i) aplicação deve ser transmitida através de um serviço de TV, por esta razão a aplicação foi implementada como uma aplicação MHP; (ii) para promover um uso extensivo do sistema foram adotados tecnologias e formatos normalizados tais como TV-Anytime e OWL; (iii) finalmente, a arquitetura foi projetada para ser modular, permitindo facilmente adoção de novas técnicas de personalização.

Com a finalidade de representar formalmente o conhecimento sobre o domínio de TV no qual será aplicado o processo de inferência, e que será explorado no processo de recomendação, foi implementada uma ontologia por meio da linguagem OWL (Web Ontology Language). Esta ontologia armazena conceitos e propriedades hierarquicamente organizadas que identificam recursos e relacionamentos comuns usados no domínio da TV, tais como categorias de programas, gêneros, tópicos de programas de TV.

Os programas de TV no AVATAR também são descritos pelos metadados do TV-Anytime, os atributos de programas de TV incluídos na ontologia são baseados neste padrão. Desta forma, o processo de mapeamento entre o conteúdo TVAnytime e instâncias específicas na ontologia OWL é claramente facilitado. 
A arquitetura de sistema é baseada em agentes, permitindo adicionar novas estratégias de recomendação e mecanismos para gerenciamento da informação sem mudanças significantes em sua estrutura geral. A arquitetura é composta pelos agentes: recomendação, ordenamento e realimentação de relevância. Agente de recomendação executa a estratégia de recomendação descrita no algoritmo. Assim, retorna um conjunto de programas de TV que são de interesses para o usuário. $O$ agente de ordenamento captura os programas de TV selecionados pelo agente de recomendação e executa um ordenamento. Para este propósito, são considerados os valores de combinação semântica e predição semântica computados pelo AVATAR.

Agente de realimentação de relevância atualiza a ontologia de perfil do usuário de acordo com as seguintes informações: (i) os dados extraídos do comportamento de visualização do usuário, (ii) o sucesso ou falha nas recomendações anteriores elaboradas pelo AVATAR. Os agentes acima foram incluídos em duas aplicações MHP devido aos seus diferentes tempos de vida. O agente de realimentação de relevância deve permanecer monitorando as ações do usuário. Os agentes de recomendação de informação e ordenamento somente são executados quando uma sugestão personalizada é requerida.

A principal contribuição do AVATAR em relação às abordagens anteriores está na capacidade de inferir novos conhecimentos a partir das semânticas dos conteúdos de TV e preferências dos usuários. O resultado deste processamento são os valores da combinação semântica, posteriormente empregados na ordenação dos programas recomendados. No entanto, as informações contextuais não foram exploradas e a situação do usuário não é considerada durante o processo de recomendação, como foi proposto e estudado no PersonalTVware.

\subsection{Recomendação Personalizada de Programas de TV baseada em Metadados do TV-Anytime}

Em Zhang e Zheng (2005) há uma proposta de um sistema para recomendação de Programas de TV que tem como base de forma similar ao PersonalTVware a utilização da especificação de metadados do fórum TV-Anytime e 
da técnica de filtragem baseada em conteúdo. As especificações do TV-Anytime definem um modelo de sistema de referência e esquemas para estruturação de metadados que descrevem o conteúdo da TV Digital de forma padronizada. De acordo com os autores Zhang e Zheng (2005), a combinação entre as preferências de usuário e descrições de conteúdo facilita uma personalização eficiente e precisa no acesso ao conteúdo. Neste trabalho foram utilizados os metadados definidos pelo TV-Anytime para descrever o histórico de uso e preferências do usuário. Os métodos de extração de preferências do usuário a partir do histórico de uso não estão especificados de forma padronizada.

No projeto de (ZHANG; ZHENG, 2005) os interesses do usuário foram obtidos explicitamente e implicitamente por meio do histórico de uso e da avaliação do usuário. Um sistema fuzzy de inferência foi utilizado como método para automaticamente obter as preferências do usuário a partir do histórico de uso. Tal mecanismo calculava a média de afinidade por determinados gêneros de programas de TV, e posteriormente atualizava o perfil do usuário. Para descrição do conteúdo e preferências do usuário, foram empregados os esquemas de descrição: CreationPreference (DS), ClassificationPreference (DS) e o UsageHistory (DS).

O CreationPreference (DS) foi utilizado para especificar as preferências do usuário relacionada à descrição de conteúdo tais como preferência por um título particular, ou um ator favorito. O ClassificationPreference (DS) foi usado para especificar as preferências por gênero, ou preferência do país de origem. Já o UsageHistory (DS) fornece a lista de ações executadas pelo usuário e os identificadores dos programas de TV associados.

O projeto tem como base o middleware MHP, e os principais componentes do sistema são: Metadata Engine, User Profile Engine, e o Filter Engine. Todos os componentes ficam localizados no dispositivo de acesso. O Metadata Engine é o responsável pela recuperação e processamento de metadados que descrevem os conteúdos audiovisuais enviados e a resolução da localização dos programas de TV. O User Profile Engine combina o histórico de uso e a informação de realimentação de relevância do usuário para obtenção das preferências do usuário por meio de lógica fuzzy.

Por fim, o Filter Engine é o responsável pelas recomendações dos programas de TV com alto valor de preferência baseado em metadados que descrevem o conteúdo e os metadados descritores das preferências do usuário. A estratégia de 
recomendação adotada por (ZHANG; ZHENG, 2005) se difere do PersonalTVware por não incorporar informação de contexto em nenhuma etapa do processo de recomendação. Além disso, arquitetura do sistema não é flexível e modular, o que inviabiliza a adoção de novas técnicas de recomendação.

\subsection{IndexTV: Um Sistema de Recomendação baseado em MPEG-7 para TV Digital}

O projeto IndexTV (ROVIRA et al., 2004) consistiu no desenvolvimento de ferramentas para descrição e acesso personalizado a conteúdo. Neste projeto, foi desenvolvido um sistema que fornece acesso personalizado ao conteúdo da TV Digital. Este sistema utiliza o padrão MPEG-7 para descrição de conteúdo. No que concerne a arquitetura do sistema, o IndexTV é baseado no modelo cliente e servidor, o lado servidor consiste de um sistema play-out DVB chamado de FlowServer (FS) e dois novos elementos: a ferramenta de catalogação e o gerenciador de metadados.

O FlowServer (FS) é um sistema de play-out consistindo de vários componentes interconectados via TCP/UDP. Esta ferramenta torna o sistema completo para play-out e gerenciamento de conteúdo interativo da TV Digital. A ferramenta de catalogação gera as descrições MPEG-7 do conteúdo audiovisual de forma semi-automática, que são as entradas do gerenciador de metadados. 0 gerenciador de metadados é responsável pelo encapsulamento, sinalização e transmissão dos metadados sincronizados com o conteúdo audiovisual por meio do sistema FlowServer. Os metadados gerados serão entregues em forma de serviços de metadados dinâmicos compatíveis com padrão de entrega MPEG-2. O transport stream MPEG-2 multiplexado é modulado e enviado para os receptores.

No lado cliente, um receptor de TV Digital (set-top box) com funcionalidades típicas de gravador de vídeo pessoal, é dotado de um mecanismo inteligente denominado de assistente de programa de TV, sendo responsável por gerar sugestões de conteúdo, que poderá ser de interesse do usuário. No assistente de programa de TV a recomendação tem como base a técnica de filtragem baseada em 
conteúdo por meio da comparação das descrições do programa de TV com as preferências do usuário.

Um mecanismo de inferência busca coincidências entre as descrições de conteúdos dos programas de TV, que o usuário não está assistindo no momento, com as suas preferências armazenadas em uma base de dados para obter um valor de preferência. Se este valor de preferência for maior ou igual ao valor de preferência do programa de TV atual que é assistido pelo usuário ou dentro de um determinado limiar, o sistema executa a recomendação deste conteúdo para o usuário.

O IndeXTV se difere do PersonalTVware principalmente por não utilizar a informação de contexto para recomendação de conteúdo, tendo como base a estratégia tradicional de recomendação simplesmente baseada na combinação dos termos que descrevem o perfil do usuário obtido explicitamente com as descrições de conteúdo.

\subsection{Sistema de Recomendação de TV Personalizada Dinâmica}

Em (DAl e COHEN, 2003) é apresentado um sistema multiagente para a recomendação de programas de TV, cujo objetivo é ajudar os usuários na seleção dos programas de TV de interesses. Neste artigo, foi apresentado a proposta de uma abordagem de recomendação denominada de recomendação de TV personalizada dinâmica que utiliza pseudo-perfis de usuários. A abordagem proposta procura tirar vantagens das técnicas de filtragem colaborativa e baseada em conteúdo, e dos métodos explícito e implícito para obtenção do perfil do usuário.

Assim, foi proposto uma técnica de filtragem colaborativa dinâmica, que aplica a ideia do pseudo-perfil de usuário, sendo este uma representação de um grupo de usuários com interesses similares. De acordo com o autor, o pseudo-perfil tem o mesmo formato que um perfil explícito ou implícito. Além disso, também foi proposto um gerente de recomendação para decidir por meio de um mecanismo de competição quais programas de TV serão entregues.

A arquitetura do sistema tem como base o modelo cliente-servidor, sendo composta pelos componentes: Explicit RS, Content-based RS, Collaborative Filtering 
RS e o Recommendation Manager. O mecanismo para rastrear o comportamento do usuário e, os agentes responsáveis pela recomendação estão localizados em um servidor, oferecendo desta forma um controle centralizado do sistema.

No lado cliente, a recomendação é disponibilizada por meio de páginas Web. $O$ agente Explicit $R S$ é responsável pela recomendação baseada em conteúdo tendo como base o perfil de usuário explícito, sendo criado durante a primeira sessão entre o sistema e usuário. O agente Content-based $R S$ é responsável pela recomendação baseada em conteúdo que explora um perfil de usuário implícito, criado com base no histórico de uso ou visualização do usuário. Contém informação importante sobre os programas de TV favoritos a que o usuário tem assistido.

O agente Collaborative Filtering $R S$ é responsável pela recomendação baseada em filtragem colaborativa, por meio da combinação dos perfis (implícitos ou explícitos) dos usuários correntes com um dos pseudo-perfis de usuários. Os programas de TV favoritos do pseudo-usuário serão recomendados para o usuário corrente. Por fim o Recommendation Manager seleciona os programas de cada agente, decide quais programas de TV serão recomendados para o usuário corrente.

O perfil do usuário agrega os interesses gerais do usuário, pode ser modificado e possui duas seções: a primeira delas possui um conjunto de características sobre o usuário; a segunda seção possui os programas de TV favoritos. Os pseudo-perfis de usuários são construídos quando novos usuários começam a usar este sistema. As características e preferências mais comuns entre os usuários são selecionadas para formar um pseudo-perfil de usuário. Este trabalho se difere do PersonalTVware principalmente por não incorporar informações contextuais durante o processo de recomendação. Além disso, a solução proposta é baseada em Web diferentemente do PersonalTVware que foi projetado para o ambiente da TV Digital.

\subsection{SenSee Framework para Acesso Personalizado ao Conteudo da TV}

O artigo (AROYO et al., 2007) apresenta a proposta de um framework denominado de SenSee que fornece funcionalidades para pesquisa personalizada, e 
o uso de informações de contexto. Segundo os autores, o SenSee pode ser usado em aplicações multimídias para fazer "recomendação de conteúdo" em ambiente doméstico, e explora ontologias para representação do perfil e contexto do usuário. Com o objetivo de demonstrar o SenSee foi desenvolvido uma aplicação para acesso personalizado aos conteúdos da TV Digital. A arquitetura de sistema do SenSee tem como base o modelo cliente e servidor. Os principais serviços estão localizados no servidor, tais como User Model Service, Ontology Service, Filter Service, CRID Authority e Metadata Service.

O User Model Service é o responsável pelo gerenciamento de informações relacionadas ao perfil do usuário e incorporação do contexto. Assim, fornece interfaces que permitem o acesso de tais informações em repositórios. O Ontology Service é responsável pelo gerenciamento de todos os vocabulários necessários para fazer o sistema "compreender" conceitos e a semântica de termos quando realiza pesquisa e filtragem. O Filter Service especifica formas diferentes de fazer filtragem e pesquisa de conteúdo. As principais são: (i) por meio do monitoramento do consumo de conteúdo; (ii) raciocínio sobre o modelo do usuário, visando deduzir a quais estereótipos o usuário pertence; e (iii) análise do modelo do usuário para recomendar conteúdo. Por fim, o Metadata Service é responsável por fornecer metadados corretos a partir de um determinado CRID, armazenar os metadados que descrevem o conteúdo e pode também ser usado para publicação de novos metadados.

Dentre os trabalhos encontrados na literatura e analisados, o projeto SenSee é o que possui maior número de similaridades com o PersonalTVware, em aspectos tais como a utilização das especificações de metadados do TV-Anytme, arquitetura baseada em cliente e servidor, filtragem baseada em conteúdo , e principalmente ao uso do contexto do usuário para melhorar a experiência de acesso personalizado aos conteúdos. O SenSeen emprega uma abordagem de incorporação contextual: contexto dirigido a consultas e pesquisas (descrita na subseção 5.1.1), onde as informações de contexto (dia, hora e localização geográfica) são simplesmente utilizadas como informações adicionais para expandir as consultas executadas.

No PersonalTVware é proposto que além das informações de contexto (dia, hora e localização geográfica) é importante considera quem é o usuário, a sua localização simbólica (casa, escritório, escola) e também a forma (dispositivo fixo, portátil ou móvel) como o usuário acessa o conteúdo. Além disso, o PersonalTVware 
propõe o emprego de aprendizagem supervisionada dependente do contexto por meio de métodos de aprendizagem de máquina para viabilizar predição de preferências contextuais de conteúdo a partir da combinação do perfil e contexto do usuário corrente, e do histórico de perfis contextuais dos usuários (base de conhecimento).

No artigo (AROYO et al., 2007) não foi descrito de que forma as informações de contexto são capturadas e como as consultas expandidas são realizadas. No SenSee, a realimentação de relevância não é explorada, e a aplicação desenvolvida é baseada em Web, enquanto que a solução proposta neste trabalho foi especialmente desenvolvida para o ambiente da TV Digital Interativa.

\subsection{Comparação entre os Trabalhos Apresentados}

Para facilitar a análise dos trabalhos descritos anteriormente foi desenvolvida a Tabela 2 que resume as principais diferenças e similaridades entre os sistemas de recomendação analisados com relação ao PersonalTVware. Foram adotados os seguintes itens comparativos entre os trabalhos apresentados:

- Técnicas de recomendação: quais são as técnicas de recomendação (técnica de filtragem, realimentação de relevância, aprendizagem de máquina etc) empregadas nos trabalhos que viabilizam a recomendação de itens;

- Abordagem de recomendação: qual é a abordagem de recomendação (baseada em perfil do usuário, baseada em contexto etc) empregada nos trabalhos. 
Tabela 2 - Comparação entre Projetos de Suporte a Sistemas de Recomendação para TV Digital

\begin{tabular}{|c|c|c|c|c|}
\hline \multirow[b]{2}{*}{ Trabalho } & \multirow[b]{2}{*}{$\begin{array}{c}\text { Técnicas de } \\
\text { Recomendação }\end{array}$} & \multicolumn{3}{|c|}{ Abordagem de Recomendação } \\
\hline & & $\begin{array}{c}\text { Baseada em } \\
\text { Perfil do } \\
\text { Usuário }\end{array}$ & $\begin{array}{c}\text { Baseada em } \\
\text { Histórico de } \\
\text { Uso }\end{array}$ & $\begin{array}{l}\text { Sensível } \\
\text { ao } \\
\text { Contexto }\end{array}$ \\
\hline $\begin{array}{l}\text { (ÁVILA; ZORZO, } \\
\text { 2009) }\end{array}$ & $\begin{array}{l}\text { Filtragem Baseada } \\
\text { em Conteúdo, } \\
\text { Regras de } \\
\text { associação- } \\
\text { algoritmo Apriori. }\end{array}$ & Sim & Não & Não \\
\hline $\begin{array}{l}\text { (COTTER e } \\
\text { SMYTH, 2000) }\end{array}$ & $\begin{array}{l}\text { Filtragem Híbrida, } \\
\text { Realimentação de } \\
\text { Relevância. }\end{array}$ & Sim & Não & Não \\
\hline $\begin{array}{l}\text { (LUCAS; ZORZO, } \\
\text { 2009) }\end{array}$ & $\begin{array}{l}\text { Regras de } \\
\text { associação- } \\
\text { algoritmo Apriori }\end{array}$ & Não & Sim & Não \\
\hline $\begin{array}{l}\text { (ZHANG; } \\
\text { ZHENG; YUAN; } \\
\text { 2005) }\end{array}$ & $\begin{array}{l}\text { Filtragem Baseada } \\
\text { em Conteúdo. }\end{array}$ & Sim & Não & Não \\
\hline $\begin{array}{l}\text { (BLANCO- } \\
\text { FERNANDEZ et } \\
\text { al., 2006) }\end{array}$ & $\begin{array}{l}\text { Filtragem Híbrida, } \\
\text { Ontologias, } \\
\text { Realimentação de } \\
\text { Relevância. }\end{array}$ & Sim & Não & Não \\
\hline $\begin{array}{l}\text { (ZHANG; } \\
\text { ZHENG, 2005) }\end{array}$ & $\begin{array}{l}\text { Filtragem Baseada } \\
\text { em Conteúdo, } \\
\text { Realimentação de } \\
\text { Relevância, Lógica } \\
\text { Fuzzy. }\end{array}$ & Sim & Sim & Não \\
\hline $\begin{array}{l}\text { (ROVIRA et al., } \\
\text { 2004) }\end{array}$ & $\begin{array}{l}\text { Filtragem Baseada } \\
\text { em Conteúdo. }\end{array}$ & $\operatorname{Sim}$ & Não & Não \\
\hline $\begin{array}{l}\text { (DAl e COHEN, } \\
2003 \text { ) }\end{array}$ & Filtragem Híbrida. & Sim & Não & Não \\
\hline $\begin{array}{l}\text { (AROYO et al., } \\
2007 \text { ) }\end{array}$ & $\begin{array}{l}\text { Consultas } \\
\text { Expandidas } \\
\text { Ontologias. }\end{array}$ & $\operatorname{Sim}$ & Não & Parcialmente \\
\hline $\begin{array}{l}\text { Infraestrutura } \\
\text { PersonalTVWare }\end{array}$ & $\begin{array}{l}\text { Filtragem Baseada } \\
\text { em Conteúdo, } \\
\text { Realimentação de } \\
\text { Relevância, } \\
\text { Aprendizagem de } \\
\text { máquina }\end{array}$ & Sim & Sim & Sim \\
\hline
\end{tabular}




\subsection{Considerações Finais}

$\mathrm{Na}$ literatura existem diversas propostas de sistemas de recomendação para tratar o problema de sobrecarga de informação no domínio da TV Digital Interativa. No entanto, por meio da análise dos trabalhos relacionados foi possível constatar que na maioria dos sistemas de recomendação projetados para o domínio da TV Digital Interativa, com exceção do SenSee (AROYO et al., 2007), o contexto do usuário não tem sido incorporado durante o processo de recomendação.

A especificação de abordagens de recomendação sensíveis ao contexto tem emergido com o objetivo de melhorar o desempenho de sistemas de recomendação em diversos domínios de aplicação (ADOMAVICIUS; TUZHILIN, 2005). Desta forma, justifica-se a realização de estudos com o objetivo de propor ou adaptar abordagens de recomendação sensível ao contexto para o domínio TV Digital Interativa visando enriquecer a experiência de interação do usuário neste importante domínio de aplicação.

Por fim, vale ressaltar que tais trabalhos analisados, em geral, são soluções que possuem um escopo limitado a implementação de sistemas de recomendação. Em contraste ao PersonalTVware que consiste em uma infraestrutura modular de suporte ao desenvolvimento e execução de sistemas de recomendação sensíveis ao contexto para TV Digital Interativa. 


\section{A Infraestrutura PersonalTVware}

O PersonalTVware consiste na proposta de uma infraestrutura modular de software de suporte ao desenvolvimento e execução de sistemas de recomendação sensíveis ao contexto para o domínio da TV Digital Personalizada. O PersonalTVware fornece componentes alinhados aos padrões de TV Digital Interativa que implementam técnicas avançadas de recomendação de conteúdo e processamento de contexto.

Desta forma, o PersonalTVware elimina dos desenvolvedores de sistemas de recomendação a necessidade de implementarem complexos algoritmos para aprendizagem de máquina, filtragem de informação, gerenciamento de perfis de usuários e processamento de informações contextuais. Em linhas gerais, o PersonalTVware deve abstrair as questões de baixo nível para o desenvolvedor, permitindo o desenvolvimento de sistemas de recomendação que ofereçam acesso personalizado ao conteúdo da TV Digital de acordo com o perfil e também o contexto do usuário.

\subsection{Descrições de Cenários de Uso}

Para ilustrar a aplicabilidade do PersonalTVware, e ajudar na compreensão deste trabalho esta seção apresenta a descrição de possíveis cenários de uso em forma de pequenas histórias.

(i) "José, um executivo de 45 anos de idade, entra no seu carro em sua casa numa segunda-feira, aproximadamente às $8 h$ da manhã para ir ao trabalho. Neste momento ele decide assistir um programa de TV de gênero jornalístico para obter informações sobre o trânsito da cidade de São Paulo por meio da TV Móvel que já veio instalada no seu automóvel. Entretanto, ele não deseja perder a concentração enquanto dirige procurando dentre os diversos programas de TV existentes. Desta forma, José acessa de forma personalizada, recomendações de programas de TV adequados ao seu contexto atual, e que provavelmente ele gostará de assistir." 
(ii) "Fernanda uma jovem estudante amazonense de 18 anos ao chegar segunda-feira às 19h30min na academia de ginástica inicia uma caminhada na esteira. Ela gosta de assistir programas de TV de gênero esportes por meio da sua TV portátil enquanto caminha na esteira. No entanto, Fernanda não deseja perder tempo procurando no EPG dentre os vários canais um programa de TV. Assim, ela costuma acessar de forma personalizada, informações sobre a programação da TV Digital da cidade de Manaus, por meio de um sistema de recomendação que apresenta uma lista de programas de TV recomendados de acordo com seu perfil e contexto atual."

Por meio dos cenários de uso apresentados é possível identificar algumas informações de contexto presentes implicitamente tais como José, Fernanda programa de TV, jornalístico, esportes, 8h, 19h30min, casa, academia de ginástica, São Paulo, Manaus, dirige, caminha, TV Portátil, e TV Móvel. Tais informações estão relacionadas às dimensões contextuais $5 \mathrm{Ws}+1 \mathrm{H}$ : identidade (who), tempo (when), localização (where), o que gosta de assistir ou atividade (what) e como (how) assiste TV.

Torna-se necessário ressaltar o aspecto dinâmico do contexto do usuário, pois o usuário poderá estar em contextos diferentes ao longo do dia. Por exemplo: "José (ator do cenário de uso (i)) ao retornar para casa às 20h deseja assistir um programa de TV voltado para o entretenimento por meio de sua TV de alta definição conectada a sua unidade receptora fixa (ou set-top box) com suporte a HDTV, que recebe o sinal digital da operadora de TV. Neste outro cenário, é possível perceber que o interesse de José foi por um diferente gênero de programa de TV.

\subsection{Levantamento de Requisitos da Infraestrutura}

Esta seção apresenta o levantamento dos principais requisitos para atender a especificação da infraestrutura proposta. Torna-se importante ressaltar que esta infraestrutura consiste em uma proposta de solução para lidar com o problema da sobrecarga de informação no domínio da TV Digital Interativa por meio de serviços voltados para suporte a recomendação personalizada sensível ao contexto. Assim, 
no escopo deste trabalho, o conceito perfil contextual do usuário (discutido em detalhes mais adiante na seção 7.6) é definido como sendo o resultado da agregação das informações do contexto corrente e perfil do usuário (especialmente dados pessoais). Dependendo do cenário em que esteja sendo utilizado o perfil contextual do usuário pode conter ou não a informação de gênero instanciada do programa de TV considerado relevante em certo contexto.

Outro conceito também empregado neste trabalho é o modelo de conhecimento. Segundo Han e Kamber (2006), um modelo de conhecimento pode ser definido como o resultado obtido do aprendizado supervisionado de uma função a partir de uma tarefa de classificação. Neste trabalho, o modelo de conhecimento será obtido a partir dos perfis contextuais dos usuários aprendidos com informação de gênero instanciada, ou seja, com rótulo da classe. Tal modelo é utilizado na tarefa de predição de preferências contextuais. Vale ressaltar que a infraestrutura proposta é composta por dois subsistemas: dispositivo do usuário e provedor de serviços. A seguir são enumerados os requisitos funcionais e requisitos nãofuncionais levantados.

\subsubsection{Requisitos Funcionais}

A seguir será apresentada a relação de requisitos funcionais (RFs) sendo classificados em dois tipos: RF-DU quando se refere a um requisito funcional relacionado ao subsistema dispositivo do usuário, e RF-PS para um requisito funcional do subsistema provedor de serviços.

- RF-DU.1 - Prover um serviço responsável pela aquisição de forma implícita, armazenamento, acesso, e conversões das informações do contexto do usuário;

- RF-DU.2 - Prover um serviço responsável pela aquisição e manipulação do perfil do usuário de acordo com as informações especificadas de forma explícita pelo mesmo;

- RF-DU.3 - Prover um serviço responsável pela integração e controle dos principais serviços da infraestrutura proposta; 
- RF-DU.4 - Criar mecanismo de realimentação de relevância que permita obter perfis contextuais dos usuários de forma explícita e implícita (avaliação dos programas de TV recomendados, monitoramento dos programas de TV assistidos) visando gerar dinamicamente a base de conhecimento;

- RF-PS.1 - Prover um serviço capaz de criar modelos de conhecimento a partir dos perfis contextuais dos usuários obtidos;

- RF-PS.2 - Prover um serviço de interpretação de contexto responsável por, de posse dos modelos de conhecimento obtidos, predizer quais serão as preferências contextuais de programas de TV que o usuário provavelmente poderá ter interesse;

- RF-PS.3 - Prover um serviço de filtragem de informações capaz de filtrar os programas de TV relevantes por meio das preferências explícitas e contextuais, e também algumas de informações de contexto relacionadas ao tempo e localização;

- RF-PS.4 - Prover serviços responsáveis pelo gerenciamento e aquisição de metadados sobre os programas de TV, capaz de coletar, converter para os padrões de metadados empregados na infraestrutura, e permitir a manipulação.

\subsubsection{Requisitos Não Funcionais}

A seguir será apresentada a relação de requisitos não funcionais (RNF) que serviram de base para construção da solução proposta:

- RNF.1 Definir uma infraestrutura que ofereça componentes para suporte ao desenvolvimento e execução de sistemas de recomendação sensíveis ao contexto, escondendo a complexidade de baixo nível para execução da recomendação de conteúdo e processamento de contexto;

- RNF.2 - Por motivo de interoperabilidade, a infraestrutura proposta deve ser baseada nas especificações de padrões de metadados flexíveis voltados para descrição e personalização de conteúdo do domínio da TV Digital Interativa, 
tais como o TV-Anytime e MPEG-7. Estas especificações fornecem um conjunto de esquemas de descrição baseadas em XML Schema que estruturam os metadados;

- RNF.3 - Especificar um modelo de usuário e contexto que forneça uma abstração de alto nível das principais entidades contextuais, seus interrelacionamentos e informações de contexto correspondentes que têm impacto na recomendação personalizada de conteúdo;

- RNF.4 - Solução proposta deverá ser independente do sistema operacional embarcado no dispositivo de acesso. Assim, necessita de máquina virtual Java (presente nos middlewares existentes) e canal de retorno disponível (uso da pilha de protocolos TCP/IP);

- RNF.5 - A infraestrutura deverá disponibilizar uma API (Application Programming Interface) para que os desenvolvedores de sistemas de recomendação tenham acesso aos principais serviços;

- RNF.6 - Por motivo de privacidade e segurança as informações referentes ao perfil e contexto do usuário devem ser armazenadas no dispositivo do usuário sendo o mesmo identificado por um código anônimo;

- RNF.7 - Por questões de escalabilidade a infraestrutura deverá permitir que o processamento da recomendação personalizada seja executado de forma distribuída, sendo dividida entre dispositivo do usuário e provedor de serviço.

\subsection{Diagrama de Casos de Uso}

De posse dos requisitos levantados na seção anterior, foram definidos casos de uso com o objetivo de facilitar a compreensão sobre o funcionamento da infraestrutura proposta por meio de um nível maior de abstração. O diagrama geral de casos de uso foi elaborado baseado na linguagem UML (Unified Model Language) (RUMBAUGH; JACOBSON; BOOCH, 1997). Assim, foram identificados os seguintes atores: 
- Usuário: representa a entidade que interage com uma aplicação interativa que utiliza o subsistema dispositivo do usuário para obter recomendação personalizada de conteúdo.

- Administrador do Provedor de Serviços: corresponde a entidade que interage com o subsistema provedor de serviços.

A Figura 19 apresenta o diagrama geral de casos de uso com os principais casos especificados para o PersonalTVware.

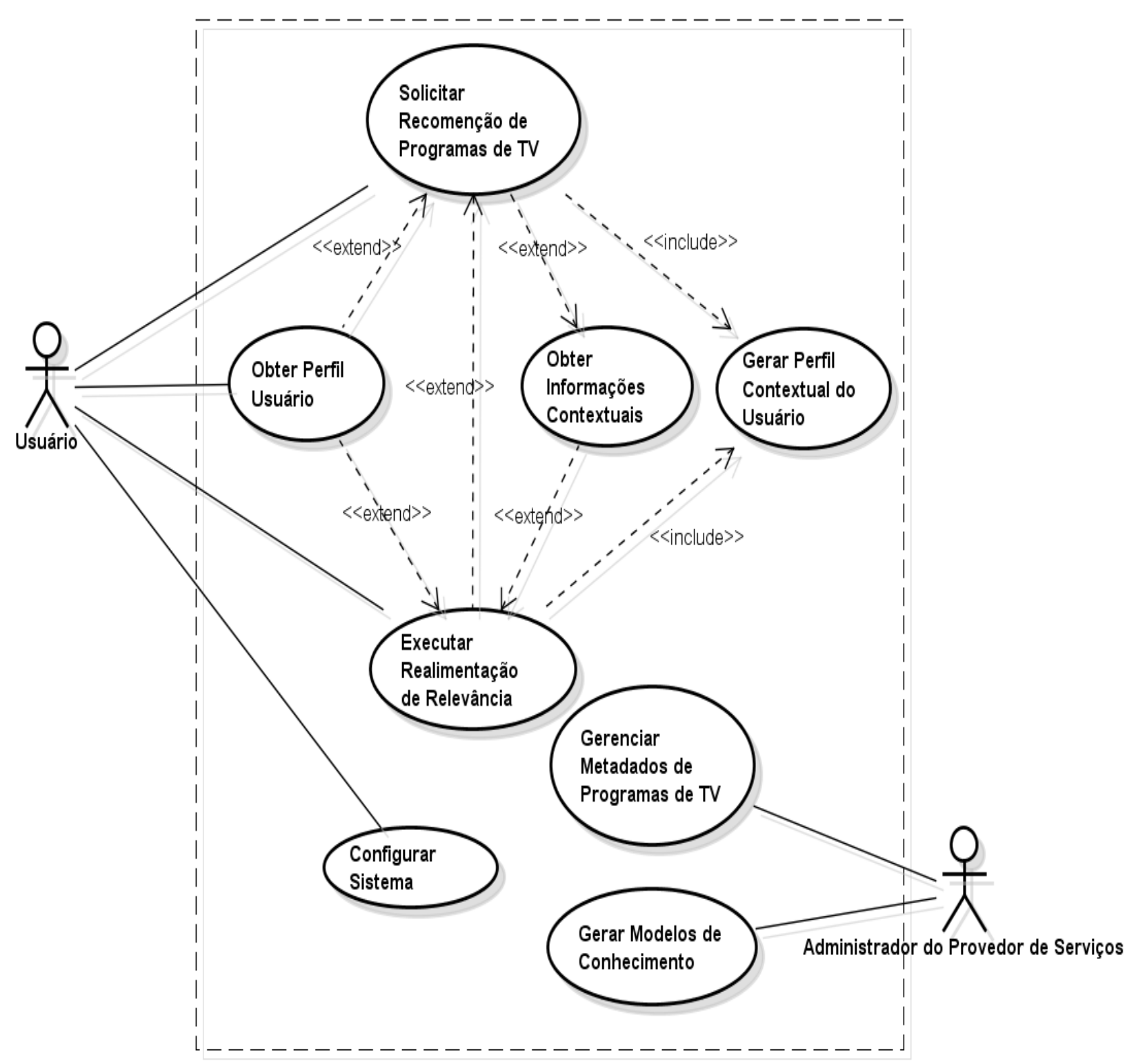

Figura 19 - Diagrama de Casos de Uso Nível 0 do PersonalTVware 


\subsubsection{Descrição dos Casos de Uso}

\begin{tabular}{|l|l|}
\hline \multicolumn{1}{|c|}{ Caso de Uso: 01} & \multicolumn{1}{c|}{ Obter Perfil do Usuário } \\
\hline Ator & Usuário \\
\hline Descrição & $\begin{array}{l}\text { O usuário via sistema de recomendação especifica de forma explícita, dados } \\
\text { pessoais tais como idade, sexo, língua, ocupação, e as suas preferências } \\
\text { explícitas relacionadas ao programa de TV, assunto de interesse, ator, autor, } \\
\text { diretor preferido. Estes dados podem ser alterados a qualquer momento. }\end{array}$ \\
\hline Evento Iniciador & Usuário acessa o serviço de gerenciamento de perfil do usuário. \\
\hline Pré-condição & O sistema de recomendação personalizada deve está em execução. \\
\hline Pós-condição & As informações do usuário devem ser armazenadas. \\
\hline Extensões & Não há extensões \\
\hline Inclusões & Não há extensões \\
\hline
\end{tabular}

\begin{tabular}{|l|l|}
\hline \multicolumn{1}{|c|}{ Caso de Uso: 02} & \multicolumn{1}{|c|}{ Solicitar Recomendação de Programas de TV } \\
\hline Ator & Usuário \\
\hline Descrição & $\begin{array}{l}\text { O usuário solicita via sistema de recomendação ao subsistema dispositivo do } \\
\text { usuário para que este execute o processo de recomendação personalizada } \\
\text { sensível ao contexto. Com isso é obtida uma lista de programas de TV. }\end{array}$ \\
\hline Evento Iniciador & $\begin{array}{l}\text { Solicitação de recomendação personalizada de programas de TV realizada } \\
\text { pelo usuário. }\end{array}$ \\
\hline Pré-condição & $\begin{array}{l}\text { Sistema de recomendação devidamente configurado em execução e } \\
\text { programação de TV disponível. }\end{array}$ \\
\hline Pós-condição & Apresentação da lista de programas de TV recomendados. \\
\hline Extensões & \begin{tabular}{l} 
Caso de Uso "Obter Perfil do Usuário", "Obter Informações Contextuais" e \\
"Executar Realimentação de Relevância" \\
\hline Inclusões
\end{tabular} Caso de Uso “Gerar Perfil Contextual do Usuário" \\
\hline
\end{tabular}

\begin{tabular}{|c|c|}
\hline Caso de Uso: 03 & Obter Informações Contextuais \\
\hline Ator & Usuário \\
\hline Descrição & $\begin{array}{l}\text { Diante da solicitação de recomendação ou realimentação de relevância é } \\
\text { acionada a captura de forma implícita das informações contextuais do } \\
\text { usuário tais como identificação do usuário, sua localização, dia e horário da } \\
\text { interação e o tipo de dispositivo de acesso. }\end{array}$ \\
\hline Evento Iniciador & $\begin{array}{l}\text { Solicitação de recomendação personalizada de programas de TV ou } \\
\text { realimentação de relevância realizada pelo usuário. }\end{array}$ \\
\hline Pré-condição & Sistema de recomendação devidamente configurado em execução e \\
\hline
\end{tabular}




\begin{tabular}{|l|l|}
\hline & programação de TV disponível. \\
\hline Pós-condição & $\begin{array}{l}\text { Armazenamento das informações de contexto, o que deverá permitir o } \\
\text { acesso posterior a tais informações. }\end{array}$ \\
\hline Extensões & Não há extensões \\
\hline Inclusões & Não há extensões \\
\hline
\end{tabular}

\begin{tabular}{|l|l|}
\hline \multicolumn{1}{|c|}{ Caso de Uso: 04 } & \multicolumn{1}{|c|}{ Gerar Perfil Contextual do Usuário } \\
\hline Ator & Usuário \\
\hline Descrição & $\begin{array}{l}\text { Ao ser solicitada uma recomendação de programas de TV ou executada a } \\
\text { realimentação de relevância é gerado o perfil contextual do usuário contendo } \\
\text { o momento da interação por meio de dados pessoais do usuário e } \\
\text { informações contextuais. Dependendo do caso de uso (No02 ou No05) que } \\
\text { dispara este caso pode conter ou não a informação de gênero de programa } \\
\text { de TV instanciada. }\end{array}$ \\
\hline Evento Iniciador & $\begin{array}{l}\text { Solicitação de recomendação personalizada de programas de TV ou } \\
\text { realimentação de relevância realizada pelo usuário. }\end{array}$ \\
\hline Pré-condição & $\begin{array}{l}\text { Sistema de recomendação devidamente configurado em execução e } \\
\text { programação de TV disponível. }\end{array}$ \\
\hline Pós-condição & Geração do perfil contextual do usuário. \\
\hline Extensões & Não há extensões \\
\hline Inclusões & Não há extensões \\
\hline
\end{tabular}

\begin{tabular}{|c|c|}
\hline Caso de Uso: 05 & Executar Realimentação de Relevância \\
\hline Ator & Usuário \\
\hline Descrição & $\begin{array}{l}\text { Permite ao subsistema dispositivo do usuário obter de forma interativa } \\
\text { (implícita ou explícita) o perfil contextual do usuário com ou sem informação } \\
\text { de gênero instanciada. }\end{array}$ \\
\hline Evento Iniciador & $\begin{array}{l}\text { Monitoramento dos programas de TV assistidos ou avaliação de programas } \\
\text { de TV recomendados. }\end{array}$ \\
\hline Pré-condição & $\begin{array}{l}\text { Sistema de recomendação devidamente configurado em execução e } \\
\text { programação de TV disponível. }\end{array}$ \\
\hline Pós-condição & Atualização da base de conhecimento. \\
\hline Extensões & Caso de Uso "Obter Perfil do Usuário" e "Obter Informações Contextuais" \\
\hline Inclusões & Caso de Uso "Gerar Perfil Contextual do Usuário" \\
\hline
\end{tabular}

\begin{tabular}{|l|l|}
\hline \multicolumn{1}{|c|}{ Caso de Uso: 06} & \multicolumn{1}{c|}{ Configurar Sistema de Recomendação } \\
\hline Ator & Usuário \\
\hline Descrição & $\begin{array}{l}\text { Permite ao usuário configurar o funcionamento do sistema de recomendação } \\
\text { tais como selecionar o método de aprendizagem de máquina (em um } \\
\text { ambiente experimental) e especificar o endereço IP do subsistema provedor }\end{array}$ \\
\hline
\end{tabular}




\begin{tabular}{|l|l|}
\hline & $\begin{array}{l}\text { de serviços. Na primeira vez que usar o sistema pode indicar o tipo de } \\
\text { dispositivo e sua localização simbólica. }\end{array}$ \\
\hline Evento Iniciador & Chamadas realizadas pelo usuário. \\
\hline Pré-condição & Sistema de recomendação em execução. \\
\hline Pós-condição & Registro das configurações do sistema. \\
\hline Extensões & Não há extensões \\
\hline Inclusões & Não há extensões \\
\hline
\end{tabular}

\begin{tabular}{|l|l|}
\hline \multicolumn{1}{|c|}{ Caso de Uso: 07} & \multicolumn{1}{c|}{ Gerenciar metadados de programas de TV } \\
\hline Ator & Administrador do Provedor de Serviços \\
\hline Descrição & $\begin{array}{l}\text { Permite ao administrador do sistema a submissão ou manipulação dos } \\
\text { metadados referentes à programação das emissoras de TV. }\end{array}$ \\
\hline Evento Iniciador & Acionamento do serviço. \\
\hline Pré-condição & Gerenciador de metadados de programas de TV em execução. \\
\hline Pós-condição & Armazenamento dos metadados dos programas de TV. \\
\hline Extensões & Não há extensões \\
\hline Inclusões & Não há extensões \\
\hline
\end{tabular}

\begin{tabular}{|c|c|}
\hline Caso de Uso: 08 & Gerar Modelo de Conhecimento \\
\hline Ator & Administrador do Provedor de Serviços \\
\hline Descrição & $\begin{array}{l}\text { Permite ao administrador do sistema selecionar o método de aprendizagem } \\
\text { de máquina no qual deseja construir o modelo de conhecimento. O(s) } \\
\text { modelo(s) de conhecimento é(são) gerado(s) através de um serviço de } \\
\text { classificação, visto em detalhes na seção } 7.6 \text {. }\end{array}$ \\
\hline Evento Iniciador & Acionamento do serviço. \\
\hline Pré-condição & $\begin{array}{l}\text { Existência de perfis contextuais de usuários coletados dos subsistemas dos } \\
\text { dispositivos dos usuários. }\end{array}$ \\
\hline Pós-condição & Modelos de conhecimentos gerados. \\
\hline Extensões & Não há extensões \\
\hline Inclusões & Não há extensões \\
\hline
\end{tabular}

\subsection{Modelagem de Usuário}

O modelo do usuário abstrai as principais classes de informações sobre o perfil do usuário, que são relevantes para viabilizar o funcionamento da infraestrutura proposta. A Figura 20 apresenta o modelo do usuário representado por meio de um diagrama de classes da linguagem UML, que foi empregado pelo PersonalTVware. 


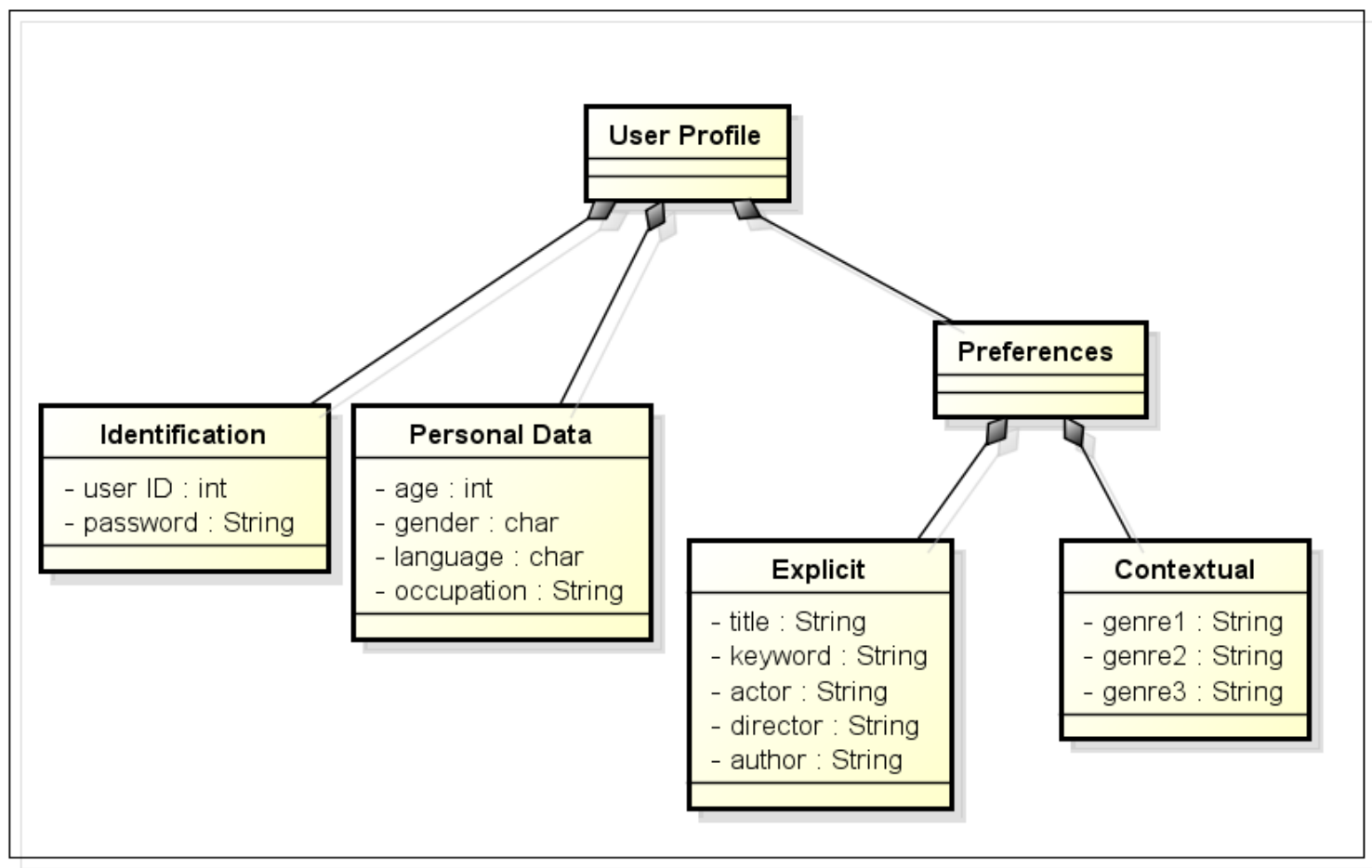

Figura 20 - Modelo do Usuário empregado pelo PersonalTVware

O modelo do usuário possui classes de informações que constituem o perfil do usuário tais como Identificação, Dados pessoais e Preferências Explícitas e Contextuais (ou Inferidas). A identificação é composta por informações que permitem distinguir um determinado perfil de usuário em relação aos demais e também permite o acesso ao sistema. Já os dados pessoais descrevem as características do usuário e raramente são alterados.

As preferências do usuário se caracterizam por conter duas subclasses de informações relacionadas aos interesses do usuário por programas de TV que não mudam com certa frequência ou que são dependentes do contexto do usuário. São utilizadas, por exemplo, as preferências por determinados diretores, atores, títulos de programas de TV e termos que expressem assuntos de interesses. O gênero é considerado uma preferência contextual, pois de acordo com a hipótese levantada nesta tese o usuário poderá ter preferências por gêneros distintos de acordo com o seu contexto.

Conforme ilustrado na Figura 20, as preferências são divididas segundo a sua forma de obtenção: explícitas e contextuais. As preferências explícitas são aquelas informações especificadas e atualizadas pelo próprio usuário, são preferências raramente alteradas. Já as preferências contextuais são inferidas automaticamente 
pelos mecanismos de aprendizagem a partir da exploração do perfil contextual do usuário (discutido em detalhes mais adiante na seção 7.6).

Neste trabalho é utilizada a linguagem de marcação XML para a representação do modelo do usuário, pois o XML foi adotado pelos padrões de metadados flexíveis para TV Digital Interativa. Assim, foi especificado um conjunto de esquemas de descrição para este trabalho, chamado de Esquemas PersonalTVware que é apresentado no Apêndice A.

$O$ espaço de nomes que identifica tais Esquemas é $O$ http://www.larc.usp.br/ fsantos/personaltVware/ com prefixo ptw.

O Esquema XML correspondente à representação do modelo do usuário (elemento raiz UserModel) importa tipos (types) dos Esquemas definidos pelo MPEG-7, referentes à parte MDS da especificação (ISO/IEC 15938-5, 2003), e também do modelo de metadados TV-Anytime (TV-ANYTIME, 2007b, 2007c), tornando a representação alinhada aos padrões da TV Digital Interativa. A Tabela 3 apresenta 0 modelo do usuário seus principais componentes, atributos representação e forma de obtenção.

Tabela 3 - Descrição do Modelo do Usuário

\begin{tabular}{|c|c|c|c|}
\hline Componente & Atributos & Representação & $\begin{array}{l}\text { Forma de } \\
\text { Aquisição }\end{array}$ \\
\hline Identificação & ID do usuário e senha. & $\begin{array}{l}\text { A identificação do usuário no } \\
\text { subsistema do dispositivo do } \\
\text { usuário e a senha são atributos } \\
\text { não representados pelo TV- } \\
\text { Anytime, portanto configura-se } \\
\text { como uma extensão. }\end{array}$ & $\begin{array}{l}\text { ID do usuário } \\
\text { gerado } \\
\text { dinamicamente } \\
\text { pelo sistema e } \\
\text { senha } \\
\text { especificada pelo } \\
\text { usuário. }\end{array}$ \\
\hline Dados Pessoais & Idade, sexo, idioma e ocupação. & $\begin{array}{l}\text { Representação obtida por meio } \\
\text { dos metadados da segunda fase } \\
\text { de trabalho do TV-Anytime (TV- } \\
\text { ANYTIME, 2007c) que } \\
\text { descrevem as características de } \\
\text { usuário. O atributo ocupação não } \\
\text { é representado pelo TV-Anytime, } \\
\text { portanto configura-se como uma } \\
\text { extensão. }\end{array}$ & $\begin{array}{l}\text { Informação } \\
\text { especificada } \\
\text { explicitamente. }\end{array}$ \\
\hline $\begin{array}{l}\text { Preferências } \\
\text { explícitas }\end{array}$ & $\begin{array}{l}\text { Título de programa de TV, } \\
\text { palavra-chave, ator, diretor, } \\
\text { autor. }\end{array}$ & $\begin{array}{l}\text { Semântica e representação } \\
\text { oferecida pelo Esquema de } \\
\text { Descrição de Preferências do } \\
\text { Usuário do MPEG-7 Usuário do } \\
\text { MPEG-7 (UserPreferences DS, } \\
\text { seção 3.3.1). }\end{array}$ & $\begin{array}{l}\text { Informação } \\
\text { especificada } \\
\text { explicitamente. }\end{array}$ \\
\hline $\begin{array}{l}\text { Preferências } \\
\text { contextuais }\end{array}$ & Gêneros de programas de TV. & $\begin{array}{l}\text { Extensão do Esquema de } \\
\text { Descrição de Preferências do } \\
\text { Usuário do MPEG-7 } \\
\text { (UserPreferences DS, seção } \\
\text { 3.3.1). }\end{array}$ & $\begin{array}{l}\text { Informação obtida } \\
\text { de inferência a } \\
\text { partir do perfil } \\
\text { contextual do } \\
\text { usuário. }\end{array}$ \\
\hline
\end{tabular}




\subsection{Modelagem de Contexto do Usuário}

Para compreender e representar a complexidade das informações de contexto exploradas por uma aplicação torna-se necessário a especificação de modelos de contextos. Algumas pesquisas relacionadas à modelagem de contexto serviram de base para a definição e representação do modelo proposto neste trabalho. O trabalho de Alves (2008), auxiliou na identificação de entidades e informações contextuais, pois apresenta uma modelagem de contexto para um ambiente colaborativo e sensível ao contexto no cenário da TV Digital Interativa.

O trabalho de Goularte (2003), auxiliou ao apresentar uma proposta de representação de contexto de forma estruturada por meio de técnicas desenvolvidas pelo autor baseadas em Esquemas de Descrição (Description Schemes - DSs) compatíveis com o padrão MPEG-7. O trabalho de Santos Júnior (2002) foi útil por sua modelagem de ambientes interativos sensíveis ao contexto e centrados no usuário, o que permite adaptação dinâmica das aplicações ao contexto do usuário.

Conforme apresentado no capítulo sobre Computação Sensível ao Contexto, Dey (2001) define contexto como sendo "qualquer informação que possa ser utilizada para caracterizar a situação de uma entidade e que uma entidade, por sua vez, pode ser uma pessoa, lugar ou objeto que é considerado relevante para interação entre usuário e aplicação, incluindo o usuário e aplicação em si”. Desta forma, neste trabalho, o modelo de contexto é voltado para representar as principais entidades e informações contextuais que são relevantes para o funcionamento da infraestrutura proposta.

Deste modo, existem duas entidades que foram identificadas: usuário e programa de TV, pois um usuário pode assistir ou avaliar $n$ programas de TV, ou ainda solicitar recomendação de programas de TV em um determinado contexto. $O$ relacionamento entre tais entidades e as informações de contexto que as circundam, constituem o contexto do usuário. A Figura 21 apresenta um diagrama de classes UML com as principais informações contextuais que caracterizam a situação de entidades abstraídas de cenários de uso, como aqueles descritos na seção 7.1. 


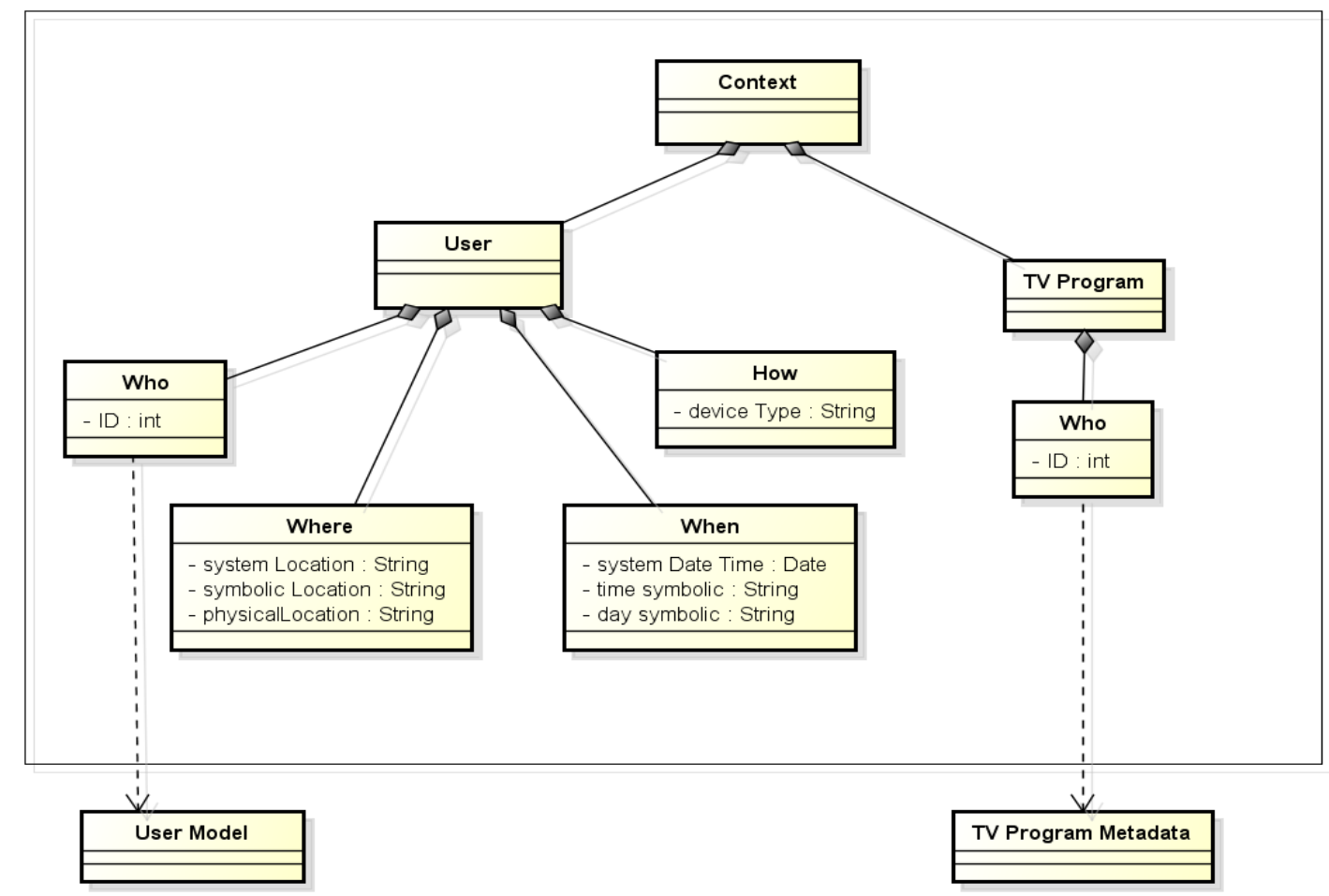

Figura 21- Modelagem do Contexto do Usuário

A Tabela 4 descreve os atributos que fazem parte do contexto do usuário conforme as dimensões de contexto $5 \mathrm{Ws}+1 \mathrm{H}$. No contexto do usuário é importante modelar sua localização, pois o usuário pode solicitar a recomendação em diversos lugares. Além disso, os usuários podem utilizar dispositivos fixos, portáteis ou móveis para recepção de TV Digital Interativa. Deste modo, torna-se importante modelar como o usuário solicita a recomendação. O tempo também deve ser modelado, pois representa o dia e período em que o usuário interage com o sistema. A atividade do usuário apesar de ter sido identificada por meio dos cenários de uso (seção 7.1) não foi modelada, pois é considerada uma informação contextual complexa de ser obtida (WANG et al. 2004).

Desta forma, deve ser objeto de estudo de trabalhos futuros. Segundo Wang et al. (2004), contextos complexos podem ser obtidos a partir da composição e/ou raciocínio sobre contextos primários (identidade, localização, tempo, dentre outros). Por exemplo, a partir de contextos primários localização do usuário e horário podese inferir que o usuário está trabalhando. Deste modo, é possível concluir que a inferência automática da atividade do usuário não é uma tarefa trivial. Neste trabalho, os atributos referentes à identificação das entidades foram usados como índices para outras fontes de informações que são necessárias para o funcionamento do PersonalTVware conforme sugerido por (DEY; ABOWD, 2000). 
Por exemplo, por meio das identificações do usuário e programa de TV é possível acessar informações tais como preferências, dados pessoais do usuário, assim como as descrições de um programa de TV representado por meio dos metadados do TV-Anytime.

\begin{tabular}{|c|c|c|}
\hline Entidade & $\begin{array}{l}\text { Dimensão } \\
\text { Contextual }\end{array}$ & Atributos \\
\hline \multirow{4}{*}{ Usuário } & $\begin{array}{l}\text { Identidade } \\
\quad \text { (who) }\end{array}$ & $\begin{array}{l}\text { - ID do usuário: Identificação (ID) de quem é o } \\
\text { usuário que está interagindo. }\end{array}$ \\
\hline & $\begin{array}{l}\text { Localização } \\
\text { (where) }\end{array}$ & $\begin{array}{l}\text { - Localização do Sistema: representa a localização } \\
\text { lógica do usuário quando interage com o sistema. } \\
\text { Por exemplo, endereço IP, coordenadas obtidas de } \\
\text { um GPS. } \\
\text { - Localização Simbólica: representa a localização } \\
\text { simbólica do usuário em que ocorre a interação. } \\
\text { Por exemplo: casa, trabalho, universidade, hotel, } \\
\text { dentre outras. } \\
\text { - Localização física: Representa a região geográfica } \\
\text { onde o usuário está no momento da interação. }\end{array}$ \\
\hline & $\begin{array}{l}\text { Tempo } \\
\text { (when) }\end{array}$ & $\begin{array}{l}\text { - Data e hora do Sistema: representa a data e hora } \\
\text { em que o usuário solicitou a recomendação. } \\
\text { - Hora Simbólica: refere-se ao período do dia em } \\
\text { que o usuário solicitou a recomendação. Por } \\
\text { exemplo: manhã, tarde, e noite. } \\
\text { - Dia simbólico: refere-se ao dia da semana. Por } \\
\text { exemplo: segunda, terça, quarta, quinta, sexta, } \\
\text { sábado e domingo. }\end{array}$ \\
\hline & $\begin{array}{l}\text { Como } \\
\text { (how) }\end{array}$ & $\begin{array}{l}\text { - Tipo de dispositivo: indica como o usuário está } \\
\text { interagindo, por meio de um dispositivo fixo, portátil, } \\
\text { ou móvel. }\end{array}$ \\
\hline $\begin{array}{l}\text { Programa de } \\
\text { TV }\end{array}$ & $\begin{array}{l}\text { Identidade } \\
\quad \text { (who) }\end{array}$ & $\begin{array}{l}\text { - ID do programa: Identificação (CRID, segundo a } \\
\text { terminologia do TV-Anytime - seção 3.3.2) do } \\
\text { programa de TV que o usuário está interagindo. }\end{array}$ \\
\hline
\end{tabular}

O Esquema XML correspondente à representação do modelo do contexto do usuário possui como elemento raiz contextModel que é o elemento de nível mais alto na estrutura proposta para representação de contexto, servindo de invólucro para os demais elementos conforme poderá ser conferido no Esquema XML do PersonalTVware (Apêndice A).

\subsection{Abordagem de Recomendação Personalizada Sensível ao Contexto}

Nesta seção serão descritos os principais mecanismos da proposta de abordagem de recomendação personalizada sensível ao contexto para TV Digital 
personalizada, que é utilizada pelo PersonalTVware. A abordagem proposta se enquadra no grupo estimação e elicitação de preferências contextuais (descrito na subseção 5.1.1). A abordagem proposta para o PersonalTVware, tem como base a filtragem de informação, e o emprego de aprendizagem supervisionada dependente do contexto para criação de modelos de conhecimento, posteriormente utilizados na etapa de predição de preferências contextuais. Para isso, são utilizadas as técnicas de filtragem de informação da área de recuperação de informação e classificação da área de mineração de dados descritas nas seções 5.3, 5.4, e o conceito de perfil contextual do usuário, que será apresentado a seguir na subseção 7.6.1.

\subsubsection{Conceito de Perfil Contextual do Usuário}

Um perfil contextual do usuário é definido, neste trabalho, como sendo o registro a ser utilizado nas tarefas de classificação e predição, sendo formado por uma agregação de atributos que representam as informações que constituem o contexto corrente, perfil do usuário (especificamente dados pessoais) e o atributoclasse, ou seja, o atributo alvo com classes pré-definidas. Cada classe corresponde ao gênero de um determinado programa de TV (preferência contextual). Este gênero pode ser obtido a partir da interação do usuário, como assistir ou avaliar um programa de TV, ou ainda pode ser inferido para este usuário, dependendo do caso de uso em que esteja sendo utilizado o perfil contextual do usuário.

Tabela 5 - Atributos que compõem o perfil contextual do usuário

\begin{tabular}{ll}
\multicolumn{1}{c}{ Atributos } & \multicolumn{1}{c}{ Origem } \\
\hline $\begin{array}{l}\text { - Sexo; } \\
\text { - Idade; } \\
\text { - Idioma; } \\
\text { - Ocupação. }\end{array}$ & Modelo do usuário - Dados pessoais \\
\hline - Localização Física; \\
$\begin{array}{l}\text { - Localização simbólica; } \\
\text { - Dia simbólico; }\end{array}$ \\
$\begin{array}{l}\text { - Hora simbólica; } \\
\text { - Tipo de dispositivo. }\end{array}$ \\
\hline
\end{tabular}


A Tabela 5 apresenta os atributos selecionados que compõem o perfil contextual do usuário, destacando a origem dos mesmos. Adicionalmente, em trabalhos futuros tais atributos podem ser complementados ou até mesmo substituídos por outros de maior expressividade. Vale ressaltar que, por questões de privacidade, não aparece a identificação do usuário (ID do usuário) no perfil contextual do usuário, pois esta informação não é explorada no processo de predição.

\subsubsection{Aprendizagem Supervisionada Dependente do Contexto}

Esta é a etapa de aprendizagem (ou treinamento), onde o algoritmo de classificação constrói o modelo de conhecimento por meio da análise ou aprendizagem do conjunto de treinamento composto por perfis contextuais dos usuários (registros) com seus rótulos de classes associados, ou seja, atributo-classe Gênero instanciado. No contexto da classificação os perfis contextuais dos usuários podem ser referenciados como tuplas, instâncias, exemplos, ou casos de testes. Uma tupla, $X$, pode ser representada por meio de vetor de atributos $\mathrm{n}$-dimensional, $\mathrm{X}=\left(x_{1}, x_{2}, \ldots, x_{n}\right)$. A Figura 22 ilustra o processo de aprendizagem supervisionada dependente do contexto.

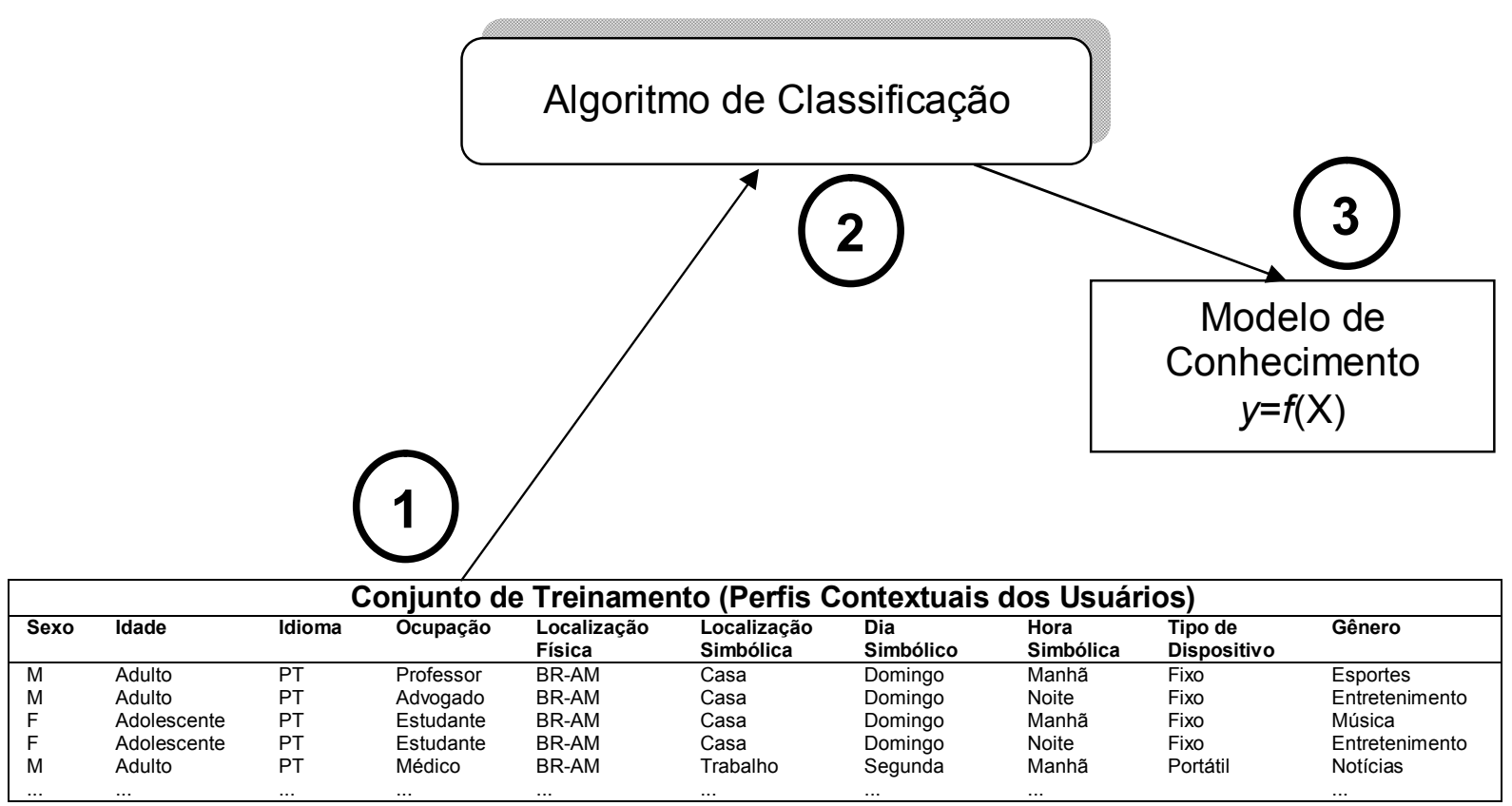

Figura 22 - Etapa de aprendizagem ou treinamento. Adaptado de (HAN; KAMBER, 2006). 
O conjunto de treinamento (1) é obtido por meio da técnica de realimentação de relevância (descrita na seção 5.5), e posteriormente analisado pelo algoritmo de classificação (2) para criação do modelo de conhecimento. Vale ressaltar que o modelo de conhecimento é representado de acordo com a técnica de classificação empregada pelo classificador tais como árvore de decisão, uma rede bayesiana, uma rede neural, modelo vetorial, dentre outros. O modelo de conhecimento (3) obtido pode ser compreendido como uma função, $y=f(X)$, que permite predizer o rótulo $y$ do atributo-classe de um dado perfil contextual do usuário $X$.

\subsubsection{Predição de Preferências Contextuais}

Esta é a segunda etapa (Figura 23), onde dado um perfil contextual do usuário $X$ com o atributo-classe Gênero não instanciado (1), deseja-se descobrir o rótulo $y$ do atributo-classe associado para um determinado usuário, ou seja, a preferência contextual (gênero de programas de TV). Para que isso ocorra, é necessário que o algoritmo de predição (2) utilize o modelo de conhecimento $y=f(X)$ (3) obtido na etapa anterior, que permite predizer o rótulo y do atributo-classe de um dado perfil contextual do usuário $X$ construído a partir da solicitação de uma recomendação.

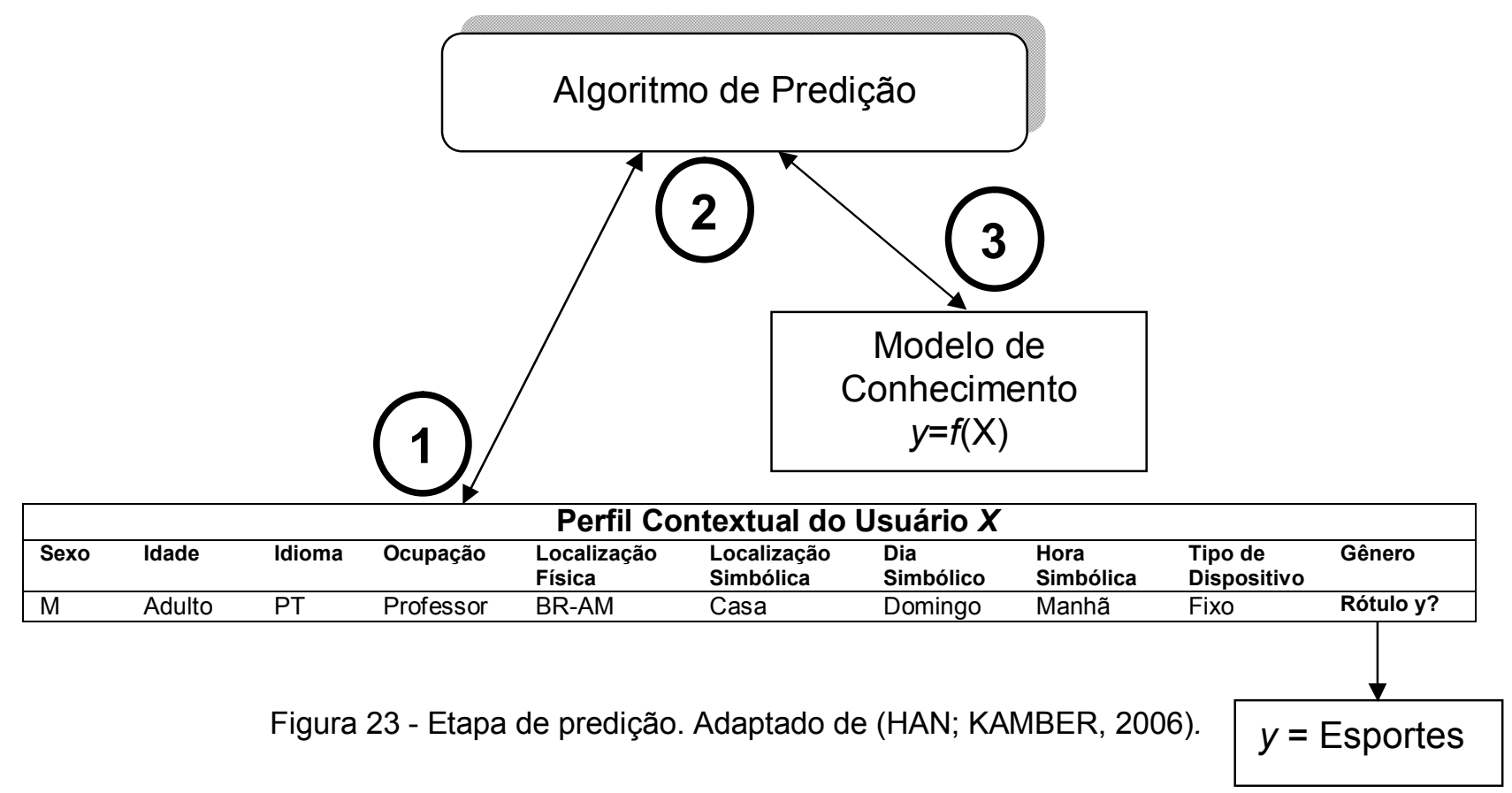


A partir do perfil contextual do usuário $X$ com o rótulo $y$ inferido, ou seja, o gênero (preferência contextual) descoberto torna-se possível a geração de recomendação sensível ao contexto por meio da etapa de filtragem de informação sensível ao contexto descrita a seguir na subseção 7.6.4. Neste trabalho, os valores dos gêneros obtidos pela predição estão de acordo com especificação de metadados do TV Anytime (TV-ANYTIME, 2007b).

\subsubsection{Filtragem de Informação Sensível ao Contexto}

O objetivo desta etapa é filtrar os programas de TV que provavelmente serão relevantes e adequados ao perfil e contexto do usuário. Desta forma, o processo de filtragem explora além das preferências explícitas, as preferências contextuais inferidas na etapa anterior (vista na subseção 7.6.3), bem como as informações contextuais (dia e horário, lugar de origem do programa de TV e do usuário), e os metadados dos programas de TV.

A técnica de filtragem empregada é a filtragem baseada em conteúdo ( $F B C$ ) (vista na subseção 5.3.1) que consiste em comparar os termos que descrevem o perfil do usuário com as descrições dos conteúdos, visando obter uma lista de conteúdos que provavelmente serão de interesses do usuário. A comparação entre o perfil do usuário com as descrições dos conteúdos pode ser realizada por meio de uma linguagem de consulta de metadados (vista na seção 3.4) ou métrica de similaridade comumente utilizada, que é o cálculo do cosseno do ângulo entre dois vetores (ADOMAVICIUS; TUZHILIN, 2005).

A similaridade entre os vetores que representam o perfil do usuário e programa de TV indica o grau de relevância. No entanto, este método apesar de ser muito utilizado em sistemas de recomendação baseados em dados semiestruturados, não oferece a flexibilidade necessária para que seja possível customizar recomendações ou definir consultas sobre documentos XML que representam o conteúdo e perfil do usuário (ADOMAVICIUS; TUZHILIN, 2005). Deste modo, foi empregada a linguagem de consulta de metadados, que oferece a possibilidade de elaboração de expressões de consulta complexas sobre os 
documentos XML (com estruturas de descrição inter-relacionadas) sendo o seu uso recomendado para TV-Anytime (TV-ANYTIME, 2007b).

\subsection{Arquitetura do PersonalTVware}

A arquitetura proposta neste trabalho foi projetada a partir dos requisitos de software para construção de sistemas sensíveis ao contexto (vistos na seção 4.5), com o objetivo de oferecer suporte ao desenvolvimento e execução de sistemas de recomendação sensíveis ao contexto de forma modular e flexível. Também tem como base o padrão de arquitetura de software MVC (Model-View-Controller). Por motivo de escalabilidade e privacidade o processo de recomendação será realizado por meio de uma arquitetura distribuída.

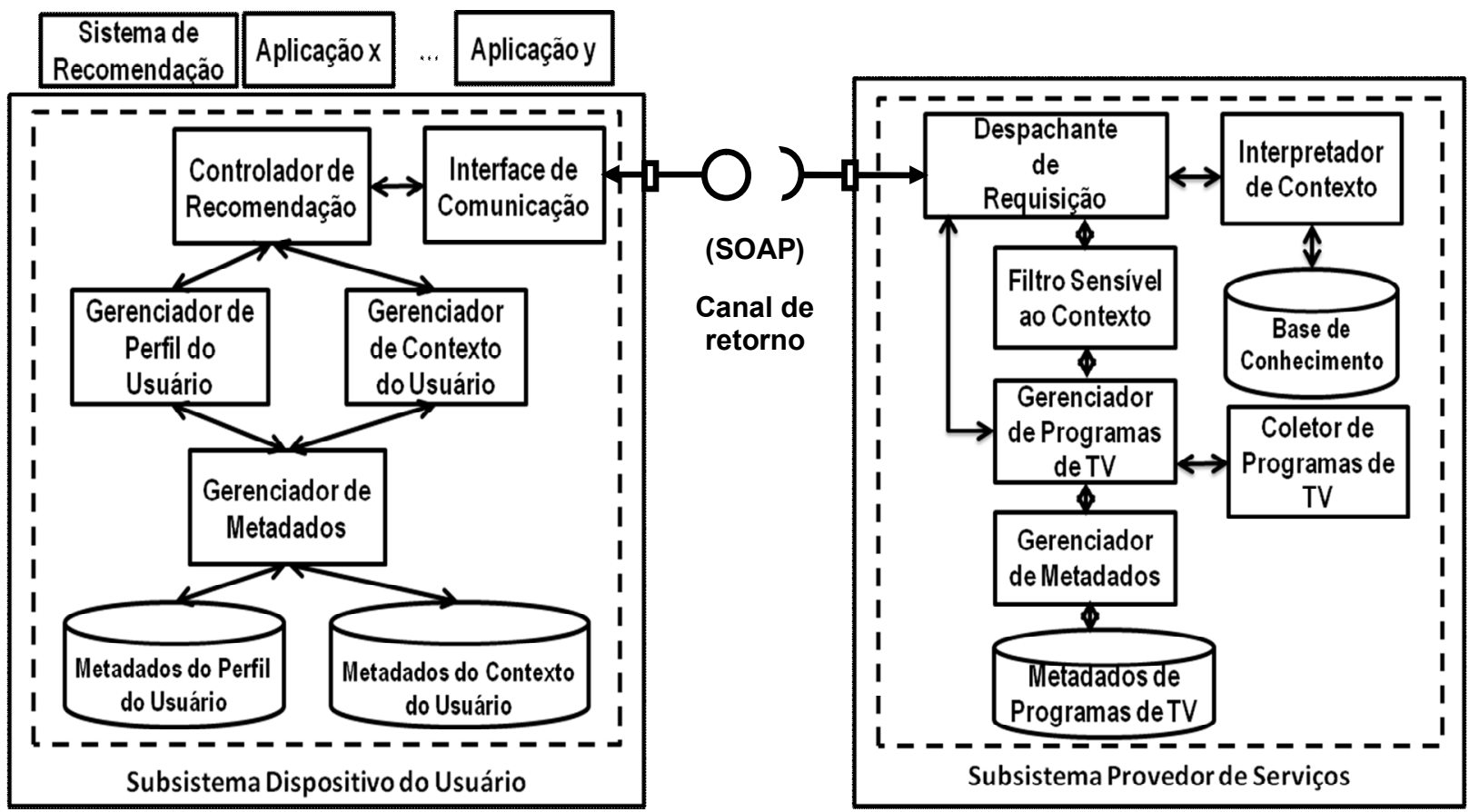

Figura 24 - Arquitetura do PersonalTVware

Conforme ilustrado na Figura 24, a arquitetura do sistema é composta por dois subsistemas: dispositivo do usuário e provedor de serviços. O subsistema dispositivo do usuário representa o lado cliente e concentra os módulos responsáveis pelas atividades de controle ou orquestração da recomendação, gerenciamento de perfil e contexto do usuário, tratamento de metadados e comunicação com o subsistema provedor de serviços. O subsistema dispositivo do 
usuário é independente de plataforma de suporte a interatividade e poderá ser implementado em um set-top box, um computador ou ainda em uma TV Portátil que possua sistema operacional com máquina virtual Java.

Já o subsistema provedor de serviços representa o lado servidor sendo composto por módulos responsáveis pelas atividades de filtragem de conteúdo, interpretação de contexto, coleta e gerenciamento dos metadados referentes aos programas de TV. Além disso, o PersonalTVware segue o modelo de comunicação bi-direcional de referência do TV-Anytime para transporte de metadados por meio da pilha de protocolos TCP/IP via canal de interatividade (TV-ANYTIME, 2007a). A comunicação entre os subsistemas da arquitetura foi padronizada por meio da utilização de Serviços Web, especificamente o protocolo SOAP e linguagem WSDL.

\subsubsection{Controlador de Recomendação}

No subsistema dispositivo do usuário, o módulo Controlador de Recomendação é o módulo central do PersonalTVware, pois faz a intermediação entre um sistema de recomendação sensível ao contexto e os demais módulos da arquitetura. É responsável pela integração dos demais módulos e orquestração do fluxo de execução do processo de recomendação, conforme será descrito na seção 7.8. Os seus serviços são expostos para as aplicações através de uma API (PersonalTVware API).

Dentre os seus principais serviços, é responsável pela técnica realimentação de relevância (do inglês, feedback relevance) (descrito na seção 5.5), que permite obter de forma interativa os registros de perfis contextuais dos usuários com informação de gênero instanciada, sendo armazenados em uma base de conhecimento posteriormente explorada pelos métodos de predição.

No PersonalTVware a técnica realimentação de relevância pode ser realizado de forma explícita ou implícita. Na forma explícita o usuário pode selecionar dentre os programas de TV que foram recomendados aqueles considerados relevantes em certo contexto. Enquanto que na forma implícita adotou-se um algoritmo similar ao apresentado por Yu e Zhou (2004). 
Tal algoritmo explora a $\beta$ razão entre o tempo que o usuário assistiu a um programa de TV $\left(T_{r}\right)$ e a sua duração total $\left(T_{t}\right)$ se o valor obtido for maior que um limiar (50\% em nossos experimentos) o gênero do programa de TV será considerado relevante, e o perfil contextual do usuário será gerado. O valor do limiar empregado foi definido de forma empírica. Sendo também empregado por Yu e Zhou (2004). A equação eq.(2) que retrata este algoritmo é apresentada a seguir:

$$
\beta=\frac{T_{r}}{T_{t}} \in[0,1]
$$

É importante também destacar que, neste trabalho, o perfil contextual do usuário pode também ser obtido quando o usuário solicita recomendação de programas de TV. No entanto, neste cenário de uso, o perfil contextual do usuário é obtido sem a informação de gênero instanciada, que posteriormente será descoberta por meio das etapas de classificação e predição (vista na seção 7.6) do módulo Interpretador de Contexto.

\subsubsection{Gerenciador de Perfil do Usuário}

O módulo Gerenciador de Perfil do Usuário gerencia o acesso e aquisição de forma explícita das informações que constituem o perfil do usuário. Por meio de seus componentes o usuário poderá especificar informações tais como dados pessoais (idioma, idade sexo e ocupação), interesses gerais ou preferências explícitas (título de um programa de TV, palavra-chave relacionada com um assunto de interesse), ator, autor e diretor preferido. As informações que constituem o perfil do usuário serão representadas por meio de documento XML estruturado a partir do elemento raiz <ptw:UserProfile> presente no conjunto de Esquemas XML do PersonalTVware (Apêndice A).

Além disso, por razões de privacidade e segurança, o perfil do usuário será armazenado no dispositivo do usuário, evitando o envio de dados privados dos usuários para os provedores de serviços. Vale ressaltar que no subsistema do dispositivo do usuário pode haver mais de um perfil de usuário, ou seja, vários usuários podem utilizar o mesmo dispositivo, de modo que a diferenciação é feita 
por meio do atributo de identificação do usuário. Um fragmento de um exemplo de documento XML com os descritores instanciados é apresentado na Figura 25. O prefixo ptw corresponde ao espaço de nomes do PersonalTVware, os demais são importados dos padrões empregados.

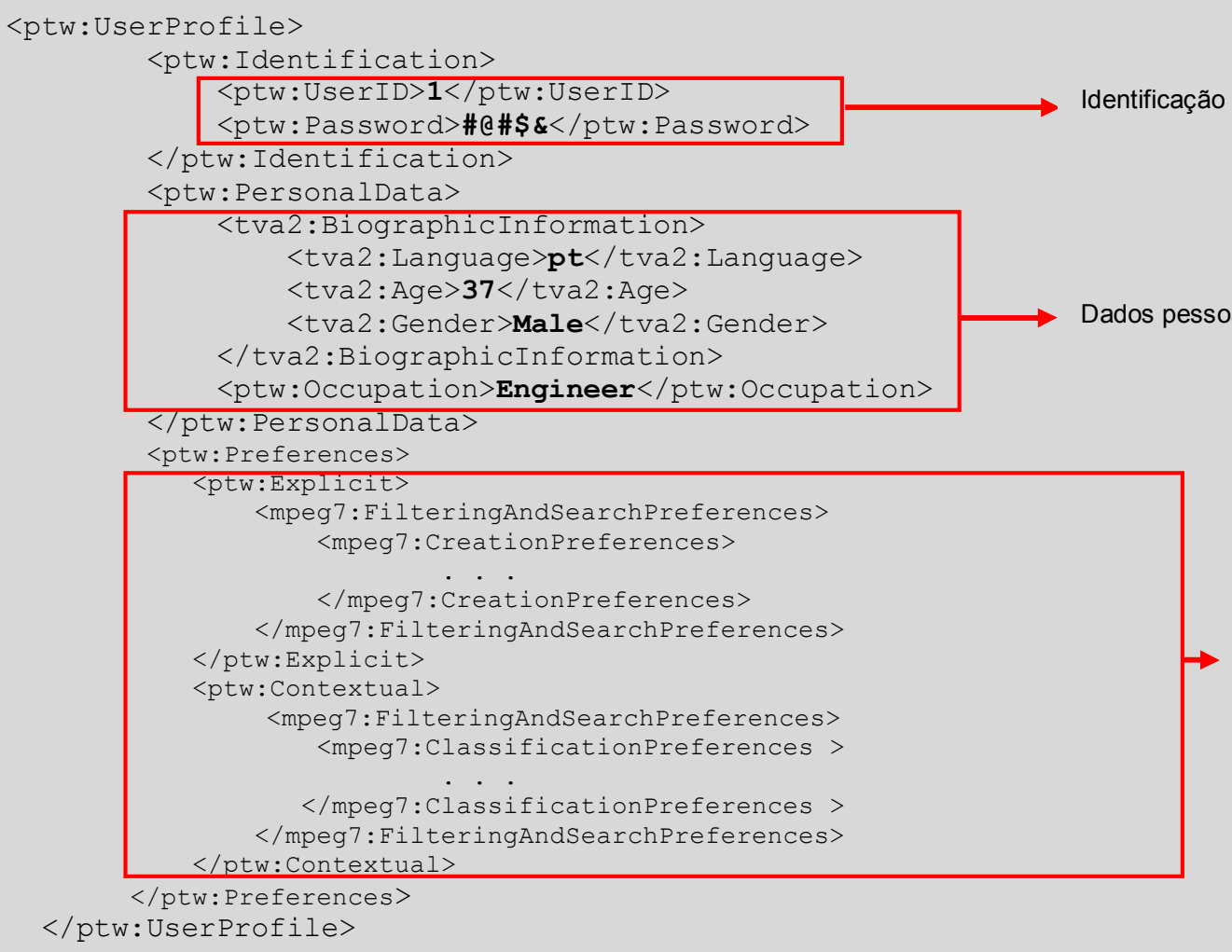

Figura 25 - Exemplo de descrição de um perfil de usuário

\subsubsection{Gerenciador de Contexto do Usuário}

O módulo Gerenciador de Contexto do Usuário gerencia o acesso, aquisição de forma automática, e conversões das informações do contexto do usuário. São obtidas informações tais como identidade, dia da semana, período do dia, localização, tipo de dispositivo de acesso e a identificação de um programa de TV (baseado em CRID). As informações de contexto devem ser obtidas por meio de APls da plataforma de software empregada. Vale ressaltar que não faz parte do escopo deste trabalho propor ou implementar várias tecnologias para aquisição de informação de contexto referente à localização. Assim, neste trabalho para fins de experimentos foi explorado o endereço IP (Internet Protocol). 
O contexto do usuário será capturado em dois casos de uso: no momento da solicitação da recomendação de programas TV ou na execução da realimentação de relevância (descritos na subseção 7.3.1). As informações que constituem o contexto do usuário serão representadas por meio de um documento XML estruturado a partir do elemento raiz <ptw: Context> presente no conjunto de Esquemas XML do PersonalTVware (Apêndice A). Também pode haver contextos de vários usuários persistidos no dispositivo de acesso, de modo que a diferenciação é feita por meio do atributo de identificação do usuário.

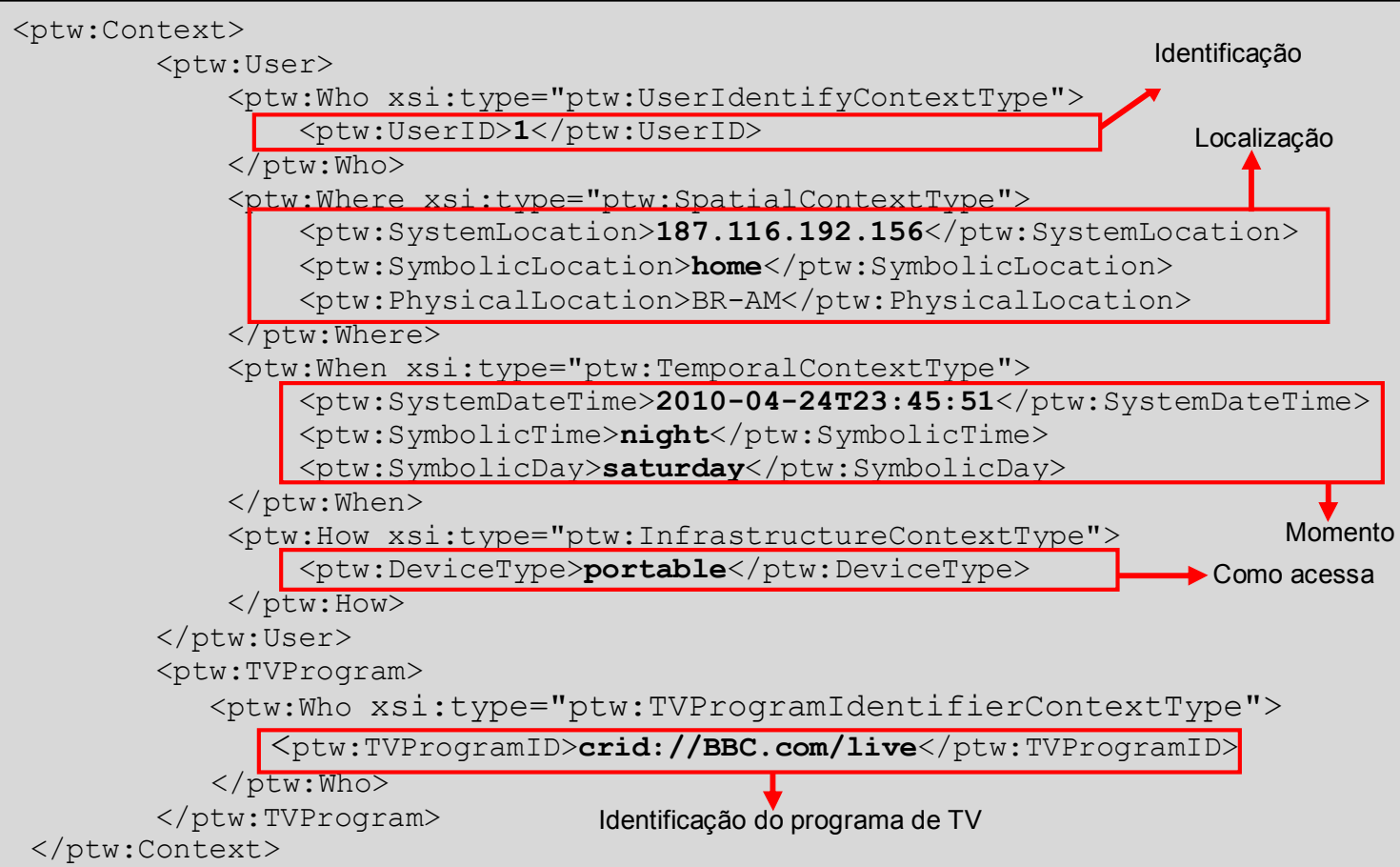

Figura 26 - Exemplo de descrições de um contexto do usuário

\subsubsection{Interpretador de Contexto}

O módulo Interpretador de Contexto proposto é composto por componentes de software que permitem o aprendizado supervisionado dependente do contexto e a predição de preferências contextuais por gêneros de programas de TV a partir do perfil contextual do usuário. Para isso, foi empregada uma abordagem de recomendação sensível ao contexto apresentada na seção 7.6. Deste modo, este módulo emprega uma base de conhecimento com os perfis contextuais dos usuários com informação de gênero instanciada para obter os modelos de conhecimentos. 
No que se refere à predição, no momento da solicitação da recomendação, o PersonalTVware obtém o perfil contextual do usuário corrente sem informação de gênero instanciada sendo aplicado ao método utilizado na tarefa de predição. Daí então, a partir dos modelos de conhecimentos obtidos o interpretador retorna o gênero previsto, ou seja, a preferência contextual inferida. O módulo Interpretador de Contexto implementa diferentes métodos de aprendizagem de máquina como rede bayesiana, árvore de decisão e rede neurais, e também raciocínio baseado em casos (RBC) (HAN; KAMBER, 2006).

\subsubsection{Filtro Sensível ao Contexto}

O módulo Filtro Sensível ao Contexto é responsável pela filtragem dos programas de TV que provavelmente serão relevantes para o usuário de acordo com o seu perfil e contexto. Abordagem de filtragem conforme apresentado na subseção 7.6.4 explora as preferências explícitas e as contextuais inferidas para o usuário pelo módulo Interpretador de Contexto.

Também leva em consideração dados pessoais (idioma), algumas informações de contexto (dia e hora, lugar de origem do programa de TV e do usuário), e os metadados dos programas de TV. A Figura 27 ilustra uma expressão de filtragem construída em XQuery que permite obter uma lista de programas de TV a partir do repositório de metadados.

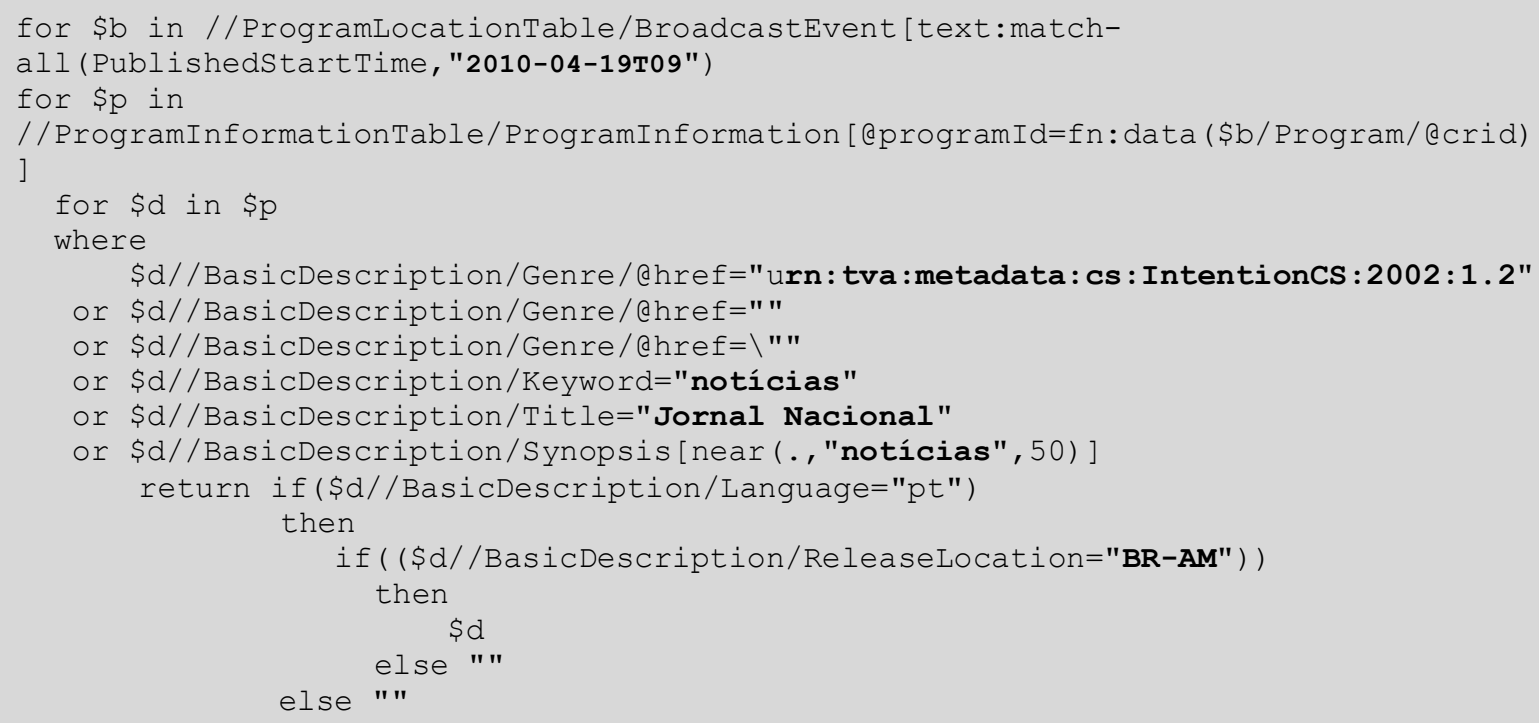

Figura 27 - Fragmento de uma expressão XQuery 


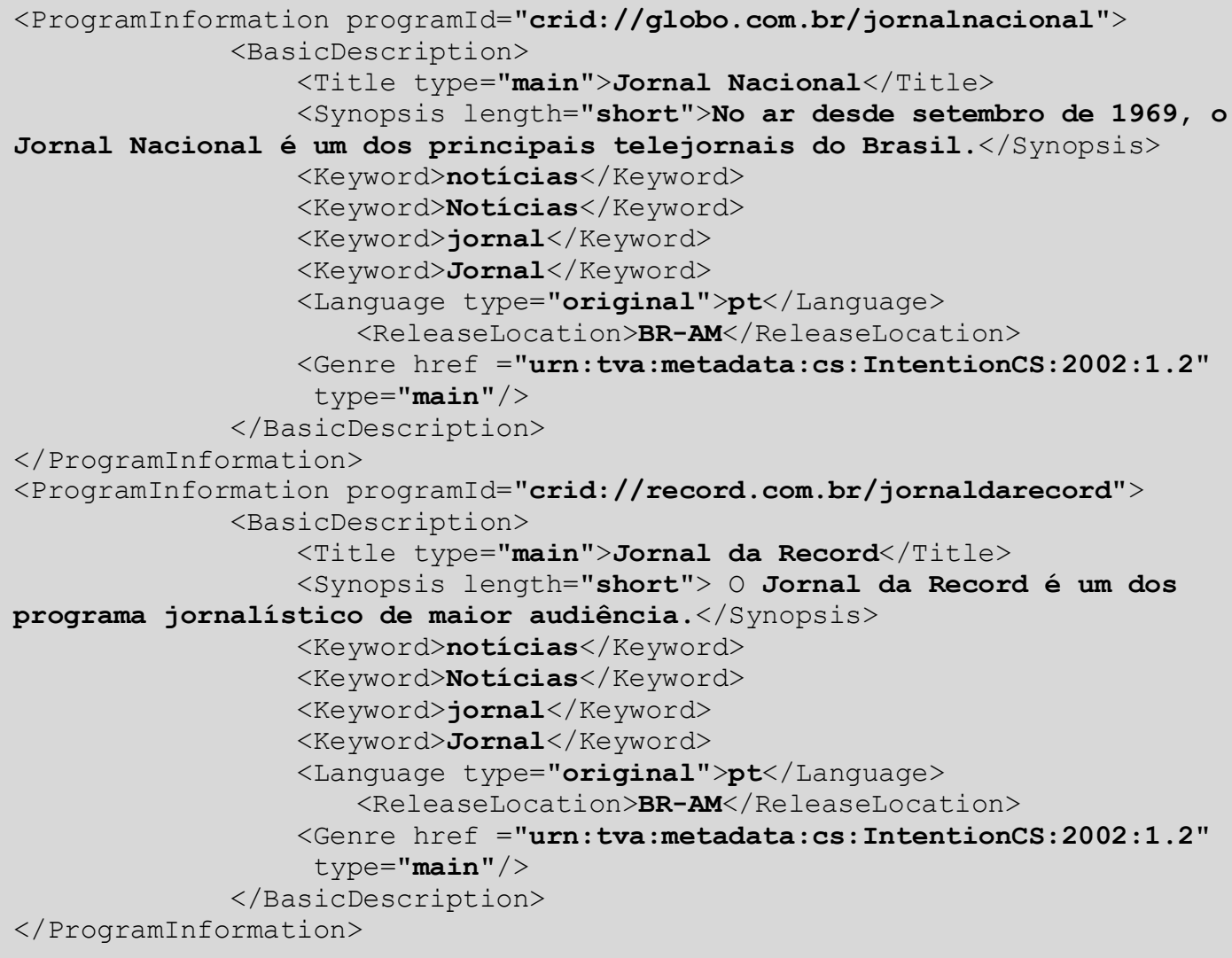

Figura 28 - Fragmento do resultado da filtragem de programas de TV

Após a obtenção da lista de programas de TV que combinam com o perfil e contexto do usuário, o mesmo pode avaliar dentre os programas de TV filtrados aqueles considerados relevantes. Esta ação permitirá ao sistema reter novos perfis contextuais do usuário com informação de gênero instanciada. Por questões de limitação de recursos computacionais dos dispositivos de acesso, ambos os módulos Interpretador de Contexto e Filtro Sensível ao Contexto estão localizados no subsistema provedor de serviços.

\subsubsection{Gerenciador de Programas de TV}

O módulo Gerenciador de Programas de TV gerencia a inserção, o acesso e atualização das informações referentes aos programas de TV. Por meio deste módulo é possível manipular as descrições básicas sobre um programa de TV, informações referentes à programação da publicação do programa de TV, e o provedor de serviço responsável. Conforme apresentado na Figura 28 os metadados 
que descrevem um programa de TV serão representados por meio de documento XML estruturado a partir do elemento raiz <TVAMain> presente no conjunto de Esquemas XML do TV-Anytime (TV-ANYTIME, 2007b).

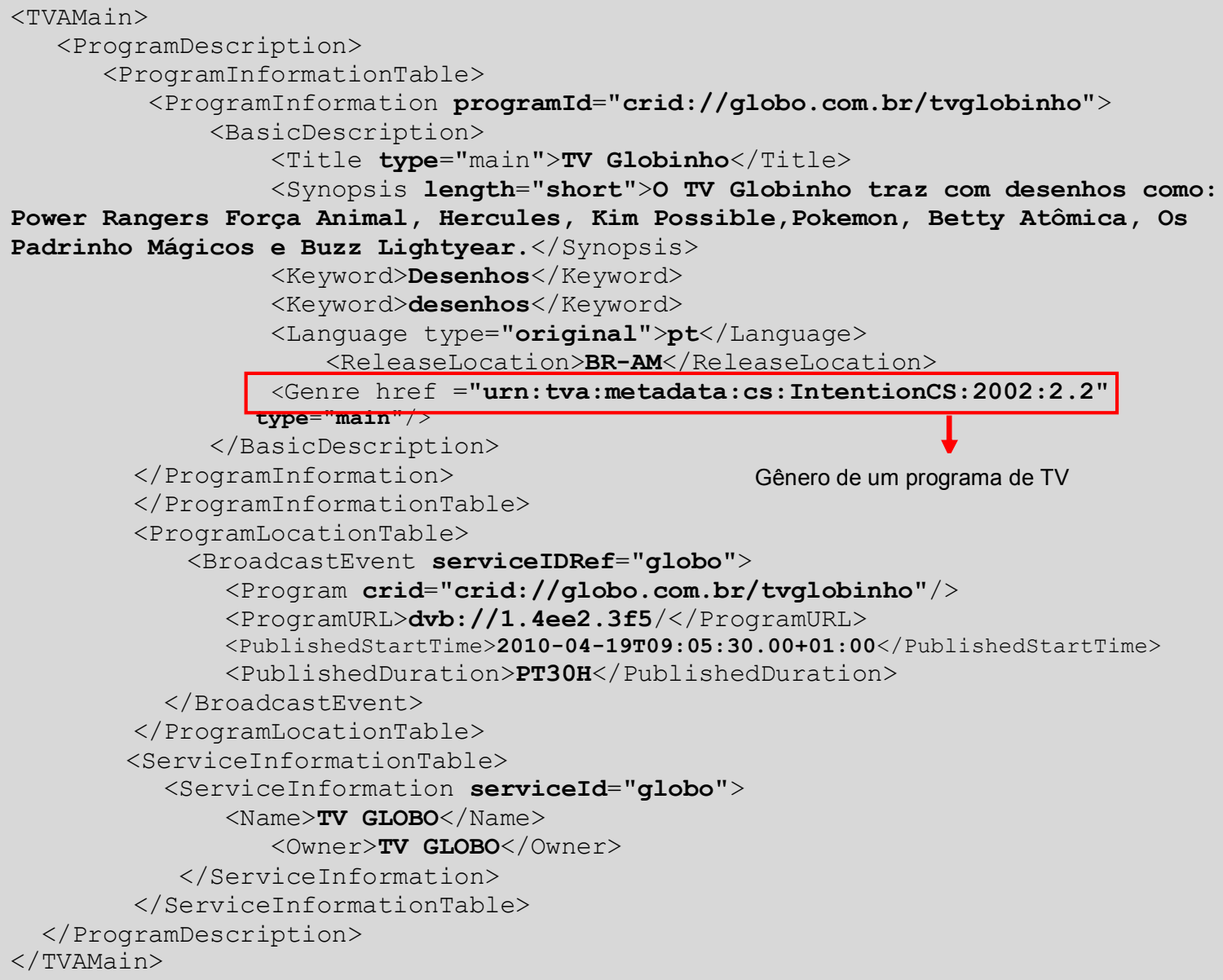

Figura 29 - Exemplo da descrição completa de um programa de TV

\subsubsection{Coletor de Programas de TV}

O módulo Coletor de programas de TV é composto por componentes que oferecem suporte para coleta de metadados referentes aos programas de TV. Deste modo, por meio de tais componentes é possível a atualização do repositório de metadados de programas de TV. Tais metadados podem ser obtidos por meio de uma aplicação Web ou a partir das tabelas SI (Service Information). O coletor baseado em Web permite ao administrador do sistema por meio de uma aplicação a submissão de metadados referentes aos programas de TV. No caso do coletor SI, é o componente responsável por extrair os metadados das tabelas SI provenientes de 
cada emissora de TV, a partir de uma unidade receptora (set-top box) do sinal de TV conectada ao sistema. Além disso, transforma os metadados obtidos para o formato XML do TV-Anytime.

\subsubsection{Gerenciador de Metadados}

Em ambos os subsistemas, o módulo Gerenciador de Metadados fornece suporte ao demais módulos da arquitetura sendo responsável pela recuperação, armazenamento, manipulação e validação de documentos XML que representam os metadados do contexto, perfil do usuário e programas de TV. Pode-se afirmar que este módulo desempenha as funções do elemento funcional Gerenciamento de Armazenamento Local do modelo funcional do TV-Anytime no que se refere à manipulação de metadados armazenados no dispositivo. Desta forma, este módulo atua como um mediador entre os demais módulos e os repositórios de metadados, fornecendo um conjunto de métodos que abstraem a complexidade envolvida no gerenciamento de metadados.

\subsubsection{Interface de Comunicação}

O módulo Interface de Comunicação viabiliza a comunicação entre os subsistemas dispositivo do usuário e provedor de serviços por meio de um cliente de Serviços Web que envia requisições via protocolo SOAP sobre o canal de interatividade. As requisições estão relacionadas às tarefas de filtragem de conteúdo, interpretação do contexto, realimentação da base de conhecimento e consultas sobre programas de TV. Além disso, este módulo é responsável pelo recebimento da lista de programas de TV recomendados para cada usuário. 


\subsubsection{Despachante de Requisição}

O módulo Despachante de Requisição é encarregado de recebe as requisições oriundas do subsistema dispositivo do usuário, e encaminhá-las aos módulos adequados de acordo com o tipo de requisição recebida. Este módulo deve ser implementado como uma interface de Serviço Web.

\subsection{Processo de Recomendação Sensível ao Contexto}

Assumindo que o usuário tenha especificado explicitamente seu perfil inicial e que o sistema também já tenha sido treinado visando gerar os modelos de conhecimento a partir da base de conhecimento. Conforme ilustrado na Figura $30 \mathrm{o}$ processo de recomendação inicia quando o módulo Controlador de Recomendação recebe uma requisição do sistema de recomendação para recuperar uma lista de programas de TV para um determinado usuário identificado pelo seu ID do usuário. A captura da identificação do usuário que utiliza o dispositivo no momento da interação é realizada quando o mesmo efetua o login no sistema de recomendação.

O módulo Gerenciador de Contexto é acionado para capturar e representar as informações contextuais deste usuário (visto na subseção 7.7.3). Em seguida, o módulo Controlador de Recomendação, de posse do ID do usuário consulta os dados pessoais do usuário por meio do módulo Gerenciado de Perfil do Usuário (visto na subseção 7.7.2), e as informações contextuais obtidas por meio do módulo Gerenciador de Contexto. Tais informações são agregadas para criar o perfil contextual do usuário (visto na seção 7.6), sem informação de gênero instanciada. Posteriormente, o módulo Controlador de Recomendação encaminha o perfil contextual do usuário por meio do módulo Interface de Comunicação para o módulo Despachante de Requisição que deverá acionar o módulo Interpretador de Contexto para predizer a preferência contextual (gênero de programa de TV) por meio do método de aprendizagem escolhido.

Após receber preferência contextual inferida pelo módulo Interpretador de

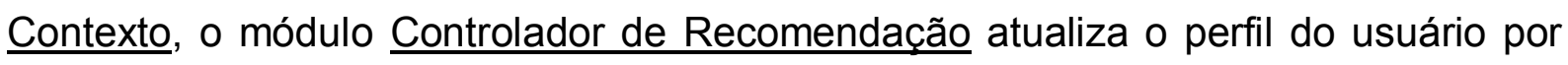


meio do módulo Gerenciador de Perfil do Usuário com a preferência contextual inferida anteriormente. Finalmente, o módulo Controlador de Recomendação obtém as preferências (explícitas e contextuais) e informações contextuais do usuário para enviá-las por meio do módulo Interface de Comunicação para o módulo Despachante de Requisição que deverá acionar ao módulo Filtro Sensível ao Contexto.

Em seguida, este módulo realiza a filtragem de programas de TV por meio de expressões de consultas (visto na subseção 7.7.5) que permitem comparar as informações contextuais e preferências (explícitas e contextuais) com as descrições de programas de TV obtidas por meio do módulo Gerenciador de Programas de TV. O resultado da filtragem será uma lista de programas de TV encaminhada ao módulo Controlador de Recomendação, e posteriormente apresentada pelo sistema de recomendação ao usuário. A partir desta lista o usuário poderá avaliar dentre os programas TV que foram recomendados, aqueles que o mesmo considera relevantes. Desta forma, o sistema será realimentado com novos perfis contextuais com informação de gênero instanciada.

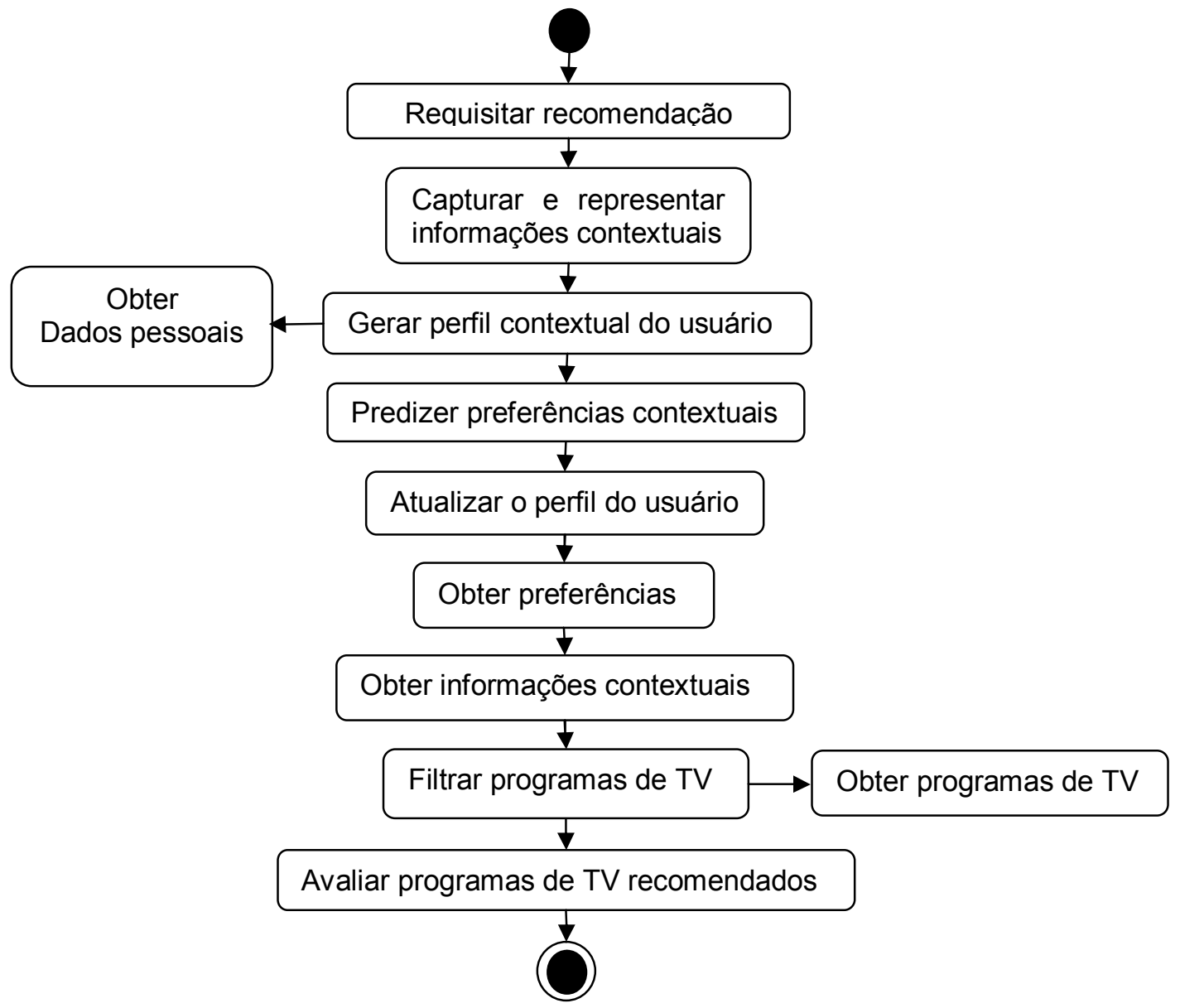

Figura 30 - Diagrama de Atividades do Processo de Recomendação 


\subsection{Projeto e Implementação do Protótipo}

Nesta seção serão descritos o projeto e implementação do protótipo do PersonalTVware por meio de diagramas de classes que representam um modelo lógico das estruturas abstratas dos subsistemas: dispositivo do usuário e do provedor de serviços. Também será representado por meio de diagramas de sequência o funcionamento da infraestrutura através da troca de mensagens e operações realizadas entre os objetos do sistema. Finalmente, serão apresentadas as tecnologias e ferramentas utilizadas para o desenvolvimento do protótipo.

\subsubsection{Pacote e Classes}

As principais classes que modelam o PersonalTVware são apresentadas por meio de diagramas de classes da UML. As classes foram separadas em pacotes que refletem os módulos abordados na arquitetura da infraestrutura.

\section{Subsistema do Dispositivo do Usuário}

As principais classes do subsistema do dispositivo do usuário são apresentadas na Figura 31. 


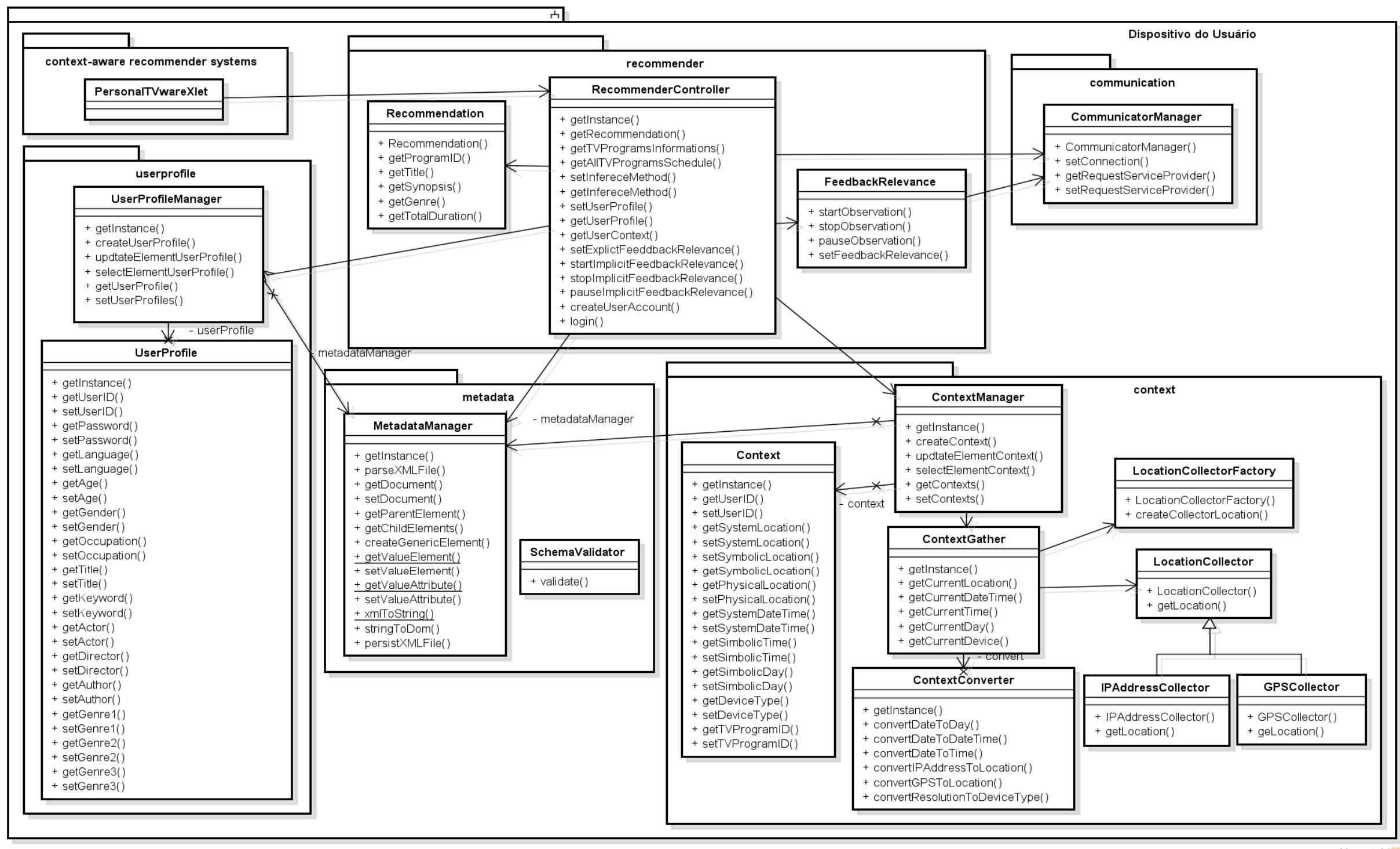

Figura 31 - Diagrama de Classes - Dispositivo do Usuário 
O módulo Gerenciador de Perfil do Usuário é representado pelo pacote userprofile e contém duas classes: UserProfileManager e UserProfile. Estas classes são responsáveis pela manipulação e entrega das informações explícitas de perfis de usuários. A classe UserProfile representa um perfil de usuário, e possui os métodos getters e setters que permitem manipular as tais informações, além disso, é auxiliar à classe UserProfileManager responsável pelas tarefas de criação, seleção e atualização de perfis de usuários.

Já o pacote context se refere ao módulo Gerenciador de Contexto do Usuário e implementa as classes necessárias para manipulação das informações contextuais. Existem sete classes no pacote, a saber: ContextManager, Context, ContextGather, Contextconverter, LocationCollectorFactory, Locationcollector e IPAddresscollector. A classe context representa um contexto do usuário e possui métodos getters e setters que permitem a manipulação das informações contextuais obtidas de forma implícita através dos sensores lógicos da classe ContextGather. Já a classe ContexManager com o auxilio da classe Context é responsável pelas tarefas de criação, seleção e atualização de contextos de usuários.

A classe Contextconverter, funcionalmente é um conversor de informações, que realiza a conversão de informações de fontes de contexto em dados legíveis para a plataforma. A classe LocationSensorfactory é uma fábrica de coletores de localização representados pela classe Locationsensor. Este padrão de projeto viabiliza que sejam implementados diferentes sensores lógicos de localização de acordo com a plataforma de hardware e software do dispositivo de acesso. Para este projeto foi utilizado IP por meio classe IPAddressSensor.

O pacote metadata (referente ao módulo Gerenciador de Metadados) contém duas classes principais, sendo elas: MetadataManager e SchemaValidator. Quaisquer classes que necessitem realizar operações comuns em arquivos XMLs devem utilizar a classe MetadataManager. A classe SchemaValidator realiza a validação de documentos XMLs. A classe CommunicatorManager do pacote communication é um cliente de serviços Web sendo responsável pela comunicação com o subsistema provedor de serviços via 
canal de interatividade. Por meio do método (setRequetsServiceProvider ()) desta classe é possível o envio dos perfis contextuais com informação de gênero instanciada presentes no dispositivo, bem como o recebimento de informações (lista de programas de TV filtrados, gêneros inferidos, dentre outros) oriundas do provedor de serviços.

Finalizando o diagrama referente ao subsistema dispositivo do usuário, há o pacote recommender que corresponde ao módulo Controlador de Recomendação. Existem três classes no pacote recommender, a saber: RecommenderController, Recommendation e FeedbackRelevance. A classe Recommendation é auxiliar à classe RecommenderController, pois representa as informações básicas sobre os programa de TV obtidos dos metadados oriundos da lista de programas de TV recomendados. A classe FeedbackRelevance é responsável por monitorar de forma implícita ou explícita a interação do usuário. Quando um usuário interage com um programa de TV de forma explícita por meio de uma avaliação é registrado o perfil contextual do usuário na base de conhecimento por meio do método (setFeedbackRelevance ()).

Já na forma implícita o controle da totalização do tempo de observação de um programa de TV é realizado intrinsecamente pelos métodos (startobservantion()), (stopobservation()) (pauseobservation()) . Vale ressaltar que a identificação do programa corrente dá-se através do seu CRID (Content Reference IDentifier) que, segundo o TVAnytime, significa um identificador que referencia um conteúdo. Por fim, a classe RecommenderController é incumbida de orquestrar o fluxo das operações do PersonalTVware de acordo com o que for requisitado pelas as aplicações sensíveis ao contexto. Por exemplo, a lista de recomendação de programas de TV pode ser obtida por meio do método (getRecommendation()) que executa o processo de recomendação baseando-se no perfil contextual do usuário sem informação de gênero instanciada, que será obtida pelo método de predição corrente.

\section{Subsistema do Provedor de Serviços}

As principais classes do subsistema provedor de serviço são apresentadas na Figura 32. 


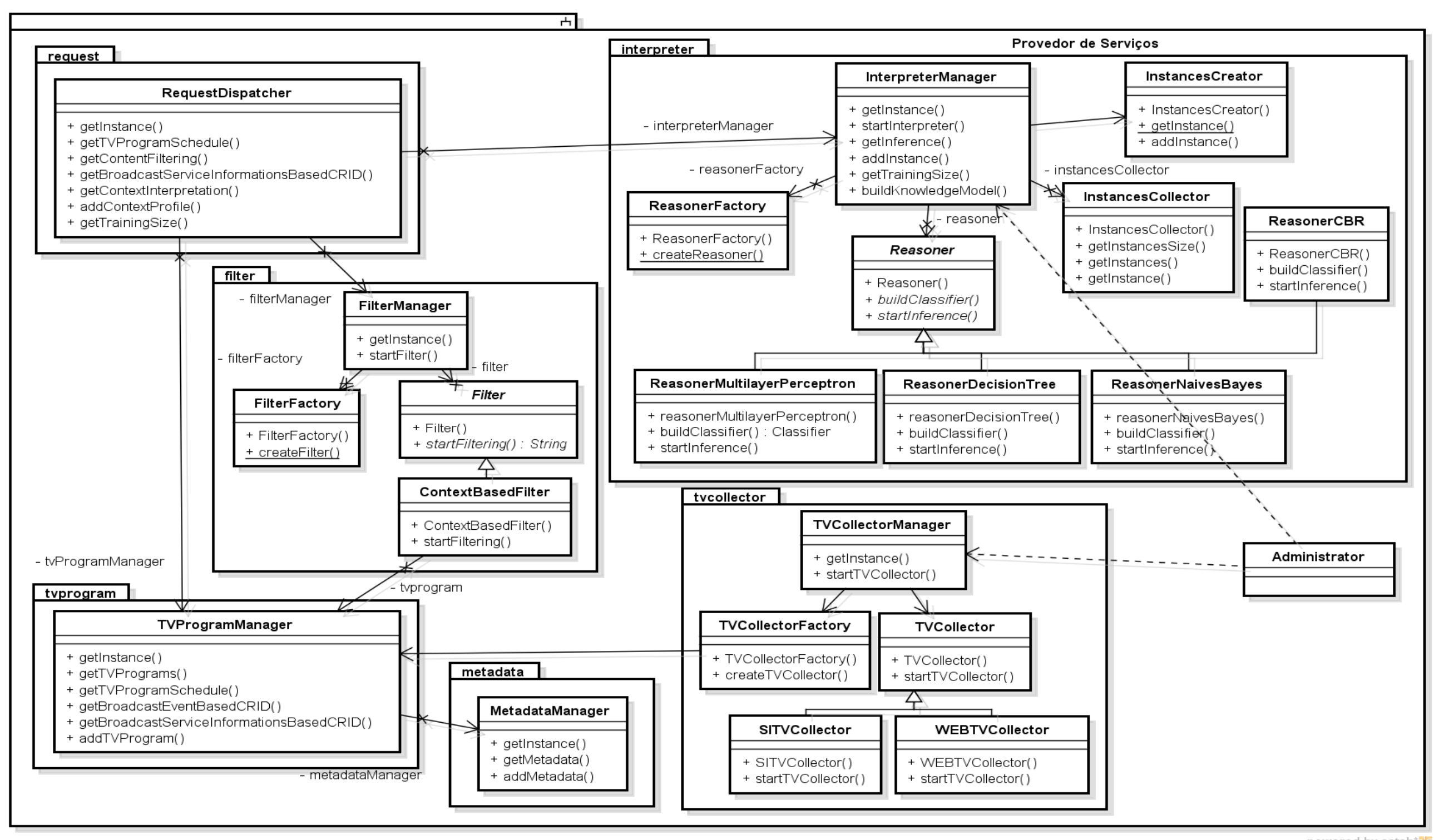

Figura 32 - Diagrama de Classes - Provedor de Serviços 
No diagrama referente ao subsistema provedor de serviço há o pacote interpreter que é composto por um conjunto de classes que juntas formam o serviço de interpretação de contexto (classificação e predição a partir do perfil contextual do usuário). A classe InterpreterManager é responsável pelas tarefas de acionar o processo de aprendizagem (ou classificação) visando criar o modelo de conhecimento para predizer gêneros (ou preferências contextuais) e adicionar instância (perfil contextual do usuário) na base de conhecimento. Tais tarefas são apoiadas pelas classes Instancescreator, Instancescollector, Reasoner e ReasonerFactory.

Pelo diagrama da Figura 32 também é possível observar que a infraestrutura suporta a utilização de quatro métodos de aprendizagem: algoritmo C4.5 (árvore de decisão) - ReasonerDecisionTree; perceptron multicamadas com algoritmo back-propagation (redes neurais) - ReasonerMultilayerPerceptron; classificador bayesiano ingênuo (aprendizagem bayesiana) ReasonerNaiveBayes; ou raciocínio baseado em casos - ReasonerCBR. Cada método de aprendizagem foi representado por meio de uma subclasse da classe Reasoner conforme o padrão de projeto adotado.

O pacote request, refere-se ao módulo Despachante de Requisição. A classe RequestDispatcher representa a interface de Serviço Web para obtenção das requisições submetidas pela classe RecommenderController, e a chamada do método correspondente à operação solicitada. O pacote filter é formado por um conjunto de classes que viabilizam o serviço de filtragem de conteúdo. A classe FilterFactory é uma fábrica de filtros representados pela classe Filter. Este padrão de projeto permite a implementação de filtros baseados em abordagens distintas. Para este projeto foi implementado a filtragem baseada em contexto (subseção 7.7.5) por meio da classe ContextBasedFilter.

O pacote tvprogram é formado pela classe TVProgramManager. Com esta classe é possível realizar operações básicas como adicionar ou obter informações sobre os programas de TV representados por meio de metadados do padrão TV-Anytime. Já o pacote tvcollector é composto por um conjunto de classes que formam o serviço de coleta de metadados de programas de TV. É possível notar que as classes WEBTVCollector e sITVCollector foram especificadas para suportar dois tipos de coletas. 
A classe SITVCollector, apesar de estar representada na arquitetura proposta, não foi implementada devido a falta de transmissão das tabelas SI pelos provedores de serviços da região onde este trabalho foi desenvolvido. Logo, a coleta dos metadados dos programas de TV foi por meio da Web. Por fim, o pacote metadata tem a classe MetadataManager que oferece suporte às demais classes do subsistema para realizar operações comuns em documentos XMLs.

\subsubsection{Funcionamento da Infraestrutura}

Para melhor entendimento sobre o funcionamento do PersonalTVware, esta seção apresenta alguns diagramas de sequência correspondentes às operações com os objetos instanciados a partir das classes descritas na seção anterior. Tais diagramas são acompanhados pela descrição dinâmica de funcionamento, e estão relacionados com os principais casos de uso visto na seção 7.3. No subsistema do dispositivo do usuário é importante ressaltar que o acesso a sua implementação deve ser feita exclusivamente por meio da classe RecommenderController.

\section{Caso de Uso 1: Solicitar Recomendação de Programas de TV}

O sistema de recomendação sensível ao contexto conforme ilustrado no diagrama de sequência da Figura 33 ao solicitar uma recomendação de programas de TV por meio do método getRecommendation(userID) da classe RecommenderController, primeiramente é capturado as informações contextuais relacionadas ao contexto de usuário, ressaltando que userID corresponde a identificação do usuário, e as representa no formato XML.

O método responsável desta operação é o getUserContext (userID) da classe ContextManager, retornando o objeto Context. Logo em seguida o perfil do usuário também é obtido por meio do método getUserProfile (userID) da classe UserProfileManager que retorna o objeto UserProfile. De posse dos objetos referentes ao contexto e perfil do usuário, a execução do método buildcontextProfile(context, userProfile) da classe 
RecommenderController vem logo a seguir com a finalidade de gerar o perfil contextual do usuário com informação de gênero não instanciada, ou seja sem o rótulo $y$ de classe.

O próximo passo consiste em informar o método de predição a ser empregado no processo de descoberta de preferência contextual, dado que atualmente existem quatros: algoritmo C4.5 (árvore de decisão); perceptron multicamadas (redes reurais); classificador bayesiano ingênuo (aprendizagem bayesiana); raciocínio baseado em casos (RBC). O método para esta operação corresponde ao setInferenceMethod(method) da classe Recommendercontroller. Em seguida, é acionado o método getInferedPreference (contextualProfile) também da classe RecommenderController encarregado de obter a preferência contextual inferida por meio do perfil contextual do usuário. A partir deste momento se estabelece a conexão entre módulos dos subsistemas dispositivo do usuário e provedor de serviços por meio do método setConnection (url).

Os

métodos

setRequestMethod (method)

e getRequestServiceProvider (contextualProfile, inferenceMethod) da classe CommunicatorManager viabilizam o envio por meio de um cliente de Serviço Web via canal de interatividade, três argumentos, a saber: a indicação de qual método deverá ser acionado pela classe RequestDispatcher, neste caso "getContextInterpretation ( )"; o perfil contextual do usuário; e o método de predição que será empregado para obter as preferências contextuais.

Deste modo, o método startinterpreter(method) da classe Interpreter Manager inicia a tarefa de predição retornando a(s) preferência(s) inferida(s) pelo método getInference(contexualProfile). A partir deste momento é necessário atualizar o perfil do usuário com a(s) preferência(s) inferida(s) na etapa anterior. Assim, é acionado o método updateUserProfile(userID, inferedPreference) da classe RecommenderController, sendo encarregado de executar esta operação por meio do método updateElementUserProfile(userID, inferedPreference) da classe UserProfileManager. 


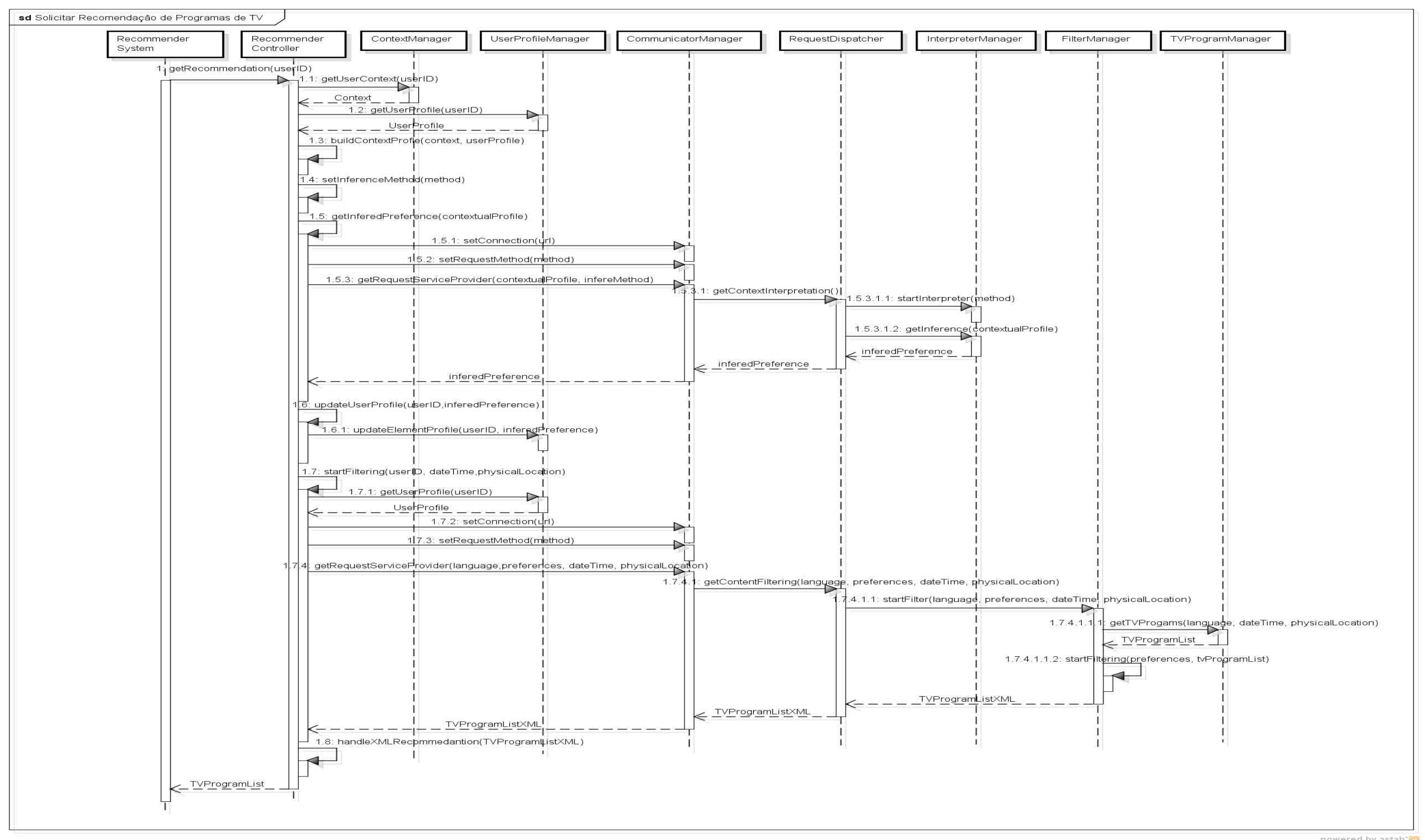

Figura 33 - Caso de uso: Solicitar Recomendação de Programas de TV 
A Figura 34 apresenta um exemplo de perfil do usuário completo atualizado com algumas preferências contextuais inferidas.

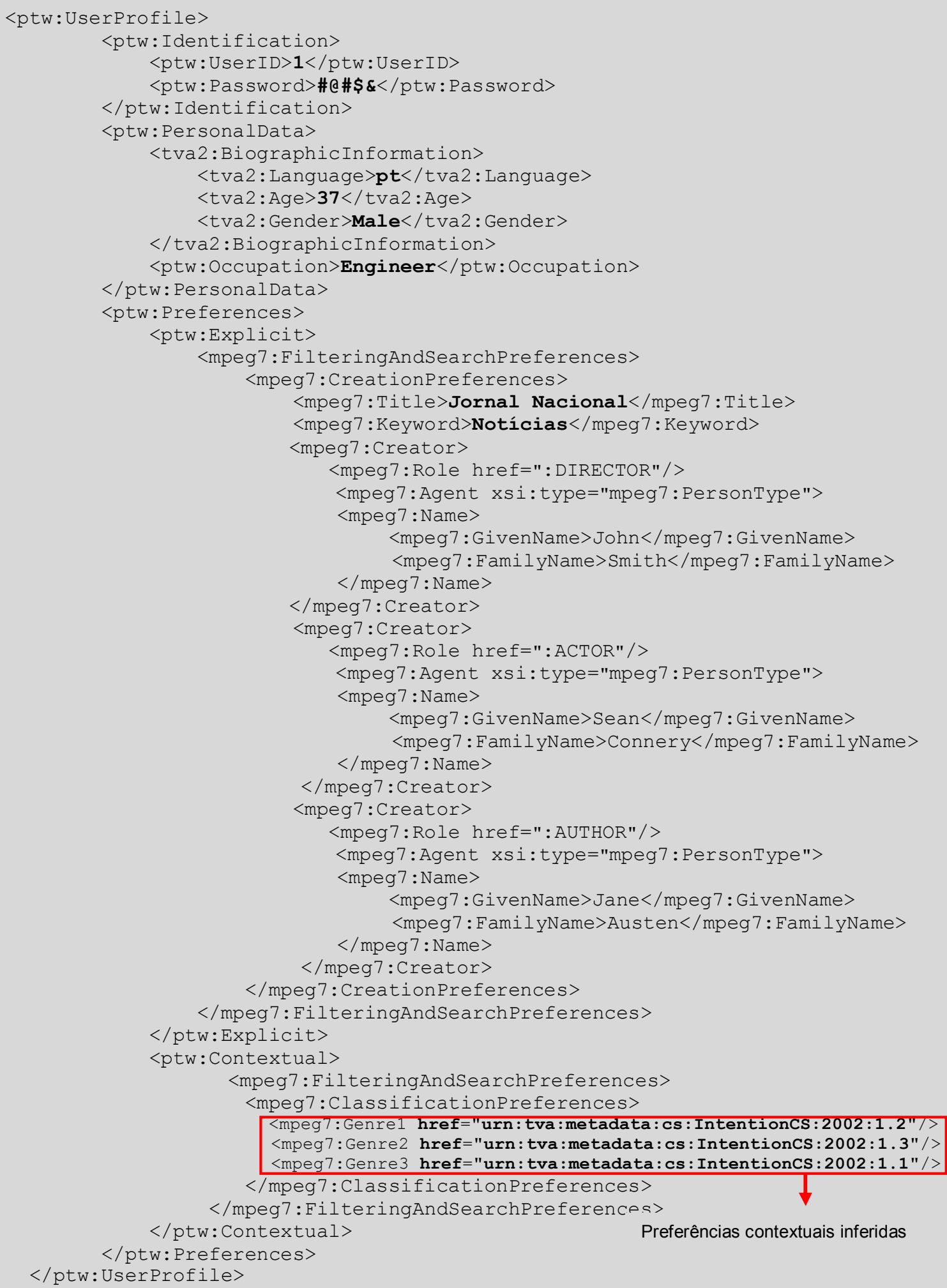

Preferências contextuais inferidas

Figura 34 - Exemplo de perfil de usuário com preferências inferidas 
A próxima etapa consiste em realizar a filtragem de programas de TV. Assim, é acionado o método startFiltering(userID, dateTime, physicallocation) da classe RecommenderController, que inicia o processo de filtragem. Primeiramente, são obtidas algumas informações do perfil do usuário tais como idioma e preferências (explícitas, contextuais).

A partir deste momento se estabelece uma conexão entre módulos dos subsistemas dispositivo do usuário e provedor de serviços por meio dos métodos setConnection ( $u r l$ ), setRequestMethod (method) getRequestServiceProvider(language, preferences, dateTime, physicallocation) da classe CommunicatorManager. Tais métodos viabilizam o envio por meio de um cliente de Serviço Web via canal de interatividade, a indicação de qual método deverá ser acionado pela classe RequestDispatcher, neste caso "getcontentFiltering()", as preferências do usuário, idioma, e as informações contextuais (dia e horário corrente, localização física) .

Deste modo, o método startFilter(language, preferences, dataTime,physicallocation) inicia filtragem de programas de TV. Primeiramente obtém por meio do método getTVProgramas(language, dateTime, physicallocation) da classe TVProgramManager uma lista de todos os programas de TV que estão sendo ou que serão exibidos no dia e hora corrente em um determinada região, e também no idioma do usuário.

Posteriormente, executa a filtragem por meio do método startFiltering (preferences, tvProgramiist) que retorna uma lista de programas de TV que combinam com as preferências do usuário. A Figura 35 apresenta através de um exemplo um fragmento de uma lista obtida com dois programas de TV sendo representados em XML. 


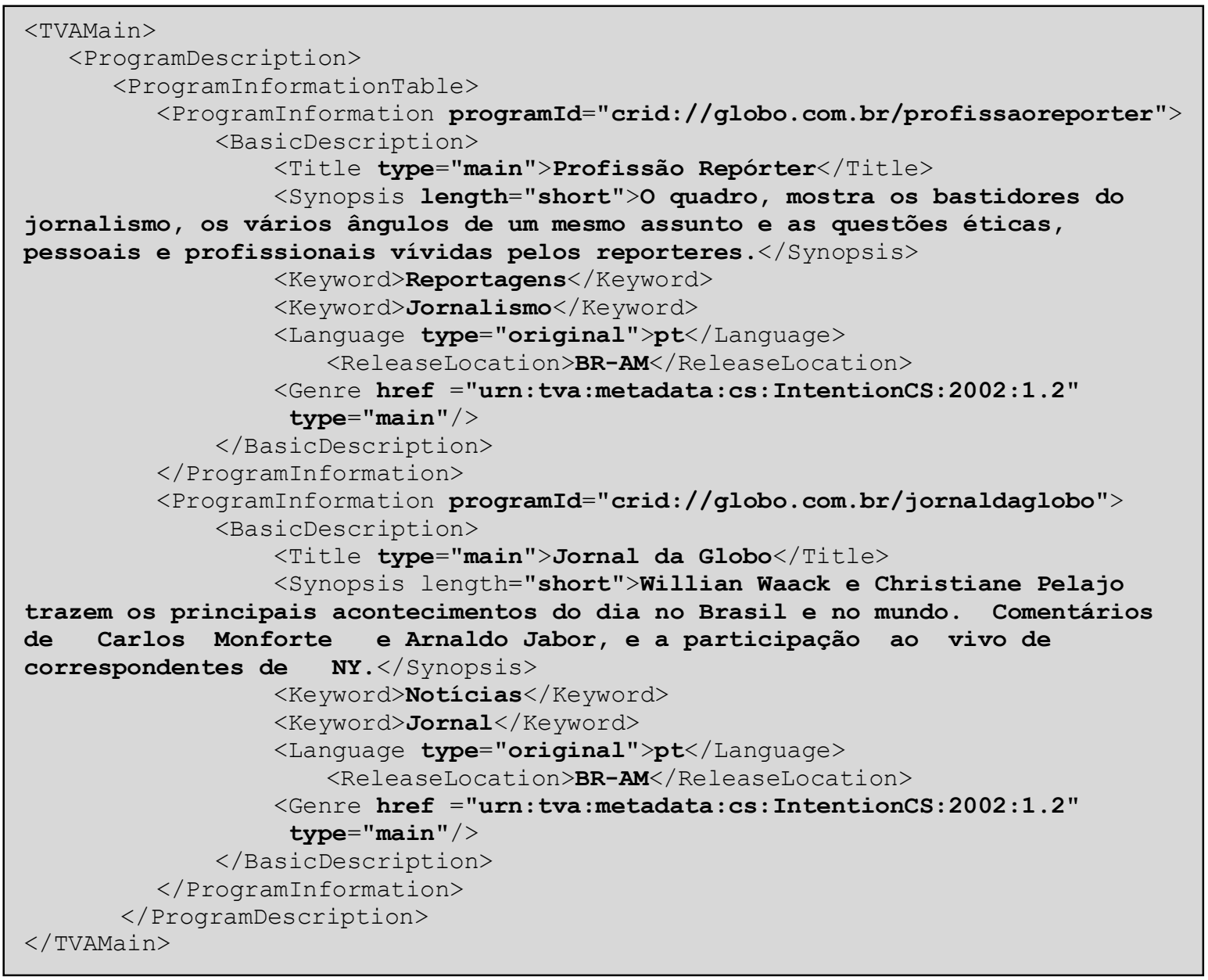

Figura 35- Exemplo de uma lista de programas de TV filtrados

Por fim, é empregado o método privado handleXMLRecommendation (TVProgramListXML) para fazer um parser na lista de programas de TV e extrair as informações dos programas de TV recomendados.

\section{Caso de Uso 2: Executar Realimentação de Relevância}

A realimentação de relevância permite ao PersonalTVware obter de forma explícita ou implícita o perfil contextual do usuário com informação de gênero instanciada, sendo posteriormente armazenado na base de conhecimento. Na forma explícita, conforme ilustrado no diagrama de sequência da Figura 36 após receber uma lista de programas de TV como resultado da solicitação de recomendação, o usuário decide avaliar dentre os programas de TV recomendados aquele(s) que considera relevante(s). 
Esta avaliação é informada pelo método setExplicitFeedbackRelevance (userID, CRID) da classe RecommenderController, de forma que o argumento CRID indica a identificação do programa de TV, posteriormente empregado pelo método getGenre (CRID) da classe auxiliar Recommendation para obter a informação de gênero do programa de TV avaliado como relevante.

Em seguida são capturadas as informações relacionadas ao contexto e o perfil do usuário (ressaltando que userID corresponde a identificação do usuário) sendo representadas no formato XML. Os métodos responsáveis desta operação são getUserContext(userID) da classe Contextmanager e getUserProfile(userID) da classe UserProfileManager, retornando os objetos Context e UserProfile.

De posse dos objetos referentes ao contexto e perfil do usuário, a execução do método buildContextProfile(context, userProfile, genre) vem logo a seguir com a finalidade de gerar o perfil contextual do usuário agora com informação de gênero instanciada obtida anteriormente pelo método getGenre (CRID) da classe auxiliar Recommendation .

O próximo passo consiste em registrar o perfil contextual do usuário na base de conhecimento através da execução do método setFeedbackRelevance (contextProfile) da classe FeedbackRelevance. A partir deste momento se estabelece uma conexão entre módulos dos subsistemas dispositivo do usuário e provedor de serviços por meio dos métodos setConnection ( $u r l$ ), setRequestMethod (method) getRequestServiceProvider(preferences, dateTime) da classe CommunicatorManager.

Tais métodos viabilizam o envio por meio de um cliente de Serviço Web via canal de interatividade, a indicação de qual método deverá ser despachado pela classe RequestDispatcher, neste caso "addContextProfile()". Ao final do processo, o perfil contextual do usuário é adicionado a base de conhecimento por meio do método addInstance (instance) da classe InterpreterManager. 


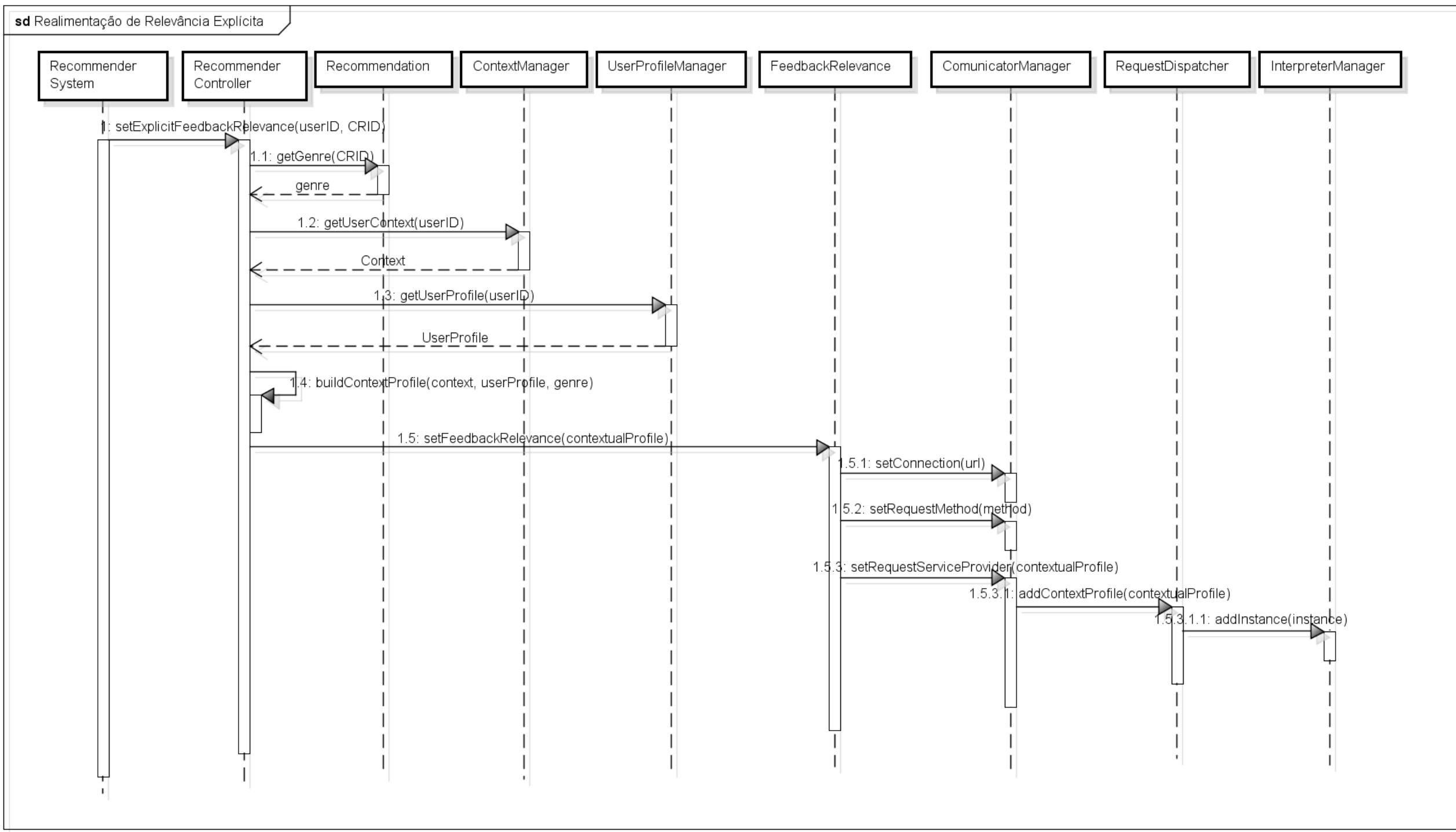


Na forma implícita, conforme ilustrado no diagrama de sequência da Figura 35 no momento em que o usuário inicia a observação de um programa de TV via sistema de recomendação, o PersonalTVware é notificado por meio do método startImplicitFeedbackRelevance(userID, CRID), de forma que o argumento CRID indica a identificação do programa de TV. Logo em seguida por meio do método startobservation(CRID) da classe FeedbackRelevance inicia a contabilização do tempo de observação deste programa de TV por meio da captura da hora inicial.

Ao final da observação deste programa de TV pelo usuário, o PersonalTVware é notificado por meio do método stopImplicitFeedbackRelevance(CRID) que aciona 0 método stopobservation(CRID) da classe FeedbackRelevance para iniciar o processo de obtenção de uma percentagem de tempo que determinará se o perfil contextual do usuário deverá ser gerado. Assim, a partir deste momento o método getFinaltime() obtém a hora final de observação e o método getWatchingTime () retorna o tempo total de observação do programa de TV.

Em seguida, através do método getTotalDurantion(CRID) da classe auxiliar Recommendation é obtida a duração total do programa de TV, que é passada como argumento, além do tempo total de observação do programa de TV para 0 método getRatioobservationTime(watchingTime, TVProgramDuration) da classe FeedbackRelevance.

Este método retorna a razão entre os dois tempos obtidos baseado na equação do algoritmo (descrito na subseção 7.7.1). Desta forma, se o valor da razão obtida for superior ao limiar ( $50 \%$ foi empregado nos experimentos) então será gerado e registrado um novo perfil contextual do usuário com informação de gênero instanciada conforme descrito anteriormente na abordagem de realimentação de relevância explícita. 


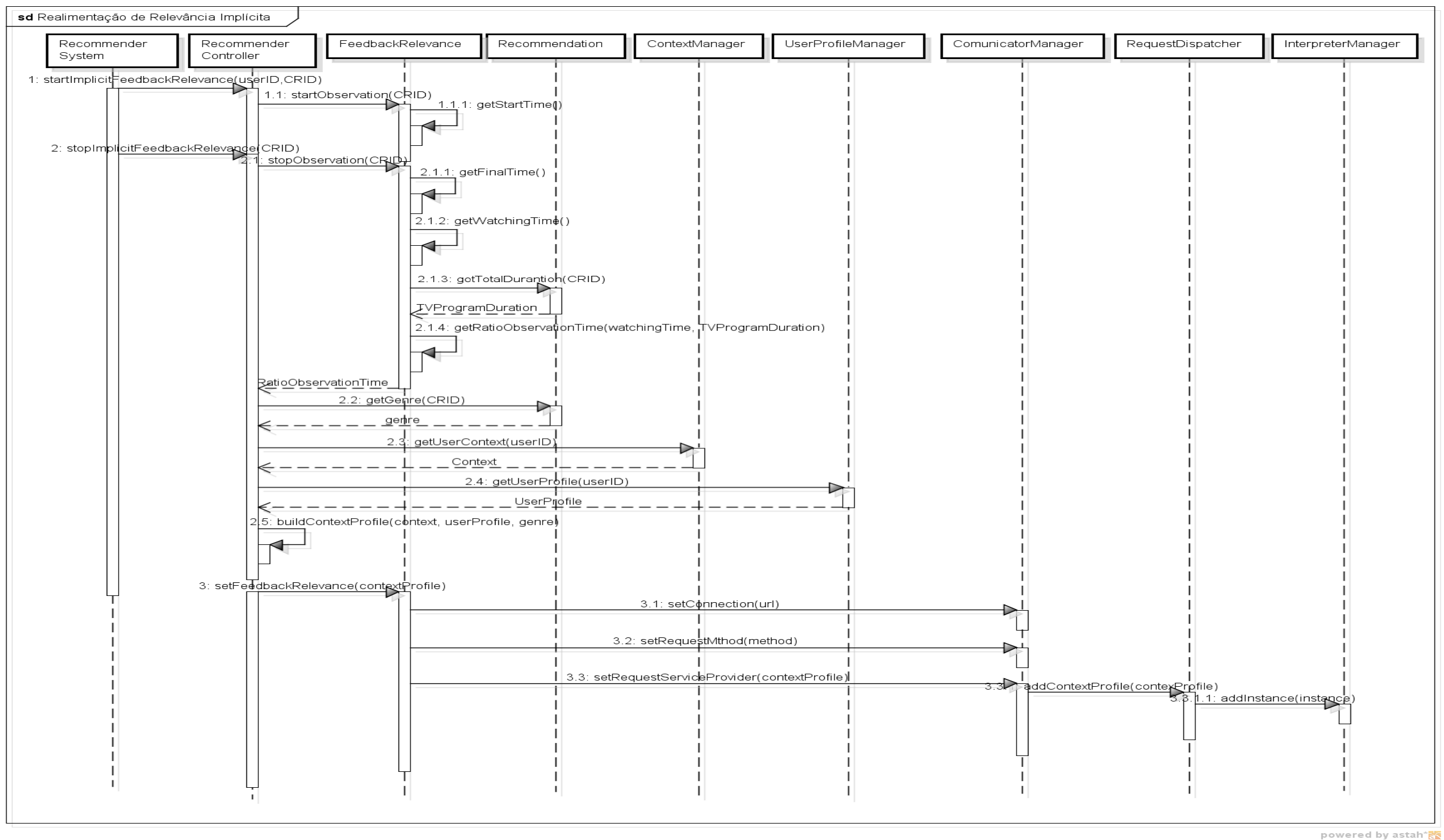

Figura 37 - Caso de uso: Executar Realimentação de Relevância de forma implícita 


\section{Caso de Uso 3: Gerar Modelo de Conhecimento}

O modelo de conhecimento é obtido por meio da aprendizagem supervisionada dependente do contexto conforme descrita na seção 7.6. Cada método de aprendizagem de máquina é baseado em um modelo de conhecimento diferente (WITTEN; FRANCK, 2005). Tal modelo é gerado a partir uma base de conhecimento composta por instancias de perfis contextuais de usuários com informação de gênero instanciada.

Assim, torna-se necessária a execução da realimentação de relevância descrita nos casos de usos anteriores visando criar a base de conhecimento. Conforme ilustrado no diagrama de sequência da Figura 38 a geração do modelo de conhecimento pode ser iniciada a partir do administrador do sistema no subsistema provedor de serviços por meio do acionamento do método buildKnowledgeModel (method) da classe InterpreterManager. Tal método recebe com argumento de entrada a indicação de qual método de aprendizagem de máquina deverá ser empregado para geração do modelo de conhecimento.

Posteriormente, o método de aprendizagem de máquina selecionado deve ser instanciado, o método que realiza esta operação é o createReasoner (method) da classe Reasonerfactory. Conforme já foi dito, o PersonalTVware fornece atualmente suporte a quatro métodos de aprendizagem de máquina: algoritmo C4.5 (árvore de decisão); classificador bayesiano ingênuo (aprendizagem bayesiana); perceptron multicamadas (redes neurais); e raciocínio baseado em casos (RBC).

O próximo passo consiste em carregar em memória todas as instâncias de perfis contextuais de usuários obtidos por meio do método getIntances(instances) da classe Instancescollector. Em seguida, o modelo de conhecimento é, em fim, gerado pelo método buildClassifier(instances) do objeto corrente instanciado da classe Reasoner. 


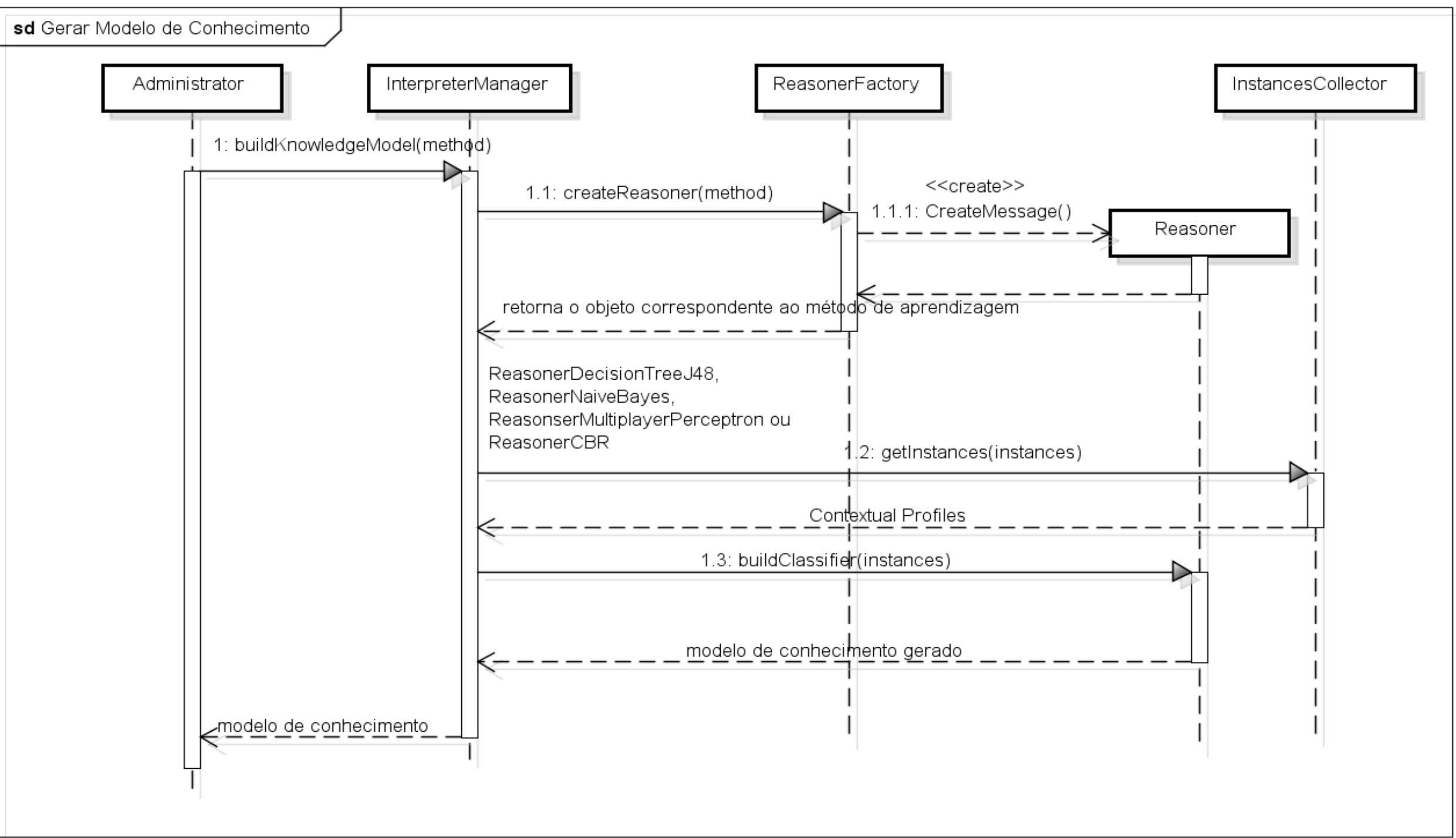

Figura 38 - Caso de uso: Gerar Modelos de Conhecimento 


\subsubsection{Tecnologias e Ferramentas adotadas}

Um dos requisitos não funcionais (visto na seção 7.2) deste trabalho, é que o PersonalTVware seja independente de plataforma de software. Deste modo, a sua implementação foi feita em Java, o que torna necessária a utilização de uma máquina virtual Java para sua execução, sendo normalmente encontrada em middlewares para TV Digital Interativa. No que se refere à utilização de padrões para comunicação e integração de componentes e serviços adotou-se a tecnologia de Serviços Web por meio da implementação: Apache Axis v. 1.4 (APACHE, 2006). Para a interpretação e validação de documentos XMLs foi empregado um analisador (parser) que utiliza a interface DOM (Document Object Model).

Este analisador utiliza estruturas baseadas em árvores na memória com os dados do documento XML, permitindo, assim a sua manipulação. Entretanto, devido ao problema de limitações de memória e processamento nos dispositivos de acesso torna-se importante a investigação de outras abordagens em futuras implementações pois o DOM tem a característica de consumir muita memória e processamento. Uma alternativa ao DOM pode ser o SAX, (Simple API for XML), sua principal vantagem é o menor gasto de memória, contudo impossibilita validação, saltos e leituras em trechos anteriores do documento XML.

Neste trabalho, a implementação dos métodos de aprendizagem de máquina (árvore de decisão, classificador bayesiano ingênuo, e redes neurais) foi realizada por meio das APIs da ferramenta Weka (WAIKATO, 2010) que contempla uma série de métodos de aprendizagem de máquina implementados. A Weka utiliza um arquivo no formato ARFF (Attribute-Relation File Format) que contém um conjunto de registros que são utilizados na tarefa de predição, no caso deste trabalho o conjunto destes registros corresponde à base de conhecimento de perfis contextuais de usuários com informação de gênero instanciada. O Apêndice $B$ apresenta $O$ cabeçalho do arquivo ARFF criado para este trabalho.

Já para implementação do método de aprendizagem de máquina Raciocínio Baseado em Casos (RBC) foram utilizadas as APIs o framework Lucene (LUCENE, 2009). Tais APIs implementam técnicas tradicionais da área de recuperação de informação (RI), como o cálculo da métrica da similaridade que tem como base o modelo matemático vetorial. 
No modelo vetorial a similaridade é obtida por meio do cálculo do cosseno do ângulo entre vetores (ADOMAVICIUS; TUZHILIN, 2005) (visto na subseção 5.4.4). Com isso, considerando os perfis contextuais de usuários como casos sendo representados por vetores, a similaridade entre casos pode ser calculada por meio da utilização das APIs do Lucene. A principal vantagem foi à transferência do custo de implementação do cálculo da similaridade do modelo vetorial para o framework empregado.

Por fim, para manipulação de metadados dos programas de TV no lado servidor e a realização da filtragem de programas de TV foi empregada a linguagem XQuery (W3C, 2007) por meio do XML Database Exist (EXIST, 2009). A linguagem XQuery (vista na seção 3.4) foi escolhida, porque oferece recursos avançados que permitem a especificação de expressões complexas para realização de pesquisa e filtragem sob documentos XML, sendo uso também recomendada pelo TV-Anytime Fórum.

\subsection{Integração do PersonalTVware com os Sistemas de Recomendação}

O acesso aos principais serviços do PersonalTVware é feito por meio da PersonalTVware API, sendo visível aos sistemas de recomendação executados na camada de aplicação de middlewares. Desta forma, os sistemas de recomendação simplesmente solicitam os serviços por meio de chamadas aos principais métodos das classes do pacote recommender (visto na seção 7.9) da PersonalTVware API.

O sistema de recomendação pode ser baseado em Xlet (aplicação interativa) e implementado por meio da linguagem Java. Neste caso, os serviços da PersonalTVware API podem ser acessados de forma direta. No contexto do Sistema Brasileiro de TV Digital, o seu middleware Ginga, oferece suporte para desenvolvimento de dois tipos de aplicações: as aplicações declarativas baseadas na linguagem NCL e as procedurais implementadas na linguagem Java. 


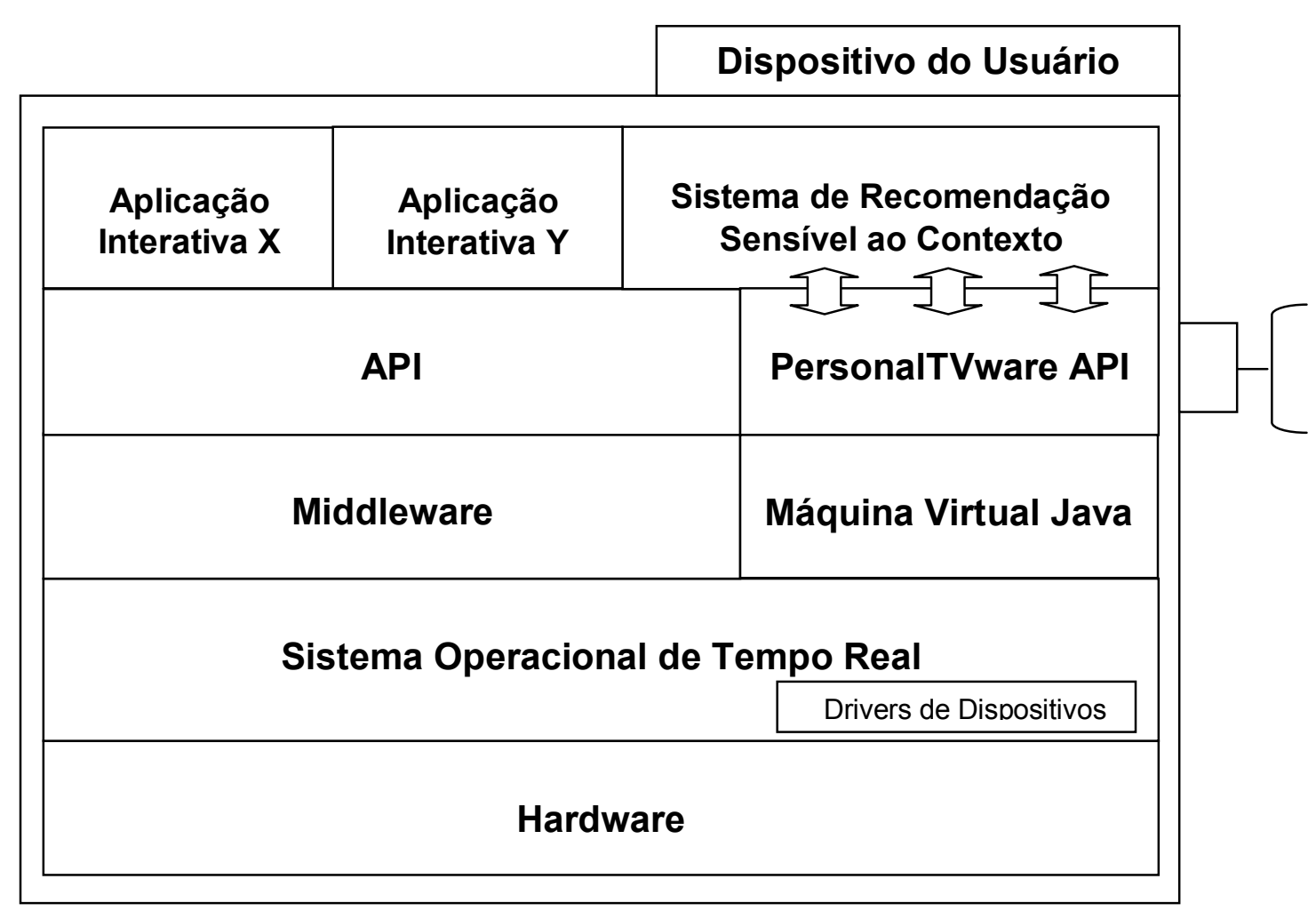

Figura 39- Integração entre sistema de recomendação e PersonalTVware API

No caso de sistemas de recomendação escritos em NCL e Lua é possível a integração por meio de scripts implementados através de ferramentas como LuaJava (LUAJAVA, 2004) a comunicação com PersonalTVware API e estes, por sua vez solicitarem seus serviços.

\subsection{Considerações Finais}

Este capítulo apresentou uma infraestrutura modular de software para suporte ao desenvolvimento e execução de sistemas de recomendação sensíveis ao contexto para TV Digital Interativa. A solução proposta apresenta características particulares, que a diferencia das soluções similares, dentre elas:

- O fornecimento de uma infraestrutura constituída de componentes que abstraem a complexidade das técnicas de recomendação e processamento de contexto para ser empregado por desenvolvedores de sistemas de recomendação sensíveis ao contexto para TV Digital Interativa; 
- Infraestrutura proposta independente de sistema operacional utilizado, característica esta que facilita a adaptação ou porte da solução proposta para outra plataforma desejada, por exemplo, IPTV;

- A arquitetura modular da infraestrutura e os padrões de projetos adotados viabilizam de forma flexível a incorporação de novos componentes que adotem outros métodos de aprendizagem de máquina ou técnicas de filtragem de conteúdo para suporte a recomendação personalizada. 


\section{Estudo de Caso}

Este capítulo descreve os experimentos conduzidos para validar as funcionalidades do PersonalTVware e avaliar a qualidade da recomendações obtidas por meio de uma aplicação protótipo. Assim, foi desenvolvido um estudo de caso baseado em ambiente de TV Digital Interativa. O estudo de caso consistiu no desenvolvimento de um protótipo de sistema de recomendação sensível ao contexto. Conforme ilustrado na seção 7.10, o protótipo utiliza a PersonalTVware API para ter acesso aos principais serviços da infraestrutura proposta.

Este sistema de recomendação poderá ser utilizado como alternativa ao tradicional Guia Eletrônico de Programação (EPG). O EPG tradicional é limitado a apresentar longas listas de programas de TV, as preferências dos usuários, e recursos de personalização raramente são consideradas. Consequentemente, os usuários acabam desperdiçando demasiado tempo procurando por informações sobre seus programas de TV de interesse, e muitas vezes não conseguem encontrálas em tempo hábil. Desta forma, o EPG, torna-se pouco atraente para os usuários (ÁVILA; ZORZO, 2009).

\subsection{Aplicação Protótipo}

Para validar o PersonalTVware foi desenvolvido um protótipo do sistema de recomendação sensível ao contexto para TV Digital Interativa. Por meio deste sistema de recomendação o usuário pode solicitar recomendações de programas de TV que sejam adequadas ao seu perfil e contexto. Desta forma, foram implementados os principais casos de uso descritos na seção 7.3. O sistema de recomendação oferece funcionalidades que permitem ao usuário definir configurações de funcionamento (definir o endereço IP (Internet Protocol) do provedor de serviços, selecionar o método de aprendizagem de máquina, indicar localização simbólica), cadastrar seu perfil, solicitar lista de recomendação, realizar 
realimentação de relevância, acessar informações detalhadas sobre os programas de TV e também sobre seu contexto corrente.

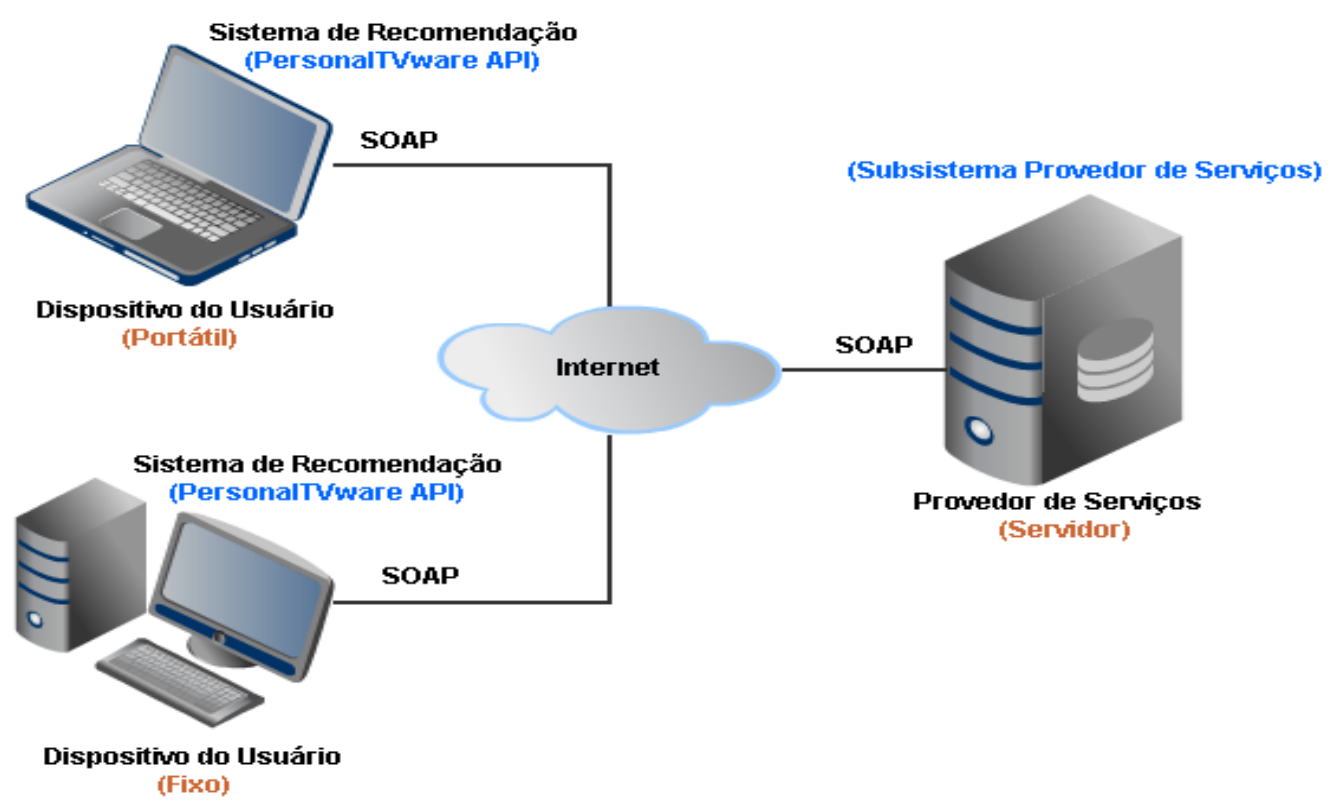

Figura 40 - Ambiente de Experimentos

Conforme ilustrado na Figura 40 a PersonalTVware API e o sistema de recomendação foram instalados em dispositivos tais como notebooks e desktops, que simularam receptores de TV Digital (portátil e fixo) do lado usuário. O sistema de recomendação foi desenvolvido em linguagem Java, sendo baseado em $\mathrm{Xlet}^{3}$, e executado por meio de emulação de ambiente de TV Digital. Para simulação do provedor de serviços, e instalação do subsistema provedor de serviços foi utilizado um servidor (plataforma: Intel Core 2 Duo CPU 6400, 2.13GHz, 4 GB de RAM, Windows XP, máquina virtual Java - Java SE 6 -1 1.6.0_05) com conexão permanente a Internet. O objetivo foi configurar uma infraestrutura de comunicação que simulasse o ambiente de TV Digital Interativa.

Por meio da Figura 41 é possível observar a tela de recomendação de programas de TV do Xlet que apresenta a lista personalizada de programas de TV e informações sobre o contexto corrente do usuário. Por meio desta tela o usuário pode avaliar dentre os programas de TV recomendados aqueles que o mesmo considera realmente relevantes. Também pode acessar informações detalhadas sobre os programas de TV por meio da tela ilustrada na Figura 42.

\footnotetext{
${ }^{3}$ Xlet: é o termo empregado para aplicação de TV Digital desenvolvida em Java.
} 


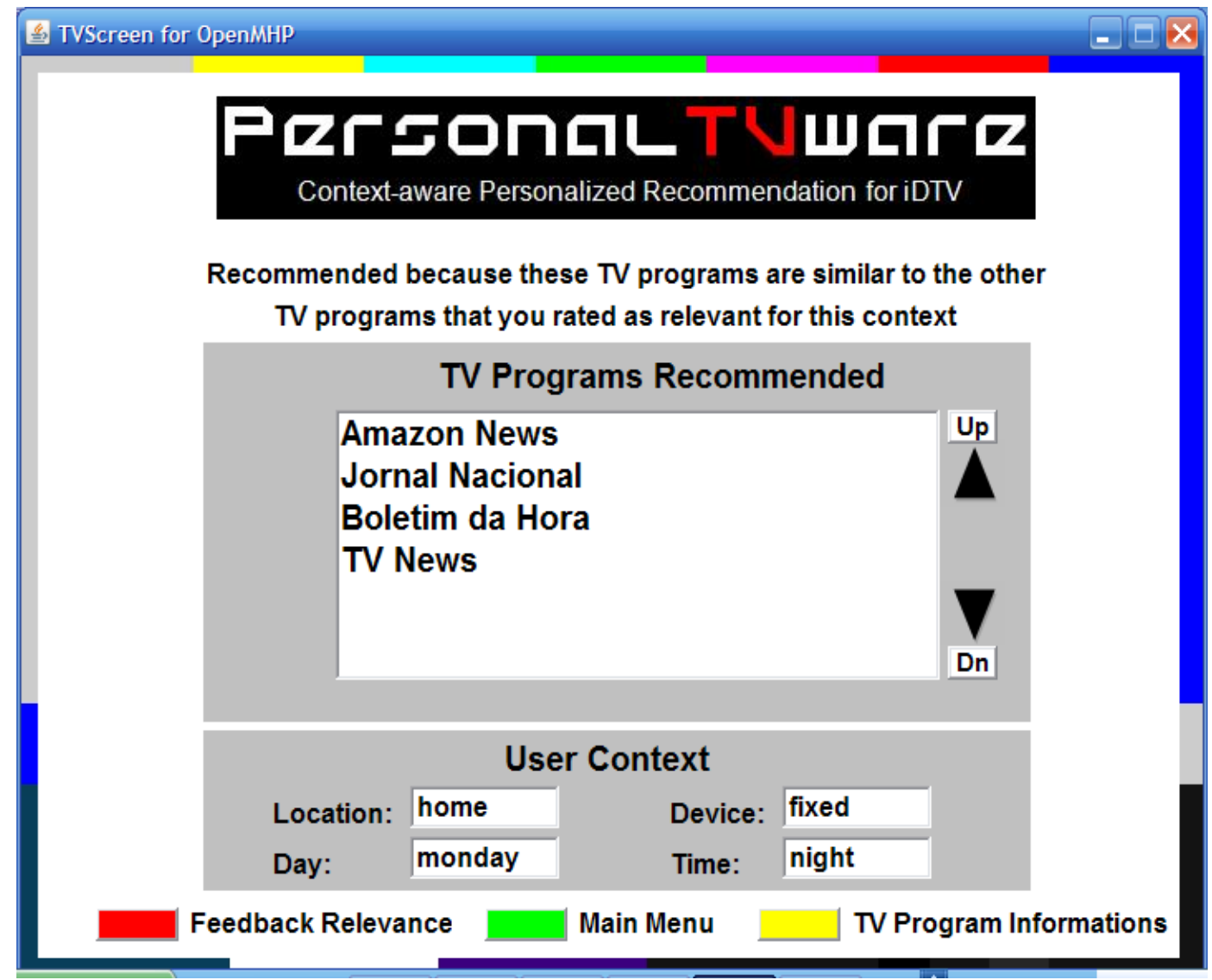

Figura 41 - Tela de Recomendação de Programas de TV

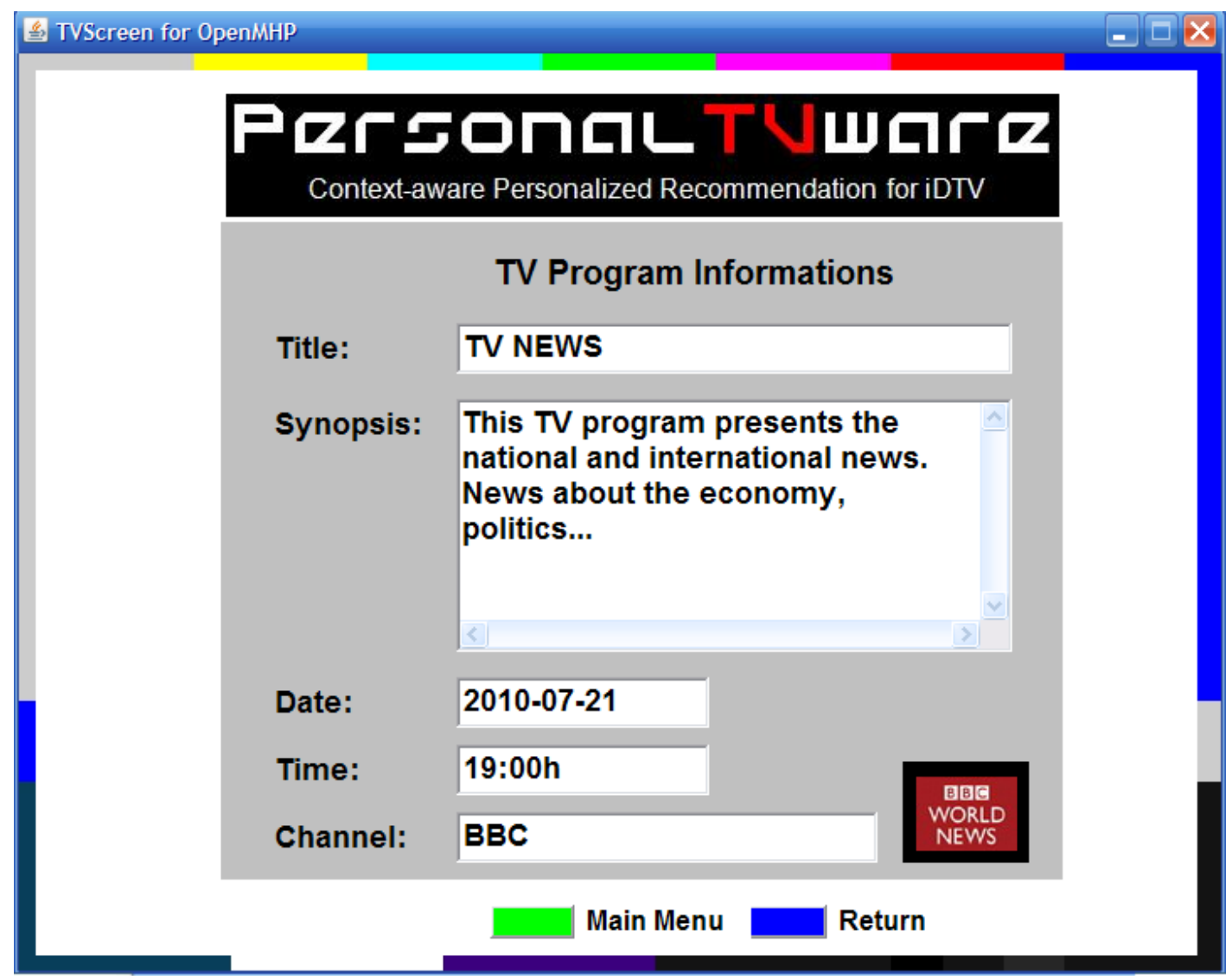

Figura 42 - Tela de Informações sobre Programa de TV 


\subsection{Experimentos}

Os experimentos realizados neste trabalho tiveram os seguintes objetivos: (i) verificar a qualidade das recomendações obtidas e o grau de satisfação dos usuários com relação ao sistema de recomendação implementado a partir do PersonalTVware; (ii) verificar a diferença da qualidade das recomendações quando explorado ou não o contexto do usuário no sistema de recomendação implementado; e (iii) verificar qual método de aprendizagem de máquina proporciona as melhores recomendações. A seguir são descritos os dados explorados nos experimentos, e a metodologia empregada nos experimentos.

\subsubsection{Obtenção dos Dados}

Para realização dos experimentos dois tipos de dados são necessários: os perfis contextuais de usuários e os metadados referentes à programação das emissoras de TV. Deste modo, foram convidados 10 estudantes de graduação da Universidade do Estado do Amazonas, que utilizaram o sistema de recomendação durante o período de um mês. Cada estudante assumiu um perfil de usuário hipotético, visando representar diferentes perfis de usuários. Com isso, a partir dos registros da interação dos estudantes, 2208 perfis contextuais de usuários com informação de gênero instanciada foram obtidos.

Complementarmente, para avaliar o estudo de caso sob uma perspectiva quantitativa, foi necessária a obtenção de uma coleção de documentos XML, sendo composto por 2426 metadados de programas de TV de 14 canais correspondente a uma semana de programação da TV. Tais metadados foram representados de acordo com a especificação de metadados do padrão TV-Anytime (TV-ANYTIME, 2007b) e coletados em Web sites especializados na publicação da programação das emissoras de televisão. No período da realização dos experimentos, os metadados que compõe as tabelas SI não eram distribuídos pelos provedores de serviços. 


\subsubsection{Metodologia para Realização de Experimentos}

Para realização dos experimentos foi empregado o método Holdout (HAN; KAMBER, 2006). Neste método, os dados obtidos são divididos em dois conjuntos independentes, um conjunto de treinamento e um conjunto de teste.

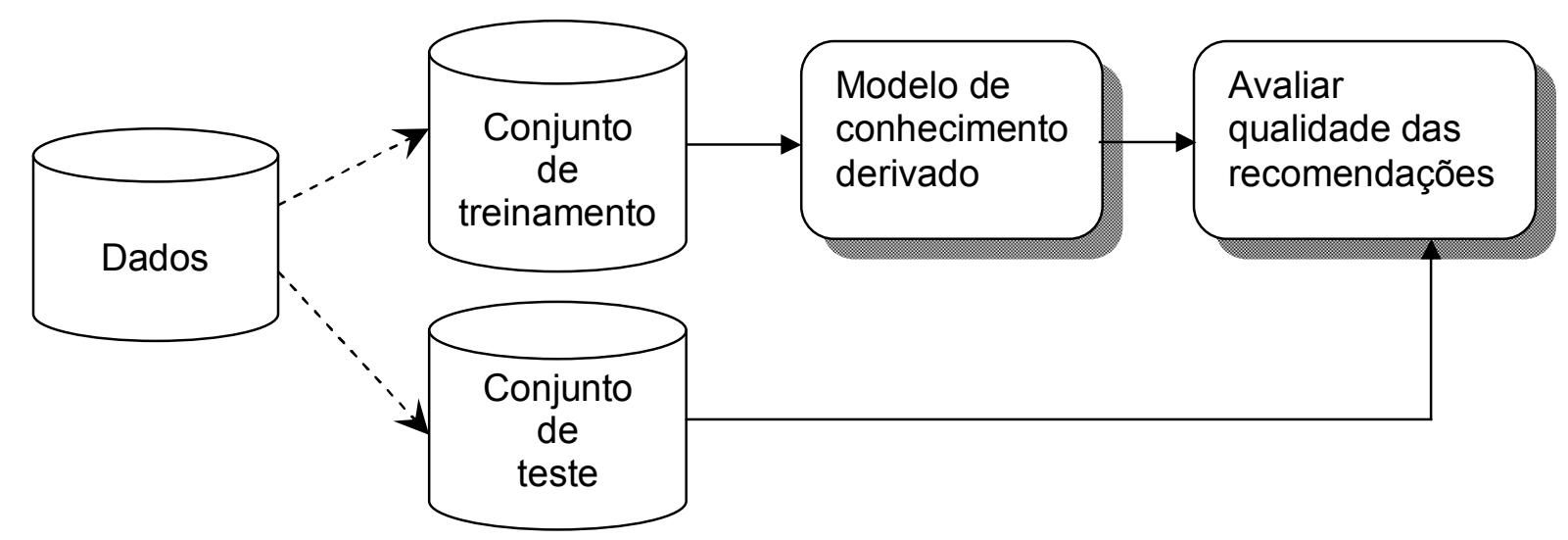

Figura 43 - Método Holdout. Adaptado de (HAN; KAMBER, 2006).

Conforme ilustrado na Figura 43 o conjunto de treinamento (ou a base de conhecimento) é utilizado para derivar o modelo de conhecimento, cuja qualidade das recomendações é estimada por meio do conjunto de teste. Desta forma, os experimentos foram realizados em três etapas. A Figura 44 apresenta um diagrama de atividades descrevendo a ordem da execução de cada etapa.

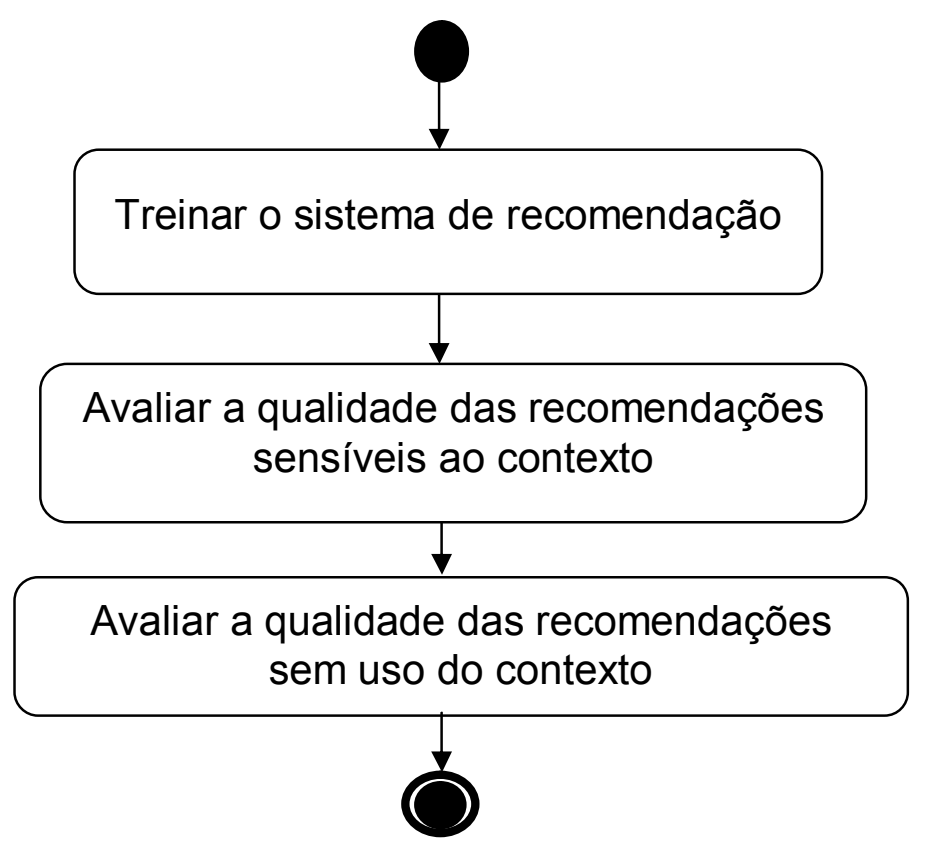

Figura 44 - Etapas da metodologia para realização de experimentos 
A primeira etapa foi de treinamento do sistema de recomendação que durou uma semana. Neste período foi gerado o conjunto de treinamento (ou base de conhecimento) composto por perfis contextuais de usuários com informação de gênero instanciada, ou seja, com rótulo de classe.

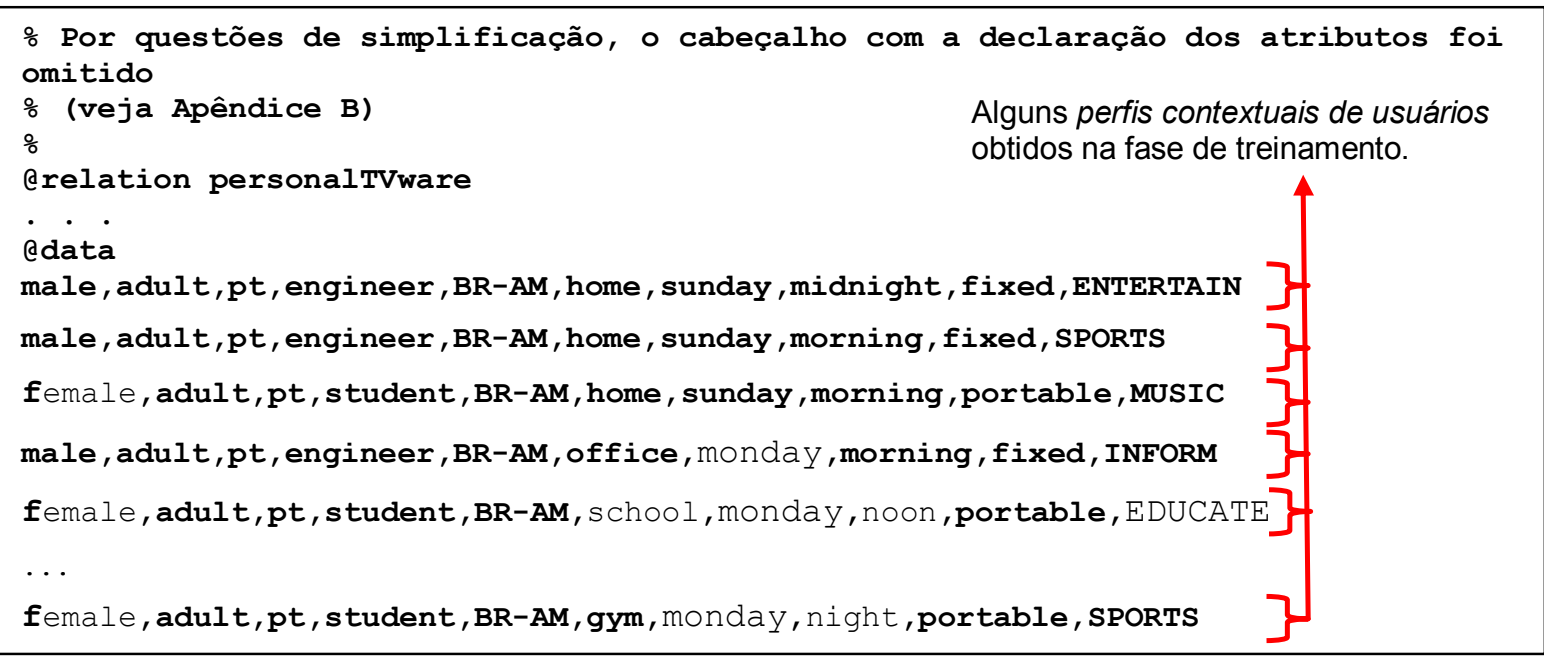

Figura 45 - Arquivo ARFF com perfis contextuais de usuários

$\mathrm{Na}$ Figura 45 há um fragmento do arquivo ARFF utilizado pelo PersonalTVware como conjunto de treinamento. O treinamento consistiu na utilização do sistema de recomendação pelos usuários em diversos contextos, onde os perfis contextuais de usuários foram obtidos por meio da técnica de realimentação de relevância (descrita na subseção 5.5). Por exemplo, cada usuário selecionava dentre os programas de TV apresentados na grade programação das emissoras, o programa de TV que considerava relevante, de acordo com o dia da semana, período do dia, sua localização e o tipo de dispositivo de acesso que utilizava. Deste modo, o perfil contextual do usuário correspondente era obtido.

A segunda etapa consistiu em avaliar a qualidade das recomendações sensíveis ao contexto geradas de acordo com cada método de aprendizagem de máquina suportado pelo PersonalTVware. Nesta etapa, os usuários receberam recomendações de programas de TV. O experimento foi realizado em lote pelos usuários, que consistia em selecionar os programas de TV considerados relevantes dentre aqueles que foram recomendados pelo sistema de recomendação por meio de cada método de aprendizagem de máquina avaliado. O objetivo deste experimento foi analisar qual método proporcionava a recomendação mais adequada ao perfil contextual do usuário com atributo-classe não instanciado. 
Com isso, os usuários realizaram este experimento em cada período do dia durante uma semana, o que constituiu o conjunto de teste. Finalmente, na terceira etapa, os métodos de aprendizagem de máquina não foram empregados. A função de predição foi desabilitada, logo, somente o perfil do usuário definido de forma explícita foi utilizado para geração das recomendações. O objetivo foi verificar a qualidade das recomendações sem a predição de preferências contextuais a partir da exploração do contexto e de métodos de aprendizagem de máquina. Cada usuário realizou este experimento pelo o menos 3 vezes ao dia, um experimento por período, ao longo de uma semana. Com a conclusão dos experimentos foi realizada a avaliação dos resultados obtidos conforme será descrito na próxima seção.

\subsection{Resultados}

A qualidade das recomendações foi mensurada por meio das métricas precisão, revocação e medida F (ZAIER; GODIN; FAUCHER, 2008). Neste trabalho, a precisão foi usada para mensurar a habilidade de o sistema de recomendação apresentar somente programas de TV relevantes para o perfil contextual do usuário corrente. Enquanto, que a revocação foi usada para mensurar a habilidade de o sistema de recomendação apresentar para um perfil contextual do usuário a fração de todos os programas de TV relevantes dentre o número total de programas de TV relevantes indicado na fase de treinamento. Admitindo-se que ambas as métricas possuem o mesmo grau de importância foi utilizada a métrica harmônica medida $F$ que combina em única fórmula as métricas de precisão e revocação.

Tabela 6 - Comparação entre as médias da métricas obtidas

\begin{tabular}{lccc}
\hline \multicolumn{1}{c}{ Método } & Precisão & Revocação & Medida F \\
\hline Raciocínio baseado em casos (RBC) & 0,834 & 0,920 & 0,841 \\
\hline Algoritmo C4.5 & 0,861 & 0,620 & 0,680 \\
\hline Classificador bayesiano ingênuo & 0,797 & 0,593 & 0,636 \\
\hline Perceptron multicamadas & 0,774 & 0,582 & 0,606 \\
\hline Perfil do usuário & 0,511 & 0,174 & 0,247 \\
\hline
\end{tabular}


Para efeito de análise comparativa a Tabela 6 apresenta as médias das métricas obtidas das recomendações sensíveis ao contexto baseadas em quatros métodos de aprendizagem de máquina, e recomendações não sensíveis ao contexto sendo baseadas somente em perfil do usuário.

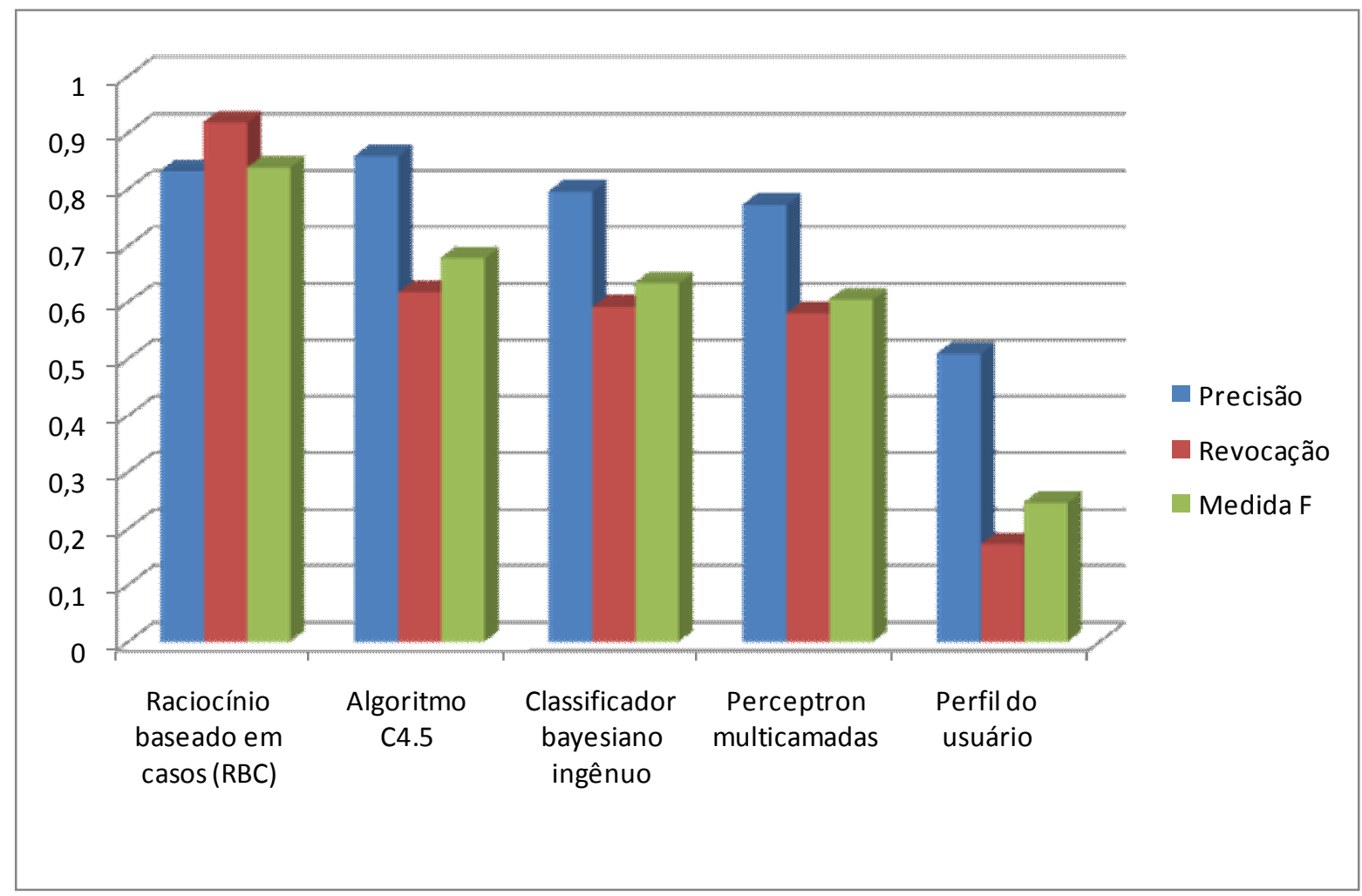

Gráfico 1 - Médias das métricas obtidas

Analisando a Tabela 6 e o Gráfico 1 é possível notar que a média das medidas $\mathrm{F}$ do método $\mathrm{RBC}$ está mais próxima de um. Tal resultado indica que a qualidade das recomendações foi superior quando empregado o método RBC. Consequentemente, o sistema de recomendação apresentou uma qualidade de recomendação superior quando comparado a qualidade obtida por meio dos demais métodos experimentados. Por meio da relação entre precisão e revocação (descrita na subseção 5.6.3) é possível afirmar que a razão deste resultado foi a menor discrepância entre as medidas de precisão e revocação obtidas pelo sistema de recomendação.

Já quando o algoritmo C4.5 foi experimentado, o sistema de recomendação apresentou uma precisão ligeiramente melhor em relação aos outros métodos, pois todos os programas de TV recomendados eram relevantes ao perfil contextual do usuário, contudo nem todos os programas de TV relevantes foram recomendados. 
Assim, a revocação do algoritmo $\mathrm{C} 4.5$ foi inferior a revocação do método RBC, o que implicou na redução do valor da medida $F$ do algoritmo C4.5. Tal resultado foi devido ao fato que na recomendação obtida a partir do método RBC todos os programas de TV relevantes ao perfil contextual do usuário, que foram indicados no conjunto de testes foram recomendados, e com menor número de programas de TV não relevantes. O que configura de acordo com relação entre precisão e revocação (descrita na subseção 5.6.3) um caso aceitável.

Complementarmente, pela ocorrência de maior revocação, tem-se que o método RBC pode ser configurado para retornar maior número de gêneros de programas de TV em relação aos demais métodos, que retornam somente um gênero por perfil contextual do usuário. Esta característica favorece os usuários que possuem interesses por mais de um gênero de programa de TV em determinados contextos. Neste trabalho o método RBC foi configurado para retornar três gêneros por predição.

Analisando os resultados obtidos dos métodos: classificador bayesiano ingênuo e perceptron multicamadas, nota-se que não houve grandes variações na qualidade do sistema de recomendação. No entanto, a qualidade das recomendações oferecidas por ambos os métodos ficou abaixo do algoritmo $\mathrm{C} 4.5 \mathrm{e}$ do método RBC. A razão deste resultado foi devido ao fato das recomendações apresentarem maior número de programas de TV não relevantes ao perfil contextual do usuário, e menor número de programas de TV relevantes dentre os indicados no conjunto de teste que deveriam ser recomendados. O que configura de acordo com relação entre precisão e revocação (descrita na subseção 5.6.3) um caso não aceitável.

Também é possível notar que a qualidade das recomendações foi expressivamente inferior a todos os métodos restantes quando empregado somente o perfil do usuário definido explicitamente e sem o uso de contexto. Tal resultado demonstra que a ausência da exploração do contexto impacta diretamente na qualidade das recomendações. Foi constatado que somente explorado o perfil do usuário as recomendações tendem apresentar gêneros de programas de TV que geralmente não são interessantes para os usuários em determinados contextos, o que compromete a precisão e revocação do sistema.

O Gráfico 2 apresenta o gráfico de Precisão-Revocação (ZAIER; GODIN; FAUCHER, 2008) (YU; ZHOU, 2004), o qual integra as métricas de precisão e 
revocação para avaliar a qualidade de um sistema de recomendação. Neste gráfico cada ponto é um par de valores precisão e revocação. A curva mais próxima do lado direito do canto superior do gráfico (onde precisão e revocação são maximizadas) indica desempenho superior.

Deste modo, comparando os resultados obtidos das recomendações sensíveis ao contexto que empregam métodos de aprendizagem de máquina e aquelas somente baseadas em perfil do usuário, também é possível notar que método RBC foi superior aos demais. Pode ser observado que a curva de precisão e revocação está mais próxima do lado direito do canto superior do gráfico.

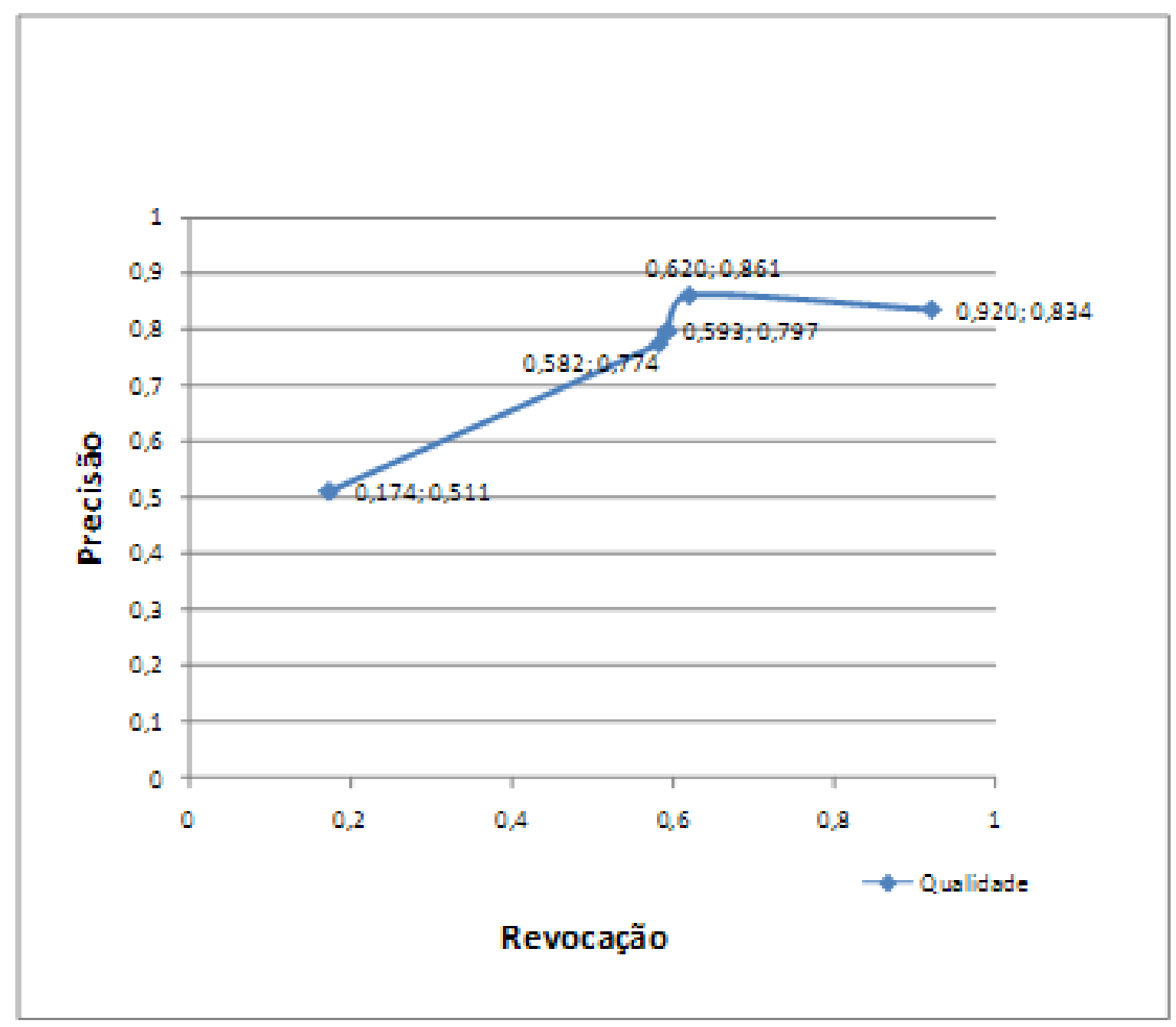

Gráfico 2 - Precisão-Revocação da eficiência do sistema de recomendação

Por meio do gráfico de Precisão-Revocação ilustrado no Gráfico 2 é possível observar a queda da qualidade do sistema de recomendação quando empregado somente o perfil do usuário. Este comportamento pode ser explicado pelo fato que sem a exploração do contexto, o perfil do usuário pode somente fornecer 
recomendações gerais resultando na redução da qualidade do sistema de recomendação.

Diante dos resultados obtidos, conclui-se que a exploração do contexto pode melhorar de forma significativa a qualidade de um sistema de recomendação, principalmente, quando empregados métodos de aprendizagem de máquina para predição de preferências contextuais, ou seja gêneros de programas de TV a partir do perfil contextual do usuário. Em relação à tarefa de predição, vale destacar que o uso do método RBC proporcionou recomendações de melhor qualidade. $\mathrm{O}$ fato de $\mathrm{O}$ sistema apresentar medida $F$ superior quando empregado o método RBC indica que a qualidade das recomendações satisfaz as necessidades de informações dos usuários.

Os usuários que participaram dos experimentos mostraram-se satisfeitos com recomendações de programas de TV apresentadas conforme a avaliação centrada no usuário descrita a na subseção 8.4.1 a seguir. Vale também destacar que o administrador do provedor de serviços durante a realização de experimentos gerou modelos de conhecimento a partir dos métodos de aprendizagem de máquina: algoritmo C4.5 (árvore de decisão), perceptron multicamadas (redes neurais), classificador bayesiano ingênuo (aprendizagem bayesiana) e raciocínio baseado em casos. O tempo de criação dos modelos de conhecimento variou conforme o método adotado. Tais informações podem ser observadas na Tabela 7.

\begin{tabular}{lc}
\multicolumn{1}{c}{ Tabela 7 - Tempo de criação dos modelos de conhecimento } & $\begin{array}{c}\text { Tempo } \\
\text { (s) }\end{array}$ \\
\hline Raciocínio baseado em casos (RBC) & 0,10 \\
\hline Algoritmo C4.5 & 0,09 \\
\hline Classificador bayesiano ingênuo & 0,02 \\
\hline Perceptron multicamadas & 226,5 \\
\hline
\end{tabular}

É possível notar que o método perceptron multicamadas consumiu aproximadamente 226,5 segundos na construção do modelo de conhecimento, enquanto que com os demais não durou 1 segundo. Tal fator impactante foi devido à complexidade na geração do modelo de conhecimento por meio do uso de redes neurais. 
Torna-se importante ressaltar que o método RBC apesar de proporcionar recomendações de melhor qualidade, conforme aumenta a base de dados (ou base de conhecimento) o desempenho do sistema pode sofrer com o tempo necessário para procurar e processar casos relevantes. O tempo tende a cresce exponencialmente. Deste modo, uma possível solução é editar a base de dados. Casos que são redundantes ou que não tenham se mostrado úteis podem ser descartados para melhorar o desempenho. Neste o trabalho, o tamanho final da base de dados foi de 2208 casos.

\subsubsection{Avaliação Centrada no Usuário - Grau de Satisfação}

Pesquisas relacionadas à experiência de interação do usuário estão atraindo cada vez mais a atenção da comunidade da área de sistemas de recomendação. Tais pesquisas sugerem que o grau de satisfação do usuário nem sempre está correlacionado com a alta precisão ou revocação das recomendações (ZIEGLER et al., 2005). Assim, estão surgindo trabalhos nesta área sugerindo um conjunto de critérios o qual pode ser empregado para avaliar sistemas de recomendação do ponto de vista do usuário.

Em (PU; CHEN, 2010), é apresentado um framework centrado no usuário para avaliação de sistemas de recomendação intitulado de ResQue (Recommender System's Quality of user experience). O ResQue disponibiliza 60 questões categorizadas em 13 construtores ou categorias de critérios de avaliação. Tais critérios abrangem aspectos relacionados à facilidade de uso, interface gráfica de usuário, qualidade dos itens recomendados, inclusive a exploração do contexto.

Desta forma, o ResQue foi adotado neste trabalho para avaliação do grau da satisfação do usuário, especificamente as questões sugeridas para mensurar o grau de satisfação do usuário com relação à recomendação sensível ao contexto e somente baseada em perfil do usuário.

Com isso, cada usuário que participou dos experimentos foi convidado a responder um questionário avaliativo com questões de múltipla-escolha no formato 5-point Likert scale, e no final do questionário foi reservado um espaço para críticas e sugestões. $O$ questionário aplicado pode ser visto no Apêndice $C$. 
Com relação à avaliação da recomendação somente baseada em perfil do usuário, os usuários responderam a seguinte questão (construtor Accuracy) do ResQue: "The items (TV programs) recommended to me matched interests?", os resultados obtidos nesta questão podem ser vistos no Gráfico 3.

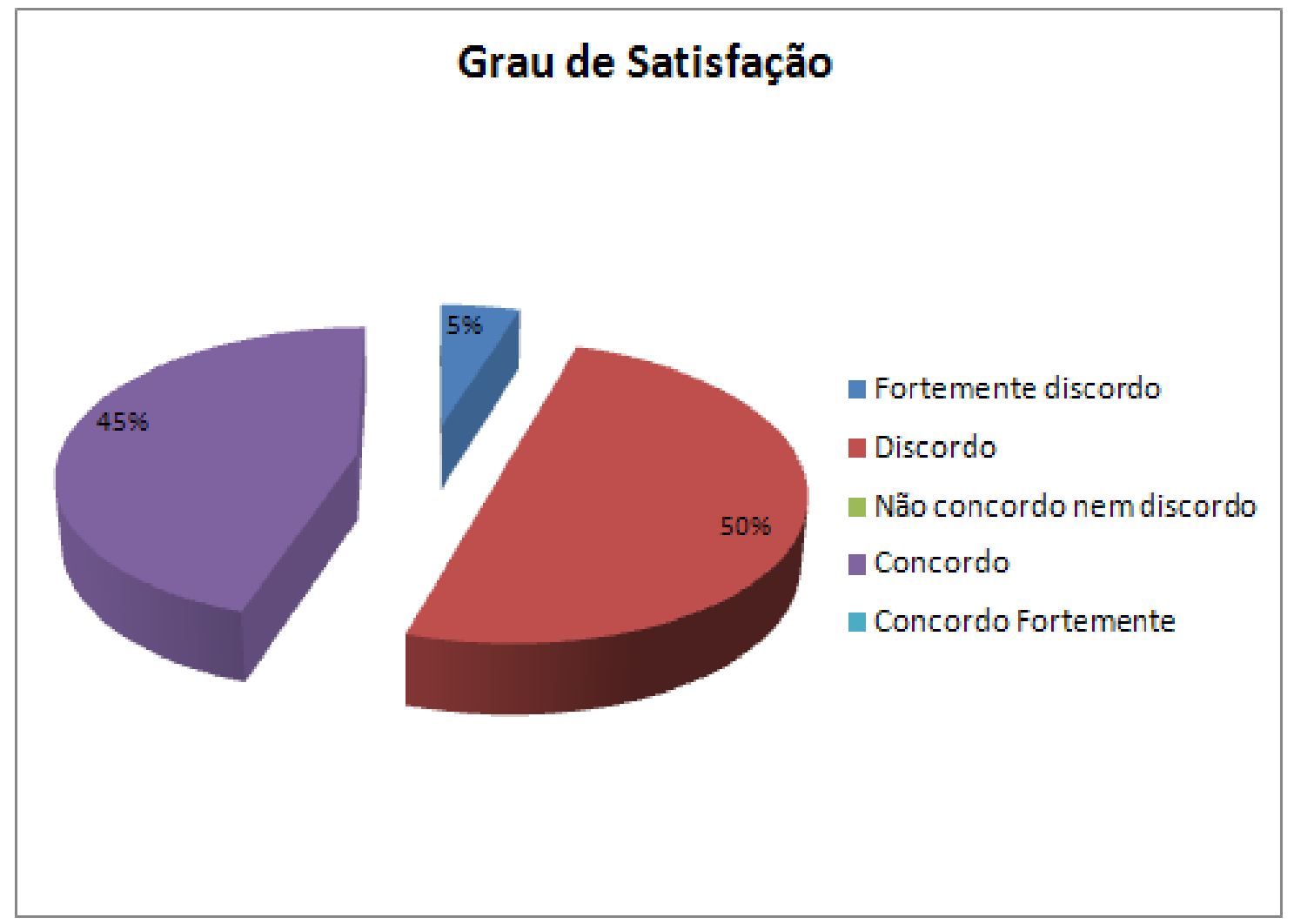

Gráfico 3 - Recomendações baseadas em perfil do usuário

Por meio do Gráfico 3 pode-se notar que $45 \%$ dos usuários responderam que concordaram com as recomendações de programas de TV, $50 \%$ dos usuários declararam que discordaram, e $5 \%$ fortemente discordaram. Esses percentuais indicam que para maioria dos usuários (55\%), os itens recomendados apesar de combinarem com os interesses especificados em seus perfis de usuário, provavelmente não eram adequados em algumas situações. Assim, foi comprovado que dependendo do contexto, o usuário poderá ter preferências por gêneros de programas de TV distintos.

Já com relação à avaliação da recomendação sensível ao contexto, os usuários responderam a seguinte questão (construtor Context Compatibility) do ResQue: "The items (TV programs) recommended to me took my personal context requirements into consideration?", os resultados obtidos nesta questão podem ser vistos no Gráfico 4. 


\section{Grau de Satisfação}

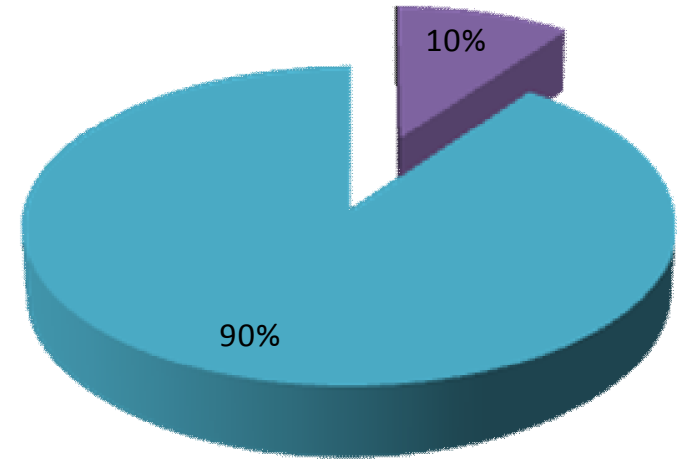

Fortemente discordo

Discordo

Não concordo nem discordo

- Concordo

Concordo Fortemente

Gráfico 4 - Recomendações sensíveis ao contexto

Nota-se por meio do Gráfico 4 que a maioria dos usuários (90\%) respondeu que concordaram fortemente com as recomendações de programas de TV levando em consideração seu contexto corrente e $10 \%$ dos usuários simplesmente concordaram com as recomendações. Tais resultados confirmam a hipótese desta tese que a exploração de informações de contexto pode melhorar a qualidade das recomendações de sistemas de recomendação voltados para TV Digital.

\subsection{Considerações Finais}

Este capítulo apresentou um estudo de caso que consistiu no desenvolvimento de um protótipo de sistema de recomendação sensível ao contexto que utiliza as funcionalidades do PersonalTVware. A implementação deste protótipo permitiu a avaliação do PersonalTVware em termos de qualidade do processo de recomendação de conteúdo e também o grau de satisfação dos usuários. 
Por meio do estudo de caso foi possível a realização de experimentos com os métodos de aprendizagem de máquina empregados para predizer preferências contextuais, ou seja gêneros de programas de TV, a partir do perfil contextual de usuário. O objetivo foi avaliar dentre os métodos de aprendizagem qual método proporcionava recomendação de conteúdo de melhor qualidade. Dentre os métodos avaliados, de acordo com os resultados obtidos, o método raciocínio baseado em casos (RBC) proporcionou as melhores recomendações.

A razão do desempenho superior do método $\mathrm{RBC}$ quando empregado neste trabalho foi a sua capacidade de predizer preferências contextuais mais próximas aos interesses dos usuários em determinadas situações. Já quando somente o perfil do usuário foi explorado a qualidade das recomendações foi imprecisa e não abrangente, ou seja muitos programas de TV não relevantes foram recomendados, e nem todos os programas de TV relevantes foram recomendados, o que configura um caso não aceitável.

A partir de outra perspectiva de avaliação de sistemas de recomendação, que é centrada no usuário, também foram avaliadas as abordagens de recomendação tradicional (baseada em perfil do usuário) e sensível ao contexto. Os resultados obtidos por meio da abordagem tradicional foram inferiores quando comparados aos resultados da abordagem de recomendação sensível ao contexto que emprega os métodos de aprendizagem de máquina.

Desta forma, foi confirmada a hipótese desta tese que a exploração de contexto além do perfil do usuário por meio de uma abordagem de recomendação que emprega aprendizagem de maquina para predição de preferências contextuais pode melhorar a qualidade das recomendações de sistemas de recomendação voltados para TV Digital Interativa. 


\section{Conclusões}

Este trabalho descreveu uma proposta de solução para o problema da sobrecarga de informação no domínio da TV Digital Interativa. O principal objetivo deste trabalho consistiu na criação de uma abordagem de recomendação de conteúdo para TV Digital Interativa que explora informações contextuais além do perfil do usuário. Para isso, a solução consistiu no desenvolvimento de uma infraestrutura modular de software com suporte à ciência de contexto para personalizar o acesso dos usuários aos programas de TV contendo assuntos que provavelmente serão de seu interesse e adequados ao seu contexto.

A infraestrutura proposta foi intitulada de PersonalTVware e segue os requisitos de software para o desenvolvimento de sistemas sensíveis ao contexto e ao modelo de referência TV-Anytime (TV-ANYTIME, 2007a) para sistemas de TV Digital Interativa.

Desta forma, o PersonalTVware foi projetado para permitir aos desenvolvedores de sistemas de recomendação ou aplicações interativas investir esforços na lógica de apresentação de seus sistemas, pois abstrai as questões de baixo nível relacionadas ao processamento de contexto e recomendação personalizada de conteúdo. Para atingir o objetivo deste trabalho foi necessário cumprir algumas etapas. A primeira delas consistiu na realização de um estudo teórico sobre tópicos relacionados à TV Digital Interativa, Sistema de Recomendação e Computação Sensível ao Contexto, apresentando os principais conceitos que fundamentaram a realização deste trabalho.

$\mathrm{Na}$ etapa seguinte, foram elaborados alguns cenários de uso para ilustrar aplicabilidade do PersonalTVware. Posteriormente, por meio do estudo da modelagem do usuário e o seu contexto, foi possível abstrair as principais entidades e informações que são exploradas pela infraestrutura. Tais modelos foram representados por meio de esquemas de descrição baseados em XML. O PersonalTVware utiliza esquemas de descrição, compatíveis com as especificações de metadados dos padrões TV-Anytime e MPEG-7, para representar e estruturar descrições de programas de TV e informações sobre usuários. Também foram 
especificados esquemas de descrição para representar as informações de contexto exploradas pela infraestrutura proposta.

Finalizada as etapas de pesquisa e modelagem, iniciou-se a especificação da arquitetura do PersonalTVware, a investigação de tecnologias para interconexão entre os módulos dos subsistemas, projeto e implementação das classes. Além disso, também foi proposto, o conceito de perfil contextual do usuário, para ser empregado na abordagem de aprendizagem supervisionada dependente do contexto e predição de preferências contextuais (descoberta de gêneros de programas de TV). Adicionalmente, para as tarefas de aprendizagem e predição foram empregadas as APIs das ferramentas Weka e Lucene. O funcionamento do PersonalTVware foi descrito a partir de casos de uso e também por meio de diagramas de sequência juntamente com suas respectivas descrições.

Finalizada as etapas que viabilizaram a concepção do PersonalTVware, para demonstrar e validar suas funcionalidades foi desenvolvido um protótipo de sistema de recomendação sensível ao contexto como estudo de caso. O sistema utiliza as descrições dos programas de TV para compará-las às preferências do usuário explícitas e inferidas a partir do seu perfil contextual do usuário e selecionar programas de TV que provavelmente serão de interesse do usuário. Experimentos foram realizados com intuito de avaliar a qualidade das recomendações, e os resultados obtidos a partir destes experimentos demonstram a eficácia e aplicabilidade do contexto em sistemas de recomendação para TV Digital Interativa.

As próximas seções deste capítulo descrevem as contribuições deste trabalho (seção 91), suas limitações (seção 9.2), apresentam sugestões de trabalhos futuros (seção 9.3) e a produção científica (seção 9.4).

\subsection{Contribuições}

A principal contribuição deste trabalho, na área de TV Digital Interativa, foi o projeto e a implementação da infraestrutura PersonalTVware, composta por esquemas XML para representação de contexto e perfil do usuário, e os subsistemas dispositivo do usuário e provedor de serviços. Por meio da utilização conjunta da infraestrutura e tais esquemas XML de descrição é possível o 
desenvolvimento de sistemas de recomendação sensíveis ao contexto para TV Digital Interativa, característica não encontrada na maioria dos trabalhos relacionados.

A proposta de uma abordagem de recomendação de conteúdo para TV Digital Interativa que explora informações contextuais além do perfil do usuário por meio do conceito perfil contextual do usuário, também é considerada uma contribuição para área de sistemas de recomendação sensíveis ao contexto. Desta forma, foi necessária a criação de uma abordagem de aprendizagem supervisionada dependente do contexto para predição de preferências contextuais (gêneros de programas de TV) posteriormente empregadas na filtragem de conteúdo, sendo uma contribuição adicional deste trabalho.

Outra contribuição deste trabalho foi a avaliação de desempenho do sistema por meio da realização de experimentos com os métodos de aprendizagem de máquina para predição de preferências contextuais por gêneros de programas de TV a partir do perfil contextual do usuário. O principal objetivo foi verificar por meio de uma análise comparativa qual método apresentava as melhores recomendações e, por conseguinte ser empregado pelo módulo Interpretador de Contexto. Os resultados indicaram que o método RBC foi superior quando empregado neste trabalho. Além disso, os experimentos serviram para validar a hipótese de que a exploração do contexto em sistemas de recomendação voltados para o domínio da TV Digital Interativa pode melhorar o desempenho deste tipo de sistema.

\subsection{Limitações}

Uma das limitações deste trabalho foi a não implementação do módulo Coletor de programas de TV baseado em tabelas SI, presente no subsistema provedor de serviços, devido à falta de transmissão de metadados que compõe as tabelas SI pela maioria dos provedores de serviços da região onde este trabalho foi desenvolvido. Neste trabalho a coleta das informações sobre os programas de TV foi realizada de modo não automático a partir de Web sites dos provedores de conteúdo. 
Outra limitação da infraestrutura é a dificuldade em efetuar predição de preferências contextuais por gêneros de programas de TV quando existem poucos perfis contextuais de usuários armazenados na base de conhecimento, o que compromete a qualidade das recomendações. Este problema é frequentemente discutido na literatura de sistemas de recomendação, sendo denominado de problema de partida fria (do inglês, cold start problem) (LAM et al. 2008). Deste modo, é necessário que haja um período de treinamento para obtenção de perfis contextuais de usuários de forma explícita e/ou implícita via os métodos de realimentação de relevância implementados neste trabalho.

Com relação à percepção do contexto, a identificação do usuário foi feita de forma explícita por meio de login. Tal abordagem é considerada intrusiva em termos de sistemas sensíveis ao contexto, sendo necessária a investigação de outros métodos menos intrusivos, requisito importante para aplicações no cenário da TV Digital Interativa. Também não foram investigadas no escopo desta pesquisa algumas questões, constituindo, assim, assuntos para trabalhos futuros, como propor ou implementar várias tecnologias para aquisição automática da localização do usuário, pois existe uma tendência de lançamento de dispositivos portáteis já equipados com GPS ${ }^{4}$. Assim, para fins de realização de experimentos foi empregado neste trabalho endereço IP (Internet Protocol).

\subsection{Trabalhos Futuros}

Devido a sua natureza flexível espera-se que novas funcionalidades sejam incorporadas ao PersonalTVware ao longo do tempo. No decorrer desta pesquisa alguns trabalhos foram identificados como possíveis propostas de trabalhos futuros. A primeira delas consiste justamente no desenvolvimento do módulo Coletor de programas de TV, precisamente o componente SITVCollector. Um trabalho importante visa adaptar a implementação do PersonalTVware de modo a utilizar as APIs do Ginga-J (ambiente procedural do middleware do Sistema Brasileiro de TV

\footnotetext{
${ }^{4}$ Global Positioning System, sistema de posicionamento global por satélite que permite obter as coordenadas geográficas de qualquer ponto do globo terrestre.
} 
Digital). Torna-se importante ressaltar que a implementação de referência do Ginga$\mathrm{J}$, ainda não estava concluída até o término deste trabalho.

É importante que sejam realizados estudos sobre a escalabilidade da infraestrutura, principalmente dos módulos do subsistema provedor de serviços, considerando um grande volume de acessos simultâneos que é típico no domínio da TV Digital Interativa. Visando estender as funcionalidades do PersonalTVware é interessante que seja realizada a investigação sobre novas técnicas de recomendação como a incorporação da técnica de filtragem colaborativa e a sua adaptação de modo que seja sensível ao contexto. Desta forma, o filtro deverá gerar recomendações a partir das avaliações anteriores de programas de TV por usuários que possuem perfis e contextos similares ao usuário alvo. Além disso, direcionamentos em interação multimodal na TV Digital (Pedrosa, 2010), como a investigação de abordagem para recomendação de modalidades de interação, ao invés de somente conteúdo.

Sugere-se também adaptação da implementação do PersonalTVware para ser utilizado em outros domínios de aplicação tais como Internet TV ou IPTV (TV sobre o protocolo IP), permitindo que os usuários possam ter acesso personalizado a conteúdos diversos como aqueles criados pelos próprios usuários. Outro trabalho consiste no desenvolvimento de uma ferramenta de autoria para criação de metadados relacionados aos programas de TV, salvando as descrições no formato TV-Anytime.

Por fim, um tema relevante a ser abordados em trabalho futuro, e que se configura como a continuidade deste trabalho é a realização de estudos mais profundos sobre o comportamento e as preferências por conteúdos dos usuários a partir de outras categorias de contexto tais como contexto da infraestrutura, contexto do ambiente ou domínio, contexto social, dentre outros. Desta vez, elaborar novas modelagens de contexto que levem em consideração informações contextuais relacionadas a fatores culturais, emocionais, sociais, regionais, conectividade, hardware e software dos dispositivos de acesso. 


\subsection{Produção Científica}

No que tange a produção científica oriunda dessa tese, foram publicados trabalhos em eventos internacionais e nacionais, listados a seguir:

SILVA, F. S.; ALVES, L. G. P.; BRESSAN, G. PersonalTVware: An Infrastructure to Support the Context-aware Recommendation for Personalized Digital TV. In: Proceedings of the IEEE International Conference on Information and Computer Applications (ICICA 2011), Dubai, UAE, 2011.

SILVA, F. S.; ALVES, L. G. P.; BRESSAN, G. PersonalTVware: Uma Proposta de Infraestrutura de Suporte a Sistemas de Recomendação Sensíveis ao Contexto para TV Digital Interativa. In: XVI Simpósio Brasileiro de Sistemas Multimídia e Web/VTVDI - II Workshop de TV Digital Interativa, 2010, Belo Horizonte, Minas Gerais. Anais do XVI Simpósio Brasileiro de Sistemas Multimídia e Web (WebMedia 2010).

SILVA, F. S.; ALVES, L. G. P.; BRESSAN, G. Exploiting Contextual Information in Recommender Systems for Interactive Digital TV. In: Proceedings of the 9th International Information and Telecommunication Technologies Symposium, Rio de Janeiro, Brazil, 2010.

SILVA, F. S.; ALVES, L. G. P.; BRESSAN, G. PersonalTVware: A Proposal of Architecture to Support the Context-aware Personalized Recommendation of TV Programs. In: Networked Television Adjunct Proceedings of the 7th European Conference on Interactive TV and Video (EurolTV 2009), Leuven, Belgium, 2009.

SILVA, F. S.; ALVES, L. G. P.; BRESSAN, G. PersonalTVware: Uma Proposta de Arquitetura Sensível ao Contexto para Suporte a Recomendação Personalizada de Conteúdo no Cenário da TV Digital Interativa. In: I Simpósio Brasileiro de Computação Ubíqua e Pervasiva 
(SBCUP 2009), Bento Gonçalves, Rio Grande do Sul. Anais do XXIX Congresso da Sociedade Brasileira de Computação, 2009.

$\mathrm{O}$ arcabouço geral da pesquisa desta tese e os resultados finais obtidos foram publicados em (SILVA et al., 2011). Em (SILVA et al., 2010a) foi descrito o projeto e a implementação do PersonalTVware. Em (SILVA et al., 2010b) foi discutida a exploração de informações contextuais em sistemas de recomendação para TV Digital Interativa. Os primeiros resultados deste trabalho englobando a proposta da arquitetura e mais um processo de recomendação personalizada sensível ao contexto foram publicados em (SILVA et al., 2009a). Uma visão preliminar e de alto nível da arquitetura da infraestrutura, bem como direcionamento de algumas extensões foi publicada em (SILVA et al., 2009b).

Do ponto de vista de trabalhos em regime de colaboração, foram publicados os seguintes artigos:

ALVES, L. G. P.; SILVA, F. S.; BRESSAN, G. CollaboraTVware: Uma Proposta de Infra-estrutura Ciente de Contexto para Suporte a Participação Colaborativa no Cenário da TV Digital Interativa. In: XIV Simpósio Brasileiro de Sistemas Multimídia e Web (WebMedia 2008), Vila Velha, Espírito Santo. Anais do XIV Simpósio Brasileiro de Sistemas Multimídia e Web (WebMedia 2008).

ALVES, L. G. P.; SILVA, F. S.; BRESSAN, G. CollaboraTVware: A ContextAware Infrastructure with Support for Collaborative Participation in Interactive Digital TV Environment. In: International Journal of Advanced Media and Communication (IJAMC), Vol. 3, No. 4, 2009.

ALVES, L. G. P.; KULESZA, R.; SILVA, F. S.; BRESSAN, G.; BRESSAN, G. Análise Comparativa de Metadados em TV Digital: In: XXIV Simpósio Brasileiro de Redes de Computadores/WTVD 2006 - II Workshop de TV Digital, Curitiba, Paraná. Anais do XXIV Simpósio Brasileiro de Redes de Computadores, 2006. 
Nos trabalhos supracitados houve colaboração em aspectos relevantes da infraestrutura do PersonalTVware. Em particular, em (ALVES et al., 2006), foi realizada uma análise comparativa entre padrões de metadados flexíveis para TV Digital, que serviu de base para escolha dos padrões TV-Anytime e MPEG-7 adotados neste trabalho. Em (ALVES et al., 2008), e (ALVES et al., 2009), são estabelecidas as bases arquiteturais deste trabalho, bem como a modelagem de contexto. 


\section{REFERÊNCIAS BIBLIOGRÁFICAS}

ABOWD, G. D.; MYNATT, E. D. Charting past, present, and future research. In: Ubiquitous Computing. ACM Transactions on Computer-Human Interaction (TOCHI), v.7, n.1, p.29-58, 2000.

ADOMAVICIUS, G.; TUZHILIN, A. Toward the Next Generation of Recommender Systems: A Survey of the State-of-the-Art and Possible Extensions. In: IEEE Transactions on Knowledge and Data Engineering, v.17, n.6, p.734-749, 2005.

ADOMAVICIUS, G.; TUZHILIN, A. Context-Aware Recommender Systems. In: Proceedings of the ACM Conference on Recommender Systems. ACM 978-1-60558093-7/08/10, p.335-336, 2008.

APACHE. Web Services - Axis. 2006. Disponível em: <http://ws.apache.org/axis/>. Acesso em: 19 jan. 2009.

ABNT. NBR 15603-1. Televisão digital terrestre - Multiplexação e serviços de informação (SI) - Parte 1: Serviços de informação do sistema de radiodifusão. Rio de Janeiro, 2007.

. NBR 15607-1. Televisão digital terrestre - Canal de interatividade Parte 1: Protocolos, interfaces físicas e interfaces de software. Disponível em <http://www.abnt.org.br>. Acesso em: mai. 2008.

. NBR 15606-2 .Televisão digital terrestre - Codificação de dados e especificações de transmissão para radiodifusão digital - Parte 2: Ginga-NCL para receptores fixos e móveis - Linguagem de aplicação XML para codificação de aplicações. 2007. Disponível em <http://www.abnt.org.br>. Acesso em: mai. 2008.

.NBR 15606-4.Televisão digital terrestre - Codificação de dados e especificações de transmissão para radiodifusão - Parte 5: Ginga-J Ambiente para a execução de aplicações procedurais (VERSÃO DRAFT 05/2008). 2008. Disponível em www.openginga.org/00.001.85-006-4.pdf. Acesso em: 18 de mai. 2008.

ATSC - Advanced Television Systems I. ATSC Standard A/53B with Amendments 1 and 2: ATSC Digital Television Standard, Rev. B, 2001. Disponível em <http://www.atsc.org>. Acesso em: 18 mai. 2008. 
ALVES, L. G. P. CollaboraTVware: Uma Infra-Estrutura Ciente de Contexto para Suporte a Participação Colaborativa no Cenário da TV Digital Interativa. 2008. 203 p. Dissertação (Mestrado) - Escola Politécnica, Universidade de São Paulo, São Paulo, 2008.

ALVES, L. G. P.; KULESZA, R.; SILVA, F. S.; JUCA, P.; BRESSAN, G. Análise Comparativa de Metadados em TV Digital. In: XXIV Simpósio Brasileiro de Redes de Computadores / WTVD 2006 - II Workshop de TV Digital, 2006, Curitiba, Anais do XXIV Simpósio Brasileiro de Redes de Computadores, p.87-98, 2006.

ÁVILA, P. M.; ZORZO, S. D. A Personalized TV Guide System: An Approach to Interactive Digital Television. In: Proceedings of the IEEE International Conference on Systems, Man, and Cybernetics, San Antonio, 2009.

ÁVILA, P. M. Recommender TV: Suporte ao Desenvolvimento de Aplicações de Recomendação para o Sistema Brasileiro de TV Digital. 2010. 89 p. Dissertação (Mestrado) - Universidade Federal de São Carlos, São Paulo, 2010.

AROYO, L.; BELLEKENS, P.; BJORKMAN, M.; HOUBEN, G. J.; AKKERMANS, P.; KAPTEIN, A. Sensee Framework for Personalized Access to TV Content. In: Interactive TV: A Shared Experience, Amsterdam, the Netherlands, p.156-165. Springer. Heidelberg, 2007.

BAZIRE, M.; BREZILLON, P. Understanding Context Before Using It. In: $5^{\text {th }}$ International and Interdisciplinary Conference, CONTEXT-05, p.29-40, 2005.

BALTRUNAS, L. Exploiting contextual information in recommender systems. In: Proceedings of the ACM Conference on Recommender Systems, p.295-298, 2008.

BASILICO J.; HOFMANN T. Unifying collaborative and content-based filtering. In: ACM International Conference Proceeding Series, 2004.

BELOTTI, V. SOPHIE: Context Modelling and Control. Diploma Thesis, Swiss Federal Institute of Technology Zurich, 2004.

$\mathrm{BOOCH}, \mathrm{G}$; RUMBAUGH, J.; JACOBSON, I. The Unified Modeling Language

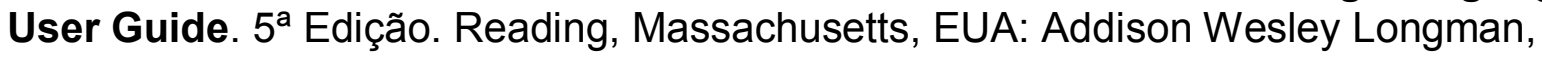
Inc, 1999. 483 p. 
BULCÃO N. R. F. Um Processo de software e um modelo ontológico para apoio ao desenvolvimento de aplicações sensíveis ao contexto. 2006. 262 p. Tese (Doutorado) - Instituto de Ciências Matemáticas e de Computação, Universidade de São Paulo, São Carlos, 2006.

BURKE, R. Hybrid Recommender Systems: Survey and Experiments. In: User Modeling and User-Adapted Interaction Journal, v.12, n.4, p.331-370, 2002.

BLANCO-FERNANDEZ, Y. Propuesta Metodológica para el Razonamento Semántico en Sistemas de Recomendación Personalizada y Automática. Aplicación Al Caso de Contenidos Audiovisuales. 2007. 320 p. Tese (Doutorado) - Departamento de Enxeneria Telemática E.T.S.E. de Telecomunicación, Universidade de Vigo, 2007.

BLANCO-FERNANDEZ, Y.; PAZOS-ARIAS, J. J.; GIL-SOLLA, A.; RAMOSCABRER, M.; LOPES-NORES, M. AVATAR: An Improved Solution for Personalized TV based on Semantic Inference. In: IEEE Transactions on Consumer Electronics, v.52, n.1, p.223-231, 2006.

BLANCO-FERNANDEZ, Y.; LOPES-NORES, M.; PAZOS-ARIAS, J. J.; GIL-SOLLA, A.; RAMOS-CABRER, M. Exploiting Digital TV User's Preferences in a Tourism Recommender System base don Semantic Reasoning. In: IEEE Transactions on Consumer Electronics, v.56, n.2, p.904-911, 2010.

BREZILLON, P.; POMEROL, J.C. Contextual knowledge sharing and cooperation in intelligent assistant systems. In: Le Travail Humain, 62(3):223-246, 1999.

BREZILLON, P.; ROCHA, J. P. Context-Aware Comuting: A Guide for the Pervasive Computing Community. In: 2004 IEEE/ACS International Conference on Pervasive Services (ICPS'04), p.39-48, 2004.

BROWN, P. J.; BOVERY, J. D.; CHEN, X.: Context-Aware Applications: From the Laboratory to the Marketplace. In: IEEE Personal Communications, v.4, n.5, p.5864, 1997.

CALVI, C. Z.; PESSOA, M. R.; FILHO, J. G. P. Um Interpretador de Contexto para Plataformas de Serviços Context-Aware. In: XXV Congresso da Sociedade Brasileira de Computação, 2005, São Leopoldo - RS, Anais do XXXII Seminário Integrado de Software e Hardware, p.1990-2004, 2005. 
CARVALHO, F. B. S.; ALENCAR, M. S. Análise da Transmissão do Canal de Retorno do Sistema Brasileiro de TV Digital via Power Line Communications. III Fórum de Oportunidades em Televisão Digital Interativa, Poços de Caldas, MG, 2005.

COTTER, P.; SMYTH, B. PTV: Intelligent Personalized TV Guides. In:

Proceedings of the 12th Innovative Applications of Artificial Intelligence (IAAI-2000) Conference. AAAI Press. 2000.

CHALMERS, D. Contextual Mediation to Support Ubiquitous Computing. 2002. 279 p. Tese (Doutorado) - Imperial College of Science, Technology and Medicine, Universidade de Londres, Londres, 2002.

CHORIANOPOULOS, K. Personalized and mobile digital TV applications. Multimedia Tools and Applications. In: Kluwer Academic Publishers, v.35, n.2, p.110, 2008.

CHEN A. Context-Aware Collaborative Filtering System: Predicting the User's Preferences in Ubiquitous Computing. In: CHI 2005. Doctoral Consortium. 2005.

CROWLEY, J. L.; COUTAZ, J.; REY, G.; REIGNIER, P. Perceptual Components for Context Aware Computing. In: BORRIELLO, G.; HOLMQUIST, L.E UbiComp 2002: Ubiquitous Computing. Heidelberg: Springer-Verlag, 2002. p.117-134. (Lecture Notes in Computer Science, 2498).

DAI, W.; COHEN, R. Dynamic Personalized TV Recommendation System. In: Proceedings of the Workshop on Personalization in Future TV, Pittsburgh, PA, 2003.

DEY, A. K.; ABOWD, G. D. Towards a Better Understanding of Context and Context-Awareness. Presented at the CHI 2000 Workshop on the What, Who, Where, When, Why and How of Context-Awareness, April 1-6, 2000.

DEY, A. K. Understanding an Using Context. In: ACM Personal and Ubiquitous Computing Journal, v.5, n.1, p.4-7, 2001.

DiBEG. Digital Broadcasting Experts Group. Disponível em: <http://www.dibeg.org>. Acesso em: 18 mai. 2008. 
DIX, A.; RODDEN, T.; DAVIES, N.; TREVOR, J.; FRIDAY, A.; PALFREYMAN, K. Exploiting Space and Location as a Design Framework for Interactive Mobile System. In: ACM Transactions on Computer-Human Interaction, v.7, n.3, p.285-321, 2000.

DVB. Digital Video Broadcasting. ETSI EN 300 74: Framing structure, channel coding and modulation for digital terrestrial television version 1.2., 1999. Disponível em<http:www.etsi.org>. Acesso em: 18 mai. 2008.

DVB-TVA. Digital Video Broadcasting (DVB); Carriage and signaling of TVAnytime information in DVB transport streams. 2005. ETSI TS 102323 v1.2.1 Technical Specification. Disponível em: <http://webapp.etsi.org/exchangefolder/ts_102323v010201p.pdf>. Acesso em: 14 mar. 2008.

EXIST. Open Source Native XML Database. Disponível em:< http://exist.sourceforge.net/credits.html>. Acesso em: 03 jun. 2009.

FORSTADIUS, J.; LASSILA, O.; SEPPANEN, T. RDF-Based Model for ContextAware Reasonig in Rich Service Environment. In: Proceedings of the $3^{\text {rd }}$ International Conference on Pervasive Computing and Communications Workshops (PerCom Workshops), p.15-19, 2005.

GOLDBERG, D.; NICHOLS, D. OKI B. M.; TERRY, D. Using Collaborative Filtering to Weave an Information Tapestry. In: Communications of The ACM, v.35, n.12, 1992.

GOULARTE, R. Personalização e adaptação de conteúdo baseadas em contexto para TV Interativa. 2003. 262 p. Tese (Doutorado) - Instituto de Ciências Matemáticas e de Computação, Universidade de São Paulo, São Carlos, 2003.

GU, T.; PUNG, H. K.; ZHANG, D. Q. A Service-Oriented Middleware for Building Context-Aware Services. In: Journal of Network and Computer Applications, v.28, n.1, p.1-18, 2005.

GWIZDKA, J. What's in the context? In: Proceedings of Workshop on The What, Who, Where, When, and How of Context-Awareness, Conference on Human Factors Computing Systems (CHI 2000), 2000.

HAYKIN, S. Redes neurais: princípios e prática. Bookman, 2001. 
HAN, J.; KAMBER, M. Data Mining: Concepts and Techniques. Elsevier, 2006.

HENRICKSEN, K.; INDULSKA, J.; McFADDEN, T.; BALASUBRAMANIAM, S. Middleware for distributed context-aware systems. In: Lecture Notes in Computer Science, 3760:846-863, 2005.

HERLOCKER, J. L.; KONSTAN, J. A.; TERVEEN, L. G.; RIEDL, J. T. Evaluating Collaborative Filtering Recommender Systems. In: ACM Transactions on Information Systems, v.22, n.1, p.5-53, 2004.

INSTINCT - IP-based Networks, Services and Terminals for Converging systems. Disponivel em http://www.ist-instinct.org/. Acesso em: 18 jan. 2008.

ISO/IEC 13818-1 International Organization for Standardization / International Eletrotecnical Committee. Information Technology - Generic Coding of Moving Pictures and Associated Audio Information - Part 1: Systems, 2000.

.13818-6. International Organization for Standardization / International Eletrotecnical Committee. Information Technology - Generic Coding of Moving Pictures and Associated Audio Information - Part 6: Extension for Digital Storage Media Command and Controls, 1996.

.14496-10. International Organization for Standardization / International Eletrotecnical Committee. Information Technology - Information Technology Generic Coding of Moving Pictures and Associated Audio Information - Part 10: Advanced Video, 2005.

.15938-1. MPEG-7 Overview. 2004. Disponível em: <http://www.chiariglione.org/MPEG/standards/mpeg-7/mpeg-7.htm>. Acesso em: 30 jun. 2008.

15938-5. Multimedia Description Schemes. Information Technology Multimidia Content Description Interface - Part 5. MPEG Systems SubGroup, 2003.

JIANGSHAN, X.; ZHANG, L.; LU, H.; LI. Y. The Development and Prospect of Personalized TV Program Recommendation System. In: Proceedings of the IEEE $4^{\text {th }}$ International Symposium. on Multimedia Software Engineering (MSE'02), 2002. 
LAM, X. N.; VU, T.; LE, T. D.; DUONG, A. D. Addressing cold-start problem in recommendation systems. In: Proceedings of the $2^{\text {nd }}$ International Conference on Ubiquitous Information Management and Communication. Suwon, Korea, p.208-211, 2008.

LEITE, L. E. C.; LIMA, O.; SOUZA FILHO, G. L.; MEIRA, S. R. L.; TEDESCO, P. C. A. R. Uma Arquitetura de Serviço para Avaliação de Contextos em Redes de TV Digital. In: Simpósio Brasileiro de Redes de Computadores, 2007, Belém - PA. Anais do XXV Simpósio Brasileiro de Redes de Computadores, 2007.

LI Q.; KIM B. M. An Approach for Combining Content-based and Collaborative Filters. In: Proceedings of the Sixth International Workshop on Information Retrieval with Asian Languages, p.17-24, 2003.

LUA. Disponível em:<http://www.lua.org>. Acesso em: 20 mai. 2009.

LUCAS, A. S.; ZORZO, S. D. Personalização para Televisão Digital utilizando a estratégia de Sistema de Recomendação para ambientes multiusuário. In: XXVII Simpósio Brasileiro de Redes de Computadores e Sistemas Distribuídos (SBRC), Recife, 2009.

LUCENE. Disponível em:< http://lucene.apache.org/java/docs/index.html>. Acesso em: 20 mai. 2009.

LUGMAYR, A.; NIIRANEN, S.; KALLI, S. Digital Interactive TV and Metadata. Springer, 2004.

LUAJAVA. Disponível em <http://www.keplerproject.org/luajava/>. Acesso em: 20 mai. 2009.

MONTEZ, C.; BECKER, V. TV Digital Interativa: Conceitos, Desafios e Perspectivas para o Brasil. Ed. da UFSC, 2ª Edição, Florianópolis, Brasil, 2005.

MORRIS, S.; SMITH-CHAIGNEAU, A. Interactive TV Standards - A Guide to MHP, OCAP and JavaTV. Elsevier, Focal Press, 2005.

MORITA, M.; SHINODA, Y. Information filtering based on user behavior analysis and best match text retrieve. In: $17^{\text {th }}$ Annual International ACM-SIGIR Conference on Research and Development in Information Retrieval, p.272-281, 1994. 
McCULLOCH, W. S.; PITTS, W. A Logical Calculus of the Ideas Immanent in Nervous Activity. Bulletin of Mathematical Biophysics, n.5, p.115-133, 1943.

NETO, M. A. de M.; SÁ CARDOSO, D; DE SOUZA, C. T.; CORTĖS, M. I. Abordagem Combinada para Recomendação Personalizada Utilizando o Guia de Programação Eletrônico. In: Anais do XXX Congresso da SBC - SEMISH. Belo Horizonte. 2010.

PAL, S.; SHIU, S. Foundations of soft case-based reasoning. Wiley-Interscience, 2004.

PAPAZOGLOU, M. P. Service-Oriented Computing: Concepts, Characteristics and Directions. In: Proceedings of the Fourth International Conference on Web Information Systems Engineering (WISE'03), p.3-12, 2003.

PASCOE, J. Adding Generic Contextual Capabilities to Werable Computers. In: Proceedings of the $2^{\text {nd }}$ IEEE International Symposium on Wearable Computers (ISWC'98), Pittsburgh, EUA, p.92-99, 1998.

PEDROSA, D. C.; MARTINS JR, J. A. C.; MELO, E.; PIMENTEL, M. G. C. Componente de Interação Multimodal no Ginga. In: XVI XVI Simpósio Brasileiro de Sistemas Multimídia e Web/WTVDI - II Workshop de TV Digital Interativa, Belo Horizonte, Minas Gerais. Anais do XVI Simpósio Brasileiro de Sistemas Multimídia e Web (WebMedia 2010), 2010.

PIMENTEL, M. G. C.; GOULARTE, R. Multimídia, Web Semântica, e Engenharia de Documentos aplicados à Computação Ubíqua. In: Mini-curso apresentado no XIII Simpósio Brasileiro de Sistemas Multimídia e Web (WebMedia 2007), Gramado, RS, Brasil, 2007.

PU, P.; CHEN, L. A User-Centric Evaluation Framework of Recommender Systems. In: Proceedings of the ACM RecSys 2010 Workshop on User-Centric Evaluation of Recommender Systems and Their Interfaces (UCERSTI), Barcelona, Spain, 2010.

RAATIKAINEN, K.; CHRISTENSEN, H. B. T.; NAKAJIMA, T. Application requirements for middleware for mobile and pervasive systems. In: SIGMOBILE Mob. Comput. Commun. Rev., 6(4):16-24, 2002. 
REIMERS, U. DVB - The Family of International Standards for Digital Video Broadcasting, Springer, $2^{\mathrm{a}}$ Edição, 2004.

RIORDAN; SORENSE, H. Information Filtering and Retrieval: An Overview. Disponível em: <citeseer.ist.psu.edu/483228.html> Acesso em: 18 jun. 2008.

ROBERTSON, S. E.; SPARK JONES, K. Relevance Weighting of Search Terms. In: Journal of the American Society for Information Science (JASIS), v.27, n.3, 1976.

ROCCHIO, J. Relevance Feedback in information retrieval. In: The SMART Retrieval System: Experiments in Automatic Document Processing, p.313-23, Prentice-Hall. Inc., 1971.

ROVIRA, M.; GONZALEZ, J.; LOPEZA, A.; MAS, J.; PUIG, A.; FABREAGAT, J.; FERNANDEZ, G. IndexTV: A MPEG-7 based Personalized Recommendation System for Digital TV. In: Proceedings of the IEEE International Conference on Multimedia and Expo, (ICME, 2004), 2004.

RYAN, N.; PACOE, J.; MORSE, D. R. Enhanced reality fieldwork: the contextaware archaeologist assistant. In: DINGWALL, L.; EXON, S.;GAFFNEY, V.; LAFLIN, S.; VAN LEUSEN. M. Archaeology in the age of the Internet: Computer Applications \& Quantitative Methods in Archaeology. Oxford: Archaeopress, p.269274, 1999.

SETTEN, M.V.; POKRAEV, S.; KOOLWWAIJ, J. Context-aware Recommendations in the Mobile Tourist Application COMPASS. In: W. Nejdl and P.De Bra (Eds.): AH 2004, LNCS 3137, p.235-244, Springer-Verlag Belin Heidelberg, 2004.

SILVA, F. S.; ALVES, L. G. P.; BRESSAN, G. PersonalTVware: A Proposal of Architecture to Support the Context-aware Personalized Recommendation of TV Programs. In: Proceedings of the European Interactive TV Conference (EurolTV 2009), Leuven, Belgium, p.39-42, 2009.

SOARES, L. F. G.; BARBOSA, S. D. J. Programando em NCL 3.0: Desenvolvimento de Aplicações para o Middleware Ginga, TV Digital e Web. Elsevier, 2009. 
SOARES, L. F. G.; RODRIGUES, R. F.; MORENO, M. F. Ginga-NCL: the Declarative Environment of the Brazilian Digital TV System. In: Journal of the Brazilian Computer Society, n.4, v.12, 2007, ISSN 0104-6500.

SOUZA FILHO, G. L.; LEITE, L. E. C.; BATISTA, C. E. C. F. Ginga-J: The Procedural Middleware for the Brazilian Digital TV System. In: Journal of the Brazilian Computer Society, n.4, v.12, 2007, ISSN 0104-6500.

SBC. Grandes Desafios da Pesquisa em Computação no Brasil - 2006 - 2016. Sociedade Brasileira de Computação (SBC). Relatório sobre o Seminário realizado em 8 e 9 de maio de 2006.

SBTVD. Decreto Presidencial $n^{\circ}$ 4.901, de 26 de novembro de 2003. Disponível em: <http://www.mc.gov.br/005/00502001.asp?ttCD_CHAVE=8882>. Acesso em: 10 jun. 2009.

SBTVD. Decreto Presidencial $n^{0}$ 5.820, de 29 de junho de 2006. Disponível em: <http://www.planalto.gov.br/ccivil_03/_Ato2004-2006/2006/Decreto/D5820.htm>.

Acesso em: 10 jun. 2009. Diário Ōficial da União, 30 de Junho de 2006.

SCHWALD, E. iTV Handbook: Technologies and Standards, Prentice Hall, 2003.

SCHILIT, B. N.; THEIMER, M. Disseminating Active Map Information to Mobile Hosts, In: IEEE Network, v.8, n.5, p.22-32, 1994.

SCHILIT, W. N. A System Architecture for Contex-Aware Mobile Computing, 1995. 144 p. Tese (Doutorado) - Graduate School of Arts and Sciences, Columbia University, Columbia, 1995.

SCHMIDT, A.; BEIGL, M.; GELLERSEN, H. W. There is more to Context than Location. In: Computers \& Graphics Journal, Elsevier, v.23, n.6, p.893-902, 1999.

SCHRECK, J. Security and Privacy in User Modeling. Kluwer Academic Publishers Norwell, 2003.

STRANG, T.; LINNHOFF-POPIEN, C. A context modeling survey. In: First International Workshop on Advanced Context Modelling, Reasoning And Management, Nottingham, England, 2004. 
THAWANI, A.; GOPALAN, S.; SRIDHAR, V. Context Aware Personalized Ad Insertion in an Interactive TV Environment. In: Adaptive Hypermedia 2004 TV'04: the 4th Workshop on Personalization in Future TV - Methods, Technologies, Applications for Personalized TV, Holanda, 2004.

TROUNG, K. N.; ABOWD, G. D.; BROTHERTON, J. A. Who, What, When, Where, How: Design Issues of Capture \& Acess Applications. In: ABOWD, G.D.; BRUMITT, B.; SHAFER, S. Ubicomp 2001: International Conference in Ubiquitous Computing. Heidelberg: Springer-Verlag, p.209-224, 2001.

TV-ANYTIME FORUM. TV-Anytime Forum Website. http://www.tv-anytime.org, 1999.

Broadcast and On-line Services: Search, select, and rightful use of content on personal storage systems ("TV-Anytime Phase 1"); Part 5: Rights Management and Protection (RMP) Information for Broadcast Applications, 2005. ETSI TS 102 822-5 v1.1.1 Technical Specification. Disponível em: $<$ http://webapp.etsi.org/exchangefolder/ts_10282205v010101p.pdf>. Acesso em: 18 jun. 2008.

. Broadcast and On-line Services: Search, select, and rightful use of content on personal storage systems ("TV-Anytime"); Part 2: Phase 1 - System description, 2007. ETSI TS 102 822-2 v1.4.1 Technical Specification. Disponível em: <http://webapp.etsi.org/exchangefolder/ts_10282202v010401p.pdf>. Acesso em: 18 jun. 2009.

Broadcast and On-line Services: Search, select, and rightful use of content on personal storage systems ("TV-Anytime"); Part 3: Metadata; Subpart 1: Phase 1 - Metadata schemas, 2007. ETSI TS 102 822-3-1 v1.4.1 Technical Specification. Disponível em: <http://webapp.etsi.org/exchangefolder/ts_1028220301v010401p.pdf>. Acesso em: 18 jun. 2009.

Broadcast and On-line Services: Search, select, and rightful use of content on personal storage systems ("TV-Anytime"); Part 3: Metadata; Subpart 3: Phase 2 - Extended Metadata Schema, 2007. ETSI TS 102 822-3-3 v1.2.1 Technical Specification. Disponível em: $<$ http://webapp.etsi.org/exchangefolder/ts_1028220303v010201p0.pdf $>$. Acesso em: 18 jun. 2009.

VIEIRA,V.; SOUZA, D.; SALGADO, A. C.; TEDESCO, P. Uso e Representação de Contexto em Sistemas Computacionais, Mini-curso apresentado no Simpósio de Fatores Humanos em Sistemas Computacionais (IHC 2006), Natal, Brasil, 2006. 
Modelos e Processos para o Desenvolvimento de Sistemas Sensíveis ao Contexto, Mini-curso apresentado no XXIX Congresso da Sociedade Brasileira de Computação (CSBC 2009), Bento Gonçalves-RS, Brasil, 2009.

VOZALIS, E.; MARGARITIS, K. G. Analysis of Recommender Systems' Algorithms In: - Proceedings of the 6th Hellenic European Conference on Computer Mathematics - HERCMA, Athens, Greece, p.732-745, 2003.

WAIKATO. Weka 3: Data Mining Software in Java. The University of Waikato. Disponível em: <http://www.cs.waikato.ac.nz/ml/weka>. Acesso em: 03 abr. 2009.

W3C. XQuery. World Wide Web Consortium (W3C) Recommendation, 2007. Disponível em: < http://www.w3.org/TR/xquery>. Acesso em: 25 jul. 2008.

XML Schema. World Wide Web Consortium (W3C) Recommendation, 2001. Disponível em: <http://www.w3.org/XML/Schema>. Acesso em: 18 jun. 2008.

. Web Services Activity. World Wide Web Consortium (W3C) Recommendation. Disponível em:<http://www.w3.org/2002/ws>. Acesso em: 18 jun. 2008.

. Extensible Markup Language (XML) 1.0 (Fourth Edition). World Wide Web Consortium (W3C) Recommendation, 2006. Disponível em: <http://www.w3.org/TR/2006/REC-xml-20060816/>. Acesso em: 18 jun. 2008.

Simple Object Acess Protocol (SOAP) 1.2. World Wide Web Consortium $\overline{(W 3 C)}$ Recommendation. Disponível em:<http://www.w3.org/TR/soap12-part0/>. Acesso em: 19 jun. 2008.

The Platform for Privacy Preferences 1.1 (P3P1.1). World Wide Web Consortium (W3C) Recommendation. Disponível em:< http://www.w3.org/TR/2006/NOTE-P3P11-20061113/>. Acesso em: 19 jun. 2008.

WANG, X. H.; ZHANG, D. Q.; GU, T.; PUNG, H. K. Ontology based context modeling and reasoning using OWL. In: Proc. of the Second IEEE Annual Conf. on Pervasive Computing and Communications Workshops, p.18-22, 2004.

WANT, R.; HOPPER, A.; FALCAO, V.; GIBBONS, J. The Active badge location system. ACM Transactions on Information Systems, v.10, n.1, p.91-102, 1992. 
WEISER, M. The Computer for the 21st Century. Scientific American, v.265, n.3, p. 94-104, reprinted in IEEE Pervasive Computing, Jan-Mar. 2002, p.19-25, 1991.

WITTEN, I. H.; FRANCK, E. Data Mining: Practical Machine Learning Tools and Techniques, Elsevier, 2005.

YU, Z; ZHOU, X. TV3P: an adaptive assistant for personalized TV. In: IEEE Transactions on Consumer Electronics, v.50, Issue 1, 2004, p.393-399. 2004.

ZAIER, Z.; GODIN, R.; FAUCHER, L. Evaluating Recommender Systems. In: IEEE Transactions on Consumer Electronics, v.650, p.393-399, 2008.

ZIMMERMAN, J.; KURAPATI K., BUCZAK A. L.; SCHAFFER D. GUTTA S.; MARTINO J. TV Personalization System. Design of a TV Show Recommender Engine e Interface. In: Personalized Digital Television: Targeting Programs to Individual Viewers, 2004.

ZHANG, H.; ZHENG, S.; YUAN, J. A Personalized TV Guide System Compliant with MHP. In: IEEE Transactions on Consumer Electronics, v.51, n.1, p.731-737, 2005.

ZHANG, H.; ZHENG, S. Personalized TV Program Recommendation based on TV-Anytime Metadata. In: Proceedings of the Ninth International Symposium on Consumer Electronics, (ISCE 2005), p.242-246, 2005.

ZIEGLER, C. N.; MCNEE, S.M.; KONSTAN, J.A.; LAUSEN, G. Improving Recommendation Lists through Topic Diversification. In: Proceedings of WWW 2005, ACM Press (2005), p.22-32, 2005. 


\section{APÊNDICE A - Esquemas PersonalTVware}

Neste apêndice é apresentado um conjunto de Esquemas utilizados no trabalho. Tais Esquemas são utilizados na representação dos seguintes itens: modelo do usuário e contexto da interação do usuário. É importante mencionar que o Esquema referente ao contexto da interação do usuário tem como base a abordagem de representação de contexto proposta por Goularte (2003).

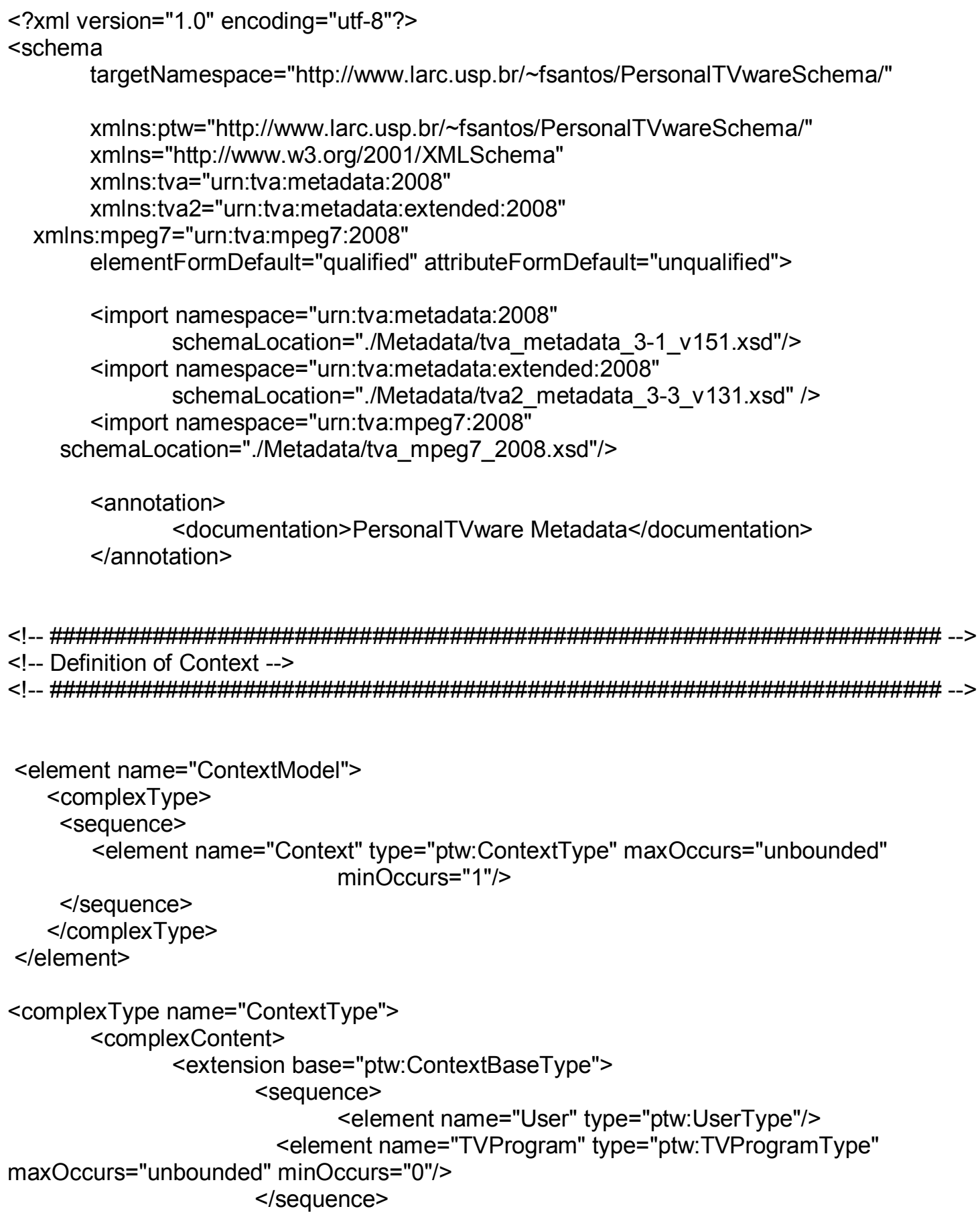




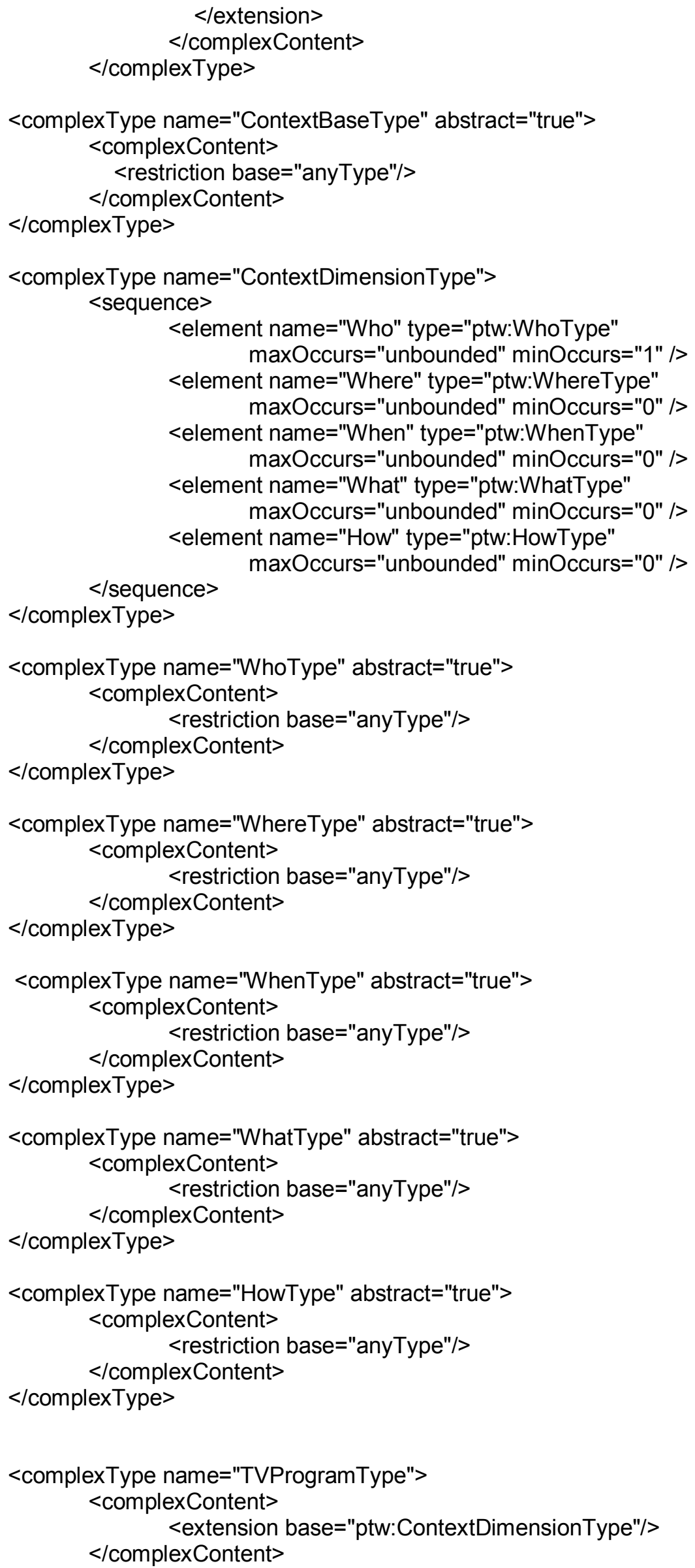




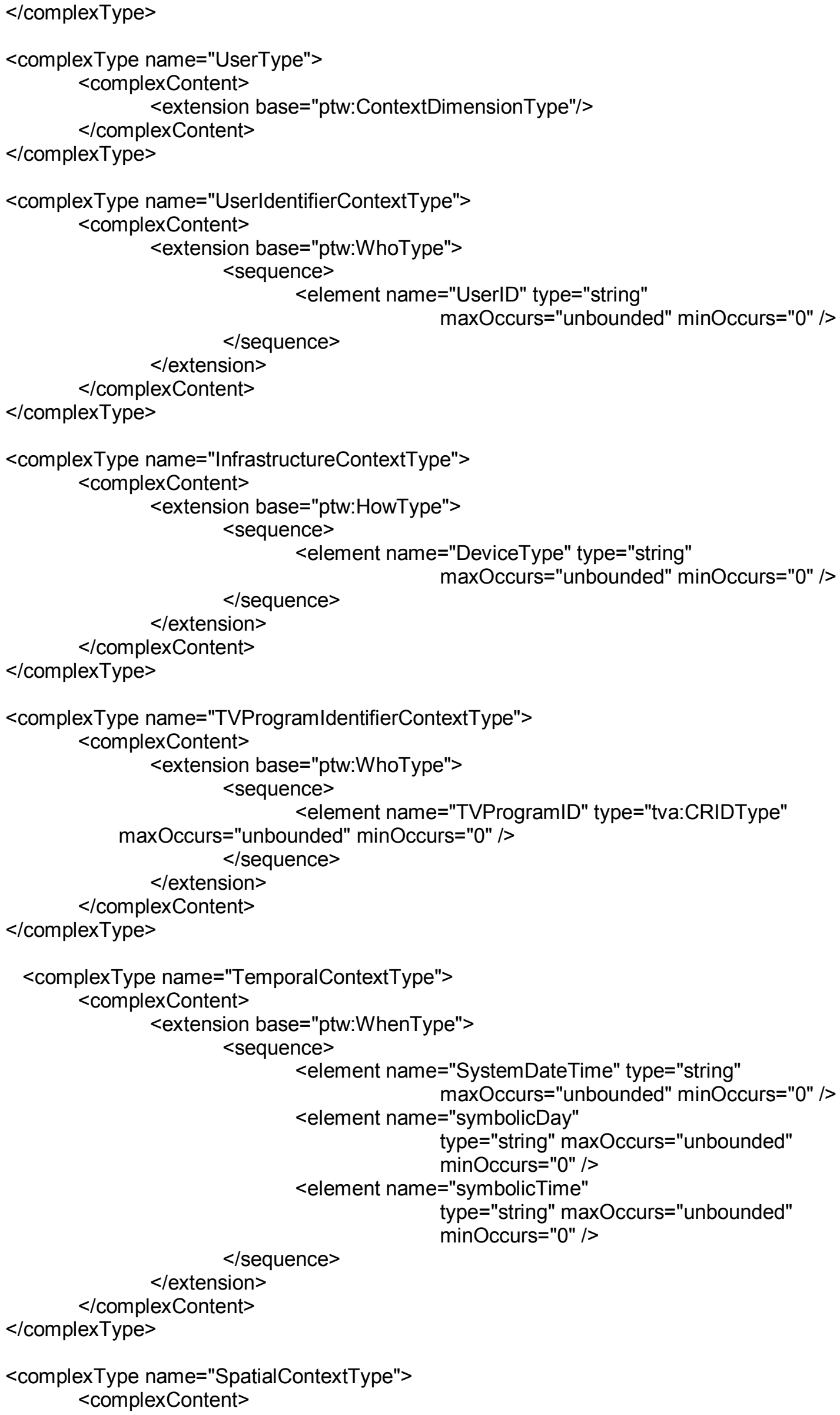




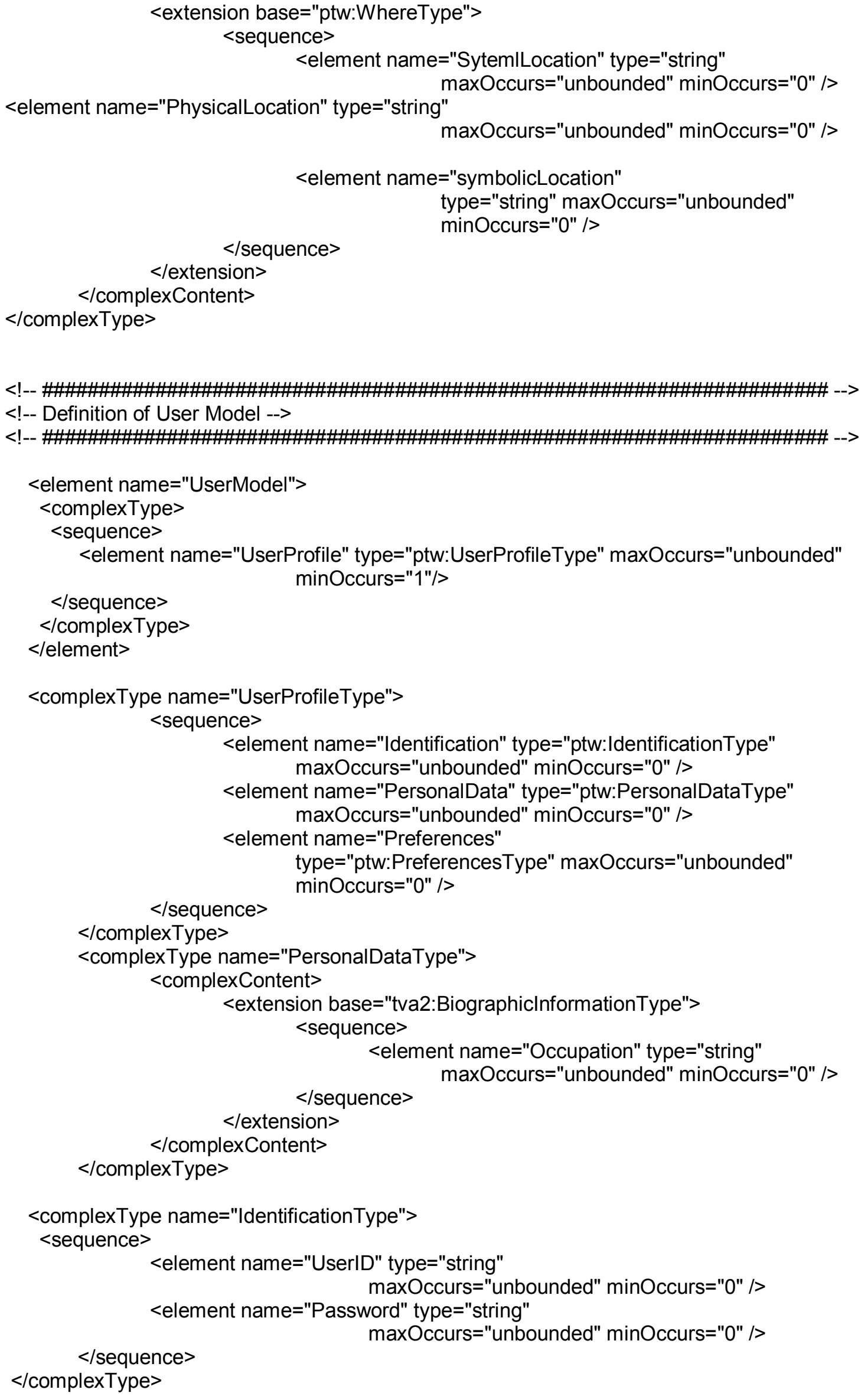


$<$ complexType name="PreferencesType">

$<$ sequence>

<element name="Explicit" type="mpeg7:FilteringAndSearchPreferencesType"

maxOccurs="unbounded" minOccurs $=" 0 "$ />

<element name="Contextual" type="mpeg7:FilteringAndSearchPreferencesType"

maxOccurs="unbounded" minOccurs="0" />

$</$ sequence $>$

$</$ complexType>

$</$ schema $>$ 


\section{APÊNDICE B - ARFF do perfil contextual do usuário}

Este apêndice apresenta o cabeçalho do arquivo no formato ARFF (AttributeRelation File Format) desenvolvido nesta tese conforme o perfil contextual do usuário modelado.

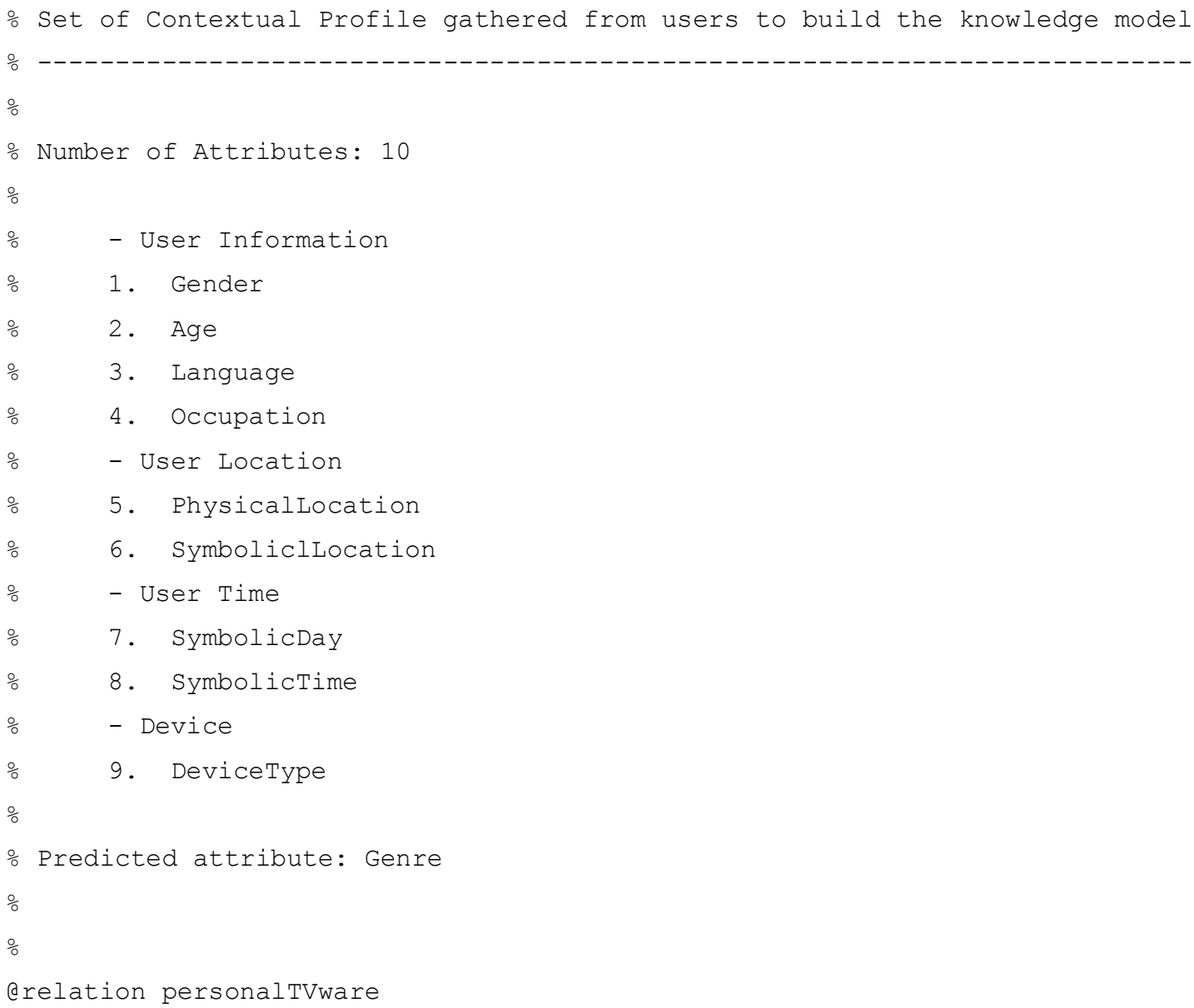


eattribute Physicallocation $\quad\{B R-S P, B R-M G, B R-R J, B R-S C, B R-A C, B R-A L$, $B R-A P, \quad B R-A M, \quad B R-B A, \quad B R-C E, \quad B R-D F, \quad B R-G O, B R-E S, \quad B R-M A, \quad B R-M T, B R-M S, \quad B R-P A, \quad B R-P B$, $B R-P R, \quad B R-P E, \quad B R-P I, \quad B R-R N, B R-R S, B R-R O, B R-R R, B R-S E, B R-T O\}$

eattribute SymbolicLocation \{'home', 'office', 'station', 'stop',

'airport', 'gym', 'school', 'museum', 'library', 'bank', 'hospital', 'police', 'mountain', 'sea', 'lake', 'transport', 'sky', 'hotel', 'restaurant',

'supermarket', 'park', 'resort', 'stadium', 'in transportation', 'on foot'\}

cattribute SymbolicDay

\{'monday', 'tuesday', 'wednesday',

'thursday', 'friday', 'saturday', 'sunday'

attribute SymbolicTime

\{'morning', 'noon', 'night', 'midnight'\}

dattribute DeviceType

\{'fixed', 'portable', 'mobile'\}

dattribute Genre

\{ 'CARTOON/ANIMATION' , 'INFORM' ,

'ENTERTAIN', 'EDUCATE', 'SPORTS', 'RETAIL', 'PERSONAL', 'RELIGION', 'MUSIC' \}

edata 


\section{APÊNDICE C - Questionário}

Este apêndice apresenta o questionário com duas questões do framework ResQue aplicado aos usuários que participaram dos experimentos com o PersonalTVware.

1. The items (TV programs) recommended to me took my personal context requirements into consideration?"

() Strongly disagree

() Disagree

() Neither agree nor disagree

() Agree

() Strongly agree

Justify your answer:

2. The items (TV programs) recommended to me matched interests?

() Strongly disagree

() Disagree

() Neither agree nor disagree

() Agree

() Strongly agree

Justify your answer: 